\title{
Binge eating : notes and data
}

Citation for published version (APA):

Jansen, A. T. M. (1990). Binge eating : notes and data. [Doctoral Thesis, Maastricht University]. Maastricht University. https://doi.org/10.26481/dis.19900608aj

Document status and date:

Published: 01/01/1990

DOI:

10.26481/dis.19900608aj

Document Version:

Publisher's PDF, also known as Version of record

\section{Please check the document version of this publication:}

- A submitted manuscript is the version of the article upon submission and before peer-review. There can be important differences between the submitted version and the official published version of record.

People interested in the research are advised to contact the author for the final version of the publication, or visit the DOI to the publisher's website.

- The final author version and the galley proof are versions of the publication after peer review.

- The final published version features the final layout of the paper including the volume, issue and page numbers.

Link to publication

\footnotetext{
General rights rights.

- You may freely distribute the URL identifying the publication in the public portal. please follow below link for the End User Agreement:

www.umlib.nl/taverne-license

Take down policy

If you believe that this document breaches copyright please contact us at:

repository@maastrichtuniversity.nl

providing details and we will investigate your claim.
}

Copyright and moral rights for the publications made accessible in the public portal are retained by the authors and/or other copyright owners and it is a condition of accessing publications that users recognise and abide by the legal requirements associated with these

- Users may download and print one copy of any publication from the public portal for the purpose of private study or research.

- You may not further distribute the material or use it for any profit-making activity or commercial gain

If the publication is distributed under the terms of Article $25 \mathrm{fa}$ of the Dutch Copyright Act, indicated by the "Taverne" license above, 


\section{binge eating}





\title{
binge eating notes and data
}

\author{
proefschrift \\ ter verkrijging van de graad van doctor \\ aan de Rijksuniversiteit Limburg te Maastricht, \\ op gezag van de Rector Magnificus, Prof. Dr. F.I.M. Bonke, \\ volgens het besluit van het College van Dekanen, \\ in het openbaar te verdedigen op \\ vrijdag, 8 juni 1990 om 16.00 uur \\ door \\ Anita Theodora Maria Jansen \\ geboren op 18 december 1960 te Utrecht
}


Promator

Beoordelingskommissie
Prof. Dr. M. A. van den Hout

Prof. Dr. L. Boon (voorzitter)

Prof. Dr. C.A.L. Hoogduin

Prof. Dr. F. ten Hoor

Dr. N. Nicholson

Prof. Dr. W. Vandereycken

CIP-DATA KONINKLIJKE BIBLIOTHEEK, DEN HAAG

Jansen, Anita Theodora Maria

Binge eating : notes and data / Anita Theodora Maria

Jansen. - Maastricht : Datawyse. - III.

Thesis Maastricht. - With ref.

ISBN 90-5291-027-8

SISO 606.3 UDC [616.89:613.25](043.3)

Subject headings: bulimia nervosa / binge eating /

restrained eating.

produktie en layout: Datawyse Maastricht, Ruud Leliveld omslag: Ruud Jansen

druk: Krips Repro Meppel

uitgave van dit proefschrift was mede mogelijk door de financiële steun van Duphar Nederland B.V. fabrikant van Fevarin ${ }^{\circledR}$, Koninklijke Ahold B.V., Merck Sharp \& Dohme en de Suikerstichting Nederland 
ter nagedachtenis aan mïn ouders

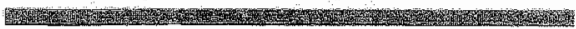




\section{how to read this book}

For forming an idea of the subject of the present study chapters 1 and 2 are recommended. Besides the clinical notes (sect. 1) and the laboratory model (sect. 2) the problem under study is formulated in chapter 2.

The author considers chapter 5 to be the most important part of the dissertation. In chapter 5 , the present author's empirical contributions to the question why dieters counterregulate / binge eat are collected. Looking back, the author feels that sections 5.8 and 5.3 may be the most important ones. In 5.8 an experimentum crucis is presented. The findings contradict generally accepted ideas and put the etiology of counterregulation in a new light. In 5.3 a theory that achieved great popularity, is subjected to a straightforward test. Chapter 5 is, logically, preceded by chapter 4, in which an overview of the empirical studies is presented.

The interested reader should also read chapter 3 . In sections $3.2,3.3$ \& 3.4 popular theories for explaining counterregulation/binge eating are closely examined. In 3.2 the blind acceptance of the set point theory is criticized; in 3.3 the biopsychiatric $5-\mathrm{HT}$ explanation of binge eating is critically examined; in 3.4 the cognitive view is presented and criticized for its lack of empirical background. In 3.5 an alternative model to explain overeating after exposure to various stimuli is presented to the reader. The model states that overeating results from a learned response.

In chapter 6 the main empirical findings are discussed. It is concluded that future research should concentrate on the model presented in 3.5 . 


\section{contents}

\section{THE CLINICAL PICTURE}

1.1 a historical note 9

1.2 diagnostic remarks 10

1.3 prevalence 12

\section{A LABORATORY MODEL}

2.1 introduction 15

2.2 obesity and the externality hypothesis 16

2.3 restraint and the disinhibition hypothesis 17

2.4 many stimuli are 'disinhibiting' 18

2.5 how does the "disinhibitive' mechanism work? 25

2.6 summary 27

\section{ON THE 'DISINHIBITIVE' MECHANISM}

3.1 introduction 29

3.2 being below set-point 29

3.2.1 set point theory in the eighties 29

3.2.2 the set point hypothesis 30

3.2.3 four critical comments on the set point concept 34

3.2.4 set point theory and counterregulation in the lab 36

3.3 a lowered 5-HT-level 38

3.3.1 5-HT and binge eating 38

3.3.2 five critical notes 41

3.3.3 how does the model deal with counterregulation in the lab? 48

3.4 dysfunctional thoughts 50

3.4.1 introduction 50

3.4.2 general dysfunctional thoughts 50

3.4.3 general dysfunctional thoughts lead to binge eating via depression 52

3.4.4 speclfic dysfunctional thoughts and binge eating/counterregulation 53

3.4.5 critical comment 53

3.5 an alternative account of counterregulation: classically conditioned compensatory responses $\quad 54$

3.5.1 introduction 54

3.5.2 conditioned compensatory responses (CCRs) 54

3.5.3 cephalic phase responses (CPRs) 56 
3.5 .5 a new model for binge eating a counterregulation: CCR (hypoglycemia) following from CPR (insulin relecase) 62

3.5.6 Cops and counterregulation 63

3.5.7 CCRs and clinical implications 64

3.6 summary 65

4 OVERVIEW OF THE EMPIRICAL STUDIES 69

\section{EMPIRICAL DATA}

5.1 clinical and non-clinical binges 72

5.2 non-regulation of food intake in restrained, emotional, and external eaters 83

5.3 does bingeing restore bulimics' alleged 5HT-deficiency? 92

5.4 is counterregulation of dieters after forced consumption of a preload dependent on mood? 98

5.5 cognitions and self-talk during food intake of restrained and unrestrained eaters 106

5.6 no evidence that dieters counterregulate outside the laboratory $\quad 112$

5.7 restrained eaters are rapidly habituating sensation seekers 119

5.8 on being led into temptation: 'counterregulation' of dieters after smelling a 'preload' 125

5.9 a case of bulimia successfully treated with cue-exposure $\quad 133$

6 DISCUSSION

6.1 general discussion 139

6.2 fundamental research 141

6.3 clinical issues $\quad 142$

SUMMARY 145

SAMENVATING 749

LITERATURE 153

DANKWOORD 167

PUBLICATIONS 169

CURRICULUM VITAE 171 


\section{the clinical picture}

\section{1 a historical note}

Binge eating, i.e. the rapid consumption of large amounts of food in a discrete period of time (APA, 1987), is widely believed to be of rather recent origin. A popular idea, especially noticeable in the lay press, is that binge eating primarily emerged during the last twenty years, and that the roots of binge eating are, in fact, socio-cultural (Lowenkopf, 1982; Orbach, 1978; 1986). However, although the prevalence may have increased recently (cf. 1.3), the very occurrence of episodic binge eating is certainly nothing new. The well-known Asterix and Obelix comic strips illustrate the old Roman custom to indulge in excessive eating and to vomit afterwards, the latter being a commonplace method of controlling weight. But better documented historical antecedents of the present concept of binge eating can also be found in writings from the last three centuries. In the early part of the 18th century, several physical and medical dictionaries paid attention to the voracious appetite. In several reports, binge eating appeared on the scene under the headings of 'fames canina' (hunger of a dog), 'boulimus' (hunger of an ox) and 'caninus appetitus', the last designation referring to 'boulimus' followed by vomiting (for overviews: Stein \& Laakso, 1988; Pope \& Hudson, 1984). Craving for food and pathological overeating were discussed extensively by Robert Whytt in 1764 (Silverman, 1987), and in 1797 the term 'bulimy', i.e. "a disease in which the patient is affected with an insatiable and perpetual desire of eating" was included in the Encyclopaedia Britannica. In the 19th century, Lasègue (1873) and Gull $(1873,1888)$ observed that binge eating could be part of the anorexia nervosa syndrome. In France 'boulimie' and in Germany 'hyperorexia' were discussed (see Stein \& Laakso, 1988). Clearly, binge eating was already present centuries ago; from the beginning of the 18 th century up to and including the 19th century, several medical textbooks more or less briefly referred to what we now call 'binge eating'.

In the early part of the present century, binge eating was described more extensively in several case histories. The most familiar ones are "Nadia" described by Janet in 1903, "Ellen West", recorded by Binswanger in 1944, and "Laura" noted down by Lindner in 1954 (Casper, 1983; Pope \& Hudson, 1984; Pope et al., 1985; Stein \& Laakso, 1988). In the descriptions of these three individual cases, it is impressive how they are characterized by a typical and similar symptom pattern, which also strongly resembles case descriptions of binge eating individuals today. 
Nadia, Ellen, and Laura were preoccupied with food and were often plagued by an irresistible craving for food which usually ended up as a binge. They alternated periods of merely dieting and losing weight with binge eating episodes. The hate of their bodies was prominent. Apparently, binge eating was not an isolated phenomenon but was accompanied by dieting practices and abhorrence of body shape.

\section{2 diagnostic remarks}

Interest in the clinical picture, characterized by a typical pattern of binge eating alternating with attempts at controlling body weight, experienced an upsurge during the last twenty years. The syndrome was described under a variety of diagnostic labels, such as 'dysorexia' (Guiora, 1967). 'thin fat people' (Bruch, 1973), 'compulsive eating' (Rau \& Green, 1975), 'bulimarexia' (Boskind-Lodahl, 1976), 'dietary chaos syndrome' (Palmer, 1979), "bulimia" (APA, 1980), 'binge-eating' (Wardle \& Beinart, 1981) and 'bulimia nervosa' (Russell, 1979; APA, 1987). The clinical descriptions to which these labels refer hardly differ and three core features were always emphasized in them: first, the occurrence of episodic binge eating, associated with a subjective loss of control over food intake; second, the presence of behavior designed to control body weight; and third, extreme concerns about body shape and weight (Fairburn \& Garner, 1986; Russell, 1985).

In the Diagnostic and Statistical Manual of Mental Disorders (DSM) the clinical picture appeared for the first time in the third edition. The term 'bulimia' was used (APA, 1980). The DSM III criteria for bulimia were particularly criticized for the reason that here 'bulimia' was, in fact, merely a description of binge eating, thereby referring to one of the symptoms instead of the full syndrome in which three core features (binge eating, behavior designed to control body weight, and extreme concern about shape and weight) are present (Fairburn \& Garner, 1986; Russell, 1985). In the revised edition of the DSM III (APA, 1987), the term 'bulimia nervosa" (BN) took the place of 'bulimia". At the moment, this label is generally accepted and widely used. According to the DSM III-P, BN is characterized by recurrent episodes of uncontrollable binge eating in which large amounts of food are rapidly consumed in a discrete period of time. The bouts of overeating are followed by strategies to prevent weight gain, such as self-induced vorniting, intake of laxatives and/or diuretics, vigorous exercise, and strict dieting (APA, 1987). Recently, chewing and spitting out food without swallowing it has also been identified as a common behavior to prevent weight gain (Mitchell et al., 1988). BN is independent of actual weight; individuals within the normal weight range, as well as under-and overweight subjects, can meet the criteria of $B N$ (APA, 1987; Wardle \& Beinart, 1981). Unlike DSM III, the revised edition 
does include the criteria of behavior designed to control body weight and extreme concern about body shape and weight.

Although the DSM III-R apparently represents a step forward in the description and classification of $B N$, all least three issues call for elucidation through research.

1 In the diagnostic manual, binges are defined as "rapid consumption of a large amount of food in a discrete period of time" (APA, 1987; $\mathrm{p} .67$ ). One of the main and intriguing points in studies on binge eating is the question whether a particular eating bout should be interpreted as a binge or not. What exactly determines whether an eating episode is a binge? it is clear that especially the adjectives "rapid" and "large" are subject to highly personal interpretation.

2 "A depressive mood that may be part of a Depressive Disorder is commonly observed" (APA, 1987; p. 67). Earlier; in the 18th century, the specification of an "extra-ordinary appetite, usually accompanied by a defection of the spirits" (Stein \& Laakso, 1988, p.207), indicated that depressive symptoms were already found to be associated with binge eating centuries ago. And throughout the historical descriptions "links between depression and bulimia were a recurrent theme; most descriptions of bulimia also refer to symptoms that could be indicative of depression. Recent empirical data confirmed the high prevalence of depression among binge eating individuals (Swift et al., 1985; Lee et al., 1985; Cooper \& Fairburn, 1986). In the past decade, the role of depression in the etiology of bulimia nervosa has been discussed extensively, and special attention was paid to the question whether depression is a cause, an epiphenomenon, or a consequence of binge eating. Some authors even wonder whether bulimia nervosa actually is a mood disorder. Although an extensive review of the relationship between binge eating and depression is beyond the scope of this dissertation, the importance of this relationship is acknowledged and it is mentioned obliquely in connection with the biological and cognitive views on the etiology of $\mathrm{BN}$.

3 "Some people with this disorder are subject to Psychoactive Substance Abuse or Dependence, most frequently involving sedatives, amphetamines, cocaine, or alcohol" (APA, 1987" p.67). The co-occurrence of addictive behaviors and overeating and similarities between them have recently attracted attention (Brisman \& Siegel, 1984; Wardle, 1987c; Lacey \& Moureli, 1986; Lacey \& Evans, 1986; Filstead, Parela \& Ebbit, 1988). However, so far the alleged analogy between binge eating and addictive behaviors has not been an object of direct tests. The present dissertation mentions several efforts to distinguisth possible common pathogenic processes in addictions and BN experimentally. Though refining DSM III-R was not the first aim of the studies included in this book, the issues mentioned above and raised by DSM $\| 1 / \mathrm{R}$ were touched upon in some of the present empirical investigations (for (1) see 5.1, for (2) see $3.4 .3 \& 5.4$, for (3) sere $3.5,5.7,5.8 \& 5.9$ ). 
As the early clinical descriptions showed, binge eating already occurred before the modern cultural stress on thinness of Western society came up. However, today binge eating is claimed to be far more prevalent than several centuries or even years ago (Casper, 1983). Whether this alleged increase in binge eating reflects an actual increase in prevalence or whether it is merely a matter of improved obsenvation is unknown. Indirect observations, such as the number of clinical registrations and the growing attention for binge eating in popular magazines, suggest an increase in the prevalence of binge eating, but empirical findings on the prevalence rates of bingeing and binge-related behaviors vary extremely: percentages between $1 \%$ and $79 \%$ were reported (Halmi et al., 1981; Hawkins \& Clement, 1980; Pope, 1984; Pope \& Hudson, 1984; Healy et al., 1985; Pyle et al., 1981, 1983; Cooper \& Fairburn, 1983; Fairburn \& Cooper, 1984; Cooper et al., 1987; Thelen et al., 1987; Rosenzweig \& Spruill, 1987). The divergence may be partly due to sample procedures (e.g. using student samples vs representative samples). However, the confusion about a rather fundamental issue may be at least as important: what exact combination of features constitutes a 'case'? The diagnostic criteria used in various studies differed in strictness as to the inclusion, definition, and frequency of symptoms. Concerning the inclusion, some studies merely inquired into 'binge eating' and the presence of strategies to control weight gain (e.g. Thelen et al., 1987; Rosenzweig \& Spruill, 1987; Cooper, Charnock \& Taylor, 1987), while others also investigated concern about shape and weight (e.g. Cooper \& Fairburn, 1983; Fairburn \& Cooper, 1983; Fairburn \& Cooper, 1984; Healy et al., 1985). Furthermore, it may be clear that especially the definition of 'binge eating' is subject to highly personal interpretation. And as to frequency, some authors used strict criteria of at least one binge eating episode a week (e.g. Pyle et al., 1983; Healy et al., 1985), while others also included individuals who 'sometimes' binged (e.g Fairburn \& Cooper, 1983). As could be expected, the use of more stringent criteria concerning the inclusion, definition, and frequency of symptoms, made the number of cases decline significantly. It is therefore unclear to what extent 'cases' found in various prevalence studies are comparable with clinical cases; the community rate of clinically relevant binge eating remains unknown (Cooper et al., 1987; Healy et al., 1985). Wardle (1980) pointed out that food craving, difficulty in stopping to eat once started and bingeing were present in normal young people: "dietary restriction, craving for food, and eating binges are not of themselves abnormal, although their frequency may be higher in the clinical population. In addition, the content of the binges may differentiate normal and clinical groups, although no data exist on this issue." (Wardle \& Beinart, 1981, p. 102). Obtaining such data was the aim of one of the empirical studies included in this dissertation (see 5.1). 
In sum, binge eating was already noticed long ago but its prevalence rate is supposed to have increased lately. Reliable data are lacking, however. When binge eating is not an isolated phenomenon but is accompanied by extreme concern about body weight/shape and behavior designed to control body weight, it is called bulimia nervosa. In the present dissertation, attention is focussed on bulimia nervosa and, more specifically, on the isolated act of binge eating. 
First of all attention will be restricted to the isolated act of bingeing and, secondly, the focus will almost entirely be on well-controlled lab studies. Two decades ago, Abramson \& Seligman (1977) argued that psychopathological phenomena might be understood better through laboratory research. And experiments on psychopathological phenomena, such as anxiety, depression and obsessive-compulsive disorders really led to new and interesting insights into the etiology and maintenance of these disorders (see Abramson \& Seligman, 1977). Binge eating also can be mimicked in the laboratory. The miniature binge that can be provoked is supposed to be analogous to the naturally occurring binge, while the conditions of its occurrence can be controlled and studied optimally.

Historically, the binge model has its roots in Schachter's $(1968,1971)$ work on obesity. Schachter studied the eating behavior of obese and normal weight people after various experimental manipulations, such as the induction of anxiety or the consumption of a preload. The 2 (weight status) $\times 2$ (experimental manipulation) factorial design, with the amounts eaten by the subjects as the dependent variable, demonstrated remarkable differences in eating behavior between the experimental (obese) and control (normal weight) groups. In the next section of the present chapter, Schachter's main experimental findings will be presented briefly and his externality hypothesis will be discussed. It should be noted that, although his original hypothesis could not stand critical tests and replication studies, Schachter was the pioneer of a fruitful series of experimental studies on eating behavior. His classic experimental paradigm is very elegant. Although by and by it became clear that it was not obesity per se, but the restraint in food intake that determined the amount eaten after various experimental manipulations, Schachter's experimental paradigm remained very well applicable and is still widely used. In the third section, restraint and the disinhibition hypothesis are discussed. The large variety of experimental manipulations which elicit an overeating response in restrained subjects is reviewed in the fourth section. After reading the fifth section, the reader will unfortunately still be in the dark as to why restrained subjects overeat after various experimental manipulations. 
In the late sixties, Schachter and his co-workers carried out a series of lab studies in which they studied the eating response of obese and normal weight subjects after food loading, fear induction, or adrenalin injections (Schachter et al., 1968; Schachter 1971; Nisbett, 1968a, 1968b). Food loading, fear induction, and adrenalin injection all increase sympathetic activation. In this way, gastric motility is inhibited and blood sugar will increase, that is, a physiological state of low hunger emerges (see Cannon, 1920). Schachter (1971) found that low hunger manipulations, remarkably, did not have any effect on the amount eaten by obese subjects but it certainly did decrease the amount eaten by normal weight individuals. Two studies likewise showed that after experimental manipulation of anxiety, normal subjects ate less while obese subjects ate the same amount (McKenna, 1972; Abramson \& Wunderlich, 1972).

11 appeared that the eating response of the obese was not related to any internal sensation. Moreover, manipulations of presumed 'dinner time', palatability, smell, sight, and visual prominence of food cues demonstrated that the eating behavior of obese people was primarily externally controlled or stimulus bound (Wooley \& Wooley, 1975; Rodin, 1980). The 'externality hypothesis' was born: "eating by the obese seems unrelated to any internal, visceral state, but is determined by external food-relevant cues such as the sight, smell, and taste of food" (Schachter, 1971, p.130). The eating behavior of normal weight people, on the other hand, appeared to be mainly determined by internal stimuli.

Schachter's externality hypothesis has been criticized for two reasons. First, support for Schachter's hypothesis was equivocal. Many replication studies and also new tests of the hypothesis failed to demonstrate a clear relationship between overweight and external responsiveness on the one hand, and normal weight and internal responsiveness on the other (Pudel, 1975; Price et al, 1975; see also the overviews by Wooley \& Wooley, 1975; Rodin, 1981; Bennet \& Gurin, 1982; Ruderman, 1986b). Instead of the overweight-external vs. normal weight-internal dichotomy, externally as well as internally responsive subjects were found in each weight category (Herman \& Mack, 1975; Hibscher \& Herman, 1977; for overviews: Rodin, 1981; van Strien, 1986; Ruderman, 1986b).

Second, it is not correct to draw a strict like between external and internal stimuli. With regard to tood intake, external and internal cues are closely related. In the Schachter studies, sight, smell, and taste of food were claimed to be external stimuli. However, these 'external" cues can easily trigger internal physiological responses. It has been demonstrated that 'external' factors such as the sight of food or thoughts about food, stimulate physiological hunger responses, such as an insulin response, which whets the appetite (Powley, 1977; Rodin, 1985). The eating response following the insulin release can reasonably be regarded as internally determined. Therefore the argument in Polivy et al. (1978) that 
the elevated external responsiveness serves to compensate for the deficit in internal responsiveness is not necessarily true: being hyperresponsive to 'external' cues does not automatically mean an unresponsiveness to internal cues.

In sum, from a series of lab studies Schachter hypothesized that obese people are externally oriented in their eating behavior. Normal weight individuals, on the other hand, were considered to be internally oriented. The merit of the externality hypothesis is that it stimulated a massive amount of research. However, empirical data showed that the internal vs. external dichotomy was far too simple a hypothesis to account for the processes underlying differences in 'obese' and 'normal weight' eating behavior (Rodin, 1981; Ruderman, 1986b).

\section{3 restraint and the disinhibition hypothesis}

Random deprivation of food, i.e. scarce and unpredictable food availability , heightens the external responsiveness of rats to food, even under conditions of abundance (see Rodin, 1980). Rodin speculates "that an externally imposed schedule combining both scarcity and unpredictability might be expected to encourage dependence on external cues for the regulation of eating. Given the uncertainty of such a schedule, it would be best to eat whenever possible, regardless of internal needs." (Rodin, $1980, p .235)$. In the early seventies, the idea emerged that external responsiveness was not related to overweight per se, but that it was a consequence of food deprivation (Nisbett, 1972). The attention of researchers gradually shifted from eating behavior as a function of body weight to the role of deprivation. More specifically, deprivation appeared to be a key factor in the determination of eating responses. In the mid-seventies, Herman \& Mack (1975) developed the construct of restraint. Restraint literally means self-control and, with respect to eating behavior, restraint refers to dietary self-control (Ruderman, 1983). People vary in the extent to which they are restrained eaters. Highly restrained eaters (dieters), on the one end of the continuum, constantly try to restrict their food intake, and always worry about what they eat. At the other end of the continuum, low restrained eaters (non-dieters) eat whatever they like and do not bother about it (Herman \& Mack, 1975; Herman \& Polivy, 1980 ).

Relative deprivation as a consequence of the deliberate restriction of food intake (i.e. dieting) is independent of weight: both overweight and normal weight subjects may be dieters. It became clear that the inconsistency of the above-mentioned findings on the externality of the obese could be due to differences in level of restraint rather than to differences in weight. Externality was claimed to be a correlate of restraint rather than a correlate of obesity (Ruderman, 1986b). 
With the emergence of the concept of restraint, a new hypothesis concerning the relationship between weight, externality, and eating patterns was developed. It was argued that, independent of actual weight, individuals who rated themselves as dieters showed the 'external' behaviors previously sometimes found as characteristic of the obese. Moreover, it was noted that restrained eaters were not merely characterized by dieting, but by an eating pattern alternating between dieting episodes and periodic overindulgence (Herman \& Polivy, 1980; Ruderman, 1986b). Herman \& Polivy (1980) formulated the disinhibition hypothesis, which states that breaking the self-control of restrained eaters by so-called disinhibitors will result in overeating.

\section{4 many stimuli are disinhhibiting}

Restrained eating refers to attempts to suppress eating impulses. However, attempts to suppress food intake are not always successful: restraint can be broken. Breaking restraint, i.e. the disinhibition of inhibited (restrained) eating, has been the focus of much laboratory research in the last fifteen years. The most common experimental paradigm is in accordance with Schachter's design: a 2 (restraint: yes/no) $\times 2$ (experimental manipulation: yes/no) factorial design, in which the consumption by subjects is measured after the experimental or the control manipulation. The disinhibition hypothesis boils down to the prediction that restraint and manipulation interact: restrained subjects will increase consumption after the manipulation, while unrestrained subjects will not. Subjects are usually classified as restrained or unrestrained on the basis of the median split of their restraint scores and the study is usually presented as a taste test. A variety of experimental manipulations has been studied, such as food and alcohol preloads, beliefs and emotional states. A paradigmatic experiment was reported by Herman \& Mack (1975). Fifty-seven normal weight subjects scored the Restraint Scale (see Herman \& Polivy, 1980) and were divided into low and high restraint subjects on the basis of median split. One-third of each group were given a preload of two milk shakes, one-third consumed a preload of one milk shake, and one-third were given no preioad at all. After the preload (or without a preload) subjects had to "taste" three types of ice cream. The amount eaten by each subject was registered. Results are given in figure 1.

After unrestrained eaters had eaten a large amount of preload, they ingested little ice cream, after they had eaten a little or no preload, they ingested much more ice cream. For restrained eaters the pattern was precisely the opposite: the more preload they had ingested, the more ice cream they consumed. And, vice versa, the less preload they had had, the less ice cream they took. Note that it is the interaction disinhibited (yes/no) X restraint (yes/no) which is important. In the present section, an 


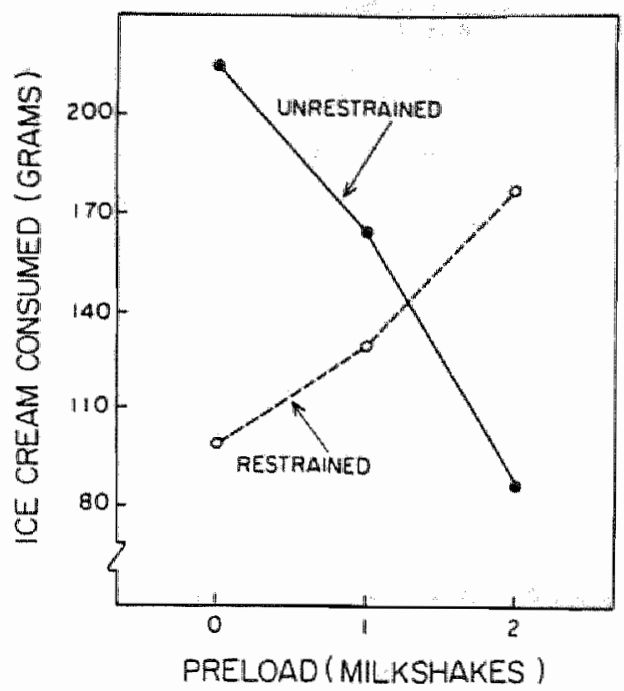

Fig. 1: ice cream consumption of restrained and unrestrained eaters after two, one or no prelload. (Reprinted from Herman \& Polivy, 1980, without permission).

overview of the experimental manipulations leading to the (dis)inhibition of restraint is presented.

preloads

It is a robust, well-known finding that dieters do not regulate their food intake as non-dieters do in the so-called 'taste test' (Herman \& Mack, 1975; Hibscher \& Herman, 1977; Herman \& Polivy, 1980; Ruderman \& Christensen, 1983). After non-dieters have eaten a preload of e.g. milk shakes, they will eat less ice cream than when they are not preloaded. In other words, non-dieters regulate their food intake. Interestingly, dieters show the opposite pattern in the studies by Herman and co-workers: they ate significantly more ice cream after a high-caloric preload than after no preload (Herman \& Mack, 1975; Hibscher \& Herman, 1977). This counterintuitive and apparently illogical behavior is called counterregulation. Others found that dieters non-regulated instead of counterregulating, that is, dieters ate the same amount with or without a preload (Ruderman \& Christensen, 1983). In both counterregulation and non-regulation, however, the interesting thing is the interaction between preload (yes/no) and restraint (yes/no).

\section{beliefs}

Dieters also counterregulate when they merely perceive the preload as high-caloric, regardless of the actual caloric content of the preload (Spencer \& Fremouw, 1979; Woody, Constanzo, Lieter \& Conger, 1981). Though Polivy (1976) originally hypothesized an effect of instructions, in 
which the subjects were told that the preload was high-or low-caloric, she failed to find a significant effect. Therefore, Polivy (1976) reanalyzed her data post hoc. After reclassification of subjects on the basis of how calorie-rich they perceived the preload to be, i.e. regardless of the instructions, Polivy (1976) argued that dieters counterregulated when they merely thought they had consumed a high-caloric preload, regardless of the actual caloric content of the preload. But Polivy's conclusions (1976) were, at least, premature. First, the post hoc analysis merely showed a marginally significant interaction between restraint and perceived amount of calories $(p<0.07)$ and, second, no further statistical analysis of the simple effects underlying this interaction was presented. Third, it should be noted that post hoc analysis should only be considered suggestive. Meanwhile, two replication studies showed that a break of restraint did occur when the preload was believed to be high-caloric and did not when the preload was believed to be low-caloric (Spencer \& Fremouw, 1979; Woody et al., 1981). Ruderman \& Wilson (1979), on the other hand, were unable to find any significant effects due to the, otherwise successful, manipulation of beliefs about the caloric content of the preload. The conflicting results may be due to Ruderman \& Wilson's (1979) experimental design: whereas Spencer \& Fremouw (1979) and Woody et al. (1981) used a between-subject design, Ruderman \& Wilson (1979) used a within-subject design. The anticipation of another 'taste test' may have been such a horrible prospect for highly restrained subjects that it elicited disinhibition during the very first challenge (ct. 3: anticipated consumption).

Recently, Heatherton, Polivy \& Herman (1989) have instructed restrained and unrestrained subjects to feel either hungry or satisfied (experimental condition) or the subjects did not receive any instruction. anything (control condition) after the ingestion of a vitamin capsule. When told to feel hungry, restrained subjects ate significantly more ice cream than when told to feel satisfied or when not told anything at all. The other way around, and surprisingly, unrestrained eaters ate significantly less when they were told to feel hungry than when they were told to feel satisfied or when not told anything at all.

\section{anticipated consumption}

To test whether anticipated dietary violation will disinhibit dieters, Ruderman, $_{\mathrm{r}}$ Belzer and Halperin (1985) studied cracker consumption by subjects expecting to consume a milk shake (diet-breaking), a salad (dietcompatible), or nothing at all after 'tasting' the crackers. Dieters actually increased their consumption in anticipation of a milk shake, whereas non-dieters decreased their food intake when expecting a milk shake (Ruderman, Belzer and Halperin, 1985). Although Ruderman and coworkers' data (1985) suggest that dieters respond to anticipated dietary violations in the same way as they do to actual and alleged dietary violation, data from Tomarken \& Kirschenbaum (1984) point in a different 
lable 1: laboratory research on the regulation of food intake in dieters and non-dieters after stimulus $A$ or $B$.

\begin{tabular}{|c|c|c|c|c|c|}
\hline $\begin{array}{l}\text { stimulus } \\
\text { A }\end{array}$ & $\begin{array}{l}\text { stimulus } \\
\mathrm{B}\end{array}$ & $\begin{array}{l}\text { dielters } \\
\text { food intake }\end{array}$ & $\begin{array}{l}\text { non-dieters } \\
\text { food intake }\end{array}$ & $\begin{array}{l}\text { hypothetical } \\
\text { explanation }\end{array}$ & authors \\
\hline \multirow[t]{3}{*}{ prelload } & no prelaad & $A>B$ & $A<B$ & $\begin{array}{l}\text { being below } \\
\text { set point }\end{array}$ & $\begin{array}{l}\text { Herman } \\
\text { \& Mack } 1975\end{array}$ \\
\hline & & $A>B$ & $A<B$ & $\begin{array}{l}\text { being below } \\
\text { set point }\end{array}$ & $\begin{array}{l}\text { Hibscher } \\
\text { \& Herman } 1977\end{array}$ \\
\hline & & $A=B$ & $A<B$ & - & $\begin{array}{l}\text { Ruderman \& } \\
\text { Christensen } 1983\end{array}$ \\
\hline \multirow[t]{4}{*}{$\begin{array}{l}\text { belief in } \\
\text { high-calorie } \\
\text { preload }\end{array}$} & $\begin{array}{l}\text { beliefin in } \\
\text { low-calorie } \\
\text { preload }\end{array}$ & $A>B$ & $A<B$ & $\begin{array}{l}\text { disinhibitive } \\
\text { thoughts }\end{array}$ & Polivy 1976 \\
\hline & & $A>B$ & $A=B$ & $\begin{array}{l}\text { disinhibitive } \\
\text { thoughts }\end{array}$ & $\begin{array}{l}\text { Spencer \& Fremouw } \\
1979\end{array}$ \\
\hline & & $A>B$ & $A=B$ & $\begin{array}{l}\text { disinhibitive } \\
\text { thoughts }\end{array}$ & $\begin{array}{l}\text { Woody, Constanzo } \\
\text { Liefer \& Conger } 1981\end{array}$ \\
\hline & & $A=B$ & $A=B$ & - & $\begin{array}{l}\text { Ruderman \& Wilson } \\
1979\end{array}$ \\
\hline $\begin{array}{l}\text { placebo } \\
\text { hunger }\end{array}$ & $\begin{array}{l}\text { placebo } \\
\text { fullness }\end{array}$ & $A>B$ & $A<B$ & $\begin{array}{l}\text { unresponsive } \\
\text { to internal cues } \\
\text { overresponsive } \\
\text { to cognitive cues }\end{array}$ & $\begin{array}{l}\text { Heatherton, Polivy \& } \\
\text { Herman } 1989\end{array}$ \\
\hline
\end{tabular}

\begin{tabular}{lllll}
\hline $\begin{array}{l}\text { anticipating } \\
\text { high calorie low calorie } \\
\text { consumption consumption }\end{array}$ & $A>B$ & $A>B$ & $\begin{array}{l}\text { disinhibitive } \\
\text { thoughts }\end{array}$ & $\begin{array}{l}\text { Tomarken \& Kirschen- } \\
\text { baum 1984 exp.1 }\end{array}$ \\
& $A=B$ & $A>B$ & $\begin{array}{l}\text { disinhibitive } \\
\text { thoughts }\end{array}$ & $\begin{array}{l}\text { Tomarken \& Kirschen- } \\
\text { baum 1984 exp. } 2\end{array}$ \\
& $A>B$ & $A<B$ & $\begin{array}{l}\text { disinhibitive } \\
\text { thoughts }\end{array}$ & $\begin{array}{l}\text { Ruderman, Belzer \& } \\
\text { Halperin 1985 }\end{array}$ \\
\hline alcohol placebo & $\mathrm{A}<\mathrm{B}$ & $\mathrm{A}>\mathrm{B}$ & $\begin{array}{l}\text { absence of } \\
\text { cognitive label }\end{array}$ & $\begin{array}{l}\text { Polivy \& Herman } \\
1976 a\end{array}$ \\
\hline
\end{tabular}


Continusation table 1

\begin{tabular}{|c|c|c|c|c|c|}
\hline $\begin{array}{l}\text { stimullus } \\
\text { A }\end{array}$ & $\begin{array}{l}\text { stimulus } \\
\mathrm{B}\end{array}$ & $\begin{array}{l}\text { dieters } \\
\text { food intake }\end{array}$ & $\begin{array}{l}\text { non-dieters } \\
\text { lood uritake }\end{array}$ & $\begin{array}{l}\text { hypottietical } \\
\text { explanation }\end{array}$ & authors \\
\hline $\begin{array}{l}\text { aware } \\
\text { of drinking } \\
\text { alcohiol }\end{array}$ & $\begin{array}{l}\text { non-aware } \\
\text { of drinking } \\
\text { alcohol }\end{array}$ & A. $s=\mathrm{B}$ & $A<B$ & $\begin{array}{l}\text { interaction between } \\
\text { physiological } \\
\text { change and } \\
\text { cognitive label }\end{array}$ & $\begin{array}{l}\text { Polivy \& Herman } \\
1976 \mathrm{~b}\end{array}$ \\
\hline \multirow[t]{3}{*}{ depressed } & non-depressed & $A>B$ & $A<B$ & $\begin{array}{l}\text { reintorcers lose } \\
\text { their effectiveness }\end{array}$ & $\begin{array}{l}\text { Baucom \& Aiken } \\
1981\end{array}$ \\
\hline & & $A>B$ & $A=B$ & loss of self-control & Frost et al. 1982 \\
\hline & & $A>B$ & $A=B$ & loss of self-control & Ruderman 1985a \\
\hline \multirow[t]{2}{*}{ anxious } & non-anxious & $A=B$ & $A<B$ & loss of self -control & $\begin{array}{l}\text { Herman \& Polivy } \\
1975\end{array}$ \\
\hline & & $A>B$ & $A<B$ & boundary model & Herman et al 1987 \\
\hline $\begin{array}{l}\text { monitoring } \\
\text { tood inlake }\end{array}$ & $\begin{array}{l}\text { non moni- } \\
\text { toring of } \\
\text { intake }\end{array}$ & $A<B$ & $A<B$ & $\begin{array}{l}\text { altered self- } \\
\text { monitoring of } \\
\text { food intake during } \\
\text { counterregulation }\end{array}$ & $\begin{array}{l}\text { Kirschenbaum \& } \\
\text { Tomarken } 1982\end{array}$ \\
\hline $\begin{array}{l}\text { explicit } \\
\text { attention }\end{array}$ & no attention & $A<B$ & $A=B$ & $\begin{array}{l}\text { monitoring } \\
\text { reintroduces diet } \\
\text { consciousness }\end{array}$ & $\begin{array}{l}\text { Polivy, Herman } \\
\text { Hackett \& } \\
\text { Kuleshnyk } 1986\end{array}$ \\
\hline $\begin{array}{l}\text { overeating } \\
\text { modal }\end{array}$ & $\begin{array}{l}\text { mon- } \\
\text { overeating } \\
\text { model }\end{array}$ & $A>B$ & $A>\mathbb{B}$ & $\begin{array}{l}\text { restraint is a state } \\
\text { which may be } \\
\text { changed by social } \\
\text { influences. }\end{array}$ & $\begin{array}{l}\text { Polivy, Herman, } \\
\text { Younger \& Erskine, } \\
1979\end{array}$ \\
\hline
\end{tabular}

direction. In one experiment, both dieters and non-dieters ate significantly more when anticipating a high-calorie meal than when expecting to eat a low-calorie meal or no meal at all. In the next experiment, restrained eaters ate the same amount when anticipating a high-calorie as when anticipating a low-calorie meal, whereas unrestrained subjects again ate more only when anticipating a high calorie meal (Tomarken \& Kirschenbaum, 1984). From the inconsistency between the findings in the Ruderman et al. (1985) and the Tomarken \& Kirschenbaum (1984) studies it 
can be concluded that anticipated dietary violations disinhibit restrained eaters merely under some circumstances (Ruderman, 19866). It still has to be determined what are the crucial conditions for overeating to occur after anticipation of dietary violation.

\section{alcohol}

The knowledge that alcohol is a classical inhibitor led Polivy \& Herman $(1976 a, b)$ to hypothesize that the consumption of alcohol should disinhibit restrained eaters and make them overeat. But Polivy \& Herman's hypothesis could not be corroborated (Polivy \& Herman, 1976a). In constrast with what had been predicted, restrained eaters ate marginally less after the consumption of alcohol than after a non-alcoholic drink, whereas unrestrained eaters ate more after the alcoholic drink than after the non-alcoholic drink. According to Polivy \& Herman (1976a), it was a post hoc seemingly important point that subjects were not aware that they were drinking alcohol. In another study, Polivy \& Herman (1976b) manipulated subjects' beliefs about the alcoholic content of the drink. They hypothesized that it was the perception of drinking alcohol instead of the actual alcoholic content which determined the subsequent eating response. It was found that when restrained eaters drank alcohol and the drink was presented as alcohol, they subsequently ate more than when they thought that they had consumed vitamin $\mathrm{C}$. Unrestrained eaters, on the other hand, ate less when they thought they had ingested alcohol than when they thought they had ingested vitamin C (Polivy \& Herman, 1976b).

\section{emotional states}

It has repeatedly been demonstrated that, apart from eating or anticipating an (alleged) high-caloric food or alcohol preload, the induction of certain emotional states also elicits an overeating response in dieters (Herman \& Polivy, 1975; Baucom \& Aiken, 1981; Frost et al., 1982; Ruderman, 1985a; Herman et al., 1987). Herman \& Polivy (1975) found that anxious unrestrained eaters (expecting painful shocks) ate less than 'non-anxious' unrestrained eaters (expecting mild shocks), whereas anxious restrained eaters ate the same amount as 'non-anxious' restrained eaters. More recently, Herman et al. (1987) have refined their anxiety hypothesis. They found that anxious non-dieters only ate less when they were initially hungry and not when satiated. And anxiety increased eating in dieters when the dieters were initially hungry, but not when satiated. Other researchers manipulated mood, e.g. by manipulating success or failure in a cognitive problem solving task (Baucom \& Aiken, 1981; Ruderman, 1985a) or by having the subjects read self-referring statements, i.e. the Velten mood induction procedure (Frost et al., 1982). The generall finding is that restrained eaters eat more when depressed, whereas mood hardly influences the amount eaten by unre- 
strained eaters. In conclusion, negative affective states generally increase the consumption of restrained eaters (Ruderman, 1986b).

\section{monitoring}

Research did not anly focus on the stimuli which disinhibit dieters; attention was also paid to experimental manipulations which prevent dieters from the typical non- or counterregulatory response. More specifically, the manipulation of monitoring practices (either self-monitoring or monitoring by others) was found to influence the dieters' food consumption. Kirschenbaum \& Tomarken (1982) showed that the introduction of self-monitoring cues could prevent dieters from overeating. Preloaded dieters who were subsequently given ice cream in a small bowl with a label giving accurate information about calorie content were able to regulate their food intake, whereas preloaded dieters who subsequently ate from a large bowl without a calorie label overate. It was a rather unexpected finding that without any self-monitoring cues (large bowls and no calorie label) restrained as well as unrestrained subjects ate much. When one cue was present, restrained eaters ate significantly more than unrestrained ones.

Polivy et al. (1986) found that heightened self-attention (the subject exactly registered how much she ate) as well as the awareness of public attention (the experimenter could see exactly how much was eaten) inhibited the consumption by dieters after a preload. Non-dieters' food consumption, on the other hand, was not influenced.

Earlier, Polivy and co-workers (1979) showed that the food intake of dieters and non-dieters after a preload is influenced by the presence of a model. In the presence of a stooge who overate, dieters, as well as non-dieters ate, significantly more than in the presence of a stooge who did not overeat (Polivy et al., 1979).

Self-observation may serve as an effective inhibitor of overeating in dieters, because the dieter's attention is refocussed on dietary concerns.

In sum, laboratory research shows that restrained eaters can be disinhibited by a motley collection of stimuli. Overeating, i.e. non-regulation of food intake or even counterregulation, is easily induced in dieters; stimuli which may act as disinhibitors are (1) actually eating a high-calorie prelload, (2) the perception (wrong or not) of having eaten a high-calorie preload, (3) the notion that a high-calorie preload will be eaten, (4) the idea of hunger (5) the notion that alcohol has been drunk (6) being anxious and (7) being depressed. Furthermore, it has been shown that self-monitoring practices prevent the dieter from overeating.

Although the data presented concern miniature binges in the laboratory, they are valuable. The model appears to be a good model. The antecedent stimuli for clinical binges seem remarkably similar to the kinds of stimuli investigated in the laboratory (Polivy \& Herman, 1985). But why use a model? A model is relatively easy to understand. It is a good means 
of learning more about reality on condondition that the mechanism c.q. the causal processes are understood. The next question, then, is: how can the disinhibition of dieters be explained? In the next section current explanations of the experimental data on the disinhibition of restrained eaters are reviewed briefly (cf. table 1).

\section{5 how does the 'disinhibitive' mechanism work?}

From table 1, it becomes clear in how many different ways the identical phenomenon of dieters' overeating after a variety of stimuli is explained. When details are ignored, the different explanations can roughly be divided into four main views: (1) a physiological view, (2) a cognitive view, (3) a view that is no view (pseudo-explanations), and (4) a blind spot (forgotten explanation).

Ad 1. The physiological explanation states that dieters are chronically hungry. Their actual weight is supposed to be below their biologically determined set point level for body weight, which should trigger an urge to binge under appropriate circumstances, e.g. after various stimuli (Herman \& Mack, 1975; Hibscher \& Herman, 1977). This explanation will be discussed in 3.2 .

Ad 2. The cognitive explanation states that the perception of having overeaten disinhibits the dieter. That is, dieters reportedly perceive the (alleged) high-calorie preload as a violation of their diet and are said to respond to that with thoughts such as "I've blown my diet, I might as well continue to eat". Such thoughts are supposed to disinhibit the dieter temporarily (Polivy, 1976; Spencer \& Fremouw, 1979; Woody et al., 1981). Anticipated dietary violations reportedly have the same cognitive effect as real or perceived dietary violations (Tomarken \& Kirschenbaum, 1984; Ruderman et al., 1985). This cognitive explanation will be discussed in 3.4 .

Ad 3. The third series of explanations is called pseudo because they are, in fact, descriptive and do not explain anything. Dieters' non-regulation or counterregulation after the induction of an anxious or depressed mood is usually "explained' as a loss of self-control (Herman \& Polivy, 1975; Frost et al., 1982; Ruderman, 1985). Strong emotions alledgedly disrupt the cognitively mediated self-control processes, and consequently restraint, resulting in overeating. Clearly, this tautological description lacks the slightest explanation of counterregulation.

Herman \& Polivy (1984) have recently integrated the different explanations in a biopsychological boundary model. The model states that consumption is regulated by biological needs as well as by psychological influences. When hunger or satiety passes a certain boundary, it is aversive and people start or stop eating. Between the boundaries of hunger and satiety there is an area of biological indifference. Normally an organism strives to be in the zone of biological indifference: the aversive- 
ness of hunger keeps consumption above a minimum level while the aversiveness of satiety keeps consumption under a maximum level. In the zone of biological indifference, psychological (e.g. cognitive and sociali) factors dominate the determination of human eating behavior. It is crucial that, according to the boundary model, dieters and non-dieters differ in the place of their boundaries. In dieters, the area of biological indifference is wider than in non-dieters: dieters have lower hunger boundaries and higher satiety boundaries, i.e. they have to be more deprived to report hunger and they can eat more before reporting satiety. Furthermore, dieters have a 'diet' boundary. Passing this diet boundary, i.e. breaking the diet, means excessive eating. The diet boundary is a cognitive one: the boundary determines the maximum amount that dieters wish to eat. But, when this diet boundary is passed, dieters eat until they reach their (highil) satiety boundary. According to Herman \& Polivy (1984), the proposal of a cognitive diet boundary may account for counterregulation: normally (i.e. when not dieting), a person eats until the satiety boundary is reached. That is, non-dieters will eat less after a preload than without one. However, dieters usually eat until they reach their diet boundary. That is, without a preload they eat little. But after a preload, the diet boundary is passed and the dieter will eat to the (high) satiety boundary is reached (Herman \& Polivy, 1984).

Post hoc, the boundary model appears to cover the findings on counterregulation after an (alleged) high-calorie preload reasonably well. The perception of having passed the diet boundary may lead the dieters to eat until their high satiety levels have been reached. However, the boundary model can be criticized for several reasons. First, when it comes to covering the non-regulation of anxious or depressed dieters, the model only holds by virtue of an auxiliary hypothesis. According to the makers of this model, anxious or depressed dieters counterregulate because emotions are more urgent than dietary concerns; the dieter has to decide how to cope with the stressor, thereby forgetting to diet (Herman \& Polivy, 1984).

Second, the model can be criticized for its lack of explanatory power. The boundary model is of a descriptive nature and does not explain why dieters regularly pass the diet boundary.

The model predicts that dieters will only overeat when they pass their diet boundary. In other words: the model will be falsified when dieters counterregulate without passing their diet boundary (cf, 5.8).

$\mathrm{Ad} 4$. The blind spot of the forgotten explanation. Curiously, the series of explanations given for laboratory data on counterregulation does not exactly parallel the different explanatory models for clinical binge eating. The physiological set point theory and the cognitive explanation appear both in the literature on lab counterregulation and in that on clinical binge eating. As was mentioned before, these explanations will be discussed more extensively in the next chapter (cf.3.2 \& 3.4). However, attention will also be paid to a biopsychiatric explanation that is hardly ever mentioned 
in the literature on experimental research, but is a popular theory when it comes to explaining clinical binge eating. This biopsychiatric theory claims that a lowered serotonin level is responsible for binge eating and the accompanying depression (cf.3.3).

In sum, dieters counterregulate after the introduction of certain stimuli. The question is why. Many explanations are offered. The explanations of laboratory data can roughly be divided into physiological, cognitive, pseudo, and forgotten explanations. The pseudo-explanations were especially criticized for their merely descriptive nature and their lack of explanatory power. Physiological and cognitive theories, as well as the forgotten explanation, will be discussed in the next chapter.

\section{6 summary}

With the introduction of a laboratory model, Schachter gave the first impulse to decades of fruitful experimental research on eating behavior. But Schachter's original hypothesis, that obese people eat in response to external stimuli and not as a consequence of internal cues, could not stand critical (replication) tests. The amount of self-reported restraint in eating behavior appeared to be a more critical determinant of eating responses. The disinhibition hypothesis was put forward: restrained eaters usually diet but they may temporarily overeat after the introduction of a so-called disinhibitor. A variety of disinhibitors (e.g. preloads, cognitions, and emotions) have been found to trigger the overeating response in dieters but not in non-dieters. Why? Several explanations have been presented. Except for the boundary model, which is claimed to be descriptive and does not explain anything, the different theories will be examined critically in the next chapter. 


\section{1 introduction}

In the past two decades, several hypotheses which should account for counterregulation or binge eating were formulated. In the present chapter, three important explanations that have been proposed to account for counterregulation, or episodes of binge eating, are reviewed. According to the set point hypothesis (cf.3.2) dieters are below their biologically determined set point for body weight, which is supposed to trigger the urge to overeat. The 5-HT hypothesis (cf.3.3) claims that binge eating is the consequence of a diet-induced hyposerotonergic brain state. The cognitive explanation (cf.3.4) states that dysfunctional thoughts concerning food intake are of primary importance in triggering an eating binge or counterregulation. The different hypotheses will be examined critically with respect to their explanatory power and the predictions that follow from them.

In section 3.5 an alternative explanation of counterregulation is presented. The alternative model states that counterregulation or binge eating is cue-controlled. Five postulates of the model are discussed.

\section{2 being below set point}

3.2.1 the set point theory in the eighties

"....in the population of normal weight individuals there exists a subpopum lation who is actively restraining their eating to maintain a socially sanctioned weight that is low relative to their biologically set or physiologically optimal level." (Woody et al., 1981, p. 382).

"Persons who score high on measures of Dietary Restraint are thought to be those whose weights are below their 'biological setpoints' (Nisbett 1972) because they vigilantly monitor and restrict their food intake." (Blanchard \& Frost, 1983, p.259).

"An alternative model presented by Nisbett (1972) proposed that everyone has a biologically determined ideal weight or set point." (Ruderman \& Christensen, 1983, p 210).

"Based largely on Nisbett's (1972) set-point hypothesis, restrained eaters are considered to be in a state of chronic hunger as a result of continual 
attempts to suppress their weight below a physiologically determined set point." (Tomarken \& Kirschenbaum, 1984, p.459).

"....following Nisbett (1972)" it is "suggested that restrained eaters (dieters) strive to maintain body weights below set point, whereas unrestrained eaters (nondieters) do not." (Esses \& Herman, 1984, p.712).

"Weight appears to be physiologically regulated around a 'set point', or a weight that one's body tries to 'defend'" (Garner et al., 1985, p.515).

"The logic of Nisbett's (1972) argument that the majority of obese resemble starved organisms because of their attempts to suppress their weight below natural levels may be extended to all chronic dieters, regardless of their weight" (Garner et al., 1985, p.539).

"Successful dieting produces weight loss, which in turn might create a state of chronic hunger, especially if such weight loss leaves the dieter at a weight below the set-point weight that is defended physiologically." (Polivy \& Herman, 1985, p.196).

"Despite these negative findings (to support Nisbett's predictions, A.J.), Nisbett's basic concept of a homeostatically defended body weight remains viable" (Ruderman, 1986b, p.248).

It is clear: Nisbett scores high on the citation index for the literature on counterregulation, c.q. binge eating. The above citations illustrate that, even in the eighties, Nisbett's set point theory is still a popular theory when it comes to the explaining of counterregulation in the lab and clinical binge eating. Researchers on counterregulation and binge eating repeatedly refer to Nisbett's set point theory to explain dieters' overeating. The set point theory, as it is cited above and described below, is a rather old-fashioned conceptualization, but it is still a leading theory in counterregulation literature. In the present section it will be argued that it is wrong to take the set point theory uncritically as being true, as too many psychologists do.

\subsection{2 the set point hypothesis}

The set point hypothesis for body weight or its correlate body fat stems from the idea that many physiological processes are regulated by homeostatic mechanisms. In the early seventies the idea took shape that an organism's amount of body fat is regulated by a homeostatic mechanism, just as there is a thermoregulatory set point. The theory states that every organism is prepared to possess a characteristic amount of fat. The idea is that the amount of body fat is registered constantly and that, via feedback processes, a homeostatic control mechanism is informed about the amounts of body fat actually present in the organism. If deviations 
from the set point are registered, i.e. it more or less fat is present than the set point level requires, processes will be started up to restore the amount of fat to the set point level.

Pioneers of the notion that there is a set point for body fat argued that the eating pattern of overweight people (cf. 2.2 \& 2.3) is, in fact, an epiphenomenon of dieting (Cabanac 1971; Cabanac \& Duclaux, 1970; Cabanac, Duclaux \& Spector, 1971; Nisbett 1972, 1974). Nisbett pointed out that there are remarkable similarities between obese and hungry individuals: both were found to be hyperemotional, hypoactive and showed decreased sexual interest. His assumption, which seems paradoxical at first sight, was that many fat people were actually hungry and 'underweight'. According to Nisbett's theory, these people should have a high set point for body weight, i.e. a high biologically preprogrammed body weight. This set point weight apparently does not fit in with the socio-cultural ideal of slenderness. With the intention of reaching the ideal weight, people go on a diet and bring down their actual weight below set point level.

Four lines of evidence that back up set point theory can be distinguished:

Cabanac's alliesthesia method

Cabanac (Cabanac 1971; Cabanac \& Duclaux, 1970; Cabanac, Duclaux \& Spector, 1971) stressed the importance of sensory feedback processes in the regulation of food intake. In several experiments it was found that the pleasantness ratings of the taste of sucrose normally decreased significantly after subjects had eaten a glucose preload. Fasting subjects and a subsample of obese subjects, however, still rated the sucrose stimulus as very pleasant after a preload of glucose (Cabanac \& Duclaux, 1970; Cabanac, Duclaux \& Spector, 1971; Guy-Grand \& Sitt, 1975). The normal decrease in perceived pleasantness of sweet stimuli after a glucose preload, is called negative alliesthesia by Cabanac (1971) and is supposed to be functional in determining the moment people stop eating because of satiety. Cabanac (1971, p.1103) argued that "a stimulus can feel pleasant or unpleasant depending upon its usefulness as determined by internal signals". He supposed that negative alliesthesia is dependent on the (dis)agreement between the actual body weight and its set point value. When actual weight corresponds to set point weight, sweet stimuli will be evaluated as unpleasant after a glucose preload, because further food intake would lead to a body weight higher than preset. With the reduction of body weight to bellow set point level negative alliesthesia (the taste of sugar becoming less pleasant after a glucose preload) disappears. For, when people are below their set point for body weight, further food intake is necessary for reaching the preset level of body weight again. Cabanac claimed that the set point of obese people is, naturally, set at a higher body weight. "If the obese person, for health or social reasons, combats his obesity, he will lower his body weight below the set 
'obese' level, negative alliesthesia will disappear and satiety will be impaired." (Cabanac, 1971, p.1107).

\section{stability of body weight under natural conditions}

The idea of body weight being regulated at a specific level or 'set point' has strong face value: the commonsensical intuitive appeal that there has to be 'something like a set point for body weight' is mainly based on the notion that body weight remains relatively constant over long periods and under various circumstances. It is astonishing that, through the years and despite enormous inter- and intra-individual differences in food intake and energy expenditure, body weight is quite stable (Keesey, 1980, 1986). The regulation of body weight is based on the balance between energy intake and energy expenditure; a stable body weight means that energy intake and energy expenditure are in balance. Despite divergent living conditions, body weight of people living in technologically advanced societies (with much 'junk' food and sedentary lives) is usually little different from the body weight of say, Eskimo (who do not eat any junk food and expend much energy on activity). And even intra-individual variations in food intake do not lead to weight changes expected because of caloric excess/debt (Keesey, 1980, Sims, 1974).

\section{resistance to displacement from body weight}

Normally, people strongly resist deliberate attempts at weight loss or weight gain. Dieters can lose weight temporarily but will soon regain it, whereas overeaters can gain weight temporarily but will soon lose it again. When dieters at reduced body weight restore their calorie intake to normal, they gain weight many times more rapidly than non-dieting normal weight subjects eating the same amount, even without overeating (Keesey, 1980). And, the other way around, normal weight students who wanted to gain weight had difficulty in adding even $10 \%$ to their normal weight (Sims, 1974). Gaining weight was difficult (for gaining weight double calorie intake was required) but it was even more difficult to maintain the increased weight: continued overeating and a larger and larger intake of food was required to maintain the overweight. After force-feeding was stopped, body weight rapidly returned to normal level, even without dieting. Energy was used less efficiently by the increase of the rate of metabolism, the so-called luxury-consumption. It is clearly difficult to maintain the displacement of weight from the normally maintained level (cf. the alleged set point). Organisms resist being displaced from their body weight set points by adjusting their rates of energy expenditure: energy is used more or less efficiently, by respectively reducing or increasing the speed of metabolism. 
stability and defense of a new; experimentally induced.

body weight

After experimentally induced lowering or elevation of the alleged set point level, this new level is defended as effectively as the original set point was (Keesey, 1980, 1986). After a lesion in the lateral hypothalamus (LH), rats lose weight rapidly. The weight loss of $\mathrm{LH}$-lesioned rats is due to higher rates of energy expenditure immediately after the lesioning (Keesey \& Corbett, 1984) and decreased food intake. The hypermetabolic state persists until body weight is reduced to the level which will eventually be maintained (Keesey \& Corbett, 1984). Thus, weight stabilizes at a lower level and the energy balance is normal again after a while. It should be noted that non-lesioned animals will be hypometabolic when their weight is lowered to the level of LH-lesioned animals. But LH-lesioned rats show normal rates of heat production and metabolic defense at these reduced levels. And, moreover, the LH-lesioned rat does not only regulate its 'new' weight precisely at the lower level, but it also defends the lowered body weight effectively when challenged, e.g. after force-feeding or dietary restriction. When an LH-lesioned animal's weight drops below its new set point, hypometabolic adjustments occur and the animal displays the same hypermetabolic response to diet-induced weight gain as a nonlesioned animal does (Keesey 1980).

The genetically determined obese Zucker rat (with an abnormally high number of large-sized fat cells), on the other hand, maintains and defends a high body weight. At this high body weight, food intake is normal and energy requirements for maintenance are normal. When challenged, i.e. in case of dietary restriction or force-feeding, the obese Zucker rat effectively defends its high weight by metabolic adjustments. These observations are interpreted as consistent with the idea that body weight is regulated around an elevated set point in the Zucker rat (Keesey, 1980).

In sum, set point theory postulates the existence of a mechanism that determines how fat a body will be. The mechanism aims at a balance in energy input and energy output. A change in set point in fact means a change in the regulation of the input-output balance at a higher or lower body weight level. Arguments for the existence of a such a mechanism are: (1) dieters do not show the normal decrease in sweet preference after ingestion of glucose (2) the stability of body weight over long periods, (3) organisms have great difficulty in keeping their reduced or heightened body weight for a long time, and (4) atter the 'set point' is experimentally lowered or elevated, this new level is defended as effectively as the original "set point' was.

However, several critical remarks can be made about the set point idea. First, the concept of a set point will be critically examined. Second, it is questionable whether the set point theory is appropriate for explaining counterregulatory or binge eating behavior: being below set point re- 
quires successful dieting. But is successful dieting really as important as set point theory implies?

\subsection{3 four crifical comments on the set point concept}

the significance of alliesthesia

Cabanac's concept of alliesthesia can be criticized for at least two reasons. First, it should be noted that the experimental findings on alliesthesia are unequivocal. Esses \& Herman (1984) found that both dieters and non-dieters showed negative alliesthesia. After a glucose preload, dieters even valued the sucrose solutions as less pleasant than non-dieters. Second, the basic idea is that negative alliesthesia has biological significance. It is assumed to be functional in the regulation of body weight. Wooley, Wooley \& Dunham (1972b), however, challenged this idea: they found a simitar decrease in perceived pleasantness after intake of a non-caloric but equally sweet solution as the glucose preload. The authors are right in arguing that "it is highly unlikely that ingestion of 200 $\mathrm{ml}$ of $25 \%$ glucose (approximately 200 calories) would eliminate all need for food (...) regardless of physiological need, such subjects may still find certain nonsweet tastes (i.e. bacon and eggs) pleasant even after ingestion of a considerable amount of glucose solution.." (Wooley, Wooley \& Dunham, 1972b, p.768).

\section{post hoc selection of fitting and unfitting findings}

As was mentioned before, after a lesion in the lateral hypothalamus, rats regulate and defend their new weight precisely. According to set point theorists, this finding is a shining example of a new set point. After a lesion in its ventromedial hypothalamus (VMH), however, a rat is hyperphagic until it has reached a higher body weight, but stable weight is maintained only when the quality and the nature of the diet (i.e. the flavor, texture, sweetness, and smell) remain the same. In the case of dietary manipulations, VMH-lesioned rats do not show metabolic adjustments to defend the induced obesity. That is, when the diet is less palatable, the body weight is soon restored to normal levels, without metabolic defense of the former weight (Keesey \& Corbett, 1984). And, vice versa, when the diet is very palatable, VMH-lesioned rats become very obese (Keesey, 1980). Although Bennet \& Gurin (1982, p.96) claim that, in response to the palatability of the diet, VMH-lesioned rats "reset their set point and then eat as much as they need to keep the fat store constant at the new level" (sicl), Keesey (1980, p.153) argued that "it seems inappropriate to view the effects of such lesions in terms of an altered set point". According to this prominent set point theorist, "the point is that VMH-lesioned rats do display certain regulatory deficits, particularly in the defense of their obesity. For this reason they are not well suited for studying the issue now under consideration, namely, how body weight is regulated around a high 
set point" (Keesey, 1980, p.154). This poses serious problems for the theory. Why are LH-lesions (data fitting with the theory) in advance far more convenient than VMH-lesions (non-fitting data)?

\section{circularity}

With respect to individual diagnoses (how should someone's set point for body fat be determined?) and with respect to the exact mechanism of action people do not shrink from putting forward circular arguments. Concerning the first issue, set point theory stemmed from the observations that body weight is normally very stable and difficult to change over longer periods. Because of this it is circular to reason that the set point of someone's body weight is the body weight to which he spontaneously returns (cf. Bennet \& Gurin, 1982) or to claim that the actual weight of an organism is below its set point "when they become more efficient at utilizing a given amount of food" (Mrosovsky, 1983, p. 201-202). Mrosovsky (1983) even seriously proposed to determine whether someone is at or below his set point by using Cabanac's alliesthesia method. Both criteria (a more efficient utilization of energy, and Cabanac's alliesthesia method) were the very observations that led to the notion of an alleged set point. Note that here 'set point' is a descriptive label that is merely a redescription of other phenomena and does not offer any new information.

A more formal option is offered by Kleiber (see Keesey, 1980; Keesey \& Corbett, 1984). Energy needs are expressed as a power function of body weight: Kleiber's rule. This rule states that energy needs are proportional to the $3 / 4$ power of body weight, which only holds when an organism is at its set point level for body weight. Again, but now in formal arithmetical terms, it is described that with weight loss or weight gain, adjustments in energy output take place. The observation of energy adaptation, an observation that once led to the introduction of the concept of set point, is now presented as evidence of the existence of a set point level. This is like saying that someone acts crazy because he is schizophrenic and that we know that he is schizophrenic because he acts crazy. So far, independent determination of the alleged set point for body weight has not been possible. And the model lacks any unique and testable predictions when it comes to this.

The second series of circular reasoning concerns the exact mechanism of action. Set point theory claims that "..the body does 'care'. Built into every person is a control system dictating how much fat he or she could carry. We'll speak of this control system as determining a setpoint for body fat.." (Bennet \& Gurin, 1982, p.6). However, the exact mechanism of action is still unknown. The anthropomorphistic notion that there is a system in the body which attempts to maintain a 'preferred' fat content gets bogged down in homuncular reasoning. The functional details of the system are not yet understood. What 'mechanism' is informed in what way about what state of the organism? 
the precision of the model

The term set point presumes a fairly precise, accurate and hardly changeable mechanism. However, this does not fit in with all the facts.

Empirical data show a remarkable facility changing the set point for body weight by a change in the diet. Set point can be changed by a more or less varied and palatable diet (Sclafani, 1980; Bennet \& Gurin, 1982) and it can be heightened after long-term fat feeding, that is after months of high-fat diet (Van Itallie, 1984). Moreover, exercise has been found to lower 'set point' level (Bennet \& Gurin, 1982). It is not appropriate to talk about a fairly precise energy regulatory mechanism when this mechanism can relatively easily be changed by variations in energy input or output. It is questionable whether observations that could falsify the theory are possible. This is slightly reminiscent of psychoanalysis: everything is possible.

In sum, the set point concept lacks preciseness and falls a prey to post hoc and circular reasoning. Mrosovsky \& Powley (1977) hit the nail on the head when they, tentatively, stated that using of the term set point is just "a redescription of the data that adds nothing but the illusion of understanding". The concept of 'set point' is merely a non-explanatory classification of observations. As the physiological basis of the concept set point is not yet understood, it is of great importance that the concept be used appropriately. As a descriptive term, 'set point' could be convenient. In fact, set point refers to an adaptation in energy metabolism after weight has been challenged. But when it is claimed to be explanatory, it should lead to unique predictions, i.e. predictions other than adaptation in energy metabolism when weight has been challenged. If the physiological mechanisms by which weight or fat are regulated exactly are discovered, the idea of a set point may even prove unnecessary.

Meanwhile, the set point theory has generated and stimulated much sophisticated research on energy metabolism (see e.g. Scheurink, 1989). In this research, short-term regulation is differentiated from long-term regulation and, in the latter, insulin appears to play an important part. Researchers of counterregulation/binge eating should first update their knowledge before concluding uncritically that dieters counterregulate and bulimics binge eat because "they are below their biologically determined set point for body weight".

3.2.4 set point theory and counterregulation in the lab

Set point theory implies that a person's body weight will be lowered to a sub set point level after a period of successful dieting and, that at that very moment, the body tries to restore its weight to set point level by means of binge eating. Dieting and bingeing do usually co-occur (Polivy \& Herman, 1985). Repeated dieting is claimed to be a risk factor for bulimia nervosa and about $80 \%$ of patients with bulimia nervosa tried to lose weight by strict dieting prior to the onset of binge eating (Pyle et al., 1981; Fairburn 
\& Cooper, 1982; Striegel-Moore, Silberstein \& Rodin, 1986; Rossiter, Wilson \& Goldstein, 1989; Mizes, 1985; Fairburn "Cooper \& Cooper, 1986). Furthermore, about $50 \%$ of the anorexia nervosa patients develop binge eating episodes about 9 to 18 months after the onset of the strict dieting practices (Wardle \& Beinart, 1981; Polivy \& Herman, 1985; Laessle et al., 1989), and non-clinical dieters report significantly more binge eating than non-dieters (Wardle, 1980). The above-mentioned data on the co-occurrence of dieting and bingeing have been derived retrospectively from clinical reports. They therefore have to be handled with caution when it comes to the chronology and temporal relationship between dieting and bingeing. Also, the laboratory studies on counterregulation presented earlier (cf. chapter 2), which show that especially dieters are prone to disinhibition and overeating, are in fact of a correlational nature. It should therefore not be ruled out that bingeing causes dieting or that there is a third underlying mechanism which explains the co-occurrence of dieting and bingeing. There are few direct data supporting the causality between dieting and binge eating (Fairburn, Cooper \& Cooper, 1986); only two empirical studies were carried out. In the early fifties, Keys and co-workers (1950) studied 36 soldiers on a semi-starvation diet for 24 weeks. After several months the soldiers had lost $26 \%$ of their initial weight. When food was available again, after the experiment, the soldiers indulged in severe binge eating episodes. It was not until the amount of body fat was normal again that the excessive food intake stopped. And lately, Wardle \& Beales (1988) have studied the effects of dieting on laboratory food intake regulation: Overweight subjects took part in a weight loss treatment program, in which some of them dieted and some did not. After three weeks, only the 'dieters', who had lost more weight than the non-dieters, showed the typical laboratory phenomenon of counterregulation.

These data support the idea that dieting is a sufficient condition for binge eating. However, there is one anomaly which the set point theory can not account for. If a set point for body weight really exists, anorexia nervosa patients are certainly below their set point. However, $50 \%$ of the anorexia nervosa patients never binge eat, despite the fact that they are starving themselves. Clearly, being below set point is not a sufficient factor for binge eating.

In sum, retrospective data suggest that dieting increases the chance of binge eating. However, empirical data are scarce and a serious anomaly ( $50 \%$ non-bingeing anorexia nervosa patients) cannot be covered by the set point theory.

When the set point theory is put forward to explain the lab data on counterregulation, the implicit assumption is made that counterregulating, highly restrained subjects are, in fact, underweight or at least significantly food-deprived. In this case the classification of subjects into dieters and non-dieters is crucial. The experimental data on counterregulation are 
mainly based on the classification of subjects into dieters and non-dieters by means of the empirically derived Restraint Scale (RS; Polivy, Herman \& Warsh, 1978). Lately, however, the RS has been subject to psychometric as well conceptual criticism (Blanchard \& Frost, 1983; Johnson, Lake \& Mahan, 1983; Ruderman, 1983, 1985b; Stunkard \& Messick, 1985; van Strien et al, 1986a, 1986b; Wardle, 1986, 1987a; Ganley, 1988; Heatherton et al., 1988). Psychometrically, the RS has been criticized for its factor structure and, conceptually, for its seemingly paradoxical entanglement of dietary restriction and overeating. For the sake of relevance, attention will only be paid to the last point of criticism.

Set point theory presumes that counterregulating subjects are below their set point, whereas regulating subjects are not. In laboratory experiments high scorers on the RS, i.e. dieters, were found to counterregulate, in contrast to low scorers, li.e. non-dieters. This presupposes that high scorers on the RS are below their set point weight, whereas low scorers are not. However, the RS has been criticized because the scale may measure both the tendency to overeat and the intention to restrict food intake. Then, there may be a tautological element in the finding of counterregulation in high scorers: they were beforehand selected on disinhibitive tendencies. Heatherton et al. (1988) only found the typical counterregulation pattern when subjects were classified as restrained or unrestrained by the RS, which measures both intention to restrict and overeating (see above). The pattern disappeared when subjects were re-classified on the basis of pure measures of restraint (i.e. the TFEQ: Three Factor Eating Questionnaire). Likewise, Wardle \& Beales (1987) did not find counterregulation at all in high scorers on another pure measure of restraint (i.e. the restraint subscale of the DEBQ: Dutch Eating Behavior Questionnaire). From these lab studies on counterregulation it appears that dieting (and consequently being below the hypothetical set point) is insufficient for predicting counterregulation: what counts in these studies is a combination of intention to diet and an overeating tendency: This issue will be further dealt with in 5.2 .

\section{3 a lowered 5-HT level}

\subsubsection{5-HT and binge eating}

In the previous section it was noted that the restriction of calorie intake and binge eating is certainly not a one-to-one relationship. In this section the possible role of a selective restriction of carbohydrate intake in binge eating is reviewed in detail.

1 This section is a marginally changed version of the submitted article "Food, Mood and 5-HT" written by A. Jansen, M.A. van den Hout, A. Tuiten \& F. ten Hoor. 
In the past decade an intriguing hypothesis about serotonin ( $=5$-hydroxytryptamine $=5-H T$, depression and carbohydrate craving has gained in popularity. Fernstrom \& Wurtman (1972) found a relationship between the composition of meals, i.e. consumption of proteins and carbohydrates, and the synthesis of 5-HT in the rat brain. Eating a meal which is rich in carbohydrates and poor in protein is conducive to the synthesis of central $5-\mathrm{HT}$, while a meal which is rich in protein and poor in carbohydrates decreases the synthesis of serotonin. In its turn, a low level of 5-HT in the brain is found to stimulate carbohydrate intake, while a high level of this neurotransmitter stimulates the intake of protein.

According to Wurtman and co-workers $(1981 ; 1982 ; 1984 b ; 1985 ; 1986)$, carbohydrate craving may be caused by a disturbance in this serotonergic regulation. More specifically, they suggest that, since there is an overlap between appetitive and affective disorders, carbohydrate craving "reflects a misuse of the foods as though they were drugs, i.e., to produce by increasing brain serotonin synthesis, mood changes associated with serotoninergic anti-depressants" (Wurtman \& Wurtman, 1986; p.99). Indirect support for this view comes from the often found association between depression and a lowered 5-HT activity (van Praag et al., 1987a, $1987 \mathrm{~b}$ ) on the one hand, and, on the other hand the finding that approximately $70 \%$ of the obese carbohydrate cravers satisfy the DSM criteria for major depression (Leckie \& Withers, 1967). Also, Stunkard reported about the 'dieting depression" in the obese as early as 1957. Moreover, Rosenthal \& Heffernan (1986) reported that at least a subgroup of depressives periodically overeat themselves, in particular on carbohydrates. Thus, there are some clinical data to support the hypothesized food, mood, and 5-HT connection.

Recently, some authors (Kaye et al., 1984; Kaye \& Gwirtsman, 1985; Rosenthal \& Heffernan, 1986; Rock \& Yager, 1987; Goldbloom, 1987) extrapolated the hypothesis about carbohydrate craving and a lowered serotonergic functioning to bulimia nervosa (BN). Clinical reports, psychometric data and family studies show that BN goes together with depression more often than could be suspected on the basis of chance (Hudson et al., 1982; Leckie \& Withers, 1967; Swift et al., 1985; Cooper \& Fairburn 1986; Lee et al., 1985). Following Wurtman and co-workers, Rosenthal \& Heffernan (1986), Kaye et al. (1984), Kaye \& Gwirtsman (1985), Rock \& Yager (1987) and Goldbloom (1987) hypothesized that $\mathrm{BN}$ and depression may share a decreased activity of the serotonergic system. This hypothesis of hyposerotonergic activity in BN fits in with the observations that dieting is an important factor that predisposes people to the development of binge-eating (Wardle, 1980; Polivy \& Herman, 1985; Ruderman, 1986), while the composition of the diet of periodically bingeing people is supposed to be characterized especially by the avoidance of carbohydrates (Beumont et al., 1981; Pope \& Hudson, 1984; Johnson et al., 1982; Goldbloom, 1987). Consumption of some carbohydrates by these alleged carbohydrate-avoiding dieters is supposed to lead, almost 
unavoidably, to an excessive binge on carbohydrates. It was speculated that the avoidance of carbohydrates by dieters will lower the serotonergic activity in the brain and will end up in a carbohydrate-rich binge in order to heighten the 5.HT level again (Wurtman \& Wurtman, 1984a; Kaye et al., 1984; Kaye \& Gwirtsman, 1985; Goldbloom, 1987; Goldbloom et al., 1988; Brewerton et al., 1988; Hansen et al., 1988). This hypothesis has been tested by the present author (cf. 5.3 ).

Furthermore, concerning the 5-HT mood association, carbohydrates appear to have an effect on the improvement of mood (Spring et al., 1987). Schweiger and co-workers (1986b) experimentally contirmed that changes in mood during dieting are dependent on macronutrient intake: mood elevated with increasing carbohydrate proportions of nutritionall intake. Thus, though it remains to be established directly if serotonergic pathways are involved, there is at least one experimentally demonstrated association between mood and carbohydrate consumption.

In sum, from a variety of sources there is converging evidence that carbohydrate bingeing and depression are empirically related. It is hypothesized that the linking biological marker for these disorders is a lowered 5-HT transmission. The carbohydrate-binge is thought to be a form of "self-medication" (Kaye et al., 1984; Kaye \& Gwirtsman, 1985; Rosenthal \& Heffernan, 1986; Wurtman \& Wurtman, 1986; Rock \& Yager, 1987; Goldbloom, 1987). While some people with 5-HT dysfunctioning will mainly complain of depression and consider their carbohydrate bingeing and weight gain as secondary, others primarily complain of obesity or $\mathrm{BN}$ and consider their dysphoria as secondary. In both forms the bingeing of carbohydrates raises the central synthesis of $5-\mathrm{HT}$ and will thus diminish the dysphoria (Wurtman \& Wurtman, 1986; Rosenthal \& Heffernan, 1986).

State generally, it is hypothesized that a particular disregulated brain state $\mathbf{A}$ [5-HT deficiency] produces a particular mood state $\mathbf{B}^{1}$ [depressed mood] as well as a particular behavior $\mathrm{B}^{2}$ [bingeing]. The function of $\mathbf{B}^{2}$ is considered to restore $\mathbf{A}$ and thus to improve $\mathbf{B}^{\mathbf{1}}$.

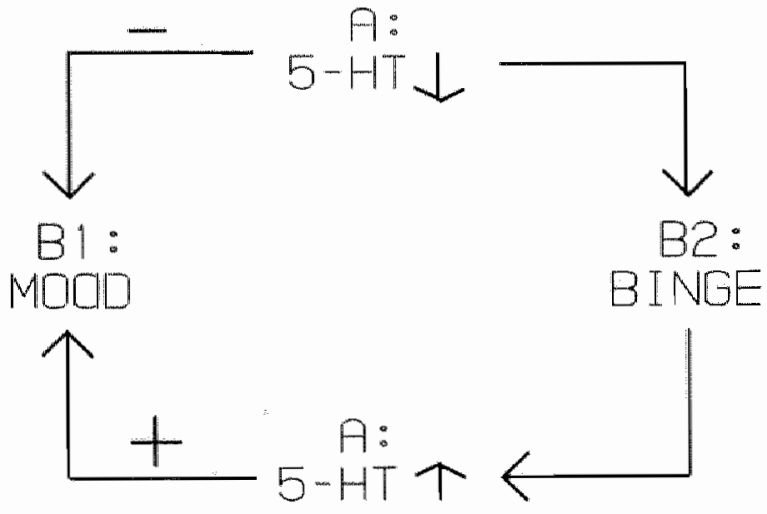

figure $2: 5 \mathrm{HT}$ madel 
Here we will concentrate on the assumption that lowered 5-HT induces carbohydrate bingeing, which in its turn raise central 5 -HT function. First, this line of reasoning will be critically examined. Secondly, it is discussed how the 5-HT model deals with counterregulation in the lab.

\subsection{2 five critical notes}

increased functionally active 5-HT through bingeing is unproven In the seventies, it was documented that increasing the ratio of the large neutral amino acid tryptophan (TRP) to the other large neutral amino acids (tyrosin, phenylalanin, leucin, isoleucin, valine, and methionin) raises the TRP, and thus $5-\mathrm{HT}$, level in the brains of rats (Fernstrom \& Wurtman, 1972). The TRP ratio can be heightened either by the consumption of a carbohydrate-rich/protein-poor meal, or by direct administration of tryptophan.

A remarkable and unexpected finding is, then, that oral administration of TRP in obese carbohydrate cravers (Wurtman \& Wurtman, 1981; Wurtman et al., 1981b; Heraief et al., 1985) and bulimics (Krahn \& Mitchell, 1985) did not have a diminishing effect on their craving for carbohydrates, resp. bingeing behavior. Following the 5-HT hypothesis about carbohydrate bingeing, one would suspect that increasing the plasma TRP ratio, either by consumption of a carbohydrate-rich/protein-poor meal or by administration of TRP, to result in an increased 5-HT turnover and thus in a lowered preference for/intake of carbohydrates. According to Heraief et al. (1985) "The mechanisms that (...) caused the drug (i.e. fenfluramin) to be more effective than the nutrient amino acid, have not been clarified" (p.289). This unexpected finding, that an increased TRP ratio does not have a diminishing effect on carbohydrate bingeing behavior, raises a crucial question: does eating carbohydrates or directly having TRP injected, really lead to a sufficient heightening of the 5-HT activity in the brain for behavioral effects to occur? There are several reasons why this can be doubted. Four crucial steps will be discussed: (1) does eating carbohydrates heighten the plasma TRP ratio?, (2) does an increased plasma TRP ratio lead to an increased TRP level in the brain?, (3) does an increased level of TRP in the brain raise the level of central 5-HT?, and (4) is a heightened 5-HT level in the brain really functionally active? About the first step; it was shown in several studies (Fernstrom et al., 1979; Heraief et al., 1983; Moller, 1985; Lieberman et al., 1986; Schweiger et al., 1986a, 1986b) that changing the composition of a meal indeed alters the plasma TRP ratio in humans. A meal which is rich in carbohydrates and poor in protein will lead to an increased TRP ratio, while a meal which is poor in carbohydrates and rich in proteins will decrease the TRP ratio. Differences in plasma TRP ratios after differently composed meals merely vary between 0.065 and 0.160 (Fernstrom et al., 1979). 
The second step deals with what happens with TRP after the plasma ratio has been enhanced, e.g. by direct administration of TRP or by the consumption of a carbohydrate-rich/protein-poor meal. It should be noted that TRP is the precursor of both serotonin and nicotinic acid ribonucleotide. BN is often accompanied by depression, and depression is associated with an enhanced cortisol concentration. Cortisol activates the enzyme TRP pyrrolase (Hoes et al., 1981). Induction of TRP pyrrolase means that more TRP is used for the biosynthesis of nicotinic acid ribonucleotide instead of for the biosynthesis of 5-HT (Hoes et al., 1981). Therefore it is reasonable to argue that in bulimia and depression the intake of carbohydrates or simply loading of TRP does not result in enhanced 5-HT synthesis: TRP pyrrolase activity will be induced and the TRP will especially be used for synthesis of nicotinic acid ribonucleotide instead of for that of $5-\mathrm{HT}$.

Moreover, administration of TRP may even endanger the synthesis of 5-HT: in the synthesis of TRP to 5-HT, but also in the synthesis of TRP to nicotinic acid ribonucleotide, pyridoxalphosphate is an important co-factor: It is the co-factor of 5-HTP to 5-HT and it is the co-factor of many transformations on the nicotinic acid pathway. When pyridoxalphosphate is only marginally present, which is often the case when people are dieting, and the nicotinic acid pathway is activated, too, e.g. through administration of TRP "especially the TRP 5-HT pathway will be at risk. There will be a decreased transformation of 5-HTP to 5-HT because especially the enzyme 5-HTP decarboxylase is sensitive to depletion of the co-factor pyridoxalphosphate (Scriver \& Whelan, 1969).

All in all, it may thus be questioned whether the elevated TRP ratio heightens the synthesis of 5-HT in depressed or dieting subjects.

The third step deals with the question whether an increased level of TRP in the brain raises the level of central 5-HT. Crucial is the supposed involvement of feedback processes in the control of 5-HT release. A change in brain TRP concentrations leads to an (in)activation of the enzyme tryptophan hydroxylation, by which brain 5-HT levels are maintained at normal concentrations. Green (1978) reported that central synthesis of 5-HT is controlled by the amount of released $5-\mathrm{HT}$ : increased 5-HT concentrations in the brain are followed by a decrease in 5-HT synthesis. According to Sanders-Bush (1982), increasing TRP concentration enhances the rate of 5-HT synthesis but does not necessarily enhance 5-HT release. However, Fernstrom (1985) argues that the end-product-inhibition by which the formation of $5-\mathrm{HT}$ is decreased or increased as a consequence of suppression or stimulation of the enzyme TRP hydroxylation is a relatively impotent mechanism of control and that recent data do not support the idea of rate of TRP hydroxylation control by end-product-inhibition. Thus, data concerning the involvement of feedback processes are equivocal.

With respect to the fourth step, whether a heightened 5-HT level in the brain is indeed functionally active, Green (1978) argued that turnover 
rates for $5-\mathrm{HT}$ calculated of $5-\mathrm{HT}$ synthesis do not reflect functional activity, since the amine normally is synthesized in excess of functional needs. The amount of 5-HT released is only a proportion of that which is synthesized. There are also indications for relatively stable intraneuronal serotonin pools, which are unavailable for release (Green, 1978; Sanders-Bush, 1982). And Aghajanian (1972) observed that administration of large doses of TRP result in a marked decrease in firing frequency of the raphe neurons. In sum, it might be a rewarding enterprise to unravel the complicated issue of feedbackmechanisms, end-product-inhibition, functional activity, and so on.

Finally, concerning the fourth step of a really functionally active 5-HT level in the brain, the observations of Trulson (1985) should be mentioned. By studying the effects of dietary experiments on the functional activity of 5-HT neurons in cats, Trulson (1985) did not find any change in activity of 5-HT containing neurons despite significant changes in brain 5-HT and 5-HIAA content. The increased 5-HT concentration following a TRP diet without competitive neutral amino acids was not functionally active and seemed to be catabolized intraneuronally (Trulson, 1985). Neither did the decreased 5-HT level after a TRP-free diet affect the functionally active 5-HT level. "The present data suggest that manipulations of dietary TRP does not alter the functional activity of brain serotoninergic neurons in contrast to previous hypothesis." (Trulson, 1985; p. 1071).

To sum up, it has been shown that eating a carbohydrate-rich/proteinpoor meal elevates the plasma TRP ratio in people. But there is a plausible alternative pathway for TRP to go; the extra TRP may be used for the synthesis of nicotinic acid ribonucleotide instead of for that of $5-\mathrm{HT}$. Furthermore, when more $5-\mathrm{HT}$ is synthesized it is important to know if more $5-\mathrm{HT}$ is released, too. There may be feedback mechanisms at work. In addition, it may be doubted whether extra synthesis of 5-HT will be actually functional. There are indications (Trulson, 1985) that heightening the TRP ratio in the periphery does not influence the central 5-HT activity. It is, therefore, doubtful whether eating carbohydrates results in functionally active 5-HT levels in the brain.

It is unclear if carbohydrate craving results from lowered 5-HT, heightened NA, or both

There are indications that noradrenaline (NA) is involved in carbohydrate bingeing. $A$ robust phenomenon was demonstrated by Leibowitz and coworkers (1985a, 1985b). They found that stimulation of the noradrenergic activity in the PVN of the medial hypothalamus resulted in a selective preference for carbohydrates, and an actual $59 \%$ increase in carbohydrate intake, whereas the intake of protein showed a decrease of $26 \%$. Leibowitz $(1983,1984)$ claims that episodes of overeating are accompanied by a general increase in peripherical sympathetic activation, mediated by enhanced NA-ergic functioning. 
In addition, it should be noted that administration of TRP in high doses interferes with the entrance of tyrosine into the brain (Growdon, 1979; van Praag \& Lemus, 1986). Tyrosine is the precursor of catecholamines (CA $=$ dopamine, noradrenaline and adrenaline). Because tyrosine is a large neutral amino acid, just like TRP, it competes with the other LNAAs, and thus with TRP, for a place on the transportmechanism for uptake in the brain. The ratio of tyrosine to the other LNAAs determines the amount of tyrosine in the brain available for the synthesis of the catecholamines. Oral administration of TRP should lead to enhanced TRP and thus 5-HT levels in the brain but may also decrease the uptake of tyrosine, because of their shared carrier. The decreased tyrosine uptake will result in diminished CA synthesis (van Praag \& Lemus, 1986); an oral dose of 2 to $10 \mathrm{~g}$ TRP is expected to slow catecholamine synthesis down (Growdon, 1979). Moreover, eating foods which are rich in carbohydrates, increases the synthesis of serotonin (Wurtman \& Wurtman, 1984a), but, according to Leibowitz \& Shor-Posner (1986a, 1986b) also inhibits the release of NA in the PVN of the hypothalamus.

Thus, eating carbohydrates or loading TRP result in both an increased 5-HT synthesis and a decreased NA functioning in the PVN. Which of them is responsible for a diminished carbohydrate intake remains a crucial question. It may be speculated that the interaction between the NA-ergic and 5-HT systems is of crucial importance; during a binge, heightened NA-ergic activation may be interrelated with diminished serotonergic functioning.

In sum, an increase of the noradrenergic activity in the paraventricular nucleus of the medial hypothalamus may also be related to an increased carbohydrate intake and a lowered intake of protein.

\section{A lowered 5-HT functioning is not required for bingeing}

Pharmacological findings suggest that lowering the 5-HT level in the brain is not always needed to induce carbohydrate craving. In tables $2 \& 3$ the effects of pharmacological interventions are summarized.

It is striking that tricyclic antidepressives as well as MAOIs, which both enhance central $5-\mathrm{HT}$ activity either by inhibiting reuptake or breakdown of the neurotransmitter, have a reverse effect in different populations: in obese carbohydrate cravers and bulimics this enhanced serotonergic functioning leads to a decreased craving for carbohydrates, and even to a significant reduction in frequency of binge-eating episodes (see table 1). This fits in very well with the hypothesis that a decreased 5-HT activity will lead to carbohydrate craving. However, in normals, depressives, as well as in anorexia nervosa patients the enhanced $5-\mathrm{HT}$ activity results in weight gain and even in carbohydrate craving. Clearly, carbohydrate bingeing can also happen when the 5-HT functioning is not reduced. Even when 5-HT levels are pharmacologically enhanced, carbohydrate bingeing may take place. Again, the interaction between the NA-ergic and 5-HT system may be of importance; the reported effects of tricyclics and MAOls 
table 2: interventions which enhance central 5-HT activity in obese carbohydrate cravers and bulimics.

\begin{tabular}{|c|c|c|c|c|}
\hline source & subjects & drug & doselday & outcome \\
\hline $\begin{array}{l}\text { Wurtman } \\
\& \text { Wurtman } \\
1981^{*}\end{array}$ & $\begin{array}{l}\mathrm{N}=11 \\
\text { normal weight } \\
\text { carbohydrate } \\
\text { cravers }\end{array}$ & $\begin{array}{l}\text {-TAP } \\
\text {-dl-FF } \\
\text {-placebo }\end{array}$ & $\begin{array}{l}2 \mathrm{~g} \\
20 \mathrm{mg}\end{array}$ & $\begin{array}{l}\text { no change on placebo } \\
\text { and on TRP, significant } \\
\text { less carbohydrate } \\
\text { craving on FF }\end{array}$ \\
\hline $\begin{array}{l}\text { Wurtman } \\
\text { et al. } 1981\end{array}$ & $\begin{array}{l}\mathrm{N}=23 \\
\text { obese } \\
\text { carbohydrate } \\
\text { cravers }\end{array}$ & $\begin{array}{l}\text {-ITRP } \\
\text {-dl-FF } \\
\text {-placebo }\end{array}$ & $\begin{array}{l}24010 \mathrm{mg} \\
45-60 \mathrm{mg}\end{array}$ & $\begin{array}{l}\text { no change on placebo } \\
\text { and on TRP, significant } \\
\text { less carbohydrate } \\
\text { craving on FF }\end{array}$ \\
\hline $\begin{array}{l}\text { Herailef } \\
\text { et all. } 1985^{\circ}\end{array}$ & $\begin{array}{l}N=62 \\
\text { obese }\end{array}$ & $\begin{array}{l}\text {-TRP } \\
\text {-placebo }\end{array}$ & $1500 \mathrm{mg}$ & $\begin{array}{l}\text { less weight loss on } \\
\text { placebo }\end{array}$ \\
\hline $\begin{array}{l}\text { Abell } \\
\text { et al. } 1986^{*}\end{array}$ & $\begin{array}{l}\mathrm{N}=40 \\
\text { obese }\end{array}$ & $\begin{array}{l}\text {-lluvoxamine } \\
\text {-placebo }\end{array}$ & $\leq 200 \mathrm{mg}$ & $\begin{array}{l}\text { weight loss on drug and } \\
\text { on placebo }\end{array}$ \\
\hline $\begin{array}{l}\text { Mitchell } \\
\& \text { Groat } 1984^{*}\end{array}$ & $\begin{array}{l}\mathrm{N}=32 \\
\text { bulimia }\end{array}$ & $\begin{array}{l}\text {-amiltriptyline } \\
\text {-placebo }\end{array}$ & $150 \mathrm{mg}$ & $\begin{array}{l}\text { binge-eating and vomiting: } \\
52 \% \Downarrow \text { on placebo } \\
72 \% \Downarrow \text { on drug. } \\
\text { difference is not significant }\end{array}$ \\
\hline $\begin{array}{l}\text { Wermuth } \\
\text { et al. } 1977^{*}\end{array}$ & $\begin{array}{l}\mathrm{N}=19 \\
\text { bulimia }\end{array}$ & $\begin{array}{l}\text {-phenytoin } \\
\text {-placebo }\end{array}$ & $300 \mathrm{mg}$ & $\begin{array}{l}\text { number of binges } \\
\text { binges decreased } \\
\text { during drug use, } \\
\text { no relapse on placebo }\end{array}$ \\
\hline $\begin{array}{l}\text { Sabine } \\
\text { et al. } 1983^{*}\end{array}$ & $\begin{array}{l}N=50 \\
\text { bullimia }\end{array}$ & $\begin{array}{l}\text {-mianserin } \\
\text {-placebo }\end{array}$ & $60 \mathrm{mg}$ & $\begin{array}{l}\text { no difference in binge } \\
\text { eating between drug } \\
\text { and placebo }\end{array}$ \\
\hline $\begin{array}{l}\text { Agras } \\
\text { et al. } 1987^{*}\end{array}$ & $\begin{array}{l}\mathrm{N}=20 \\
\text { bulimia }\end{array}$ & $\begin{array}{l}\text {-imipramine } \\
\text {-placebo }\end{array}$ & $\leq 300 \mathrm{mg}$ & $\begin{array}{l}\text { binge-eating: } \\
72 \% \Downarrow \text { on drug } \\
43 \% \text { on placebo } \\
p \leq 0.05\end{array}$ \\
\hline $\begin{array}{l}\text { Hughes } \\
\text { et al. } 1986^{*}\end{array}$ & $\begin{array}{l}\mathrm{N}=22 \\
\text { bullimia }\end{array}$ & $\begin{array}{l}\text {-desipramine } \\
\text {-placebo }\end{array}$ & $200 \mathrm{mg}$ & $\begin{array}{l}\text { binge-eating } \\
91 \% \text { on drug } \\
19 \% \text { th on placebo } \\
\text { significant }\end{array}$ \\
\hline $\begin{array}{l}\text { Kaplan } \\
\text { et al. 1983* }\end{array}$ & $\begin{array}{l}N=6 \\
\text { bulimia }\end{array}$ & $\begin{array}{l}\text {-carbamazepine } \\
\text {-placebo }\end{array}$ & & no effect \\
\hline
\end{tabular}


continuation table 2

\begin{tabular}{|c|c|c|c|c|}
\hline source & subjecis & drug & dose/day & outcome \\
\hline $\begin{array}{l}\text { Pope } \\
\text { et. al. } 1983^{*}\end{array}$ & $\begin{array}{l}\mathrm{N}=19 \\
\text { bulimila }\end{array}$ & $\begin{array}{l}\text {-imipramine } \\
\text {-placebo }\end{array}$ & $200 \mathrm{mg}$ & $\begin{array}{l}\text { binge-eating } \\
70 \% \text { on drug } \\
0 \% \text { on placebo } \\
\text { signifiticant }\end{array}$ \\
\hline $\begin{array}{l}\text { Pope } \\
\text { et al } 1986 .\end{array}$ & $\begin{array}{l}N=10 \\
\text { bulimia }\end{array}$ & -nomifensine & $200-400 \mathrm{mg}$ & binge-eating on drug $50 \%$ \\
\hline $\begin{array}{l}\text { Pope \& } \\
\text { Hudson 1982 }\end{array}$ & $\begin{array}{l}\mathrm{N}=\mathrm{B} \\
\text { bullimia }\end{array}$ & -imipramine & $300 \mathrm{mg}$ & binge-eating $50 \%$ \\
\hline Nassr 1986 & $\begin{array}{l}N \times 5 \\
\text { bulimia }\end{array}$ & -nomifensine & $300 \mathrm{mg}$ & $\begin{array}{l}4 \text { patients completely } \\
\text { free of bulimia }\end{array}$ \\
\hline Moore 1977 & $\begin{array}{l}N=1 \\
\text { bulimia }\end{array}$ & $\begin{array}{l}\text {-diphenyl- } \\
\text { Inydantoin } \\
\text {-imipramine } \\
\text {-amitriptyline }\end{array}$ & $\begin{array}{l}100 \mathrm{mg} \\
150 \mathrm{mg} \\
150 \mathrm{mg}\end{array}$ & $\begin{array}{l}\text { recovery of bulimia only } \\
\text { on amitriptyline }\end{array}$ \\
\hline $\begin{array}{l}\text { Walsh } \\
\text { et al. } 1985^{*}\end{array}$ & $\begin{array}{l}N=30 \\
\text { bullimia }\end{array}$ & $\begin{array}{l}\text {-phenelzine } \\
\text {-placebo }\end{array}$ & $40-90 \mathrm{mg}$ & $\begin{array}{l}\text { significant reduction in } \\
\text { binge eating while on drug } \\
\text { no reduction on placebo }\end{array}$ \\
\hline
\end{tabular}

* Studies marked with an asterisk were double blind, placebo controlled.

lable 3: inlerventions which lower central 5-HIT activity in anorexia nervosa patients

\begin{tabular}{lllll}
\hline source & subjects & drug & dose/day & outcome \\
\hline $\begin{array}{l}\text { Halmi } \\
\text { et al. 1986 }\end{array}$ & $\begin{array}{l}\text { N=7.2 } \\
\text { anorexia nervosa: } \\
33 \text { bulimics, } \\
39 \text { restricters. }\end{array}$ & $\begin{array}{l}\text { amitriplyline } \\
\text { cyproheptadine } \\
\text { placebo }\end{array}$ & $\begin{array}{l}160 \mathrm{mg} \\
32 \mathrm{mg}\end{array}$ & $\begin{array}{l}\text { restricters: weight gain } \\
\text { on cyproheptadine, } \\
\text { bulimics no weight gain }\end{array}$ \\
$\begin{array}{l}\text { Vigersky } \\
\text { Q Loriaux 1977 }\end{array}$ & $\begin{array}{l}\mathrm{N}=24 \\
\text { anorexia nervosa }\end{array}$ & $\begin{array}{l}\text { cyproheptadine } \\
\text { placebo }\end{array}$ & $12 \mathrm{mg}$ & $\begin{array}{l}\text { no difference } \\
\text { in weight gain }\end{array}$ \\
\hline
\end{tabular}


are presumably due to their combined effects on 5-HT and NA metabolism. All tricyclic antidepressives and MAOIs influence both the 5-HT and the NA-system in the brain, the latter usually by means of their metabolites (van Praag \& Lemus, 1986).

In sum, pharmacological interventions show that an increase of the serotonergic activity in the brain does indeed sometimes result in a lowering of carbohydrate craving. However, in other studies an opposite effect has been documented: the heightened serotonergic activity even caused a craving for carbohydrates. Clearly, a lowered 5-HT activity is not always necessary to induce a binge on carbohydrates.

It is unclear whether hyposerotonergic activity is sufficient for bingeing

The effect of the administration of cyproheptadine, a 5-HT-antagonist, has been studied twice in patients with anorexia nervosa (see table 4).

In the first study, Vigersky \& Loriaux (1977) treated 24 anorexia nervosa patients with either cyproheptadine or a placebo, in a doubleblind experimental design. There was no significant difference in weight gain between both groups, so the authors concluded that cyproheptadine is not more effective in promoting weight gain than a placebo is. However, the authors did not match the experimental and placebo group very well. The group receiving the drug was significantly older, had been ill for a significantly longer time and used more methods for loss of weight, like drugs, diuretics and laxatives. In the placebo group, exercise and abstinence predominated. These are precisely those differences which are indicative of the bulimic-restricter distinction! And treating bulimics with a $5-\mathrm{HT}$ antagonist is not very effective in light of the hypothesis and could have distorted the results. The more so as Halmi et al. (1986) found an interesting differential effect of cyproheptadine for these subgroups (see table 4). Cyproheptadine significantly increased treatment efficiency (=weight gain) for the non-bulimic patients and significantly impaired treatment efficiency for the bulimic patients as compared with groups treated with amitriptyline and placebo. This finding seems to fit in with the hypothesis: in anorexia nervosa patients with bulimia, lowering of the 5-HT activity is not useful for weight gain, presumably because it is already lowered. In restricting patients it can be of significance to lower central serotonergic functioning and heighten carbohydrate intake. Unfortunately, the authors only studied weight changes and did not study changes in frequency of carbohydrate bingeing. Though these results are suggestive as to the issue of sufficiency, a crucial empirical question remains yet unanswered. If the hypothesized mechanism is activated experimentally, would normal healthy subjects then turn into responders, i.e. is it possible to induce carbohydrate craving in normals by lowering their central serotonergic activity? 
tabte 4: interventions which enhance central 5-HT activity in normals, depressive and anorexia nervosia paltents.

\begin{tabular}{|c|c|c|c|c|}
\hline source & subjects & drug & doselday & outcome \\
\hline $\begin{array}{l}\text { Nakra } \\
\text { et al. } 1977\end{array}$ & $\begin{array}{l}N=6 \\
\text { pormals }\end{array}$ & aniltriptyline & $100 \mathrm{mg}$ & $\begin{array}{l}\text { no change in weight, } \\
\text { in } 2 \text { subjects craving for } \\
\text { sweets and appetite }\end{array}$ \\
\hline $\begin{array}{l}\text { Paykel } \\
\text { et al. } 1973^{*}\end{array}$ & $\begin{array}{l}\text { Nas } 51 \\
\text { depressives }\end{array}$ & amitriptyline & $100-150 \mathrm{mg}$ & $\begin{array}{l}\text { weight gain and carbo- } \\
\text { hydrate crawing }\end{array}$ \\
\hline $\begin{array}{l}\text { Kendier } \\
1978\end{array}$ & $\begin{array}{l}N=1 \\
\text { anorexia nervosa }\end{array}$ & amiltriptyline & $100 \mathrm{mg}$ & $\begin{array}{l}\text { weight gain resulting in } \\
\text { obesity }\end{array}$ \\
\hline $\begin{array}{l}\text { Needleman } \\
\& \text { Waber } 1977\end{array}$ & $\begin{array}{l}\mathbb{N}=6 \\
\text { anorexia nervosa }\end{array}$ & amitriptyline & $75-150 \mathrm{mg}$ & weight gain \\
\hline $\begin{array}{l}\text { Berken } \\
\text { et al. } 1984\end{array}$ & $\begin{array}{l}\mathrm{N}=40 \\
\text { depression }\end{array}$ & $\begin{array}{l}\text { amitriptyline } \\
\text { nortriptyline } \\
\text { imipramine }\end{array}$ & $\begin{array}{l}56 \mathrm{mg} \\
37 \mathrm{mg} \\
41 \mathrm{mg}\end{array}$ & $\begin{array}{l}\text { on all drugs preference } \\
\text { for sweets, hyperphagia } \\
\text { and weight gain }\end{array}$ \\
\hline $\begin{array}{l}\text { Nakra \& Gross- } \\
\text { berg } 1986\end{array}$ & $\begin{array}{l}\mathrm{N}=2 \\
\text { depression }\end{array}$ & maprotiline & $150 \mathrm{mg}$ & $\begin{array}{l}\text { carbohydrate craving } \\
\text { and weight gain }\end{array}$ \\
\hline $\begin{array}{l}\text { Katz \& Walsh } \\
1978\end{array}$ & $\begin{array}{l}\mathrm{N}=1 \\
\text { depresisive } \\
\text { anorexla nervosa }\end{array}$ & $\begin{array}{l}\text { chlorimipramine } \\
\text { \& TRP }\end{array}$ & & $\begin{array}{l}\text { resulted in hypomanic } \\
\text { obese }\end{array}$ \\
\hline
\end{tabular}

" studies marked with an asterisk were double blind, placebo controlled.

hyposerotonergic functioning is not exclusive for bingeing A decreased 5-HT turnover in the brain does not merely result in carbohydrate bingeing and nothing else. Major depressive disorders, anxiety disorders, obsessive-compulsive disorders, chronic pain, suicide, agression, and schizophrenia have all been associated with a lowered 5-HT turnover (van Praag et al. 1987a, 1987b; Herbert, 1987). Clearly, a lowered 5-HT activity in the brain does not correspond to a specific nosological syndrome. Van Praag et al. $(1986,1987)$ speculate that a disturbed aggression or impulse regulation is the broader behavioral correlate of a Iow 5-HIAA concentration in the brain.

3.3.3 how does the 5-HT model deal with counterregulation in the lab? The 5-HT model predicts that dieters will especially counterregulate after relatively carbohydrate-rich food items to compensate for their lowered 
5-HT level. But laboratory research on counterregulation has hardly concentrated on the 5-HT hypothesis. One attempt was made by Huon \& Wootton (1987), but their data are uninterpretable; no statistics whatsoever are given and their paper does not warrant further attention.

Some speculations can be made. In typical laboratory studies, the experimental manipulation is usually followed by food especially rich in carbohydrates (e.g. ice cream or sweets). (By the way, it could be argued that, apart from being rich in carbohydrates, this food is also very palatable. But in the few studies available in which the taste test consisted of less palatable carbohydrate-rich food (e.g. crackers: Ruderman, 1985; Baucom \& Aiken, 1981; or sandwiches: Polivy, 1976) disinhibition of restraint was also found). It is of interest, and in line with the 5-HT hypothesis, that ice cream had a far more pronounced effect on counterregulation than the consumption of palatable low carbohydrate/high protein food (i.e. nuts: Tomarken \& Kirschenbaum, 1984).

In a well-controlled study, Spitzer and Rodin (1987) found that subjects who ate a glucose preload ('fast' carbohydrates, producing a steep increment in blood insulin level followed by a steep decline) subsequently ingested significantly more calories than subjects who were given a fructose preload ('slow' carbohydrates, leading to a gradual increase in blood insulin level without subsequent counterdecline). Subjects who had ingested fructose regulated their subsequent food intake very well, whereas subjects preloaded with glucose 'counterregulated". The proportion between calories ingested as carbohydrates, fats, or proteins was not influenced by the type of preload. These data suggest that the type of nutrient ingested may determine subsequent food intake because of other metabolic consequences (effects on insulin and blood sugar levels; see also section 3.5 ) than that following from the proportional division of macronutrients. More data on the issue of macronutrient intake after participation in a laboratory experiment are presented in 5.6 .

In sum, the hypothesis stating that a lowered 5-HT level induces a carbohydrate binge and that the binge on carbohydrates is in its turn effective in raising the central synthesis of $5-\mathrm{HT}$, has limited explanatory power. The first and most important question is whether binges of $\mathrm{BN}$ patients are indeed carbohydrate-rich and protein-poor. This question is answered in section 5.3. If so, the second question is whether the effect of a carbohydrate-rich binge is a really enhanced functioning of central serotonergic neurons. The appears to be doubtful. The third point of interest is that carbohydrate intake may also be promoted by NA-ergic stimulation of the PVN in the medial hypothalamus. Fourth, an increase of the serotonergic activity in the brain may also result in a craving for carbohydrates. And fifth, a lowered serotonergic activity in the brain is apparently associated with many kinds of disturbed behavior, and does not exclusively predict a craving for carbohydrates. 
Counterregulation in the laboratory has hardly come up in the 5-HT discussion. Minimal and merely speculative data suggest, however, that macronutrient intake, and 5-HT levels, are of no significance when it comes to explaining lab counterregulation. As to the aspect of a lowered 5-HT level being sufficient for bingeing and counterregulation to occur, experimental tests would be welcomed. It will be of interest to know whether a pharmacologically induced lowering of the 5-HT system in normals will result in a "binge" on carbohydrates.

\section{4 dysfunctional thoughts}

\subsection{1 introduction}

An alternative view on the etiology of uncontrollable binge eating and lab counterregulation is a cognitive one. The primary importance of cognitive factors in the etiology and continuance of eating disorders has been stressed by several authors (Bruch, 1973; Polivy 1976; Gartinkel \& Garner, 1982; Fairburn, 1984; Rossiter \& Wilson, 1985; Garner, 1986; Ruderman, 1985c "1986a; Wilson, 1986; Johnson \& Pure, 1986; Fairburn, Cooper \& Cooper, 1986; Strauss \& Ryan, 1988). The cognitive factors may include dysfunctional thoughts (e.g., Fairburn, Cooper \& Cooper, 1986), perceptual distortions (e.g., Bruch, 1973; Garfinkel \& Garner, 1982), as well as poor interpersonal problem solving (e.g., Johnson \& Pure, 1986). However, in the present section, attention will only be focussed on the dysfunctional thoughts because of their alleged direct relevance to binge eating episodes.

Dysfunctional thoughts can roughly be divided into general and specific dysfunctional thoughts. General dysfunctional thoughts concern matters not directly related to focd intake, such as the idea that one has to be perfect in all aspects of behavior. The specific thoughts, on the other hand, directly concern food intake behavior. Note that the two may be related; e.g. eating one cooky may be perceived as a total lack of control (specific idea: food rich in calories is 'forbidden' food, general idea: one must have perfect self-control).

\subsection{2 general dysfunctional thoughts}

The cognitive approach states that the eating disorder follows from generally distorted patterns of thought based on erroneous underlying assumptions. Clinicians have repeatedly pointed out the unrealistic thoughts, attitudes, and beliefs concerning body weight, body shape, and eating patterns (e.g. Chiodo, 1987; Fairburn, Cooper \& Cooper, 1986). Overvalued ideals of slenderness and rigid tood rules are prominent. Selfesteem is evaluated in terms of shape and weight, and success and failure are believed to be largely determined by appearance. Being fat is associated with being a failure, unattractiv $\theta_{\text {, }}$ and unhappy, while being thin is connected with being successful, attractive, and happy. Such ideas 
are, of course, directly related to eating and eating problems but they may be specific instances of the more general assumption that one has to be perfect all-round and have total self-control.

Clinical notes indicate that the bulimic's faulty patterns of thought mainly concern logical errors, such as dichotomous thinking, overgeneralization and errors of attribution (Garner \& Bemis, 1982; Garner, 1986; Fairburn, Cooper \& Cooper, 1986) (see table 5).

table 5: dysfunctional thoughts relevant to eating disorders

\begin{tabular}{|c|c|c|}
\hline logical error & oxample & \\
\hline $\begin{array}{l}\text { dichotomous thinking } \\
\text { (=all-or-none reasoning) }\end{array}$ & thinking in extreme and absolute terms & $\begin{array}{l}\text { "Il I"mot in complete cantroll I lose } \\
\text { all control" }\end{array}$ \\
\hline overgeneralization & $\begin{array}{l}\text { extracting a rule on the basis of one } \\
\text { event and applying it to other } \\
\text { dissimilar situations }\end{array}$ & $\begin{array}{l}\text { "I used to be of normal weight, and I } \\
\text { wasn't happy. So I know gaining woight } \\
\text { isin't going to make me foel botter }\end{array}$ \\
\hline selective abstraction & $\begin{array}{l}\text { basing a conclusion om isolated details } \\
\text { while ignoring contradictory and more } \\
\text { salient ovidence }\end{array}$ & "l am special if I am thin" \\
\hline magnification & $\begin{array}{l}\text { overestimation of the silgnilicance of } \\
\text { undesitrable consequent events }\end{array}$ & $\begin{array}{l}\text { "'ve gained two pounds, so I can't } \\
\text { wear shorts anymore". }\end{array}$ \\
\hline persomalization & $\begin{array}{l}\text { egocentric interpretations of inpersonal } \\
\text { revents of overinterpretation of events } \\
\text { relating to the self }\end{array}$ & $\begin{array}{l}\text { "l am embarrassed when } \\
\text { other people see me eat" }\end{array}$ \\
\hline superstitious thimking & $\begin{array}{l}\text { believing in the causie-effect relationship } \\
\text { of noncontingent ovents }\end{array}$ & $\begin{array}{l}\text { "Hf I al a swoel, it will be } \\
\text { converted instantly into stomach tat" }\end{array}$ \\
\hline
\end{tabular}

Atter Garner \& Bemis, 1982 , without permission.

However, the clinical impressions received little empirical attention. Ruderman (1985c, 1986a) showed that scores on a questionnaire measuring restrained eating patterns (the Restraint Scale; RS) and scores on a questionnaire measuring bulimic symptoms (the Bulimia Test: BULIT) were significant and negatively related to scores on a questionnaire measuring rationality (the Rational Beliefs Inventory; $R B M$ ). Thus, the more distorted the eating patterns that were reported, the more rigid, perfectionist and irrational the belliefs that were subscribed to. According to Ruderman (1986b), it is "consistent with the observation that bulimics tend to react to minor dietary violations or other frustrating situations by 
binge eating" (p. 196) that people scoring high on the RS and BULIT also scored high on the RBI-factor "reactions to frustrating situations'. However, this ad hoc interpretation may be somewhat premature. Strauss and Ryan (1988), for instance, did not find any empirical support for the notion that normal weight bulimics and people with subclinical eating disorders are characterized by a greater number of logical errors (overgeneralization, selective abstraction, catastrophizing, personalization) than normal controls. Please note that a non-eating disordered psychiatric control group was used in none of the studies. Irrationality may be a more general characteristic of (sub) clinical psychopathology and should, therefore, not be considered as etiologically specific straight off.

3.4.3 general dysfunctional thoughts lead to binge eating vio depression

At first sight, the logical errors that binge eaters often make closely resemble the dysfunctional thoughts found to be associated with depression (Fairburn, Cooper and Cooper, 1986). The co-occurrence of bulimia nervosa and depression (ct. 1.2) has particularly stimulated research on prevalence and neuro-endocrinological aspects (Halmi, 1985; Altshuler \& Weiner, 1985; Cooper \& Fairburn, 1986; Hinz \& Williamson, 1987; Levy et al., 1989) but research has hardly concentrated on the similarity of dysfunctional thoughts. In two studies, however, the hypothesis of shared cognitive dysfunction in bulimia and depression was studied but could not be supported. Schlesier-Carter et al. (1989) controlled statistically for the level of depression and found that the maladaptive cognitions and behaviors in bulimia are not simply expressions of an affective disorder but reflect a distinct disorder (i.e. bulimia). Earlier, Ruderman (1986a) had pointed out that although binge eating subjects often showed a depressed mood, they did not show the typical depressive distortions in thought which characterize people with a primary depressive disorder.

Thus, the irrational cognitions found in bulimia nervosa are not identical to the depressive thoughts that characterize primary depressive disorders. Although, no evidence for the similarity between cognitive distortion in bulimia nervosa and in depression could be demonstrated, Laessle et al. (1988) argued that bulimics' depression may follow from the irrational attitudes and beliefs characteristic of bulimia. In particular the pursuit of perfectionism and body dissatisfaction are supposed to lead to depression (Laessle et al., 1988). These cognitive characteristics of patients with eating disorders were really significantly related to depression scores (Laessle et al., 1988; Strauss \& Ryan, 1988). Because Greenberg (1986) has shown that it is in particular the co-occurrence of depression and dietary restraint which predicts binge eating behavior, it might be of interest to further investigate the role of depression in binge eating/counterregulation of dieters. Exploration of this issue will be presented in 5.4 . 
3.4.4 specific dysfunctional thoughts and binge eating/counterregulation

According to cognitive theory, dieters possess a cognitive 'diet boundary' (Herman \& Polivy, 1984; cf. 2.5). The start of a binge is held to be related to this boundary: dieters overeat because they think they have passed their diet boundary. The idea of passing the boundary leads to a complete loss of control: "The slightest transgression from rigidly prescribed dieting leads the patient to conclude that she might as well give in to the urge to eat since perfect self-control has been "blown'. "(Garner, 1986, p.319). Even minor dietary indiscretions are considered to be indicative of a complete absence of self-control: "I try not to eat. But if I had pizza, it's over for the day", and "ffI ate that much I might as well go ahead and eat more. Usually it ends up in a binge" (Chiodo, 1987, p.42). Analogous to the notion that disinhibitive thoughts such as "I've blown my diet, I might as well continue to eat" are held to be the antecedent of clinical binge eating behavior, it is also assumed that such disinhibitive thoughts trigger the counterregulatory response in the laboratory (cf. 2.5).

\subsection{5 critical comment}

The notion that disinhibitive thoughts trigger a clinical binge or lab counterregulation has never been tested directly. "Despite the paucity of supporting evidence, the cognitive explanation for the putative association between dieting and overeating has a remarkable degree of acceptance. This is probably because it is credible to clinicians. Patients with bulimia nervosa describe abandoning their controls after breaking their rules." (Fairburn, Cooper \& Cooper, 1986, p.401).

One of the aims of the present author was to subject the cognitive explanation of counterregulation to direct experimental tests. From the cognitive theory several predictions can be deduced. First, the most straightforward assumption is that dieters showing disinhibitive behavior will be characterized by disinhibitive thoughts such as "I've blown my diet, I might as well continue to eat". By measuring thoughts during behavioral tests, the exact relationship between such 'disinhibiting' thoughts and 'disinhibited' behavior is tested in 5.5.

Second, cognitive theory states that dieters only overeat when they perceive their diet as broken. A logical implication of this assumption is that dieters who do not perceive their diet as broken will not overeat. Data are presented in 5.8 .

Third, the cognitive theory has another experimental implication. If dieters have eaten 'too much' in the lab, this lab experience counts as diet breaking and will stimulate high intake immediately afterwards. Note that subsequent counterregulation is a unique prediction which follows from cognitive theory and not from the set point theory (cf. 3.2) and/or the 5-HT theory (ct. 3.3). A test of the prediction that disinhibited dieters will counterregulate outside the laboratory will be described in 5.6. 
In sum, cognitive theory postulates a link between dieting and bingeing. Intense body image concern leads patients to try and keep to extreme dietary rules. Dieters' negative self-concept predisposes them to depression, whereas dieting and depression together predict binge eating. Minor deviations from the dietary rules (passing the 'diet boundary') are interpreted as catastrophic and result in abandonment of all self-control. However; there is only meager empirical evidence for the presence of overall distorted cognitions and its relationship to counterregulation. The notion that disinhibitive thoughts are responsible for clinical binge eating or lab counterregulation has hitherto not even been subjected to direct experimental tests.

\section{5 an alternative account of counterregulation: classically conditioned compensatory responses}

3.5.1 introduction

The set point theory (cf. 3.2), 5-HT theory (ct. 3.3), as well as the idea of cognitive dysfunctions (cf. 3.4) do not explain counterregulation c.q. binge eating satisfactorily (cf. Table 6).

If set point, $5-\mathrm{HT}$, and cognitive theory are not workable, how can counterregulation be explained?

Some characteristics of counterregulating or binge eating subjects have hardly been discussed, but they may put the phenomenon of counterregulation in a different light. Recently, some authors have pointed out that addicts and dieters share several characteristics: both are characterized by a preoccupation with the substance, a craving for it, a loss of control over intake and relapse (Bemis, 1985; Norré \& Vandereycken, 1986; Wardle, 1987c). Moreover "epidemiological data show that bulimia and alcohol addiction often co-occur and are easily interchanged (Brisman \& Siegel, 1984; Beary, Lacey \& Merry, 1986; Lacey \& Moureli, 1986; Jonas \& Gold, 1988). Experimental support for the addiction analogy is presented in 5.7 .

3.5.2 conditioned compensatory responses (CCRs)

The addiction analogy may be useful for explaining counterregulation of dieters. Recent developments in the experimental field of addictions support a classical conditioning model of craving and tolerance. In short, the theory states that, after repeated association of cues specifically related to the substance taken (UCS), these cues (CS) will elicit a physiological response which is opposite to the unconditioned response (UCR) of the substance ${ }^{2}$ (Siegel, 1983, 1984; Siegel et al., 1981, 1982; MacCrea

2 Note that, in 1927, Pavlow reterred to this phenomenon in terms of 'paradoxical conditioning:. 
table 6: theories: explanations \& predictions

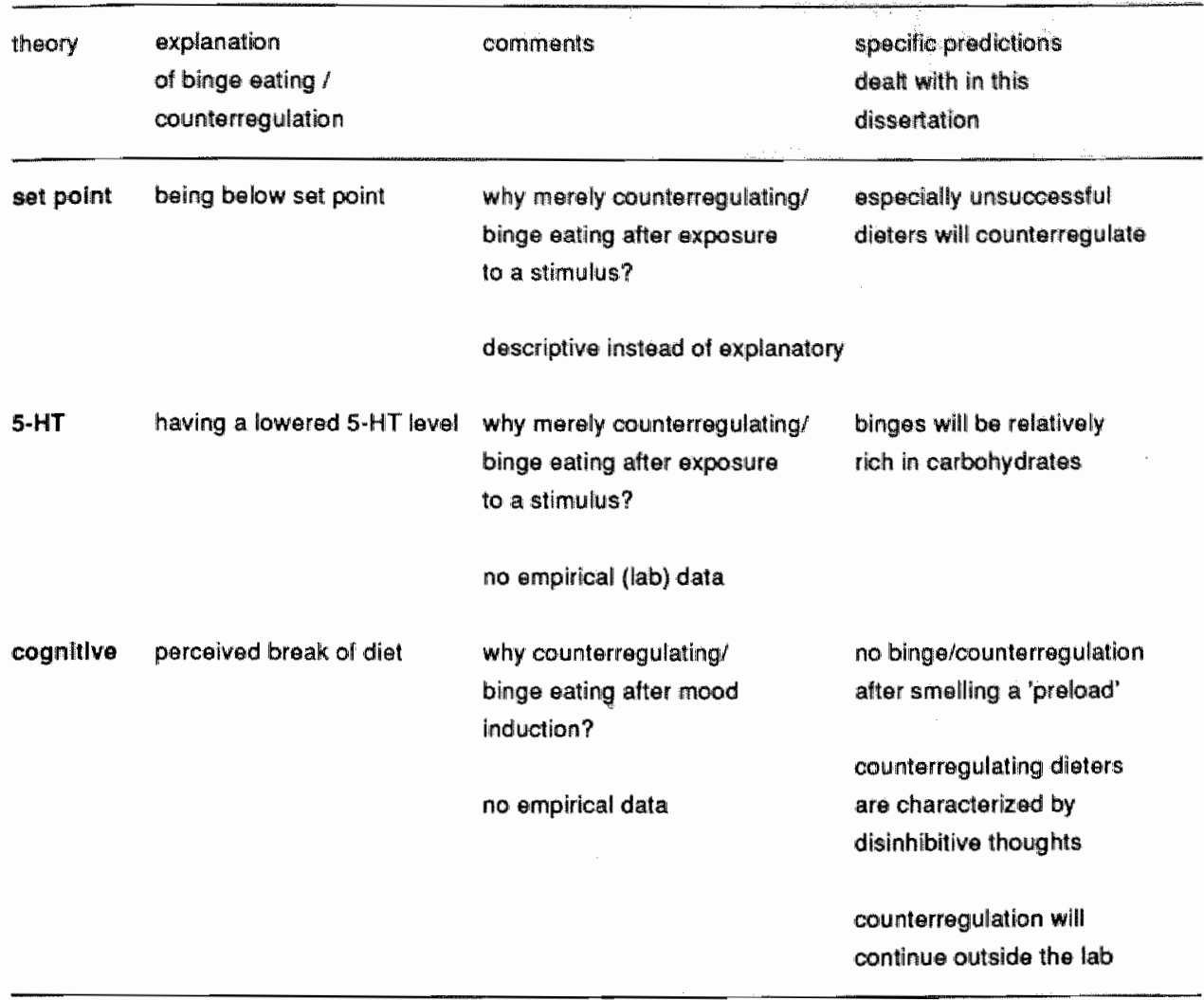

et al., 1987). For example, experiments show that dogs repeatedly injected with epinephrine (UCS) show the usual tachycardia response (UCR) to the epinephrine administrations. The injection ritual is a cue which is specifically associated with the UCS and atter a series of injection rituals (CS) and drug (UCS) pairings, the CS has become a reliable predictor of the UCS. At that very moment, dogs display a compensatory response in anticipation of the epinephrine: they show a bradycardia in advance (CCR) (see Siegel, 1983). This counterdirectional response is an anticipative conditioned compensatory response (CCR): it prepares the organism for the intake of a substance. Compensatory CRs thus contribute much to tolerance: they increasingly cancel the effects of the substance taken, so that the response to a drug decreases in the course of successive administrations (Siegel, 1983). The CCR is supposed to be subjectively experienced as craving.

The notion of preparatory responses associated with the intake of food is not new. Years ago the idea aiready took shape that exaggerated 
cephailic $^{3}$ phase responses (CPRs) to food stimuli stimulated overeating. As will soon be clear, the CPR-model does not explain counterregulation/binge eating adequately. However, CPRs may be related directly to the CCRs. Therefore, attention will first be focussed on the preparatory CPRs, before the compensatory model is outlined.

\subsection{3 cephalic phase responses (CPRs)}

CPRs are the earliest physiological reactions of an organism which is exposed to food (Powley, 1977; Powley \& Berthoud, 1985). More specifically, CPRs are predigestive hormonal reflexes which occur in response to food cues such as smell, taste, and appearance. They are fast responses which start in the first minute after stimulus presentation, peak within five minutes and return to baseline within ten minutes (Powley, 1977; Powley \& Berthoud, 1985). The responses are of parasympathetic neural origin, are organized in the lateral hypothalamus $(\mathrm{LH})$ and can be inhibited by the activity in nuclei of the ventromedial hypothalamus (VMH) (Powley, 1977). Lesions in the VMH of animals elicit exaggerated CPRs (note that VMH lesions may be followed by hyperphagia and obesity, $\mathrm{cf}$. 3.2).

CPRs play an important metabolic anticipatory role. Functionally, they prepare the organism for the consumption of food by priming the mechanisms that will have to transport, break down, and store incoming nutrients (Berthoud et al., 1981; Tordoff \& Friedman, 1989). CPRs include secretion of saliva, insulin, gastric juices, Free Fatty Acids (FFA) mobilization and greater gastric motility (Powley \& Berthoud, 1985; Rodin, 1985). Relevant human research has mainly concentrated on the cephalic salivation response.

\section{anticipated salivation responses}

Fifteen years ago, Wooley \& Wooley $(1973,1975)$ indicated salivation responses as an alledgedly objective and useful new measure of hunger. A general finding is that, in response to palatable food stimuli, subjects show an increase in salivation as compared to baseline salivation levels (Guy-grand \& Goga, 1981; Nirenberg \& Miller "1982; Christensen \& Navazesh, 1984). However, despite the initial optimism, research data on salivation as an objective measure of hunger are confusing and, at least, equivocal. In various studies, significant correlations between subjective hunger ratings and salivation measures were found (Wooley \& Wooley, 1973; Durrant and Royston, 1979; Hodgson \& Greene, 1980; Booth \& Fuller in Sahakian, 1981) whereas no significant correlations were reported in other studies (Guy-grand \& Goga, 1981; Blundell \& Freeman in

3 The word 'cephalic' means 'pertaining to the head' and here it refers to the activities of the afferent limb originating in the olfactory, visual and qustatory receptors in the head (Berthoud et al, 1981). 
Sahakian, 1981; Nirenberg \& Miller, 1982; Christensen \& Navazesh, 1984). And, as might be clear from table 7 , the salivation response has been found to be sensitive to many factors.

The duration of food deprivation, manner of stimulus presentation, experimental instructions, palatability of the food items presented, caloric content of a preload and the use of appetite suppressant drugs may play a role (Wooley \& Wooley, 1973, 1975; Wooley, Wooley \& Woods 1975; Wooley, Wooley \& Williams, 1976; Sahakian, 1981; Wooley \& Wooley, 1981; Herman et al., 1981; Klajner et al., 1981; Legoff et al., 1987, 1988).

diefing, heightened salivation, and counterregulation

CPR theory states that dieting or chronic hunger leads to an overresponsiveness of CPRs which, in fact, reflect an irresistible biological imperative to eat (Johnson \& Wildman, 1983; Klajner et al., 1981; Herman et al., 1981). According to the theory, the exaggerated CPRs function as a corrective physiological defense against the energy shortage resulting from food deprivation: oversecretion (exaggerated CPRs) leads the organism to ingest enough calories to restore the metabolic balance.

Thus, CPA theory predicts that (1) dieters will show stronger salivation responses than non-dieters and (2) these exaggerated salivation responses lead to an actually higher intake of food. Let us review the evidence.

table 7: the influence of various variables on salivation response

\begin{tabular}{|c|c|c|c|c|c|}
\hline variable & test situation $A$ & test situation $B$ & salivation & subjects & study \\
\hline \multirow[t]{6}{*}{$\begin{array}{l}\text { lood } \\
\text { deprivation }\end{array}$} & more deprived & less deprived & $A=B$ & & $\begin{array}{l}\text { Wooley; Wodlay \& Williams, } \\
1976\end{array}$ \\
\hline & more deprived & less deprived & $A=B$ & & Hodgson \& Gireane, 1980 \\
\hline & more deprived & less deprived & $A=B$ & $\begin{array}{l}n=20 \\
\%\end{array}$ & $\begin{array}{l}\text { Christensen \& Navazeash, } \\
1984\end{array}$ \\
\hline & more deprived & less deprived & $A=B$ & $\begin{array}{l}n=19 \\
\%\end{array}$ & Brummer \& Pudel, 1981 \\
\hline & more deprived & less deprived & $A>B$ & $\begin{array}{l}n=19 \\
\cdots\end{array}$ & Franchina Slank, 1988 \\
\hline & more deprived & less deprived & $A>B$ & & $\begin{array}{l}\text { Wooley, Wooley \& Williams, } \\
1976\end{array}$ \\
\hline
\end{tabular}


continuation table 7

\begin{tabular}{|c|c|c|c|c|c|}
\hline Variatibia & lest sinuation & test situation & sallvation & subjects & study \\
\hline \multirow[t]{13}{*}{$\begin{array}{l}\text { gitimulus } \\
\text { presumation }\end{array}$} & no lood stimult & $\begin{array}{l}\text { mere prestentation } \\
\text { of food cues }\end{array}$ & $A<B$ & & $\begin{array}{l}\text { Wooley, Wooley \& Williams, } \\
1976\end{array}$ \\
\hline & no lood stimuli & $\begin{array}{l}\text { mere presentation } \\
\text { of food cues }\end{array}$ & $A<B$ & $\begin{array}{l}n=10-1 ? \\
n=14+1 ?\end{array}$ & Guy-Grand \& Goga, 1981 \\
\hline & no food stimuli & $\begin{array}{l}\text { mere presientation } \\
\text { of food cues }\end{array}$ & $A<B$ & $\begin{array}{l}n=25 \\
+/ ?\end{array}$ & Wirenberg \& Miler, 1982 \\
\hline & no food stimuli & $\begin{array}{l}\text { mere presentation } \\
\text { of food cues }\end{array}$ & $A<B$ & $\begin{array}{l}n=20 \\
-1-\end{array}$ & $\begin{array}{l}\text { Christensen \& Nawazesh: } \\
1984\end{array}$ \\
\hline & no food stimuli & $\begin{array}{l}\text { mere presientation } \\
\text { of food cues }\end{array}$ & $A=B$ & & Hodgsion \& Greene, 1980 \\
\hline & no lood stimuli & $\begin{array}{l}\text { mere presientation } \\
\text { of food cues }\end{array}$ & $A=B$ & & $\begin{array}{l}\text { Pangborn, Whiterly \& Jones } \\
1979\end{array}$ \\
\hline & no food stimuli & $\begin{array}{l}\text { looking at, sniffing } \\
\text { and touching }\end{array}$ & $A=B$ & $n=10$ & Brummer \& Pudel, 1981 \\
\hline & no food stimuli & $\begin{array}{l}\text { olfactory and } \\
\text { tactille stimulation }\end{array}$ & $A<B$ & & $\begin{array}{l}\text { Pangborn. Whiterly \& Jones, } \\
1979\end{array}$ \\
\hline & no tood stimuli & tasting the food & $A<B$ & (humgry) & Hodgson \& Greene, 1980 \\
\hline & no food stimuli & imagination food & $A=B$ & & Wooley at al., 1978 \\
\hline & & & & $-1 / 4$ & \\
\hline & no lood stimuli & thinking of food & $A<B$ & $\begin{array}{l}n=4 \\
2+/ 7 \\
2-/ ?\end{array}$ & Wooley \& Wooley, 1973 \\
\hline & no tood stimuli & hypnosis & $\mathbf{A}<\mathbf{B}$ & $n=7-1$ & Goidfine et al., 1970 \\
\hline palatabillity & unpalatable & palatabla & $A=B$ & $n=? / t$ & Klajmer ot al., 1981 \\
\hline & unpalatable & palatable & $\mathrm{A}<\mathrm{B}$ & $\ln =20-1$ & $\begin{array}{l}\text { Christensen \& Navazesh. } \\
1984\end{array}$ \\
\hline
\end{tabular}


continuation lable 7

\begin{tabular}{|c|c|c|c|c|c|}
\hline variable: & test silutiation $A$ & test situation $B$ & salivation & subjacts & study \\
\hline \multirow[t]{5}{*}{ preload } & high cialorile preloau & low calorie preload & $A<B$ & $n=10 \cdot d ?$ & $\begin{array}{l}\text { Wooliby, Wooloy \& Willams, } \\
1976\end{array}$ \\
\hline & hilgh calorie preload & low calorie proload & $A=B$ & $n=10+1 ?$ & $\begin{array}{l}\text { Wooley, Woolsy \& Williams, } \\
1976\end{array}$ \\
\hline & high calorie preload & low callorie preload & $A=B$ & $\begin{array}{l}n=178 / 4 \\
n=8 ? \%\end{array}$ & $\begin{array}{l}\text { Wooloy, Woolley \& Williams } \\
1978\end{array}$ \\
\hline & high calorie proload & low calorie preload & $A>B$ & $n=+?$ & Herman et al. 1981 \\
\hline & high calorie preload & low callorie prelload & $A<B$ & $\mathrm{n}=18+1 ?$ & Durrrant \& Poyston, 1979 \\
\hline \multirow{3}{*}{$\begin{array}{l}\text { appetite- } \\
\text { suppressant } \\
\text { drugs }\end{array}$} & without drugs & whth drugs & $A>B$ & & Wooley, Woollay \& \\
\hline & without drugs & whth drugs & $A<B$ & $\begin{array}{l}n=14-/ ? \\
\text { (hungry) }\end{array}$ & Sahakian, 1981 \\
\hline & without drugs & with drugs & $A>B$ & & Wooley \& Wooley, 1981 \\
\hline \multirow[t]{6}{*}{ instiructions } & explectation to eat & $\begin{array}{l}\text { expectation not } \\
\text { to eat }\end{array}$ & $A>B$ & $\begin{array}{l}n=2+1+ \\
n=2-1\end{array}$ & Wooley \& Wooley, 1973 \\
\hline & expectation to eat & $\begin{array}{l}\text { expectation not } \\
\text { to enat }\end{array}$ & $A>B$ & & $\begin{array}{l}\text { Wooley, Wooley } \\
\text { \& Williams, } 1976\end{array}$ \\
\hline & expectation to eat & $\begin{array}{l}\text { expectation not } \\
\text { to oat }\end{array}$ & $A=B$ & $n=20 \%$ & $\begin{array}{l}\text { Christensen \& Navazosh, } \\
1984\end{array}$ \\
\hline & expectation to eat & $\begin{array}{l}\text { expectation not } \\
\text { to eat }\end{array}$ & $A=B$ & $\begin{array}{l}n=15 \% \\
n=9+1 ?\end{array}$ & Powars all al, 1981 \\
\hline & biaing forceed to eat & non-forcied to eat & $A<B$ & & Wooley at al., 1981 \\
\hline & baing forced to eatt & non-forced to eat & $A>B$ & & Herman ot al, 1981 \\
\hline
\end{tabular}

obesity/restraintness: $-1=$ = non-obese/non-restraint; $+1-=$ obese/non-restraint; $-1+=$ non-obesel restraint: $+1+=$ obese/restraint;? = unknown 
dieters showing stronger salivation responses than non-dieters

This prediction is not always supported. In several studies it was found that dieters did salivate more than non-dieters in response to palatable food items (Klajner el al., 1981; Herman et al.. 1981; Legoff \& Spigelman 1987). In other studies, however, subjects on low-calorie diets showed lower salivation responses than control subjects (Rosen, 1981 en Durrant, 1981 in Herman et al., 1981; Wooley \& Wooley, 1981). The inconsistent findings are probably due to the types of dieters participating in the different studies. In the 'low-salivation studies', dieters were institutionalized and put on a strict diet, whereas dieters were selected for the "high-salivation studies" on the basis of their self-report scores on the Restraint Scale (RS). Dieters who are on a strict diet are really food deprived whereas dieters identified by the RS usually alternate periods of deprivation with spells of overeating. In line with this, LeGoff, Leichner, and Spigelman (1988) found that dieters who are on a highly unvaried diet (i.e. anorexia nervosa restricters) salivated significantiy less to food cues than dieters on a highly varied diet (bulimic patients). Note that this finding is in flat contradiction with CPR theory, which states that dieting per se results in exaggerated CPRs. Data indicate that successful dieting produces low CPRs (salivation responses) but that unsuccessful dieting, i.e. alternation of dieting and overeating, produces exaggerated CPRs (salivation responses).

the exaggerated salivation response leads to an actually higher intake of food

A crucial prediction of CPR theory is that exaggerated CPRs will be followed by overeating. Animal studies show that the higher the cephalic response of rats before they are placed on a 'snack bar' diet (chocolate chip cookies, salami, cheese), the greater the increase in body weight (Berthoud et al., 1981). The authors assume a causal relationship between the amplitude of CPRs, appetite and likelihood that obesity will develop in the rat, and they stress the similarity to human obesity. However, empirical data on CPRs and human eating behavior is scarce. In contrast to the relationship between subjective hunger and salivation levels, on which the bulk of research has concentrated (see earlier), the correlation between salivation and the amount of food ingested has received surprisingly little empirical attention. So tar, two studies were carried out. Klajner et al. (1981) found that heightened salivation in dieters after exposure to palatable food was not followed by overeating. Wardle (1987b) found a correlation between subjective hunger ratings and food intake $(r=0.56)$ but, like Klajner et al., she failed to find a significant correlation between salivation and food intake. These findings contradict the CPR theory, which predicts that food cues affect physiological reflexes (CPRs) and subsequent behavior. 
In sum, empirical studies on the relationship between exaggerated salivation responses and actual food intake do not support the CPR assumption that exaggerated salivation has to be eaten away. Moreover, the findings of low salivation levels in 'real' dieters and high salivation flows in dieters who regularly overeat do not support the assumption of CPR theory that it is deprivation which triggers exaggerated anticipatory responses. They rather suggest that it is the behavior with occasional overeating which results in exaggerated CPRs. What is the cause of this? Acknowledgement of the learned nature of CPRs may be fruitful.

\subsubsection{CPRs are learned responses}

The intake of food (Unconditioned Stimulus $=$ UCS) triggers metabolic responses (Unconditioned Responses $=$ UCRs). Sight, smell, taste, chewing, or swallowing of food naturally have a temporal contingency with feeding. These stimuli may therefore stant to act as Conditioned Stimuli (CSs) which can trigger a Conditioned Response ( $=$ CR), i.e. a CPR. Obviously (remember Pavlov ${ }^{4}$ ), CPRs are conditioned responses: they can be under control of any arbitrary external stimulus that previously reliably preceded the actual ingestion of food (Wooley \& Wooley 1973, 1981; Powley, 1977; Booth, 1981; Berthoud et al. 1981; Rodin, 1985). The mere anticipation of food or sham feeding (i.e. the sight, smell, taste, chewing, or swallowing of food without it entering the gastrointestinal tract) and cognitive processes (e.g. the thought of food or even hypnotic suggestion of food) have been found to elicit responses (CPRs) in order to prepare the organism for the digestion of food (Goldfine et al., 1970; Simon et al., 1986; Powley, 1977; Sahakian et al., 1981; Johnson \& Wildman, 1983; Rodin, 1985).

When the learned nature of CPRs is taken into account, i.e. CPRs being classically conditioned responses to cues that have come to predict food intake, it becomes understandable why anorexia nervosa restricters and systematically deprived subjects show decreased CPRs while unsuccessful dieters and bulimics show elevated CPRs (see page). In the case of 'total' deprivation, i.e. a low-calorie and unvaried diet, food cues (CS) are less predictive of extreme food intake (UCS) than in the case of a diet-splurge eating pattern, which is usually found in high scorers on the RS. Clearly, it is not dietary restraint in itself, but it may be the nature of the CS (food cues) UCS (extreme food intake) probability relationship which determines the salivation flow. Note that when someone starts to restrict food intake successfully (e.g. anorectics) "food cues (CSs), like smell and sight, become less predictive of food intake (UCS). Classical conditioning theory then predicts an extinction of the salivation $\mathrm{CR}$. In the cases of bulimics or unsuccessful dieters, CSs are regularly followed by

\footnotetext{
4 In fact, this is the way in which Pavlov and co-workers discovered the principle of
} classical conditioning (Windholz, 1989). 
particularly strong UCSs (large/extreme food intake). UCS strength is a powerful determinant of the strength of the CR. Classical conditioning theory therefore correctly predicts relatively high salivation CRs in bulimics and unsuccessful dieters. Intermittent dieting (diet-splurge) will never fulfill the preconditions necessary for inhibitory conditioning or extinction, whereas real dieting does.

In sum, bingers and addicts share some characteristics. This observation drew attention to a possible common mechanism underlying craving. tolerance, and excessive substance intake. In the case of addictions, as well as in eating behavior, classically learned preparatory responses are relevant. These responses are functional in preparing the organism for the intake of a substance. The idea of learned preparatory responses explains the differences in salivation responses between restricters and bulimics quite well. But can the model also explain counterregulation satisfactorily?

3.5.5 a new model for binge eating \& counterregulation: CCR (hypoglycemia) following from CPR (insulin release) One of the anticipatory responses (CPRs) is the release of insulin. Insulin, a small protein produced in the $\beta$ cells of the pancreas, facilitates the entry of glucose in cells and, in that way, lowers the amount of glucose in the blood. Anticipatory insulin release can be elicited by any stimulus which has temporarily been associated with feeding (Deutsch, 1974). This is convenient: food intake heightens blood sugar level and anticipative insulin release allows a better tolerance of the glucose. Especially the taste of sweetness stimulates insulin release, which subsequently lowers blood sugar level and stimulates appetite (Deutsch, 1974; Berthoud et al., 1981; Geiselman \& Novin, 1982). Thus, CSs such as tasting or smelling food trigger a CPR (anticipative insulin release) which, in its turn, elicits a decline in blood sugar level. Normally, food intake heightens blood sugar level: the hypoglycemia in anticipation of food intake is therefore, in fact, a conditioned compensatory response (CCR). The hypoglycemia (CCR) may be subjectively experienced as hunger/craving and, in that way, stimulate food intake in order to heighten blood sugar level $\left.\right|^{5}$.

5 Note that the intake of food (UCS) leads to the release of insulin (UCR1) as well as to an increase in blood sugar (UCR2). Apart from insulin being a conditioned reaction (CR) to food stimuli such as the smell of food (CS), the release of insulin may also be considered an unconditioned stimulus (UCS2), leading to a decline in blood sugar level (UCR3). In the strict sense, then, insulin release is a CR and a UCS. Although use of the term 'compensatory response" may, therefore, be debatable (Eikelboom \& Stewart, 1982) in terms of physiological prociesses, from a functional perspective the use of the term "compensatory response" is useful. When the temporal dynamics of the conditioning process are considered the ultimate response is always a decline in blood sugar level. 
Empirical data support the notion that it is possible to condition blood sugar level. After repeated intravenous injections of insulin (which are usually followed by a decline in blood sugar level) rats learn to show a hyperglycemic response to a placebo (Siegel, 1972). Rats thus learn to anticipate the insulin administration (and subsequent hypoglycemia) with a compensatory , hyperglycemic, response. And; the other way around, after repeated intravenous injections with glucose, rats learn to show a hypoglycemic response to a placebo (Deutsch, 1974). Rats thus learn to anticipate the glucose administration with a compensatory, hypoglycemic, response. Deutsch (1974) also showed that, in rats, an initially neutral taste cue can elicit a glycometabolic effect if it has been paired with glucose administration in a classical conditioning paradigm. Human obesity has repeatedly been attributed to hyperinsulinemia and the hypoglycemia resulting from it (Geiselman \& Novin, 1982; Tordoff \& Friedman, 1989). In the literature on bulimics' binge eating, however, the notion of a learned hypoglycemia in anticipation of a binge has hardly been pointed out. Some authors touched upon the idea of hypoglycemia (e.g. Wooley \& Wooley, 1985) but were unable to specify the exact, i.e. learned, nature of the alleged hypoglycemia.

Others studied bulimics' glucose and insulin levels after a meal or a glucose injection. The data are equivocal. Normal blood glucose and insulin levels in bulimics were reported by Hohlstein et al. (1986) and Weingarten et al. (1988), whereas Schweiger et al. (1987) reported abnormally high insulin and glucose levels in bullimics who had eaten a meal. It should be noted, however, that the present author's CCR model for binge eating/counterregulation specifies anticipative responses and not responses following a meal. Moreover, the studies mentioned were one-off, and did not use explicit CSs, which means that the learned nature of hypoglycemic responses was not taken into account. As far as the present author knows, there is only one study on anticipative glucose and insulin levels in bulimic subjects: in line with the hypothesis stated earlier, Thompson et al. (1988) found an elevated insulin/glucose ratio in counterregulating restrained subjects after they had eaten a prelload.

The model of conditioned compensatory hypoglycemia may explain counterregulation in the lab and it may have clinical implications.

\subsubsection{CCRs and counterregulation}

The CCR-model is unique in the sense that it has, hitherto, been the only model which offers one unifying and satisfactory explanation for the motley collection of disinhibitors that have been identified. With respect to the explanation of counterregulation after the different disinhibitors, it was noted before (see section 2.3) that counterregulation occurs on several occasions. One single behavior, counterregulation, is repeatedly explained in different ways, depending on which disinhibitor attention is focussed. However, for sake of parsimony one single mechanism that 
underlies all the counterregulatory challenges should be looked for. It is hypothesized by the present author that the different disinhibitors all act as conditioned stimuli with an identical consequence:

\section{CSs ('disinhibitors') - CPR (insulin oversecretion) - CCR (hy- poglycemia) $\rightarrow$ counterregullation.}

Eating a calorie-rich preload, the perceived breach of a diet, being in a low mood or being anxious are all stimuli which could be conditioned to the excessive intake of food (UCS) in dieters. These CSs may therefore elicit a hyperinsulinemia response (CPR) which, in its turn, will be followed by a hypoglycemia (CCR). The hypoglycemia is subjectively experienced as craving or hunger and, therfore, leads to counterregulation.

As well as covering existing findings quite well post hoc, the model also provides straightforward and unique predictions. One implication is that if certain cues (olfactory, taste, visual CSs) are sometimes followed by particularly strong UCSs (high-calorie intake) it is to be expected that unsuccessful dieters will show strong conditioned responses (CCRs) to any cue that typically predicts food intake. It follows that counterregulation in dieters should occur not only if an actual high calorie preload is consumed or anticipated (as e.g. cognitive theory would predict). It is predicted that, in contradiction with any current cognitive theory, counterregulation will also occur when dieters are merely smelling a preload. Data of this experimentum crucis are given in 5.8 .

\subsubsection{CCRs and clinical implications}

The clinical implications follow from the assumption that binges result from exaggerated CCRs that are due to probabilistic CS (cue) UCS (extreme food intake) contingencies. It would be expected that the urge to binge is cue-dependent, i.e. binges will occur in stereotyped stimulus configurations. There are clinical impressions that back up this inference and there is a therapeutic implication. If bingeing results from prior CSUCS contingencies it follows that when the probabilistic connection between CS (cue) and UCS (extreme food intake) is broken, the exaggerated CCRs will be extinguished and so will actual bingeing behavior. Controlled testing of this therapeutic implication is beyond the scope of this dissertation. Meanwhile in section 5.9 a case study is presented of a bulimic patient who was successfully treated along the lines traced out above. Though this $n=1$ study is, of course, far from decisive, it at least suggests that the classical conditioning model of CCRs is therapeutically useful and warrants clinical trials.

In sum, the classically conditioned compensatory model appears to provide a promising explanation of binge eating. The neo-Pavlovian response model of binge eating and counterregulation postulates that: 
CPRs are conditioned responses to food cues

[hyperinsulinemia is a CPR]

CPRs mediate compensatory responses (CCRs)

[hyperinsulinemia elicits hypoglycemia]

CPRs/CCRs are particularly strong if strong UCSs are presented [hypoglycemia is particularly strong in the case of intermittent dieting/overeating]

CPRs/CCRs are experienced as hunger or craving

[hyperinsulinemia/hypoglycemia is experienced as hunger or craving]

CPRs/CCRs promotes overeating

[hyperinsulinemia/hypoglycemia promotes bingeing/counterregulation]

\section{6 summary}

Dieting and bingeing usually co-occur. Even in the eighties, an outdated variant of the set point hypothesis is repeatedly put forward to explain this co-occurrence. The set point theory states that every individual has his/her own, biological ly predetermined, 'set point' for body weight. When someone's body weight drops below its alleged 'set point", processes are started up to return to the 'set point'. One of these processes is overeating. Four lines that back up the set point theory were outlined: (1) some people do not show the usual decline in sweet preference after eating a glucose preload, (2) body weight remains relatively constant over long periods and under various circumstances, (3) organisms show a strong resistance to weight loss or weight gain, (4) experimentally induced new body weights are also stable and are defended effectively. However, researchers' application of the set point theory to counterregulation can be criticized for several reasons: (1) the decrease of perceived pleasantness after intake of a sweet solution is not always supported in dieters and the relevance to the alleged set point weight is doubtful, (2) the literature promotes the idea that data have been selected post hoc, (3) there is some circular/homuncular reasoning when it comes to determining someone"s set point for body weight, (4) the model lacks preciseness: a set point can relatively easily be changed by diet composition and/or exercise level. Especially when it comes to explaining the lab data on counterregulation, three problems of using the theory emerge: (1) it is untestable whether counterregulating dieters, who are usually unsuccessfu/dieters, are below their set point for body weight, and (2) some dieters counterregulate and other dieters do not, which dependends on the presence of a 'disinhibitor', (3) there are also successful dieters. Because of this, auxiliary hypotheses will always be needed. It is con- 
cluded that the 'set point' notion is not a satisfactory explanation of counterregulation.

Because of the fact that not all dieters overeat, attention is turned to the selective restriction of carbohydrate intake, instead of to the restriction of total calorie intake. The restriction of the relative carbohydrate intake lowers central 5-HT level. This diet-induced hyposeratonergic functioning is assumed to lower mood and to elicit a carbohydrate-rich binge: by eating a relatively large amount of carbohydrates during a binge, 5-HT level should be raised. In this way, mood will also be improved. However, several criticall comments can be given on the 5-HT idea: (1) the assumption that bingeing is functional in raising the 5-HT level is doubtful, (2) it is unclear whether carbohydrate craving results from a lowered 5-HT level, a heightened NA level, or the combination of the two, (3) a lowered 5-HT level is not needed to induce bingeing, (4) it is unclear whether a lowered 5-HT level is sufficient for bingeing and (5) hyposerotonergic functioning is not sufficient for bingeing; other neurotic disorders (e.g. the obsessive compulsive disorders) have also been associated with a lowered 5-HT turnover. The 5-HT hypothesis originally focussed on bulimics' binge eating; there is no laboratory research on counterregulation and the 5-HT model.

Just like the set point hypothesis, the 5-HT model does not explain the observation that dieters do not always overeat, but merely do so after the introduction of a so-called 'disinhibitor'. Cognitive theory on the other hand, postulates an explanation for the 'disinhibition' of merely challenged dieters. According to the cognitive idea, dieters perceive their diet as broken after 'disinhibition' whereas non-disinhibited dieters, of course, do not. The perception of having broken one's diet is supposed to be a stimulus to overeating more. However, the notion that disinhibitive thoughts such as "I"ve blown my diet, I might as well continue to eat" trigger an overeating response has never been tested. Furthermore, cognitive theory fails to explain dieters' overeating after mood induction satisfactorilly.

An alternative model was presented. The underlying idea is that counterregulation/binge eating responses are cue-controlled. After organisms have been confronted with stimuli that are probabilistically related to subsequent food intake, they show anticipative physiological responses (e.g. salivation) which prepare the organism for the intake of food. These physiological anticipatory responses are classically conditioned responses to cues. The learned anticipatory responses will be stronger in proportion to the extent to which the cues are predictive of large food intake. One of the anticipative responses is the release of insulin. Insulin, released in anticipation of the food cues, leads to a decline in blood sugar level. This decrease is viewed as a compensatory response: after eating, the blood sugar level will increase. It is therefore convenient to lower blood sugar levell in advance, especially when cues predict large intake. The classically conditioned compensatory response (hypoglycemia) will 
subjectively be experienced as craving or hunger and will stimulate overeating in order to restore blood sugar level. The model explains why dieters overeat after various disinhibitors: all these challengers act as cues which elicit the preparatory (insulin release) and compensatory responses (decline in blood sugar levell). 


\section{.}




\section{4 overview of the empirical studies}

Dieting and bingeing often co-occur. In the laboratory, dieters counterregulate after a challenge whereas non-dieters do not. A current view is that dieters overeat because they restrict their food intake and are chronically hungry because of that (ct. 3.2). Section 5.1 (clinical and non-clinical binges) describes an investigation of the question whether hunger really is an important antecedent of a binge. Furthermore, when subjects are classified as dieters or non-dieters, the pitfall of tautology should be avoided: classification is usually done by means of the Restraint Scale (RS), which has been found to entangle the intention to diet and the tendency to overeat. Therefore, the question is whether it is the intention to diet or the tendency to overeat which is important in the occurrence of counterregulation. This question is answered in 5.2 (non-regulation of food intake in restrained, emotional, and external eaters). The studies showed that hunger is not a determinant of bingeing (ct. 5.1) and that successful dieting is not a prerequisite for counterregulation to occur (cf. 5.2).

Clearly, actual restriction of calorie intake is not a crucial factor in the occurrence of binge eating \& counterregulation. This observation drew attention to the selective restriction of carbohydrate intake (cf. 3.3). The underlying idea was that dieters usually deprive themselves of the intake of carbohydrates (accompanied by a relatively high protein intake) and are in this way characterized by a lowered central 5-HT level. During a binge, dieters alledgedly ingest a large amount of carbohydrates (and little protein) in order to restore 5-HT level. In section 5.3 (does bingeing restore bulimics' alleged 5HT-deficiency?) this was investigated. No support was found for the notion that dieters usually ingest relatively little carbohydrates and especially binge on carbohydrates.

Thus, the notions of hunger, actual restriction of calorie intake, and a selective carbohydrate restriction could not be supported in the studies described in chapter 5. Attention was focussed on the part that mood plays. Section 5.4 (Is counterregulation of dieters after forced consumption of a preload dependent on mood?) describes an investigation of the question whether counterregulation of dieters after forced consumption of a preload depends on mood. It did not.

It is widely held that dieters overeat after a challenge because they perceive their diet as broken (cf. 3.4). In section 5.5 (cognitions and self-talk during food intake of restrained and unrestrained eaters) it was tested whether counterregulating dieters think in a more disinhibitive way than non-dieters and non-disinhibited dieters do. They did not. Neither 
was any evidence found for the cognitive notion that, after breaking their diet in the lab, subjects will overeat for the rest of the day (cf. 5.6: no evidence that dieters counterregulate outside the laboratory).

Dieters were not characterized by so-called disinhibitive cognitions but they did report a loss of control during the confrontation with food. This loss of control was reminiscent of addictivelike behavior (cf. 3.5). Some authors touched upon the idea, but no experimental tests on the addiction analogy have been carried out so far. In section 5.7 (restrained eaters are rapidly habituating sensation seekers), experimental support was found for the notion that overeating can be viewed as addictionlike behavior. Restrained eaters habituated more rapidly to a series of neutral stimuli than unrestrained subjects did. Moreover, restrained eaters showed higher sensation seeking tendencies than unrestrained eaters. These two tendencies have been found to characterize addicts.

I have been guided by these findings. Recent experimental research on the etiology and maintenance of addictions underline the learned nature of craving and tolerance. An analogous model of classically conditioned compensatory responses was outlined for counterregulation \& binge eating (cf. 3.5). Among other things, this model predicts that cues (CSs) reliably and specifically associated with the intake of large amounts of ('forbidden') food (UCS) will elicit craving and an overeating response in dieters. In section 5.8 (on being led into temptation: 'counterregulation' of dieters after smelling a 'preload') the hypothesis was supported that dieters also counterregulate after a CS which reliably predicts food intake (the smell of food), but that has nothing to do with breaking the diet (which was most important according to cognitive notions). In 5.9 (a case of bulimia successfully treated with cue-exposure) it is demonstrated that breaking the CS-UCS connection may be an effective treatment of bulimia. 
5 empirical data 


\title{
5.1 clinical and non-clinical binges
}

\author{
Anita Jansen ${ }^{1}$, Marcel van den Hout ${ }^{1}$ \& Eric Griez ${ }^{2}$ \\ Behaviour Research and Therapy , in press.
}

\section{abstract}

In the present study, it was investigated if and in what respects clinical binges (reported by bulimic subjects) are different from non-clinical binges (reported by a non-clinical population). Furthermore, the study prospectively tested whether the DSM-III-R criteria and other varlables that are retrospectively claimed to be defining characteristics indeed differentlate binges from non-binge eating episodes. Clinical binges appeared to differ from non-clinical binges as to amount of calories ingested and duration. With respect to subjective experience, clinical and non-clinical binges did not differ. The DSM-III-R criteria for binge eating discriminate clinical and non-clinical binges quite well from non-binges. With the addition of other seemingly important variables, binges are not discriminated better from non-binges than with the DSM-III-R variables alone. It is argued that the difference belween pathological binge eating and non-clinical binge eating is mainly a matter of severity.

\section{infroduction}

An essential feature of the eating disorder Bulimia Nervosa (BN) is the recurrence of binge eating episodes. Binge eating refers to the rapid consumption of a large amount of food in a discrete period of time, during which a lack of control over eating behavior is experienced (APA, 1987). Apart from these DSM-III-A criteria for binge eating, other characteristics of a binge, as well as its antecedents and its consequences, are held to be important defining characteristics. Before a binge, $40 \%$ to $59 \%$ of the patients should feel bored and depressed (Johnson et all., 1982; Abraham \& Beumont, 1982), $78 \%$ of the patients should crave for food and $44 \%$ should feel hungry (Abraham \& Beumont, 1982). During a binge, many

1 Dept. of Mental Health Sciences / Experimental Psychopathollogy, Limburg University, P.O. Box 616, 6200 MD Maastricht, the Netherlands

2. Dept. of Clinical Psychiatry / Experimental Psychopathology, Limburg University, the Netherlands. 
patients should stuff the food into their mouth and eat too quickly to taste anything (Abraham \& Beumont, 1982; APA, 1987). And, following a binge, a depressed mood is often prominent (Cooper \& Bowskill, 1986; APA, 1987).

It is obvious that especially the DSM-III-R criteria for binge eating (rapid consumption, large amount of food, and the lack of control over eating behavior) are subject to a very personal interpretation. Eating much, eating rapidly, and finding it difficult to stop eating once started is not at all abnormal; non-psychiatric subjects also experience eating binges (Wardle \& Beinart, 1981; Rand \& Kuldau, 1986). Are there any differences between pathological binge eating and binge eating that is of no clinical significance? So far there are no data on this issue. Therefore, the first aim of the present study was to investigate whether 'non-clinical' binges (reported by non-bulimic subjects) are different from 'clinical' binges (reported by bulimic subjects) with respect to amount of calories ingested, duration, and subjective experience.

Furthermore, the DSM-III-R criteria and the characteristics of a binge that were listed above were obtained retrospectively from clinical reports but have never been tested prospectively. The second aim of the present study was, therefore, to determine prospectively whether the DSM-III-R criteria and/or the other characteristics listed above can indeed differentiate bulimic, as well as normal binges from non-binge eating episodes.

\section{method}

subjects

Data on clinical binges were obtained from 9 female subjects with $B N$ who were awaiting cognitive-behavioral therapy at the local psychiatric hospital. They were diagnosed as suffering from $\mathrm{BN}$ by the hospital staff and the first author according to DSM-III-R criteria. Data on non-clinical binges were obtained from 19 female subjects and 1 male subject who reacted to a call for binge eaters in the university newspaper ${ }^{1}$. The subjects were interviewed by the first author to make sure that they did experience (self-defined) binge eating episodes but did not satisfy the DSM-criteria for any of the eating disorders: it was made sure that the normal subjects did not exhibit such a persistent over-concern with body shape and weight as bulimic patients do. Furthermore, they only sporadically engaged in self-induced vomiting and never used laxatives and/or diuretics. They gave the impression that they did not suffer from their binges as much as patients did.

1 The text of the advertisement word fo word run as follows: "Do you have eating binges regularly? And are you willing to lake part in a questionnaire survey for a consideration? Everything is confidential and anomity will be quaranteed." 


\begin{tabular}{|c|c|c|c|c|}
\hline & $\begin{array}{l}\text { patients } \\
n=9\end{array}$ & $\begin{array}{l}\text { normals } \\
n=20\end{array}$ & $t$ & $p$ \\
\hline $\mathrm{BMI}^{1}$ & $\begin{array}{l}21.6 \\
(6.9)\end{array}$ & $\begin{array}{l}21.7 \\
(2.4)\end{array}$ & -0.1 & NS \\
\hline age & $\begin{array}{l}27 \\
(4.5)\end{array}$ & $\begin{array}{l}22.2 \\
(3.5)\end{array}$ & 3.1 & $<0.01$ \\
\hline $\begin{array}{l}\text { lime since onset of } \\
\text { binges (years) }\end{array}$ & $\begin{array}{l}7.7 \\
(4.0)\end{array}$ & $\begin{array}{l}4.2 \\
(3.0)\end{array}$ & 2.6 & $<0.05$ \\
\hline total restraint score & $\begin{array}{l}24.3 \\
(5.4)\end{array}$ & $\begin{array}{l}16.6 \\
(5.6)\end{array}$ & 3.5 & $<0.01$ \\
\hline concern for dieting & $\begin{array}{l}14.3 \\
(4.5)\end{array}$ & $\begin{array}{l}10.1 \\
(3.9)\end{array}$ & 2.6 & $<0.05$ \\
\hline weight fluctuations & $\begin{array}{l}10 \\
(4.9)\end{array}$ & $\begin{array}{l}6.5 \\
(2.9)\end{array}$ & 2.5 & $<0.05$ \\
\hline depression score (BDI) & $\begin{array}{l}27.3 \\
(6.9)\end{array}$ & $\begin{array}{l}6.1 \\
(4.9)\end{array}$ & 9.5 & $<0.001$ \\
\hline
\end{tabular}

${ }^{1} \mathrm{BM} \mid=$ Body Mass Index $\left(=\right.$ weight/height $\left.{ }^{2}\right)$

Subject characteristics are presented in table 1.

assessment

The following instruments were used:

Restraint Scale (RS; Polivy et al., 1978); measuring (a) Concern for Dieting (CD), shown in e.g. attitude towards eating and frequency of dieting and (b) Weight Fluctuations (WF).

Beck Depression Inventory (BDI) measuring level of depressed mood. Eating Diary in which subjects wrote down everything they ate and drank during 7 days. The Eating Diary asked for the time and duration of eating; the sort and amount of food ingested; whether it was a binge, a normal meal, or a snack; and whether consumption was followed by vomiting or the intake of laxatives.

Pre-eating State Form. An eating episode was defined as a period of eating marked off in time. Before each eating episode, subjects indicated whether they were bored, depressed, hungry, and craved for food on a 0 ('not at all') to $100 \mathrm{~mm}$ ('extremely') Visual Analogue Scales (VASs). 
Post-eating State Form. After each eating episode subjects wrote down what and how much they had eaten and whether it was a binge or not. On $O$ ('not at all') to $100 \mathrm{~mm}$ ("extremely") VASs they noted how depressed they were, whether they had eaten much, whether they had eaten more than planned, whether they had eaten rapidly, whether they had stuffed themselves with the food, whether they had tasted the food, and whether they had lost control over their eating behavior.

The variables on the Pre and Post-eating State Forms correspond with the DSM-III-R criteria and the characteristics/antecedents/consequences held to be important by several authors (see introduction).

\section{procedure}

All subjects were interviewed by the first author. At the start of the interview subjects filled in the RS and the BDI. During the interview, information concerning eating pattern, eating problems, time of onset, vomiting, use of laxatives, height, weight; concern with weight and appearance was gathered. At the end of the interview it was explained how they should fill in the eating diary and the pre- and post-eating forms. Subjects kept the eating diary for 7 days. From the morning of the 5 th day on, they also filled in the Pre- and Post-eating State Forms before and after the first 10 eating episodes. After the registration period the subjects returned the eating diary and the forms. Unclear issues were discussed.

\section{analysis}

1. The eating diaries provided 86 binges of patients and 106 binges of normal controls. To investigate whether 'non-clinical' binges are different from 'clinical' binges in caloric content and duration (question 1), mean calorie intake during a binge, mean duration of a binge, and mean amount of calories ingested per minute during a binge were calculated for every subject. With t-Tests it was tested whether groups differed as to these variables.

2. 32 binges of 9 patients, 43 non-binges of 8 patients, 33 binges of 17 controls and 137 non-binges of 20 controls were gathered by the forms. On the remaining forms (15 of the patients, i.e. $16 \%$, and 30 of the normals, i.e. $15 \%$ ) subjects were unable to answer the question whether the eating episode was a binge or not: they stated that these were 'semibinges'. The semibinges were not included in the data analysis (it would be interesting to further investigate the phenomenon 'semibinges'). To investigate whether 'non-clinical' binges are different from 'clinical' binges with respect to subjective experience (question 1) the mean score for the 11 variables (boredom, depression before eating, hunger, craving, depression after eating, eating much, more than planned, rapidly, stuffing the food into the mouth, tasting the food, and the loss of control over eating behaviour) were calculated for binge eating and non-binge eating episodes for each subject. On the mean scores Analyses of Variance 
(ANOVAs) were carried out. Main Factors were Group (Patient vs. Controls) and Eating Episode (Binge ws. Non-binge). Because the forms did not obtain non-binge eating episodes from all patients and binge-eating episodes from all normals, the ANOVAs were carried out on the means of 8 patients and 17 control subjects.

3. To determine prospectively whether the DSM-III-R criteria and the other characteristics listed above are reliable predictors of clinical and non-clinical binges (question 2), a factor analysis was carried out on the 11 -item form scores of the 75 patients' binges and non-binges. The factor analysis provided only one factor (Eigenvalue 4.3). Only the variable 'hunger' did not contribute to the factor. Therefore, sum scores over all variables except for 'hunger' were used in a subsequent Discriminant Analysis. By means of the patient's Discriminant Analyses (over all factors as well as only over the DSM factors) it was investigated whether normal, i.e.' non-clinical, binges could be discriminated from normal, i.e. non-clinical, non-binges.

\section{results}

are non-clinical binges different from clinical binges (question 1) with respect to calorie intake and duration?

In table 2 mean calorie intake during a binge, mean duration of a binge, and mean calorie intake per minute during a binge are given for patients (clinical binges) and normals (non-clinical binges) respectively. Clinical binges were characterized by a significantly larger calorie intake and they lasted longer than non-clinical binges. Mean amount of calories ingested per minute during a binge was not different in the two groups.

table 2: quantity of clinical and non-clinicall binges.

\begin{tabular}{lllll}
\hline & $\begin{array}{l}\text { clinical } \\
\text { binges } \\
n=9\end{array}$ & $\begin{array}{l}\text { non-clinical } \\
\text { binges } \\
n=20\end{array}$ & $t$ & $\mathrm{p}$ \\
\hline calorles waten during a binge & $\begin{array}{l}2631.7 \\
(1347.1)\end{array}$ & $\begin{array}{l}9.85 .7 \\
(512.6)\end{array}$ & 4.8 & $<0.001$ \\
duration of a binge (minutes) & 55.7 & 33.5 & 2.1 & $<0.05$ \\
& $(32.4)$ & $(18.9)$ & & \\
calories eaten per minute & 60.6 & 44.9 & 1.7 & NS \\
during a binge & $(28.8)$ & $(17.6)$ & & \\
\hline
\end{tabular}


are non-clinical binges different from clinical binges (question 1$)$ with respect to subjective experience?

Data are represented graphically in Fig. 1.

There were obviously clear differences between binges and non-binges.

As to the difference between patients and controls: a similar pattern emerged. Subjectively controls experienced the same as patients, but on a lower level. All parameters were tested with a two-way ANOVA. Results are given in table 3 .

table 3: F-values of the ANOVAs carried out on the 11 variables.

\begin{tabular}{|c|c|c|c|c|c|c|c|c|c|c|}
\hline boredom & $\begin{array}{l}\text { depression } \\
\text { belore } \\
\text { ealing }\end{array}$ & craving & hunger & $\begin{array}{l}\text { eating } \\
\text { much }\end{array}$ & $\begin{array}{l}\text { ealing } \\
\text { more thary } \\
\text { planned }\end{array}$ & tasle & $\begin{array}{l}\text { rapidity } \\
\text { of } \\
\text { oaling }\end{array}$ & $\begin{array}{l}\text { stuffing } \\
\text { the lood }\end{array}$ & $\begin{array}{l}\text { depression } \\
\text { alter } \\
\text { oating }\end{array}$ & $\begin{array}{l}\text { loss of } \\
\text { control }\end{array}$ \\
\hline \multicolumn{11}{|c|}{ imain effect for group } \\
\hline $8,6^{* * *}$ & $16.2^{* * 4}$ & $5.3^{n}$ & $\mathbb{N S}$ & NS & NS & $6.2^{*}$ & $93^{* * *}$ & $18.0^{* * * *}$ & $37.7^{-10}$ & $12.6^{* * *}$ \\
\hline \multicolumn{11}{|c|}{ maln effect for eating episode } \\
\hline $10.8^{* * *}$ & $5.1^{*}$ & $30.7^{* * *}$ & NS & $123.3^{*+6}$ & $44.1^{* * * *}$ & $16.6^{* * n *}$ & $25.1^{* * *}$ & $37.9^{* * 4}$ & $12.0^{* * *}$ & $80.0^{* * e}$ \\
\hline \multicolumn{11}{|c|}{ Interactlon effect group $X$ eating eplsode } \\
\hline MS & NS & NS & NS & NS & NS & NS & NS & $6.3^{*}$ & NS & $7.9^{\circ}$ \\
\hline
\end{tabular}

${ }^{*}=p<0.05 ; ;^{* *}=p<0.01 ; * * *=p<0.001$

As can be seen, main effects for Group emerged on boredom, craving, depression before eating, depression after eating, taste, eating rapidity, stuffing the food into the mouth, and loss of control. On these variables, patients scored higher than the controls, irrespective of the binge/nonbinge dichotomy.

Main effects for Eating Episode emerged on all variables, except for hunger, indicating overall differences between binges and nom-binges. Interactions would be of particular interest, as they would reflect different patterns in eating episodes for patients and controls. However, merely two interaction effects emerged (on 'stuffing the food' and 'controllability') and both were due to the difference between binges and non-binges being greater for patients than for normals.

do the DSM-III-R criteria and/or the other characteristics listed above predict clinical and non-clinical binges? (question 2)

With the aid of the Discriminant Analysis over the 10 variables, $90.7 \%$ of the patients' eating episodes could be classified correctly as a binge or a non-binge eating episode; 28 out of the 32 binges $(87.5 \%)$ and 40 out of the 43 non-binges ( $93 \%$ ) were classified correctly. By means of only the 

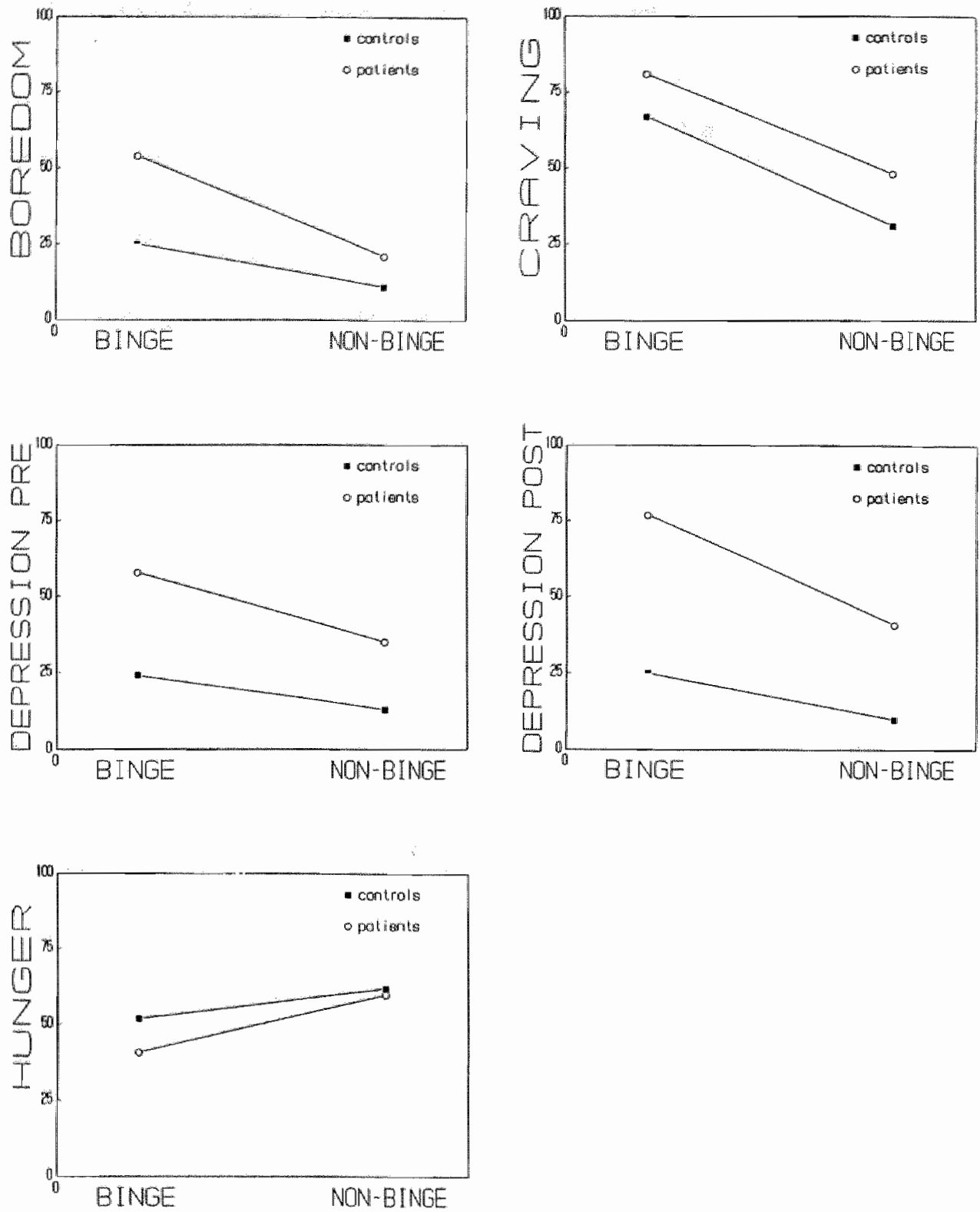

figure 1 : the subjective experiences before, during and after a binge or non-binge for 8 patients and 17 contrais. 

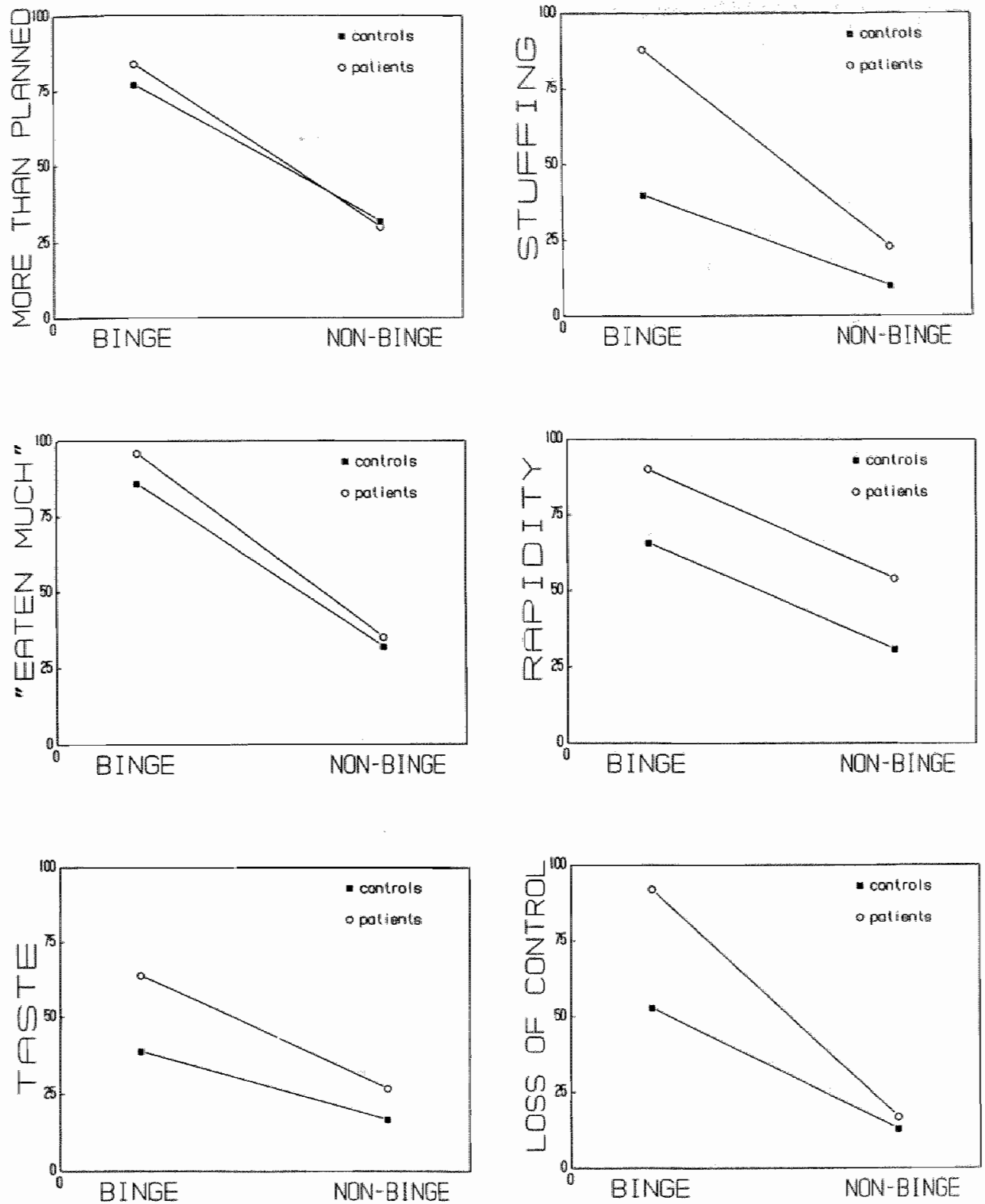
3 DSM-III-R criteria (eating much, eating rapidly, and losing control), $89.3 \%$ could be classified correctly ( 28 binges $(87.5 \%)$ and 39 non-binges $(90.7 \%))$.

The patients" Discriminant Analysis over all variables predicted merely 10 out of the 33 non-clinical binges $(30.3 \%)$ correctly, whereas all nonbinges were predicted correctly. By application of the patients' DSM-III-R Discriminant Analysis to the eating episodes of the normals, 19 out of the 33 binges $(57.6 \%)$ were classified correctly, whereas 5 out of the 137 non-binges $(3.6 \%)$ were wrongly classified as binges.

\section{discussion}

The present study led to four main findings. First, clinical binges (reported by bulimic subjects) differ from non-clinical binges (reported by 'normal' binge eaters) as to amount of calories ingested and duration. During clinical binges more calories are ingested and the binges take more time than non-clinical binges.

Second, clinical binges are not convincingly different from non-clinical binges as to quality. The same pattern of subjective experience emerged. Both clinical binges and non-clinical binges are preceded by more boredom, depression and craving than non-binge eating episodes. During clinical, as well as during non-clinical binges, less is tasted, food is eaten more rapidly, subjects stuffed themselves more with the food and more loss of control is experienced than during non-binges. After a binge, clinical as well as normal subjects are more depressed and they both report that they ate more, and more than planned, than when they were not having a binge. Except with respect to the last two variables (eating more and eating more than planned) patients merely differed from normals in the greater intensity of these feelings. Patients experienced more boredom, depression and craving before eating. They tasted the food better, ate more rapidly, and stuffed themselves more with the food than normals did. They also lost more control during eating and, afterwards, they felt more depressed.

Third, the DSM-III-R criteria for binge eating (rapid consumption of a large amount of food during which a lack of control over eating behavior is experienced) discriminate clinical binges quite well from non-binges. The addition of other variables recognized as important by clinicians (boredom, depression, craving, tasting, eating more than planned, and stuffing the food into the mouth) did not provide a better prediction than the DSM-III-R variables alone.

Fourth, with the aid of the patients' Discriminant Analysis (including all variables) not even one-third of the non-clinical binges could be predicted correctly. When only the DSM-III-R variables were used in the Discriminant Analysis, considerably more non-clinical binges $(58 \%)$ could be classified correctly. The latter supports the relevance of the use of the 
DSM variables, and not the other ones, for identification of a binge. In addition to the data of the ANOVAs and t-Tests, the Discriminant Analysis (with DSM variables) implies that the difference between pathological binge eating and binge eating that is of no clinical significance is mainly a matter of severity, that is, clinical binges are more extensive and are preceded/accompanied/followed by more negative feelings.

Assuming that severity is the main discriminant of pathological binge eating and binge eating that is of no clinical significance, the question may be asked what makes a binger into a bulimic. Patients did not only differ from normal subjects in having an eating disorder, but also in level of restraint, period after onset of eating binges, age, and depression. Although normal subjects were highly restrained, patients were significantly more restrained. Could high restraint in patients explain the patient/control differences observed? It has been argued that extreme dieters overeat because they are chronically hungry (Polivy \& Herman, 1985) and that more extreme bingeing follows from more extreme hunger as a consequence of more extreme dieting. However, in the present study, hunger did not contribute to the 'binge' factor identified by the factor analysis. Further analysis of 'hunger' showed that no more hunger was experienced before a binge than before a normal eating episode, neither by patients nor by normals. Clearly, bingeing has nothing to do with being hungry.

Patients were older and had suffered from binge eating for a longer period than normals. The transition from non-clinical into clinical problems might progress along a continuum. This would imply that some of the as yet non-clinical subjects will be clinical subjects in a few years. It would be interesting to identify exactly which factors contribute to a development from non-clinical into clinical. The fact that patients were much more depressed than normal subjects does not mean that depression is an important factor. The present study had a correlational nature and, therefore, comes quite close to the chicken-and-egg problem. The understanding of the two issues, the development of eating disorders from non-clinical into clinical and the role depression plays in this, would benefit from more empirical attention.

In sum, clinical binges differ from non-clinical binges in duration and the amount of calories ingested, but they are not convincingly different with respect to subjective experience. The DSM- III-R criteria for binge eating discriminate both clinical and non-clinical binges quite well from nonbinges. The addition of other seemingly important variables does not discriminate binges better from non-binges than the DSM-III-R variables alone do. The difference between pathological binge eating and binge eating that is of no clinical significance appears to be mainly a matter of quantity and intensity along a continuum. 
acknowledgements

Many thanks are expressed to Erik Schouten for the statistical analyses and to the employees of the Academic Anxiety Center/Nijverdal Maastricht Hospital for their hospitality. 


\title{
Nonregulation of Food Intake in Restrained, Emotional, and External Eaters
}

\author{
Anita Jansen,' Jaap Oosterlaan, ${ }^{1}$

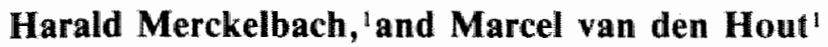

Accepted: June 20,1988

In the present study, regulation of ice cream intake after a preload was examined in 20 high and 20 low scorers (median split) on subscales of the Restraint Scale (RS) (Herman, Polivy, Pliner, Threshold, \& Munic, 1978) and the Dutch Eating Behavior Questionnaire (DEBQ) (van Strien, 1986). For each subscale it was hypothesized that low scorers would regulate their ice cream intake. High scorers on "disinhibitive" scales (i.e., the RS and the $D E B Q$-emotional and -external subscales) were expected to counterregulate after a preload. In contrast, high scorers on the "inhibitive" $D E B Q$-restraint scale were expected to regulate their ice cream intake. A robust effect was found: high scorers never regulated ice cream intake after a preload on either the disinhibitive or the inhibitive scales, while low scorers always did. For the $R S$ a significant interaction effect was found $[\mathrm{F}(1,39)=4.97, \mathrm{p}=.03]$. None of the other subscales showed interaction effects. The t tests showed that low scorers on all subscales ate significantly less after a preload than without one, while high scorers on all subscales did not differ in intake after a preload or without one. This nonregulation appears to be characteristic of people preoccupied with caloric intake, regardless of the content of the preoccupation.

KEY WORDS: nonregulation of food intake; restrained eating; external eating; emotional eating.

Department of Mental Health Sciences/Experimental Psychology, Limburg University. P.O. Box 616, 6200 MD Maastricht, the Netherlands. 


\section{INTRODUCTION}

A series of laboratory studies revealed that high scorers on the Restraint Scale (RS) (Herman, Polivy, Pliner, Threshold, \& Munic, 1978) eat more ice cream after a preload of milkshakes than without a preload, while low scorers eat less after a preload than without one (Herman \& Mack, 1975; Hibscher \& Herman, 1977). Restraint theorists claim that this so-called "counterregulation" is due to disinhibition of cognitive dietary self-control or "restraint" (Ruderman, 1986). As a consequence of their restrained eating style, restrained eaters are supposed to have a body weight below their biological boyd weight "set-point." By disrupting their restraint by taking a preload of, for example, milkshakes, they tend to indulge in a biological urge to overeat. However, to consider the experimental results on counterregulation as solid proof of restraint theory is, for several reasons, premature. First, several factor-analysis studies have identified two subscales of the RS: "concern for dieting" (CD) and "weight fluctuations" (WF) (Blanchard \& Frost, 1983; Ruderman, 1985; Wardle, 1986). Therefore, the RS cannot be seen as a pure measure of restraint. It remains to be determined whether counterregulation in samples scoring high on the RS is due to concern for dieting, weight fluctuations, or a combination of the two. Second, Wardle (1987a) and van Strien (1986) argue that inspection of the RS items reveals that it is not restraint, as such, that may be measured but rather unsuccessful dieting or disinhibitive restraint. The observation that high scorers on items such as "Do you eat sensibly in front of others and splurge alone?" and "Do you have feelings of guilt after overeating?" are in fact counterregulating in laboratory experiments underlines the predictive value of the RS. The Wardle (1987a) and van Strien (1986) reinterpretation of the RS raises an interesting issue about the association between high RS scores and counterregulation. Is it high restraint per se that predisposes to counterregulation, as restraint theorists claim, or does only a subgroup of high-restrained eaters counterregulate, as the Wardle and van Strien view suggests? More specifically, following Wardle and van Strien, one wonders if unsuccessful dieters, as identified by the RS, may counterregulate in laboratory experiments, while successful dieters may, in laboratory situations, remain able to resist the temptation to overeat. Indirect support for this interpretationof the RS/counterregulation data comes from recent experiments by Shrager et al. (1983; cited by van Strien, Frijters, van Staveren, Defares, \& Deurenberg, 1986) and Wardle and Beales (1987). By using the Three Factor Eating Questionnaire (TFEQ) of Stunkard and Messick (1985), Shrager and co-workers demonstrated that it was not the "cognitive restraint of food intake" (factor I) but the "disinhibition of cognitive restraint" (factor II) that was associated with overeating (van Strien et al., 1986). Wardle and Beales used the restrained subscale of the Dutch Eating Behavior Questionnaire (DEBQ) as a purer measure of restraint; high 
scorers on the DEBQ-restraint subscale may be considered successful dieters (van Strien, 1986). And in spite of the high correlation between the DEBQrestraint subscale and the RS $(.72$; see Wardle, 1986) and its validity in a British population (Wardle, 1987a), Wardle and Beales (1987) could not replicate the earlier laboratory findings of counterregulation by using the DEBQrestraint subscale. Wardle and Beales (1987) found no difference in regulation between high and low DEBQ-restraint scorers. However, reanalyzing their data showed that their high-restrained subjects did not regulate after the preload $[t(23)=.71, \mathrm{NS}]$, while their low scorers counterregulated even after a preload $[t(27)=1.96, p<.05]$. Counterregulation in low scorers is in sharp contrast with what was found in comparable studies. This curious behavior of low scorers, plus the fact that the ice cream intake in this study was extremely low in all groups, suggests that the Wardle and Beales findings were derived from an atypical subject sample. This study needs replication before firm conclusions can be drawn.

The DEBQ has proven to give valid indications of restrained, as well as emotional and external eating (van Strien, 1986; Wardle, 1987a). While the DEBQ-restraint subscale measures successful inhibitive eating, the emotional and external eating subscales measure disinhibitive eating patterns. Therefore, one would expect "disinhibitive eaters" (i.e., emotional and external eaters) to show the disinhibitive eating pattern of counterregulation. On the basis of the above-mentioned considerations, it was hypothesized that (1) high scorers on scales measuring disinhibitive eating patterns (i.e., the RS, DEBQ-emotional, and DEBQ-external scales) would counterregulate, while low scorers on these scales would regulate after a preload, and (2) both high and low scorers on the scale measuring inhibitive eating patterns (i.e., the DEBQ-restraint scale) would regulate after the preload. In the present study, attention was also directed at determining whether counterregulation of high scorers on the RS is due to concern for dieting, weight fluctuations, or a combination of the two.

\section{METHOD}

\section{Assessment}

Subjects were classified as high or low scorers on the basis of the median split score on the following subscales.

Restraint Scale (RS) (Herman et al., 1978)

(a) Total score on the RS: 10 items measuring attitudes toward eating, frequency of dieting, and weight fluctuations. 
(b) RS subscale Concern for Dieting (CD) (see Wardle, 1986): six items of the RS measuring attitudes toward eating and frequency of dieting (e.g.x "How often are you dieting?").

(c) RS subscale Weight Fluctuations (WF) (see Wardle, 1986): four items of the RS concerning weight fluctuations (e.g., "In a typical week, how much does your weight fluctuate?").

\section{Dutch Eating Behavior Questionnaire (DEBQ) (van Strien, 1986)}

(a) DEBQ-restraint subscale: reflecting the degree to which one eats less than he or she actually would like to eat (e.g., "Do you try to eat less at mealtimes than you would like to eat?").

(b) DEBQ-emotional subscale: measuring overeating due to "confusion between internal arousal states accompanying emotional states and physiological states of hunter and satiety" (van Strien, 1986, p. 137) (e.g., "Do you have a desire to eat when you are feeling lonely?"). A subdivision was made between eating in response to diffuse emotional states and eating in response to clearly labeled emotions.

(c) DEBQ-external subscale: reflecting overeating due to a "hyperresponsiveness to food-related cues in the environment together with unresponsiveness to internal cues of hunger or satiety" (van Strien, 1986, p. 137) (e.g., "If you see or smell something delicious, do you have a desire to eat it?").

The dependent variable was the number of grams of ice cream consumed.

\section{Subjects}

Forty female students and employees of Limburg University volunteered to participate in what they believed to be a taste test. Their mean age was 25.5 years $(\mathrm{SD}=8.1$ years $)$ and their mean body mass index $(\mathrm{BMI}=$ weight $/$ height ${ }^{2}$ ) was $22.8(\mathrm{SD}=2.7)$. High and low scorers (median split) on all subscales did not differ in age or height, but on the RS, RS/WF, and DEBQ-external scales, the BMI of high scorers was significantly higher than the BMI of low scorers.

\section{Procedure}

Subjects were asked to have breakfast, lunch, or dinner 1 to $3 \mathrm{hr}$ before participating in the study. Ice cream consumption thus served as a ca- 
loric overload and was not influenced by deprivation. After entering the laboratory, subjects were asked to complete a questionnaire. In this questionnaire, items of the RS were hidden between questions about demographic variables and items concerning general aspects of life (e.g., frequency of sporting, smoking and drinking habits, date of last menstruation, taking medicine), in order to keep the subjects blind to the purpose of the study. Subjects 1 to 20 were randomly assigned to the preload or no-preload condition; subjects 21 to 40 were assigned to one of these conditions on the basis of their RS score in relation to the median split score of the subsample of subjects already tested. Thus, being preloaded or not was determined by the median split score on the RS. Each of the four cells (RS high scorers/RS low scorers $X$ with/without preload) included 10 subjects. Subjects in the preload condition were asked to drink two milkshakes - one vanilla and one chocolateeach containing $150 \mathrm{cal}$. Ten minutes later, they were presented with three dishes, each containing $600 \mathrm{~g}$ of ice cream (chocolate, vanilla, and strawberry). Subjects in the no-preload condition were offered only the ice cream. They were instructed to taste and rate the different flavors. Subjects were encouraged to eat as much ice cream as they wanted and needed to make good taste ratings. Each subjects was left in isolation for $10 \mathrm{~min}$. After that, the ice cream that was left over was reweighed and the subject completed the DEBQ. Then, the subject's weight and height were measured. Finally, before debriefing and payment for participation, we asked subjects to state their ideas on the purpose of the study and what they had eaten before participating in the study. All subjects had eaten their usual meal; there was no reason to believe that the groups differed in level of deprivation. Also, all subjects believed that it was a taste test. Nobody guessed that we measured. the amount of ice cream eaten.

\section{RESULTS}

The median split scores for the different (sub)scales were as follows: RS/total, 12: RS/CD, 7; RS/WF, 4.5; DEBQ-restraint, 2.9; DEBQ-emotional total, 2.7; DEBQ-diffuse emotions, 3.0; DEBQ-clearly labeled emotions, 2.6; and DEBQ-external, 3.1. The results are depicted in Fig 1 . For every subscale, a $2 \times 2$ ANOVA was carried out on the food intake data. ${ }^{2}$ Main factors were Group (Low vs. High Scorers) and Condition (Preload vs. No-Preload). Because low and high scorers on the RS, RS/WF, and DEBQexternal scales differed significantly in $\mathrm{BMI}$, an analysis of covariance was carried out with BMI as the covariate. On neither of the questionnaire sub-

${ }^{2}$ Further details on this study will be published ellsewhere. 
scales were main effects found. For the RS, the ANCOVA showed a significant interaction effect $[F(1,39)=4,97, p=.03]$. On none of the other subscales were interaction effects found. However, $t$ tests showed that low scorers on all RS and DEBQ measures regulated for the preload. Regardless of the subscale used, they ate significantly less after a preload than without one. In contrast, high scorers never regulated or counterregulated after the preload, for $t$ tests showed no difference in intake after a preload or without one. ${ }^{3}$

\section{DISCUSSION}

Low scorers on all RS and DEBQ subscales ate significantly less ice cream in a preload condition than in a no-preload condition. Yet high RS and DEBQ scorers in a preload condition did not differ in ice cream intake from high scorers in the no-preload condition. High scorers, in other words, did not regulate their food intake. On the RS, and only on the RS, an analysis of covariance showed a significant Group $\times$ Condition interaction. However, here, too a $t$ test analysis showed that, in high scorers, nonregulation rather than counterregulation took place. The finding of nonregulation instead of counterregulation is in line with the observation reported by Ruderman and Christensen (1983). However, the present findings are different from those of Wardle and Beales (1987), who found no difference in regulation between high and low DEBQ-restraint scorers. The finding of regulation of low-restraint scorers supports our suggestion (see Introduction) that the Wardle and Beales findings were derived from an atypical subject sample.

The fact that, globally, identical patterns were found on all analyses (cf. Fig. 1) could have been due to common variance of the different subscales. However, intercorrelations between the scales were surprisingly low (cf. Fig. 1). Contrary to our hypothesis, differences in regulation were not confined to high vs. low scorers on the disinhibitive scales, the RS, DEBQemotional subscale, and DEBQ-external subscale. Identical differences were observed on the inhibitive DEBQ-restraint subscale. It seems, therefore, that the occurrence of nonregulation is a feature of people preoccupied with caloric intake, for whatever reason. In passing, it may be noted that the similar-

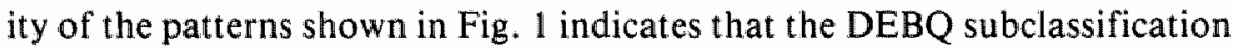
lacks predictive validity when it comes to behavior in test situations such as the present one.

The observation that both successful and unsuccessful restrained eaters displayed the pattern of nonregulation seems a prima facie evidence for the disinhibition hypothesis of restraint theorists. However, we found nonregulation instead of counterregulation. Therefore, the crucial point of

${ }^{3}$ Numerical details may be obtained from the first author. 

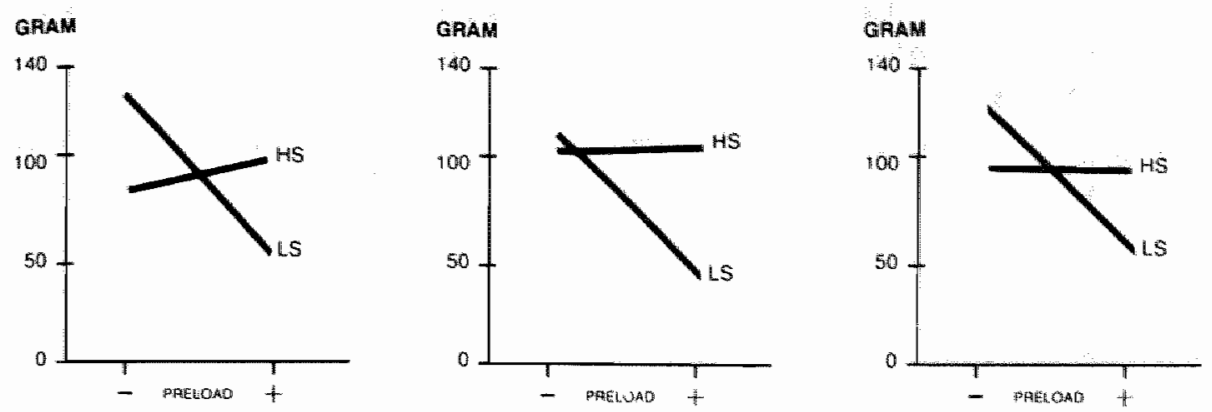

DEBQ-RESTRAINT SCALE

DEBQ-EMOTIONAL SCALE

DEBQ - EXTERNAL SCALE
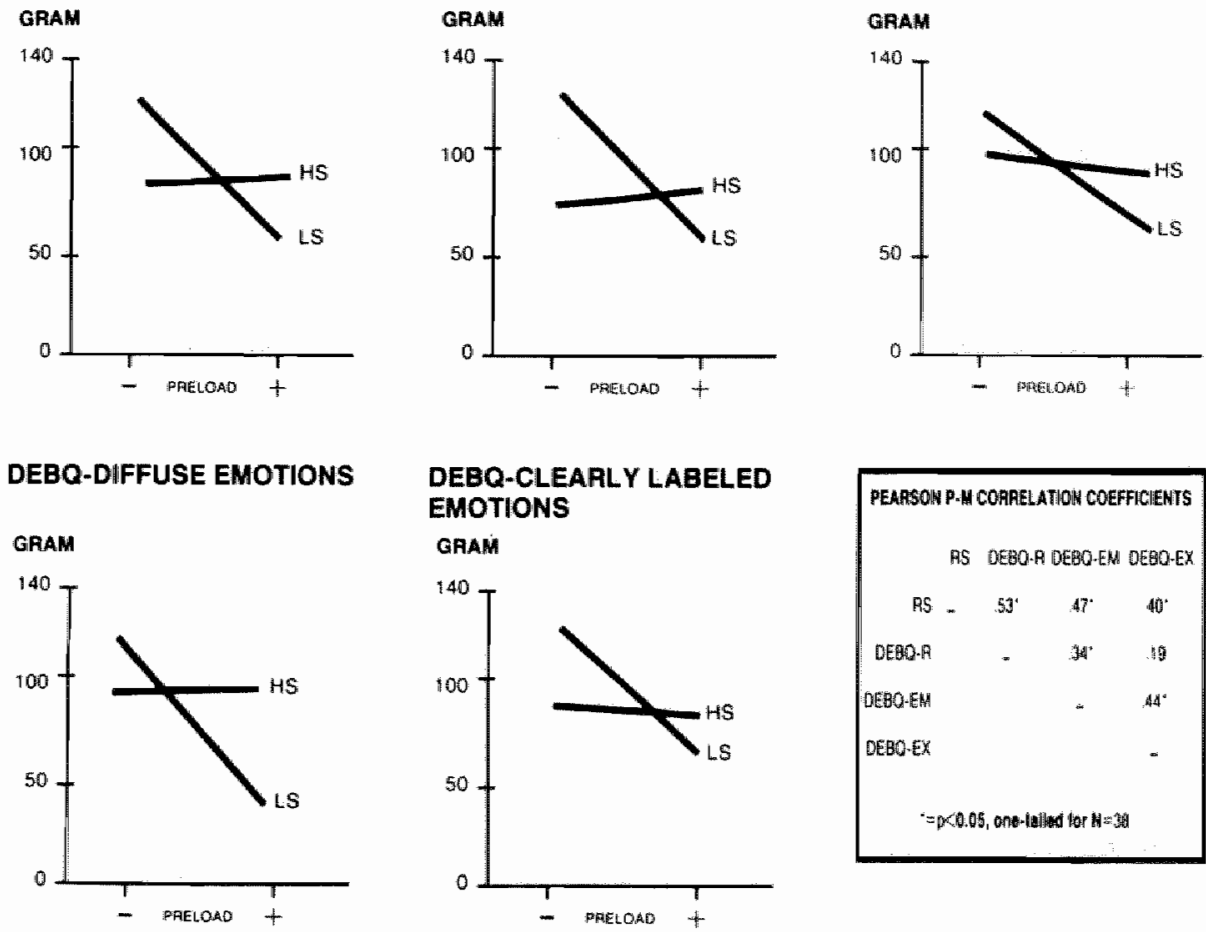

Fig. 1. Grams of ice cream consumed by high scorers (HS) and low scorers (LS). Numbers of subjects in each condition of the subscales were as follows (HS preloaded, HS without preload, LS preloaded, LS without preload): RS - 10,10, 10,10; RS/CD subscale $-10,10,10,10 ;$ RS/WF subscale $-9, \llbracket 1,11,9$; DEBQ-restraint subscale $-10,9,9,10 ;$ DEBQ-diffuse emotions subscale - 12,7,7, 12; DEBQ-clearly labeled emotions subscale-11,8,8,11; DEBQ-emotions subscale-13,6,6,13; and DEBQ-external subscale-9, 10, 10,9. DEBQ data are missing for one low and one high scorer on the RS. 
the disinhibition hypothesis is not unequivocally supported: disrupting the restraint or self-control of restrained eaters by a preload did not "disinhibit" them. The finding of nonregulation instead of counterregulation may be due to our low median split scores on the different scales. Median split scores in the studies by Herman and Mack (1975) and Spencer and Fremouw (1979) were, respectively, 17 and 16 . In these studies counterregulation was found. Although Polivy (1976) and Hibscher and Herman (1977) found counterregulation in their restrained samples with median split scores of, respectively, 11.5 and 14, nonregulation was found in the study by Ruderman and Christensen (1983) and in our own study. Median split scores were, respectively, 13 and 12. In their study, Ruderman, Belzer, and Halperin (1985) found that for subjects with restraint scores below 17.3 , consumption did not differ in the milkshake and no-milkshake conditions, whereas for those with scores above 17.3 it did. All in all, there is a trend for counterregulation to occur in studies with higher medians, and nonregulation in studies with a lower median.

How should nonregulation in people scoring high on the RS or DEBQ subscales be explained? A possible explanation for the observed nonregulation is the cognitive set of restrained subjects. It has been suggested (Polivy, 1976; Polivy \& Herman, 1985; Ruderman, 1985, 1986; Ruderman \& Wilson, 1979; Ruderman et al., 1985) that after disrupting dietary restraint by a preload, specific cognitive ideation occurs, a prototypical self-statement being, "I've blown it - I might as well continue to eat." However, contrary to this suggestion, it was observed that thinking aloud after a preload was thematically identical from restrained to unrestrained eaters. Retrospectively, too, preloaded restrained eaters did not recall more disinhibiting thoughts compared to nonpreloaded restrained eaters and preloaded as well as nonpreloaded unrestrained eaters (Jansen, Merckelbach, Oosterlaan, Tuiten, \& van den Hout, 1988). Nevertheless, analysis of reported thoughts of restrained vs. unrestrained eaters during ice cream intake revealed a difference in perceived controllability. Restrained eaters in both conditions, independent from a disinhibiting preload, reported significantly more often that they could not control themselves during ice cream tasting (Jansen et al., 1988).

This perceived lack of control during eating may link the literature on nonregulation/counterregulation to addiction model of restrained eating. Wardle (1987b) pointed out that loss of control over food intake, together with food craving and preoccupation with eating, parallels addictions. Support for the fruitfulness of the addiction analogy is given by data showing that restrained eaters, just like addicts, are likely to score high on sensationseeking measures and to habituate fast to neutral stimuli (Jansen, Klaver, Merckelbach, \& van den Hout, 1989). 
From the addiction analogy, it seems that, just like small doses of drugs increase craving in the addict, eating small amounts produces increased craving in restrained eaters. Craving for food may be experienced as lack of control over food intake and may result in nonregulation. Studies should be welcomed that evaluate the explanatory power of the addiction model when it comes to restrained eating in general and experimentally induced nonregulation in particular. 


\title{
DOES BINGEING RESTORE BULIMICS' ALLEGED 5-HT-DEFICIENCY?
}

\author{
A. JANSEY"', M. A. VAN DEN HOUT' and E. GRER ${ }^{3}$ \\ 'Deparment of Mental Health Science Experimental Psychopathology. Limburg Uniwersity, P.O. Box \\ 616. MD 6200 Madastricht and "Department of Cliniral Psychiatry/Experimental Psychopathology, \\ Limburg University, The Netherlands \\ (Recetwed 24 Febratar 1989)
}

\begin{abstract}
Suminary - The co-necturtence of bingeing and depressed mood in bulimics may be explained by one pal hogenie process: hyposerotonergic hunctioning. A retatively high carbohyt rate intake improves mood and watses 5 -WI level. Therefore, several athors sugested that the carbohydrate intake durng binges may be a form of selfmedication lo compensate for bulimics" alleged hyposerotonergic functioning. the reby improving mood. "This view, in which bingeing compersates for central $5-H$ tr deficiencies, assumes

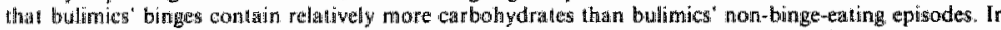
the present study $y_{n}$ bulimics' binge-erting and non-binge-eating episodes were compared as to macronutri ent and catwrie intake. However, no support was found for the hypothests that binge-eating enduances brain serotonimi
\end{abstract}

\section{INTRODUCTION}

Bulimia nervosa is characterized by rectrrent episodes of binge-eating and is often accompanied by a depressed mood (APA ${ }_{0}$ 1987). The co-occurrence of bingeing and depressed mood in bulimics may be explained by ome pathogenic process to which both the depressed mood and bingeing are functionally related. Carbohydrate intake and 5-HT (dys)functioning may be relevant here.

Schweiger, Laessle, Kittl, Dickhaut, Schweiger and Pirke (1986) showed experimentally that mood improves with increasing proportions of carbohydrate intake. The authors hypothesized that the mood changes induced by the intake of carbohydrates were mediated by central serotonergic functioning: eating episodes which are rich in carbohydrates and poor in protein will increase central 5-HT level, whereas eating episodes which are poor in carbohydrates and rich in protein will decrease the brain's serotonergic activity. Considering the relationship between depression and hyposerotonergic functioning (Rosenthal and Heffernan, 1986; van Praag. Lemus and Kahn, $1987 \mathrm{a}$, b), Schweiger et al. (1986) argued that the improved mood after having eaten relatively more carbohydrates, is mediated by a heightened central 5-HT level, while a worsened mood follows from eating eppisodes which are relatively poor in carbohydrates and thus a lowered central 5-HT level.

Considering the depressive mood and binges of bulimics on the one hand and the relationship between carbohydrate intake, 5-HT level and mood on the other hand, several authors (Kaye, Ebert, Swirtsnan and Weiss, 1984, 1985; Rosenthal and Heffernan, 1986; Goldbloom, 1987; Rock and Yager, 1987) suggested that the bingeing behavior and depressed mood of bulimics follow from hyposerotonergic functioning in the brain. "It is possible that bingeneating of carbohydrates is an attempt to enhance brain serotonin and, in this manner, serves as a form of self-medication" (Kaye er al., 1984, p. 1601). Thus, binges are supposed to be relatively rich in carbohydrates to compensate for hyposerotonergic functioning, thereby improving mood. Moreover, Rack and Yager (1987) claim that "The carbohydrate-low diet of the bulimic, except for spurts during binges, may impede normal brain serotonin metabolism. Reduced serotonin synthesis in the brain may result from the low calorie, low carbohydrate intake commonly found as the usual nonpurged diet of bulimic patients, and this pattern of modified neurotransmitter synthesis has been proposed and is being explored as a physiologic trigger of binge eating" (p. 269).

To whom all correspondence should be addressed. 
When it is claimed that carbohydrate intake during binges is an effective means to heighten the central 5-HT level, which is otherwise low, because bulimics' non-binge-eating is carbolydratepoor/protein-rich, the straightforward assumption is made that, compatatively, bulimics' binges contain significantly more carbohydrates than bulimics non-binge-eating episodes. Without this assumption, the theory that regards binge-eating as a mechanism activated to compensate central 5-HT deficiencies loses its power of explaining the (co-)oceurrence of bingeing and depressed mood in bulimics. Is it true that binges contain comparatively more carbohydrates than bulimics" non-binge-eating episodes? Indeed, it has been claimed by patients and therapists that bulimics predominantly binge on carbohydrate-rich foods (Beumont, Chambers, Rouse and Abraham, 1981 : Pope and Hudson, 1984; Johnson, Stuckey, Lewis and Schwarta, 1982; Goldbloom, 1987). However, these data are merely based on impressions of bulimics. Apart from the impression that binges are especially rich in carbohydrates, several studies also found relatively bigh fat and protein intake during binges (Mitchell, Pyle and Eckert, 1981; Abraham and Beumont, 1982; Kaye and Gwirtsman, 1985). Unfortunately only the macronutrient composition of binges was analyzed in these studies, and the macronutrient intake during non-binge-eating episodes was not. Becanse of this, it was neither proved nor negated that the carbohydrate intake during binges is relatively higher than that between binges, and consequently the effective enhancement of 5-HT by means of a binge, was neither established nor ruled out. The primary aim of the present study was to compare binge-eating with non-binge-eating episodes of bulimic patients as to macronutrient intake. On the basis of the arguments of Kaye et al. (1984) and Rock and Yager (1987) it was hypothesized that (1) patients" binges contain relatively more carbohydrates than their non-bingeeating episodes, and (2) non-binge-eating episodes of bulimic patients contain relatively less carbohydrates than the diet of unrestrained eating control $S$ s. Furthermore, (3) the authors wanted to test whether mood is positively correlated with the proportion of carbohydrates in a diet.

\section{METHOD}

\section{Subjects}

Eight female patients with bulimia nervosa, according to the criteria of DSM III-R (APA, 1987), participated in the study. For one patient the diagnosis anorexia nervosa was also made. At the time of the study, the patients were not receiving any treatment but were awaiting cognitive-behavior therapy at the Academic Anxiety Center of Maastricht.

The control group consisted of eight healthy, unrestrained eating female students and employees of Limburg University. They reported that they did not have any eating problems, which was confirmed by their low scores* on the Dutch Eating Behaviour Questionnaire (van Strien, Frijters, Bergers and Defares, 1986). S characteristics are shown in Table 1.

\section{Procedure and analysis}

Seven patients kept a food diary and a mood diary during 7 days and one patient kept her diary for 10 days. During these days, patients exactly monitored their eating and drinking behavior, time of intake, whether it was a binge or not, and whether they womited or used laxatives afterwards. Before going to sleep, $S$ s rated their global mood during the past day on a 0-100 ("extremely bad" to "extremely good") Visual Analogue Scale (VAS), Control $S$ s kept identical registrations during 4 days, while at least one of these days was a "free" day, on which they were not working or studying.

\footnotetext{
"Detailted data can be obtained from the first author.
}

Tabule 1. S thracteristics

\begin{tabular}{|c|c|c|c|c|c|}
\hline & \multicolumn{2}{|c|}{ Patients $(n=8)$} & \multicolumn{3}{|c|}{ Contra: $58(n=8)$} \\
\hline & $\mathrm{M}$ & $(\mathrm{SD})$ & $M$ & (SD) & 1 \\
\hline Age & 26.1 & $(50)$ & 22.5 & $(29)$ & Ns \\
\hline BMI* & 20.3 & $(3.1)$ & 19.3 & $(0.97)$ & $\mathrm{NS}$ \\
\hline
\end{tabular}

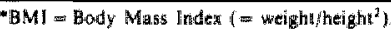


Binge-eating ensisodes were defined by the patients themselves, non-binge eating was defined by the authors as the total intake over one day, exclusive of binges. During the registration period 63 binges were recorded ower all 5 s $(M=7,9$ per patient, with a range from 3 to 15$)$. For each $S_{4}$ the mean macronutrient intake during binges, and the mean macronutrient intake during non-bingeing episodes were calculated, with the use of the computerized Becel Food Program (version NL 026) of the Unillever Research Laboratory. In addition to the proportional intake of carbohydrates, this program also yielded the amount of calories ingested and the proportional imtake of protein, fat and alcohol. $T$-tests were carried out for the food intake data. Because of the large number of 1 -tests the authors used a $1 \%$ rejection level.

In order to test whether the proportional intake of carbohydrates and mood ratings were related to each other, Pearson product-moment cortelations were calculated. The daily carbohydrate intake of patients exchuswe of vomiting periods, and the daily carbohydrate intake of control $S \mathrm{~s}$ were callculated. The daily percentage of carbohydrate intake was correlated with mood over this day for patients and control $S$ s separately.

\section{RESULTS}

The results for macronutrient intake are shown in Fig. 1.

\section{Carbahydrates}

Binges were expected to contain relatively more carbohydrates than non-binge-eating episodes. However, we did not find the slightest support for this hypothesis: the patients' carbohydrate intake during bingeing episodes was as high as their carbohydrate intake during non-binge-eating episodes $[r(14)=0.06$, NS]. Furthermore, no differences were found between relative carbohydrate intake of patients during non-binge-eating episodes and carbohydrate intake of control $S_{\mathrm{s}}[t(14)=1.22$, NS]. Neither did the proportional intake of carbohydrattes during binges differ from the control $S s$ carbohydrate intake $[t(14)=1.55, \mathrm{NS}]$.

Fal

No differences in lat intake were found between the groups. Binge-eating and non-binge-eating episodes of bulimics contained the same amount of fat $[t(14)=0.97$, NS]. The patients' intake of fat during non-binge-eating episodes did not differ from the fat intake of the control $S s$ $[x(14)=1.43, P=N S]$. Neither was any difference found between fat intake during binges and lat intake of the control $S \mathrm{~s}[t(14)=0.74, \mathrm{NS}]$.

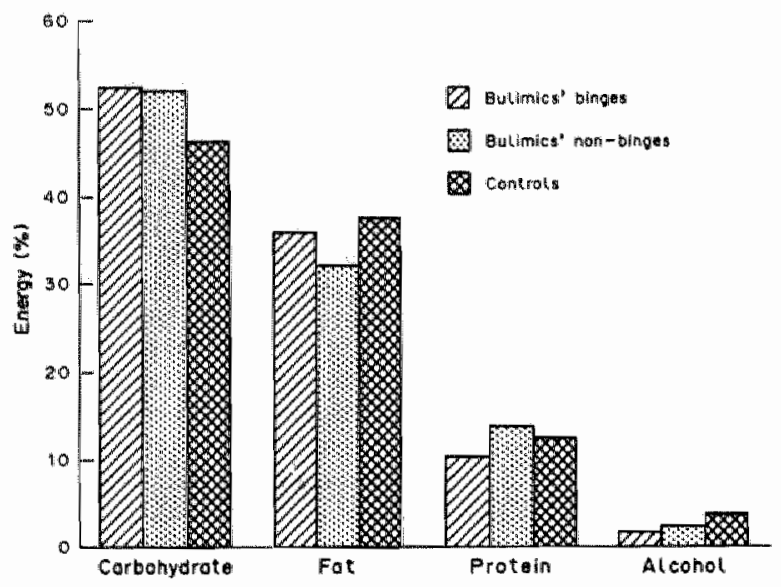

Fig. 1. Refative macrouttrient intake during bulimics. binge-eating and non-binge-eating episodes and during eating episodes of control $S \mathrm{~s}$. 


\section{Protein}

Patients ate the same amount of protein during binges as during non-binge-eating episodes $[1(14]=1.93, \mathrm{NS}]$. Nether was the protein intake during nom-binge-eating episodes different from the proten intake of the control $S \mathrm{~s}[t(14)=0.63 . \mathrm{NS}]$. Furthermore, no difference emerged betwen normals" protein intake and patients protein intake during binges $[r(14)=2.38$. NS].

\section{Alcohol}

Proportionally, there was no difference between the pattents" alcohol intake durng binge-eating episodes and non-binge-eating episodes $[(14)=0.35$, NS]. Neither did patients, during binge eating and non-binge-eating episodes differ from control $S$ s as to the intake of alcohol $[r(14)=0.56$, $\mathrm{NS}]$ and $[r(14)=0,77$. NS] respectiwely.

\section{Calories}

Data on calorie intake are depicted in Fig. 2. No difference was Cound in patients" calorie intake during binge-eating and non-binge-eating episodes $[t(1.4)=1.62$. NS $]$. The calorie intake during patients. binges was as high as that of control $S \mathrm{~s}$ over one day $[1(14)=0.56$, NS $]$. Durmg non-bingeing episodes, patients ate less than control $5 \mathrm{~s}$. This difference approached signiffcance $[1(14)=2.73, P=0.02]$

\section{Carbohydrate intake and mood}

A significant correlation was found between carbohydrate intake and mood of control $S$ s $[r=0.44, P=0.006]$. In contrast to this, no correlation was found between patients carbohydrate intake during non-vomiting episodes and mood $(r=0.06, \mathrm{NS})$.

\section{DISCUSSION}

The first hypothesis "stating that the food that is consumed during binge-eating episodes of bulimic patients contains a larger proportion of carbohydrates than that consumed during non-binge-eating episodes, was not supported. No differences were found in the carbohydrate intake between binge-eating and non-binge-eating episodes. Neither was the second hypothesis confirmed, that the carbohydrate intake in the usual diet of bulimic patients during non-bingeeating episodes is low. The bulimics' usual diet between binges contained the same proportion of

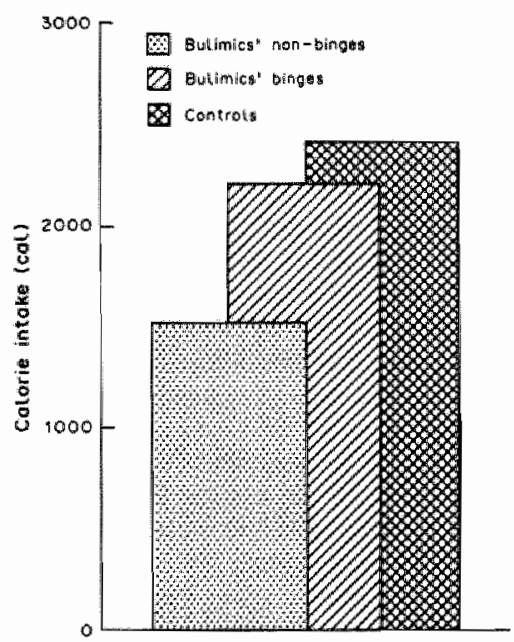

Fig. 2. Calorie intake during bulimics" binge-eating and non-binge-eating episodes, and during eating episodes of control $s s_{\text {. }}$ 
carbohydrates as the food intake of unrestrained eating control $S \mathrm{~s}$. Finally, the third hypothesis, stating that carbohydrate intake and mood are positively correlated, was confirmed for control $5 \mathrm{~s}$ oxly. For patients, no correlation between carbohydrate intake and mood was found.

From the absence of difference in carbohydrate intake during binge-eating and non-bingeeating-episodes, if may be inferred that binge-eating does not enhance brain serotonin and serve as a form of self-medication. Moreover, as the data on carbohydrate intake of controll $S$ s and on that of patients between binges show, Rock and Yagers" claim of a "carbohydrate-low diet of the bulimic, except for spurts during binges" was not supported: during non-binge-eating episodes, patients ate the same amount of carbohydrates as control $S \mathrm{~s}$ did.

The issue of the validity of the $S \mathrm{~s}^{2}$ diaries deserves some attention. Although "prospective self-monitoring provides accurate information on the frequency and extent of substance use" (Wilson, 1987, p. 341), self-monitoring is dikely to be reactive; it may affect the rate of binge-eating episodes (Wilson, 1987). However, although self-monitoring may influence the rare, and perhaps the exten of binge-eating, it seems highly unlikely that self-monitoring will change the macromutrient composition of binges.

On none of the macronutrients did the patients' intake during non-binge-eating episodes differ from the control $S \mathrm{~s}$ ' inake. If it is not the macronutrient composition of the diet of bulimics which triggers a binge, bow then, should we explain the occurrence of binges? Finding a marginally lower calorie intake of pateints during non-binge-eating episodes as compared with eating episodes of control $S$ s, supports the common notion that binges are related to dieting (Polivy and Herman, 1985). However, that dieting and bingeing are somehow related, still does not offer an explanation. A popular explanation of the urge to binge is given by the set point theory, which states that dieters are below their set point for body weight, and that this induces a biologically determined urge in them to binge, in order to restore their body weight to the set point level. However, the set point theory is rather difficult to test, and although there certainly is a correlation between dieting and bingeing (mosi bulimics diet, and many dieters binge-eat sometimes), the relationship between reduced calorie intake and binge-eating is certainly not a one-to-one relationship. Not all people who diet (e.g. anorexia nervosa restricters and suocessful restrained eaters) are plagued by binge-eating episodes. The precise mechanism which links dieting to binge-eating is still to be discovered.

Though it remains to be demonstrated directly that serotonergic pathways are involved, mood and carbohydrate intake are related to each other. For our control $S s$, the correlation between mood and carbohydrate intake was highly significant. Of special interest is, therefore, the lack of a positive correlation between carbohydrate intake (exclusive of vomiting episodes) and mood in bulimic patients. A commonsensical psychological explanation is that the patients" generally more depressed mood is primarily determined by their negative evaluation of binge-eating episodes; they are doing things they actually do not want to do and thus end up with a bad mood. The influence of carbohydrate intake on patients" mood may be subordinate.

All in all, these findings on macronutrient intake do not provide any support for the hypothesized function of a binge for heightening people's serotonergic level. Neither does this study support the notion that bulimics" non-binge-eating episodes decrease the central level of 5-HT, because they are relatively poor in carbohydrates. However, the authors are well aware that these data do not exclude the possibility of hyposerotonergic functioning in case of bulimia. Still, the fact that many psychopathologies seem to be accompanied by serotonergic dysregulation poses fundamental questions as to the explanatory power of this alleged 5-HT dysregulation in bulimia. Major depressive disorders, anxiety disorders, obsessive-compulsive disorders, chronic pain, suicide, aggression, and schizophrenia; they have all been associated with a lowered 5-HT turnover (wan Praag $1987 \mathrm{a}, \mathrm{b}$ ). And these disorders are not only characterized by 5-HT dysregulation; like bulimia nervosa, they all often go together with depression. Why then, do patients with these other psychiatric complaints, supposed hyposeroconergic brain functions and depression, not binge on carbohydrates in orcter to induce a better mood?

Finally, during the analysis of the food diaries "the authors were puzzled by an intriguing issue: what determines whether an eating episode is a binge or not? The patients themselves defined which eating episode was a binge and which one was not, but the authors were not able to detect any objective discriminating parameters between binge-eating and non-binge-eating 'meals'. 


\section{A. IAMSEN eI U}

Repeatedly, patients noted that an eating episode was a "bad" eating episode, but maintained it was not a binge. When patients were asked retrospectively why a certain eating episode was not a binge, whereas another episode was, they were often doubtful and unable to reply. This may suggest that bingeing is not an "all-or-nothing" phenomenon, as it is usually claimed to be. In contrast to the dichotomous view that eating episodes aither are or are not binges, eating episodes may be more or less binges. It might be a rewarding enterprise to explore this hypothesized continuity of bulimics" eating episodes as more or less binges: what is in binge?

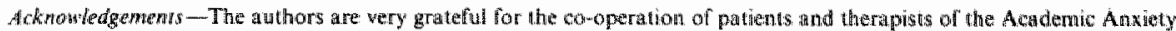
Center Matstrichi. Also, thanks are expressed to colleatgues of the Department of Human Biology for the use of their equipment to andyse the data. 


\title{
5.4 is counterregulation of dieters after forced consumption of a preload dependent on mood?
}

\author{
Anita Jansen ${ }^{1}$, Ilse Gubbens ${ }^{1}$, Sandra Gransier ${ }^{1}$, Peter de Jong ${ }^{1}$, \\ Jaap Oosterlaan ${ }^{1}$ \& Arnoud Arntz ${ }^{1}$.
}

Scandinavian Journal of Behaviour Therapy, in press.

\section{abstract}

In the present study, the question of whether the counterregulation of dieters after forced consumption of a preload is dependent on mood was examined in a 2 (dieter vs non-dieter) $\times 2$ (happy ws depressed) $\times 2$ (preload vs no-preload) factorial design. Subjects were 83: Dutch housewives (mean age 42 years) who were classified as dieter or non-dieter by the median split score on the Restraint Scale of the Dutch Eating Behaviour Questionnaire (DEBQ). A happy or a depressed mood was induced with the aid of music. Half of the subjects were forced to eat a preload. It was hypothesized that forced consumption of a preload will disinhibit the dieter when mood is depressed, but will elicit a normal regulatory reponse when the dieter is happy. It was found that happy dieters did indeed regulate their food consumption normally after a preload. However, depressed dieters also ate marginally less after a preload. Furthermore, the finding that non-dlleters never regulated their food intake. neither when happy, nor when depressed casts some doubts on the validity of the present findings. The curious results may be due to the relatively high age of the subject sample used. A replication study using a younger subject sample is desirable betore firm conclusions can be drawn as to the mood-dependence of counterregulation after a preload.

\section{introduction}

Dieters are chronically concerned with their weight and they constantly try to control, i.e. restrict, their calorie intake. In laboratory studies, it has repeatedly been shown that the eating behavior of dieters can be disin-

1 Dept. of Mentai Health Sciences / Experimental Psychopathology, Limburg University, P.O. Box 616, 6200 MD Maastricht, the Netherlands. 
hibited. The most typical finding is that after diet violation, e.g, forced consumption of a preload, dieters eat more than without one, whereas the food consumption of non-dieters is smaller after a preload than without one (Herman \& Mack, 1975; Hibscher \& Herman, 1977).

A rather intruiging question is why the dieter eats more after the diet has been broken by forced consumption of a preload. Eating a preload rich in calories would be a good motive for restricting further food intake. Eating even more after a forced preload is counterintuitive. Interestingly, experimentally induced emotional upheaval is also found to be a potent disinhibitor in dieters. Anxious non-dieters are found to eat less than nonanxious non-dieters whereas anxious dieters eat as much as non-anxious dieters (Herman \& Polivy, 1975). Dysphoric dieters eat significantly more than non-dysphoric dieters, and the intake of dysphoric non-dieters was marginally less than the intake of non-dysphoric non-dieters (Baucom \& Aiken, 1981; Frost, Goolkasian, Ely \& Blanchard, 1982; Ruderman, 1985). Although the exact process by which a negative affect disinhibits eating in dieters is still unknown (Ruderman, 1986), the experimental findings on counterregulation of dieters during emotional upheaval may help to elucidate counterregulation in dieters after forced consumption of a preload. After having been forced to eat a calorie-rich preload, the notion of having overeaten may elicit a dysphoric mood in dieters. It might be this dysphoric mood rather than being preloaded per se that exerts the disinhibiting effect. A straightforward implication of this assumption is that preloaded but non-dysphoric dieters will not counterregulate. Therefore, it is hypothesized that (1) forced consumption of a preload disinhibits eating in the dieter when he or she is in a depressed mood, while (2) forced consumption of a preload will elicit a normal regulatory response when the dieter is happy. Furthermore, it is hypothesized that (3) non-dieters will regulate their food intake after a preload independently of mood.

\section{method}

subjects

Subjects were 83 Dutch females, most of them housewives with a low level of education. Ss were recruited by means of a city newspaper advertisement, asking for fernales who were willing to participate in "a study on taste experiences". Mean age was 42.4 years $(S D=10.0$, range 20 to 61). Ss were classified as dieter or non-dieter by the median split score (3.1) of the present sample on the Restraint Scale of the DEBQ (van Strien, 1986).

Subject characteristics are given in Table 1. Dieters were significantly younger and their BMI was lower than corresponding values in the non-dieting group. 
table 1: subject characteristics.

\begin{tabular}{llll}
\hline & $\begin{array}{l}\text { non-dieters } \\
n=40\end{array}$ & $\begin{array}{l}\text { dieters } \\
n=43\end{array}$ & $t$ \\
\hline Age & $38.8(10.0)$ & $45.9(8.9)$ & $3.43^{* * *}$ \\
BMI* $^{*}$ & $23.1(4.1)$ & $25.0(3.1)$ & $2.45^{* *}$ \\
\hline
\end{tabular}

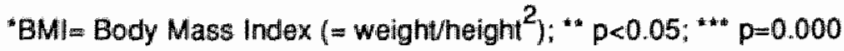

\section{assessment and materials}

The following instruments and materials were used:

A questionnaire on demographic varilables and way of life was composed by the authors. In this questionnaire the "Concern for Dietting" (CD) items of the Restraint Scale (RS; Polivy, Herman \& Warsh, 1978) were interspersed among fake items that asked about the way of life with regard to e.g. practice of sport, smoking and drinking habits and taste preferences. The $\mathrm{CD}$ items measure attitudes towards eating and frequency of dieting.

The Dutch Eating Behaviour Questionnaire (DEBQ; van Strien, 1986). The Restraint subscale reflects the degree to which a person eats less than he or she would actually like to eat. The Emotional and External subscales reflect the amount of overeating as a reaction to emotional arousal respectively external stimuli (Van Strien, 1986).

A tape with "happy" music was compiled by the authors. Among other things, the tape included fragments by Charlie Chaplin and Mozart (detailed information can be obtained from the first author). In a pilot study, the happy music proved to be effective in that it induced a happier mood.

A tape with "depressing" music. The music was 'Russia under the Moncholian yoke" by Prokofiev, played at half speed, as recommended by Clark (1988). In a pilot study, the depressing music proved to be effective in that it induced a more depressed mood.

A preload of $100 \mathrm{grams}$ of cookies, 1.e. $520 \mathrm{kcal}$.

The dependent variable was the number of grams of cookies consumed during the "taste test".

\section{procedure}

Subjects were sent a questionnaire with items asking about demographic variables and way of life, in which the "Concern for Dieting" items from the Restraint Scale (Polivy et al., 1978) were hidden. Thus, the RS/CD items would not appear salient and the subjects were kept in the dark about the purpose of the study. On the basis of their scores on the CD items of the $\mathrm{RS}$, Ss were provisionally classified as dieter or non-dieter, in order to 
enhance the probability of ending up with enough Ss in each condition. During the experiment subjects were randomly assigned to subgroups.

Subjects were asked to have breakfast, lunch, or dinner 1 to 3 hours before participating in the study in order to prevent experimental food intake from being influenced by pre-experimental deprivation. After entering the laboratory, subjects in the preload condition were given the preload and were instructed to eat it all. After tasting and rating the cookies, the subjects rated their mood on a 0 ("extremely sad") to 100 ("extremely happy") Visual Analogue Scale (VAS). Then they were left in isolation for 10 minutes listening to the tape with either the "happy" or "depressing" music. Subjects were encouraged to give in to the mood evoked by the music. In order to minimize demand characteristics, the hypothesized mood change was not explicitly mentioned, i.e. the subjects were not told whether they should become depressed or elated. Subjects in the no-preioad condition started listening to the music directly after they had rated their mood. After 10 minutes, the experimenter instructed the subject through the intercom to rate her mood again. Then the experimenter returned and the subject was offered three dishes, each containing 100 grams of cookies of different tastes. The cookies had been broken into small pieces to prevent the subject and the experimenter from seeing clearly how much had been eaten, later in the experiment. The subject had to taste each of the three sorts of cookies and was encouraged to eat as many cookies as she wanted and needed for making good taste ratings. She was left in isolation for ten minutes. During taste ratings, music was still played. After ten minutes, the cookies which were left were taken away and weighed again. Finally, the subject completed the DEBQ, the subject's height and weight were measured, and the subject was paid for participation. Subjects were asked if, and when, they had eaten before participation, and all subjects reported that they had complied with the instruction to eat between 1 and 3 hours before participation. To prevent subjects from talking about the experiment with other participants, debriefing took place after all subjects had participated in the experiment.

\section{results}

manipulation check

Mood induction was found to be successful. Before mood induction, subjects did not differ in mood level. After the mood induction, subjects in the depressive condition showed significantly lower mood scores than subjects in the happy condition $[t(79)=4.38, p=<0.000]$. This effect was mainly due to a significant lowering of mood in the depressive condition $[t(40)=4.9, p=<0.000]$. The mood scores in the happy condition did not change significantly $[t(39)=0.76, N S]$. 


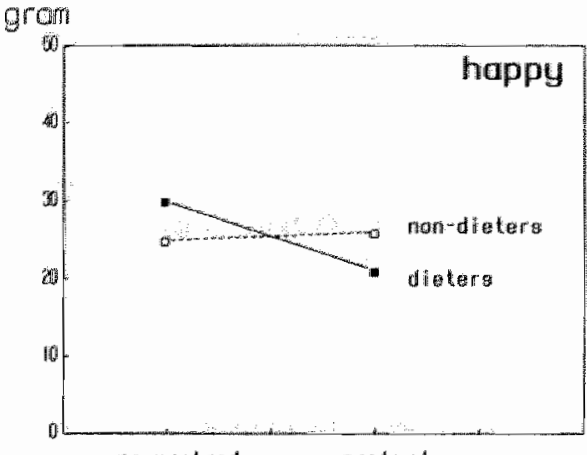

maporadod

prol oand

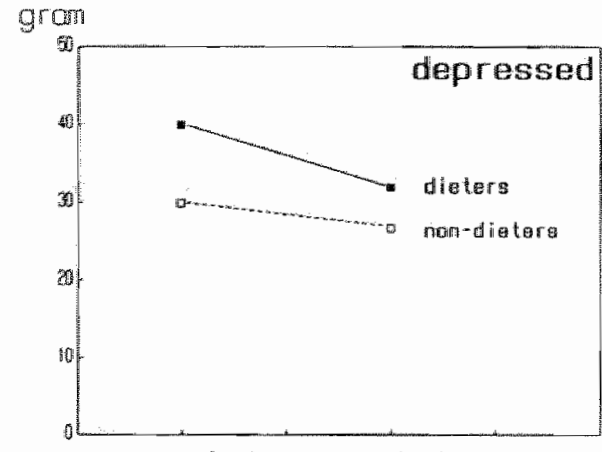

no prologd

preload

figure 1: food intake of dieters and non-dieters after a preload or no preload and in a depressed or happy mood.

lable 2: mean number of grams (sd) eaten in the different groups.

\begin{tabular}{lllll}
\hline & $\begin{array}{l}\text { depressed } \\
\text { preload }\end{array}$ & no-preload & $\begin{array}{l}\text { happy } \\
\text { preload }\end{array}$ & no-preload \\
\hline dieters & 31.5 & 39.9 & 21.0 & 29.7 \\
& $(19.6)$ & $(16.2)$ & $(9.9)$ & $(14.1)$ \\
& $n=10$ & $n=9$ & $n=11$ & $n=13$ \\
non-dieters & 27.0 & 30.3 & 25.5 & 24.9 \\
& $(18.5)$ & $(20.7)$ & $(10.0)$ & $(11.7)$ \\
& $n=12$ & $n=11$ & $n=8$ & $n=9$ \\
\hline
\end{tabular}

food intake

Results are given in Figure 1 and Table 2.

The hypotheses were tested in two ways. First, t-tests were carried out. As can be seen from Fig. 1, the first hypothesis, that dieters counterregulate when they are in a depressed mood, was not confirmed. Depressed dieters ate marginally less after a preload than without one [t(17)=1.0, NS]. Evidence was found in support of the second hypothesis "stating that forced consumption of a preload will lead to normal regulation when the dieter is happy. Dieters in the happy mood condition ate significantly less after a preload than without one $[t(22)=1.72, p=0.05]$. Hypothesis 3 states that non-dieters will regulate their food intake after a preload, independently of mood. It was found, however, that non-dieters did not regulate their food intake after a preload, neither when depressed $[t(21)=0.41, N S]$, nor when happy $[t(15)=0.1, N S)$.

Second, an analysis of covariance (ANCOVA) was carried out in order to make a closer examination of the interaction between dietary status, 
preload, and mood. Main factors were Group (Dieters vs Non-dieters), Condition 1 (Preload vs No-preload), and Condition 2 (Depressed vs Happy Mood), with BMl and Age as covariates. A marginally significant main effect was found for mood $[F(1,73)=3.6, p=0.06]$, which indicated that individuals in a depressed mood ate more than happy subjects. No further main effects were found, and neither the 2-way, nor the 3-way interactions were significant.

\section{discussion}

The present study investigated whether disinhibition of eating in dieters after a preload is mediated by a lowered mood. The hypothesis that the dieters" food intake after a preload is dependent on mood was supported: t-tests showed that dieters failed to regulate their food intake after a preload when their mood was depressed, but they did regulate their intake normally when they were happy. However, the absence of normal regulatory behavior in our non-dieting subjects, and the absence of a significant interaction effect between preload, mood, and dietary status seriously calls the validity of this finding into question. At least, the hypothesis that the non-regulation of dieters is dependent on mood was not unequivocally supported.

In addition, and most importantly, the present study does not provide any support for some typical and well-documented findings. First, by the marginally significant interaction effect between mood and dietary status we could not convincingly confirm the finding that dieters eat more when depressed and non-dieters eat the same or less (Baucom \& Aiken, 1981; Frost et al., 1982; Ruderman, 1985). In the present study, dieters as well as non-dieters ate slightly more when depressed. Second, the absence of a significant interaction effect between preload and dietary status is in direct conflict with the typical finding that dieters eat more after a preload and non-dieters eat less (Herman \& Mack, 1975; Hibscher \& Herman, 1977). In the present study, both dieters and non-dieters ate the same amount with or without a preload. Although non-regulation in dieters has been documented earlier (Ruderman \& Christensen, 1983; Jansen, Oosterlaan, Merckelbach \& van den Hout, 1988), the finding of non-regullation in non-dieters is a curious one. Non-regulation in non-dieters has only been documented once (Wardle \& Beales, 1987). How can this curious behavior of non-dieters be explained? Some possibilities are discussed below.

First, the present study shows some weaknesses. Ruderman \& Willson (1979) showed that obese and non-obese subjects react different to the consumption of a preload. Although the subjects in the present study were not extremely obese, dieters had a significantly higher BMI than non-dieters. The authors tried to minimize the effect of this difference by using BMI as covariate in the ANOVA. However, with that, the influence 
of weight cannot totally be ruled out. In the same way, age differences may have influenced the data.

Furthermore, the authors did not gather more detailed information on the actual deprivation time of subjects. Subjects all agreed with the instruction to eat between 1 and 3 hours before participating in the experiment. It should be noted, however, that the inter-individual variation between 1 and 3 hours may be large.

Second, Wardle and Beales (1987) argued that the non-regulation of non-dieters in their study could be due to a "floor effect", i.e. all subjects ate the minimum necessary. Indeed, the amounts eaten in their study were fairly small, and so are the amounts eaten in the present study. However, the cookies were rated as palatable and the mean intake of 29 grams shows that the non-dieters were not eating the absolute minimum, i.e. about 10 grams. They clearly ate more cookies than necessary for completing the taste ratings.

Third, in the present study, dietary status was assessed with the DEBQ (van Strien, 1986). In earlier studies on counterregulation, dietary status was assessed by means of the Restraint Scale (RS; Polivy et al ${ }_{\text {.1 }} 1978$ ). Remarkably, Wardle and Beales (1987) also classified their subjects as dieter or non-dieter on the basis of the median split on the DEBQ-restraint scale and they also found non-regulation of food intake in non-dieters. Earlier, Wardle (1987) reported that the restraint scale of the DEBQ measures successful dieting irrespective of tendencies towards disinhibition, whereas the RS in fact measures unsuccessful dieting, or proneness to disinhibited eating. It sounds plausible that the overeating of high scorers on the RS is due to their proneness to disinhibition and that the subjects scoring low regulate their food intake because they do not show these disinhibited tendencies.

Classifying subjects according to dietary status by means of the DEBQ may be independent of a tendency to disinhibition. Non-dieters may then, despite their low dietary status, still be prone to "overeating" in the absence of dieting. To test this, we post hoc re-classified our subjects as highly or little emotional and external eaters by means of their scores on the disinhibited "emotional" and "external" scales of the DEBQ. High scores on these scales reflect proneness to disinhibited overeating as a reaction to emotional or external stimuli. However, the post hoc classifications did not reveal any differences in outcome. Low scorers on "disinhibited" scales did not regulate their food intake in the present study.

Fourth, a median restraint score of 3.1 on the DEBQ is above average according to the norm scores (see van Strien, Frijters, van Staveren, defares \& Deurenberg, 1986). It may therefore be questioned whether our non-dieters were really unrestrained. Therefore, we compared the food intake of the lowest scorers on the DEBQ-restraint scale with the food intake of the highest scorers. Again no differences emerged.

Fifth, the calorie content of the preload was high, i.e. 500 kcal. Milk shake preloads usually vary from $250 \mathrm{kcal}$ to $440 \mathrm{kcal}$ (Wardle and Beales, 
1987). The higher the calorie content of the preload, the larger the differences are expected between the preloaded and nonpreloaded nondieters. Then, of course, preloaded non-dieters would be expected to eat significantly less than non-preloaded ones, which was not the case.

Finally, the subject sample that participated in the present study is quite different from subject samples usually participating in laboratory experiments on food intake. Usually, students 20 to 30 years old and with a high level of education are the subjects of the examination. In contrast to this, the participants in the present study were significantly older and most of them had a low level of education. A commonsensical explanation for the present findings may be that older women often report an intention to lose some weight, but they are actually only making a marginal effort to reach it. For younger people, weight and appearance may in fact be more important, which will result in more extreme and rigid dieting actually put into practice.

All in all, the present study did not provide convincing support for the notion that the disinhibiting effect of the forced consumption of a preload is dependent on mood. With respect to the influence of age, it should be noted that eating disorders such as anorexia nervosa and bulimia nervosa are more prevalent in puberty and young adulthood than later in life (APA, 1987). Therefore, the present data should be interpreted cautiously. A replication study using a younger subject sample is desirable before firm conclusions can be drawn as to the mood-dependence of counterregulation after a preload. 


\title{
COGNITIONS AND SELF-TALK DURING FOOD INTAKE OF RESTRAINED AND UNRESTRAINED EATERS
}

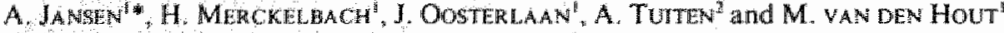 \\ Theparmen of Medical Psychology/Expermental Psychopathotogy. Limburg Universiny. PO Dox 616. \\ 6200 MD Malastrichi and "Department of Theoretical Psychology and Pswchontomics, Utrech Uniwersity. \\ The Netherlands
}

(Rectiond March 1988)

\begin{abstract}
Summary In the present study, restraned subjects failed to regulate their ice-cream intake after a preload

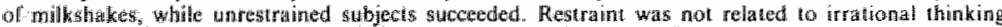
patterns, as reflected by scores on the Rational Behavior Inventory (RBI) and the Irrational Beflief Test (IBT). During the disinhibitive challenge, the self-talk of the subjects was recorded on tape. Restraned subjects in a disinhibition challenge, i.e. prelotal condition, were expected to report significantly more disinhibitive thoughts tham restrained subjects in a no-preload condjion. Unrestrained sulbeetis were

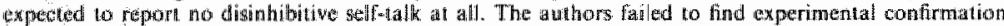
for the widely held wew that dichot wnous thoughts such as "I"ve blown ny dien, I maght as well continue

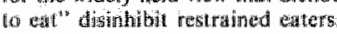

\section{INTRODUCTION}

It has repeatedly been reported that milkshake preloads disinhibit the dietary constraint of restrained eaters. High scorers on the Restraint Scale [RS] (Herman et al., 1978) eat more ice-cream after a preload of milkshakes than they do without one (Herman and Mack, 1975; Hibscher and Herman, 1977; Herman and Polivy, 1980). By manipulating subjects" beliefs concerning the caloric content of the preload, Polivy (1976) and Spencer and Fremouw (1979) demonstrated that this so-called "counterregulation" of restrained eaters also accurs when they only think they have overeaten. Therefore, these authors conclude that counterregulation of restrained eaters is cognitive in nature. The maladaptive eating behavior is supposed to follow from an irrational thinking style and dichotomous, all-or-nothing reasoning. Dietary disinhibitors, such as milkshake preloads, should induce such thoughts as "The day is wasted", "My diet is ruined for the next two days. I may as well give up now," and "I've blow my diet; I might as well continue to eat", thereby" leading restrained eaters to overeat (Polivy, 1976; Polivy and Herman, 1985; Ruderman 1985, 1986; Ruderman and Wilson, 1979; Ruderman, Belzer and Halperin, 1985).

However, self-talk during overeating has, mewer been investigated experintentally (Wardle, 1987). Although Ruderman (1985) demonstrated that irrational beliefs, as measured by the Rational Behavior Inventory [RBI] (Shorkey and Whiteman, 1977), are more prevalent among restrained than unrestrained eaters, Sanderman al. (1987) reasoned that self-statements in certain situations may not be reflected in RBI-scores.

Considering both the absence of direct evidence showing that disinhibitive self-talk is responsible for counterregulation and the imperfect association between irrational thinking and types of self-talk, the aim of the present study was 2.fold. First, the authors wanted to replicate Ruderman's findings that there is a close relationship between restraint and irrational thinking as measured by the RBI. Second, we wanted to examine self-talk of subjects during a disinhibitive challenge. It was hypothesized that (1) restrained eaters score significantly higher on measurements of irrationality than unrestrained eaters and that (2) restrained eaters in a disinhibition challenge, i.e. preload condition, report significantly more disinhibitive thoughts than restrained subjects in a no-preload condition. Unrestrained subjects were expected to report no disinhibitiwe thoughts at all.

Requests for teprints. 


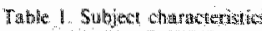

\begin{tabular}{|c|c|c|c|c|c|}
\hline & \multicolumn{2}{|c|}{ 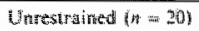 } & \multicolumn{2}{|c|}{ pestrathed $(a=20)$} & \multirow[b]{2}{*}{1} \\
\hline & 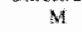 & $(\mathrm{SD})$ & in & $\mathrm{BDH}$ & \\
\hline Age & 346 & $(6)$ & 26.3 & $(9.2)$ & Ms \\
\hline BMIII & 21.5 & $(1.9)$ & 24.2 & 263 & $3 \pi y^{2}$ \\
\hline
\end{tabular}

\section{METHOD}

\section{Subjects}

Forty female students and employees of Limburg University volunteered to participate in what they believed to be a study on "the influence of thoughts on taste-testing'. Their mean age was $25.5 \mathrm{yr}(\mathrm{SD}=8.1)$ and their mean body mass index $\left(\mathrm{BMI}=\right.$ weight $/$ height $\left.{ }^{2}\right)$ was $22.8(\mathrm{SD}=2.7)$. Participants were classified as restrained or unrestrained on the basis of the median split score on the RS. Subject characteristics are shown in Table 1.

\section{Assessment}

The following instruments were used:

1. The Restraint Scale (RS) (Herman et al, 1978), measuring attitudes toward eating, frequency of dieting, and weight fluctuations.

2. The Rational Behawior Inventory (RBI) (Shorkey and Whiteman, 1977), measuring irrational thinking patterns. The total score can be broken down into 11 factors, each of which measures, a different dimension of rationality: (1) catasirophizing, (2) guill, (3) perfectionism, (4) need for approval, (5) caring and helping, (6) blame and punishment, (7) inertia and avoidance, (8) independence, (9) self-degradation, (10) projected misfortune and (11) control of emotions.

3. The Irrational Belief Test (IBT) (Jones, 1968), also measuring irrational thinking patterns. The total score can be broken down into 10 factors, each of which, again, measures a different dimension of rationality: (1) demand for approval, (2) high self-expectations, (3) blame, (4) frustration, (5) emotional irresponsibility. (6) anxious overconcern, (7) problem avoidance, (8) dependency, (9) helplessness with regard to change and (10) perfectionism.

4. The Think Alowd on Tape (TAP). Subjects were asked to provide continuous verbal expression of their thoughts during the 10 -min taste-lesting period. The reported thoughts were registered on tape.

5. The Self-Talk Questionnaire (STQ), a list of disinhibitive self-statements composed by the authors (see Table 2). 4 of the 25 statements were taken from the literature; 21 were based on an $n=1$ pilot study and intuitively chosen. For each self-statement, the frequency of howing had this thought during ice-cream tasting was rated between 0-100 ""never" to "very, very often") on a visual analogue scale (VAS).

6. The amount of ice-cream consumed was registered.

\section{Procedure}

Subjects were asked to have breakfast, lunch, or dinner I-3 h before perticipating in the study. Taste-testing thus served as a caloric overload and was not influenced by deprivation. After entering the laboratory, subjects were asked to complete a questionnaire in which items of the RS were hidden. Subjects 1-20 were randomly assigned to the preload or no-preload condition; subjects $21-40$ were assigned to one of these conditions on the basis of their RS scores in relation to the median split score of the subsample of subjects already tested. Each of the four cells (restrained/unrestrained $\times$ with/without preload) included 1.0 subjects.

All subjects completed the RBI. Then, subjects in the preload condition were asked to drink two milkshakes-one vanilla and one chocolate-each containing 150 calories. During the 10 -min interval between drinking the milkshakes and tasting the ice-cream, subjects completed the $\| \mathrm{B} T$. Participants in the no-preload condition completed the IBT directly after the RBI. All subjects were then presented with three dishes of ice-cream-one chocolate, one vanilla, and one strawberry-... 


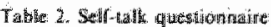

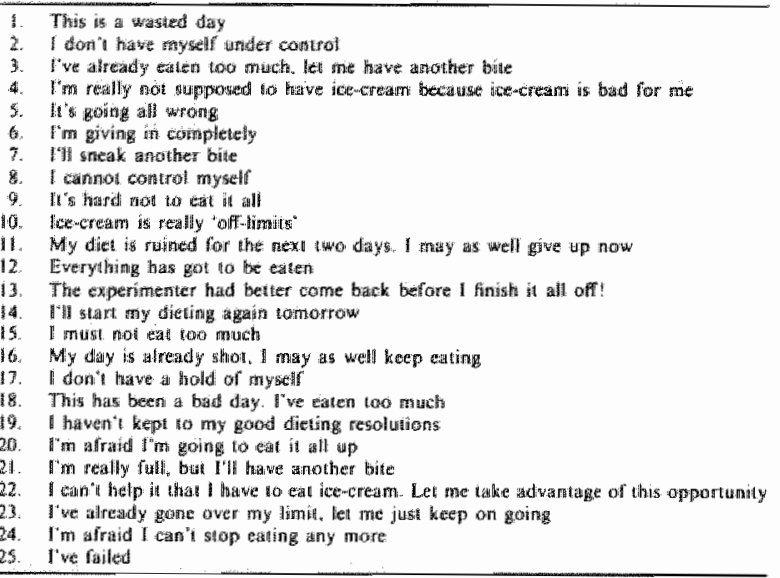

weighing $600 \mathrm{~g}$. The subjects were instructed to taste and rate the different flawors. At the same time, they were asked to express all of their thoughts aloud into the microphone of the audiotape. Subjects were encouraged to eat as much ice-cream as they wanted and needed in order to make good taste testings.

After starting the audiotape, the experimenter left the laboratory for $10 \mathrm{~min}$. When the experimenter came back, the ice-cream that remained was reweighed and the subjects completed the STQ. Then, each subject's weight and height were measured. Finally, the subjects were debriefed and paid for their participation.

\section{RESULTS}

\section{RS}

The median split score on the RS was 12. Subjects scoring |2 or more were classified as restrained exters. Scorers below 12 were classified as unrestrained eaters.

\section{Noteream intake}

Because restrained and unrestrained subjects differed significantly in BMJ (see Table 1), a $2 \times 2$ analysis of covariance was carried out on ice-cream data. Main factors were Group (restrained vs unrestrained) and Condition (preload ws no-preload), with BMT as covariate. The ANCOVA showed no main effects. The interaction Group $\times$ Condition was significant $[F(1,39)=4.97$, $P=0.03$ ] (see Fig. 1). 1 -Tests showed that unrestrained subjects regulated for a preload. In contrast. restrained subjects did not eat significantly more or less after a preload than after no preload (see Table 3).

\section{IBT and $R B I$}

No significant differences in irrationality were found between restrained and unrestrained subjects (see Table 4). Pearson P-M correlations between the RS, IBT, and RBI (total and factor scores) were calculated. Neither the RS-IBT and RS-RBI total scores (see Table 5) not the RS-IBT and RS-RBI factor scores revealed significant correlations.

\section{4. $S T Q$}

On each of the 25 STQ self-statements, a $2 \times 2$ ANCOVA (Group $\times$ Condition with BMI as covariate) was carried out. A main effect for Group was found for the statement "I cannot control myself" $[F(1,39)=4.97, P \leq 0.05]$. Thus, restrained subjects, in both conditions reported significantly more frequently than unrestrained subjects that they could not control themselves 


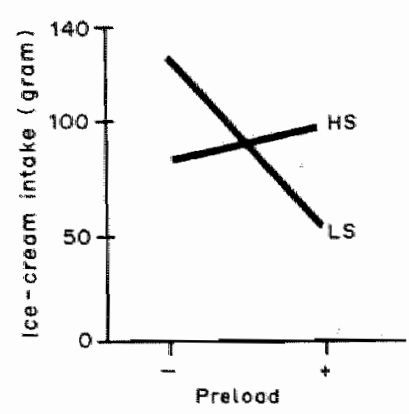

Fig. 1. Mear ice cream constumplion of high (HS) and low (LS) scorers on the Restranin scale.

\begin{tabular}{|c|c|c|c|c|}
\hline & \multicolumn{4}{|c|}{ Phelond } \\
\hline & & $-\infty$ & + & $t$ \\
\hline \multirow[t]{3}{*}{ Unerst rained } & M & 130.1 & 502 & $326 *$ \\
\hline & $\mathrm{sD}$ & 5 & 58 & \\
\hline & $\mathbf{N}$ & 1. & 10 & \\
\hline \multirow[t]{3}{*}{ Restrained } & $\mathrm{M}$ & 83.3 & 935 & $\mathrm{Ns}^{n}$ \\
\hline & $\mathrm{SD}$ & $\$ 3$ & 20 & \\
\hline & $N$ & 10 & le & \\
\hline
\end{tabular}

during ice-cream testing. Main effects for Condition were found for the following statements: "I"t start my dieting again tomorrow" (1) $[F(1,39)=4.94, P \leq 0,05]$ : "I must not eat too much" $[F(1,39)=5.11, P \leq 0.05]$; "This has been a bad day. I've eaten too much" $[F(1,39)=3.94$, $P=0.055]$; "I am really full, but I'll have another bite" $[F(1,39)=5.69, P \leq 0.05]$. These thoughis were significantly more often reported in the preload condition, independent from the restraint of subjects. No significant Group $\times$ Condition interaction effects were found.

\section{TAP}

The total number of reported thoughts was divided into 5 exhanstive and mutually exclusive categories:

(a) Non-food statements (e.g. "I really need to trim my finger nails"),

(b) Statements literally read from the taste-testing list (e.g. "Flavor one is really quite sweet"),

(c) Task-relevant statements concerning taste (e.g. "delicious") or test behavior (e.g. "I"ll have another bite"),

(d) Statements concerning associative past or future food situations (e.g. "Ice-crean makes me think of going on vacation, of silting at a cafe in the sun"), and

(e) Statements concerning food or eating behavior which were not relevani to the experimental task of tasting (e.g. "I have to force myself not to finish the strawberry ice-cream").

Statements from categories $a, b, c$, and $d$ were either a result of the experimental task or concerned past or future events. They were considered not to contain disinhibitive thoughts. We did, however, expect to find disinhibitive thoughts in category ' $\mathrm{e}$ " statements. Concerning the proportion of food items that were classified as ' $\mathrm{e}$ " statements, no difference emerged between restrained and unrestrained subjects; in the restrained group, $9.2 \%$ of the 1379 statements was

\begin{tabular}{|c|c|c|c|c|}
\hline & & Jitu nest ratined & Restraistud & $y$ \\
\hline \multirow[t]{3}{*}{$\mathrm{KBI}$} & $M$ & 28.2 & 28.5 & $\mathrm{MS}$ \\
\hline & $\mathrm{SP}$ & 49 & 54 & \\
\hline & $N$ & eq & 30 & \\
\hline \multirow[t]{3}{*}{$19 \mathrm{~T}$} & $M$ & 275.6 & $2 \geqslant 1$ & $N S$ \\
\hline & $S D$ & 26.7 & 30.7 & \\
\hline & $\mathrm{N}$ & 20 & 20 & \\
\hline
\end{tabular}

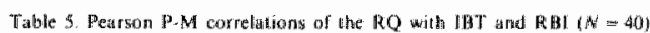

\begin{tabular}{|c|c|c|c|c|c|c|c|c|c|c|c|c|}
\hline & \multirow{2}{*}{$\begin{array}{l}\text { R日1 } \\
\text { Tolial }\end{array}$} & \multicolumn{11}{|c|}{ Pactor } \\
\hline & & $t$ & II & III & IV & $V$ & VI & $\mathrm{VH}$ & VIl:11 & $I x$ & $x$ & $\mathrm{x}$ \\
\hline RQ & -0.07 & 0.01 & -0.04 & -0.08 & -0.11 & -0.11 & -0.00 & $-0.1 \mathrm{H}$ & 0.14 & $\ldots-0.21$ & -0.04 & 0.26 \\
\hline RQ & 0.06 & 0,0003 & 0.1 & 0.24 & 0.004 & 90.06 & 0.21 & 0.07 & -61.15 & 0.1 & -0.15 & \\
\hline
\end{tabular}


classiffed ass " $e$ "; in the unrestrained group the figures were $8.9 \%$ from 1339 staternents. The binomial distribution indicates that this difference is not significant. Though the idea that category ' $\mathrm{e}$ ' statements should contain all disinhibitive thoughts seems plausible, the absence of a difference between restrained and unrestrained eaters led to an examination of the content of the category "es statements in both groups. As a first step in this content analysis two psychologists were asked to rate the statements on dichotomy. Interrater rellability between the two psychologists was low (Cohen"s Kappa $=0.41$ ). Then, 5 psychologists with experience in cognitive therapy were asked, after short training, to rate the statements independently from one another In the meantime, in order to detect whether or not the dichotomous thoughts were actually disinhibitive, and could be expected to lead to counterregulation, two bulimia nervosa patients were asked if they had ever had comparable thoughts during a binge. If they had, this was considered an indication of disinhibitiveness. However, interrater reliability among the 5 cognitive psychologists was low (Cohen's Kappa $=0.31$ ), as was the interrater reliability between the bulimia nerwosa patients (Cohen"s $K a p p a=0.42$ ). To examine whether it was al all possible to distinguish restrained from unrestrained self-talk, a behavior therapist who works with anorexia and bulimia nerwosa patients and a psychology student who was well acquainted with the concept of restraint, were asked to identify the thoughts as coming from a restrained or from an unrestrained eater. Again, interrater reliability was very low (Cohen"s Kappa $=0.19$ ).

\section{DISCUSSION}

As expectedi, unrestrained subjects regulated for a prelload; they ate significantly more ice-cream in a nopreload condition than in a preload condition. However, ice- cream intake in restrained subjects without a preload did not differ from intake of those with a preload. Therefore, it was concluded that in restrained eaters, non-regulation rather than counterregulation took place. This finding is a fairly exact replication of the data obtained by Ruderman and Christensen (1983).

On the other hand, contrary to Ruderman's findings (1985), we did not find any relationship between restraint and irrationality. Restrained subjects scored just as high as unrestrained subjects. Moreover, we found no significant correlations between restraint and factor scores on the RBI and IBT. Therefore, we conclude that irrational thinking, as measured by the RBI and IBT, is not a necessary prerequisite for the occurrence of non-regulation.

Restrained eaters are supposed to think in a dichotomous way, and dichotomous thinking is bellieved to promote disinhibitive eating behavior. That is, overeating is thought to occur because restrained eaters think that they hawe already broken their diets.

The autliors first examined whether the supposedly disinhibitive thoughts were more prevalent in restrained preloaded subjects than in subjects in the other conditions. We did, indeed, find differences in the frequency of disinhibitive thoughts between experimental groups, but indepen. dently from the restraint of subjects. With one exception. ("I cannot controll myself"), the occurrence of disinhibitive thoughts was reported as often by preloaded, unrestraned subjects as by prelouded, restrained ones. Although all preloaded subjects reported having had these thoughts more often than subjects without a preload, unrestrained subjects regulated for their preload while resurained eaters did not. Clearly, 'disinhibitive' thoughts, as reflected in self-talk are not responsible for the occurrence of non-regulation.

In the present study, it was by no means possible to differentiate restrained from unrestrained selfatalk. On dimensions of dichotomy, self-talk of restrained subjects could not reliably be differentiated from that of unrestrained subjects, not even by trained psychologists with experience in cognitive therapy. Nor did bulimic patients agree about having comparable thoughts during binges.

Before jumping to conclusions, we must say that we are aware of the methodological problems concerning the measurement of cognitions. It is questionable whether people actually do verbalize all of the things they are thinking to themselves (e.g. Nisbett and Wilson, 1977); even when asked to do so. However if they do not report these thoughts during eating, how can we be sure that these are, in fact, the thoughts that disinhibit restrained eaters? It is interesting that, even retrospectively, restrained subjects did not report thaving had these thoughts. 


\section{A. IANSEN of of}

Reirospectively, restrained subjects reported more often than unrestritined subjects that they could not control themselves during ice-cream tasting. This perceived uncontrollability was not dependent upon being preloaded or not. Clearly, this perceiwed uncontrollability is a better predictor for the occurrence of non-regulation in experimental situations like these than the supposedly 'disinhibitive' thoughts. This is also clearly in line with the finding of Ruderman et al. (1985), which suggested that "disinhibition is not an all-or-non phenomenon and that some degree of loss of control typifies restrained eaters in many situations involving lood" (p. 555 ).

All in all, the present data prowide robust confirmation of non-regulation in restrained eaters vis-á-vis unrestrained eaters. However, no differences were observed on questiontahire scores believed to reflect 'irrational' belief's or thinking. The widely held and popular view that dichotomous thinking is responsible for non-regulation could not be corroborated. It is acknowledged that the interrater agreement on classifying self-statements as disinhibitive was fairly low. Still, the fact that hypothetical, disinhibitive cognitions are apparently not freely accessible to subjects poses fundamental methodological problems for a cognitive explanation of experimental disinhibitive eating. Of course, better instruments may eventually show different data. "The fact that restrained eaters reported significantly more often not being able to control themselves was not dependent upon ha ving had a 'disinhibitor', but was a more general characteristic of our restrained eaters. Exploration of this perceived uncontrollability in non-regulation might prove most rewarding. 


\section{6 no evidence that dieters counterregulate outside the laboratory}

Anita Jansen ${ }^{1}$, Henriëtte Swijgman ${ }^{2}$ \& Marcel van den Hout ${ }^{1}$.

\section{abstract}

In the present study, it was investigated whether dieters who counterregulate in the laboratory also overeat outside the lab. Pre- and post-experimental food intake of 27 dieters and 22 non-dieters who participated in a typical laboratory experiment on counterregulation were examined. It became clear that experimentally disinhibited dieters did nol counterregulate outside the lab; neither in the short term (I.e. within 4 hours after the experiment), nor in the long term (i.e. within 24 hours after the experiment) and nor during the rest of the day. Neither did any shifts in macronutrient intake take place atter the experiment.

\section{introduction}

In the laboratory, dieters do not regulate their food intake as non-dieters do. After a preload of e.g. milk shakes, non-dieters typically eat less than without such a preload: non-dieters regulate their food intake. Dieters, however, eat the same amount of tood or even more atter the consumption of a preload than without one: dieters do not regulate or they even counterregulate (Herman \& Mack, 1975; Hibscher \& Herman, 1977; Ruderman \& Christensen, 1983; Jansen et al., 1988). Dieters' laboratory behavior has generally been considered as an appropriate model of bulimics' bingeing behavior (Polivy \& Herman, 1985).

Several theories have been proposed to account for this counterintuitive and apparently illogical behavior in bingers/dieters. A rather popular theory states that, after dieters have started to eat, they are unable to stop eating because of a dominating biological urge. According to this theory,

1 Dept. of Mental Heatth Sciences / Experimental Psychopathology, Limburg University, P.O. Box 616,6200 MD Maastricht, the Netherlands

2 Institute for Drugs, Safety and Behavior, Limburg University, the Netherlands 
extreme dieters are characterized by a lowered serotonin $(5-\mathrm{HT})$ level which can temporarily be restored by a binge. The ingestion of a relatively large amount of carbohydrates and little protein during a binge should heighten dieters' lowered serotonin level (Rosenthal \& Heffernan, 1986; Kaye et al., 1984; Goldbloom, 1987).

Others, however, state that overeating after a preload can best be explained in cognitive terms (Tomarken \& Kirschenbaum, 1984; Polivy \& Herman, 1985; Spencer \& Fremouw, 1979; Woody et al., 1981; Ruderman, Belzer \& Halperin, 1985). In the laboratory it was found that the actual consumption of a high-calorie preload is not the only food stimulus which disinhibits dieters: the mere belief that a high-calorie preload has been eaten (Spencer \& Fremouw, 1979; Woody et al., 1981), or even the anticipation of eating a high-calorie preload (Ruderman, Belzer \& Halperin, 1985) also makes dieters overeat whereas this does not make non-dieters overeat. These findings led some authors to conclude that it is just the idea of a broken diet that led to non-c.q. counterregulation in non-dieters. After dieters consider their diet broken, they supposedly think "l've ruined my diet for today, I might as well continue to eat" (Tomarken \& Kirschenbaum, 1984). Thus the idea of a lost day is supposed to lead dieters to overeat for the rest of the day.

If this is true, it follows that, after breaking their diet in a typical preload laboratory experiment, dieters will continue to overeat outside the laboratory as well. Two studies reported on this issue. Wardle \& Beales (1987) studied whether experimentally preloaded dieters counterregulated outside the laboratory. They compared the pre-experimental calorie intake of dieters and non-dieters with the calorie intake on the day of the experiment. Outside the laboratory, both dieters and non-dieters neither counterregulated nor compensated for their food intake during the experiment. This finding seems to contradict the notion that disinhibited dieters overeat in the long term. It should, however, be noted that Wardle \& Beales' subjects did not even counterregulate in the lab, so that overeating outside the building would have been miraculous in this sample. Recently, Weber, Klesges \& Klesges (1988) also studied whether dieters who overate in the lab continued to overeat outside the lab. The authors found that experimentally disinhibited dieters overate outside the lab in the short term, that is, within $\mathbf{4}$ hours after participation in a laboratory experiment. They failed to find any effect in the long term: within 8 hours after the experiment all differences had disappeared.

From these studies it therefore appears that disinhibited dieters continue to overeat outside the lab, but only in the short term and not during the rest of the day. The absence of counterregulation during the rest of the day draws attention to possible biological mechanisms. 5-HT theory predicts that dieters will overeat in the short term, that is, until their 5-HT level is heightened again. 5-HT theory also predicts a shift in macronutrient intake: during counterregulation relatively large amounts of carbohydrates and little protein will be ingested. It is possible that dieters' 
short-term overeating had the function of increasing their 5-HT level by the ingestion of relatively excessive amounts of carbohydrates. However, Weber et al. (1988) did not provide any data on macronutrient intake, and therefore we cannot be sure.

In the present study it was examined whether dieters whose diet is broken in the laboratory will overeat later on. It was hypothesized, according to cognitive notions, that experimentally disinhibited dieters will overeat in the long term (for the rest of the day or even longer). Dieters who do not break their diet and non-dieters are not expected to overeat outside the lab. In order to demonstrate a possible biological function of counterregulation, macronutrient intake in the short and in the long term was analyzed.

\section{method}

subjects

Forty-nine female students of health sciences at Limburg University participated in the present study. Mean age was 22 years $(S D=4.6)$, mean BMI (Body Mass Index = weight/height ${ }^{2}$ ) was 22.5 ( $S D=3.3$ ). Subjects were classified as dieter or non-dieter on the basis of the median split score on the Restraint Scale (Polivy et al., 1978). Dieters ( $n=27)$ scored 17.4 points on the RS, whereas non-dieters' $(n=22)$ mean score was 8 . According to the hypothesis, not all dieters counterregulate outside the laboratory; only those who overeat in the lab. Therefore, subjects were classified as either disinhibited or non-disinhibited according to the median split score of the experimental calorie intake. Mean food intake of disinhibited subjects $(n=24)$ in the lab was 367.4 calories, whereas nondisinhibited subjects $(n=25)$ ingested 56.6 calories.

\section{procedure}

Subjects participated voluntarily in a study on 'food preferences': they intensively smelled a food 'preload' and their food intake was measured afterwards (data will be published elsewhere). Subjects were seen individually between $9.00 \mathrm{a} . \mathrm{m}$. and $5.00 \mathrm{p} . \mathrm{m}$. and the number of subjects in each condition was balanced at various times of the day. After the subject had participated in the laboratory experiment, she was subjected to an inquiry into her food intake by a trained interviewer. During the dietary interview, detailed information was obtained about the kind and the quantity of the subject's food intake from the day before up to the start of the laboratory experiment. After finishing the dietary recall, the subject was asked to monitor her food intake for the rest of that day and the next day. The eating diary was given a number and the subject was assured that the eating diary would remain anonymous. Moreover, she was given a reply-paid envelope for returning the diary by post, in the hope that these actions would heighten the reliability of the diaries. 
analysis

Originally, 5 subjects participated in the laboratory experiment. All subjects except one returned the eating diary. One subject's diary could not be used because she had fallen ill. Thus, 49 subjects remained for the present data analysis. The food diaries were analyzed for calorie content and macronutrient composition with the use of the computerized Becel Food Program (NL 026) from the Dutch Unilever Research Laboratory. To this end, computer codes were assigned to the circa 3000 food items by two independent raters. The raters were blind to both the subject's dieting status and her food intake during the experiment. The interrater reliability was high (Cohen's Kappa $=0.85$ ).

Macronutrient intake is presented in energy percentages while calorie intake is given in absolute amounts. Long-term food intake was defined as all intake of food and drink within 24 hours before and after the experiment. Food intake during the rest of the day was defined as all intake of food and drink after the experiment until the subject went to sleep. Short-term food intake was defined as all intake of food and drink within four hours after the end of the experiment. Difference scores between calorie/macronutrient intake on the (post-)experimental day vs calorie/macronutrient intake on the pre-experimental day over the same period were calculated. On the difference scores in callorie, carbohydrate, protein, and fat intake ANOVAs were carried out. Malin factors were Group (Dieters vs Non-dieters) and Condition (Disinhibited vs Non-disinhibited). For analyzing simple effects, calorie and macronutrient intake on the (post-)experimental day were compared with calorie and macronutrient intake on the pre-experimental day over the same period by $\mathrm{t}$-Tests for paired observations. Because of the large number of tests, a $1 \%$ rejection level was used.

\section{results}

long-term calorie intake

Calorie intake in the 24 hours before participation in the study was compared with calorie intake in the 24 hours after participation. The ANOVA revealed neither significant Main effects (Group: $[F(1,48)=0.27$, NS], Condition: $[F(1,48)=0.2, N S]$ ) nor a significant Interaction effect $[F(1,48)=0.76$, NS]. $t$-Tests did not show any effects either: in all condiltions calorie intake in the 24 hours before participation in the study was equal to calorie intake in the 24 hours after participation.

calorie intake during the rest of the day

Calorie intake in the hours after participation in the study until the subject went to bed was compared with calorie intake in comparable hours on the previous day. Again the ANOVA did not reveal any significant Main effects (Group: $[F(1,48)=0.66, N S]$, Condition: $[F(1,48)=0.39, N S]$ ) and no 


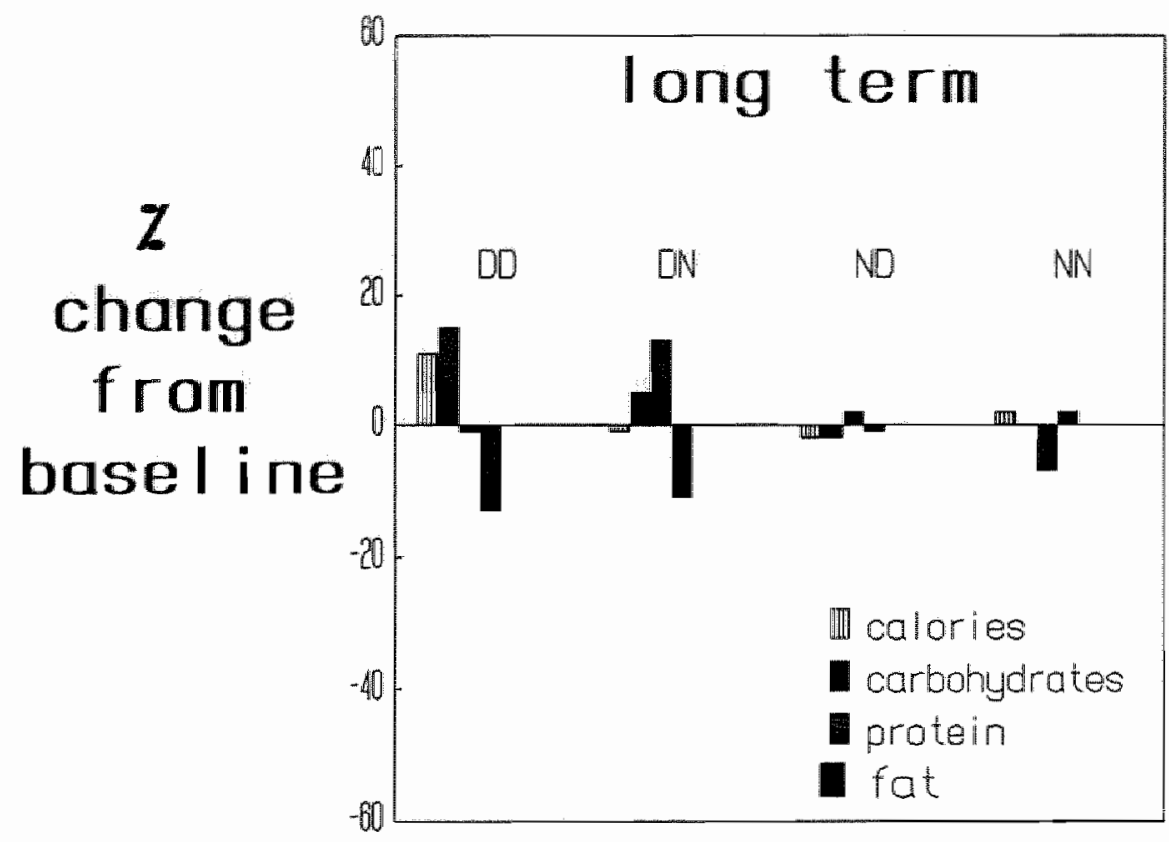

figure 1: dieters" and non-dieters' post-experimental food intake in the long term, expressed in percentage change from their pre-experimental intake.

significant Interaction effect $[F(1,48)=0.18, N S]$ emerged. Neither did $t$-Tests show any effects: in all conditions calorie intake during the rest of the day after participation in the study was equal to calorie intake on comparable times the day before.

short-term calorie intake

Calorie intake in the 4 hours after participation in the study was compared with calorie intake in comparable hours on the previous day. Again no significant Group $[F(1,48)=1.0, N S]$ and Condition $[F(1,48)=0.32$, NS] effects emerged. The Interaction effect was not significant either $[F(1,48)=0.8, N S]$. $t$-Tests showed a trend for disinhibited dieters to eat less calories in the four hours after participation in the study than in comparable times on the previous day $[t(9)=2.35, p<0.05]$. No further effects were found: in the remaining three conditions, calorie intake in the 4 hours after participation in the study was equal to calorie intake on comparable times the day before.

is there a shift in macronutrient intake?

ANOVAs as well as t-Tests did not reveal any shifts in macronutrient intake after participation in the experiment; neither during the rest of the day, nor in the short and in the long term. 


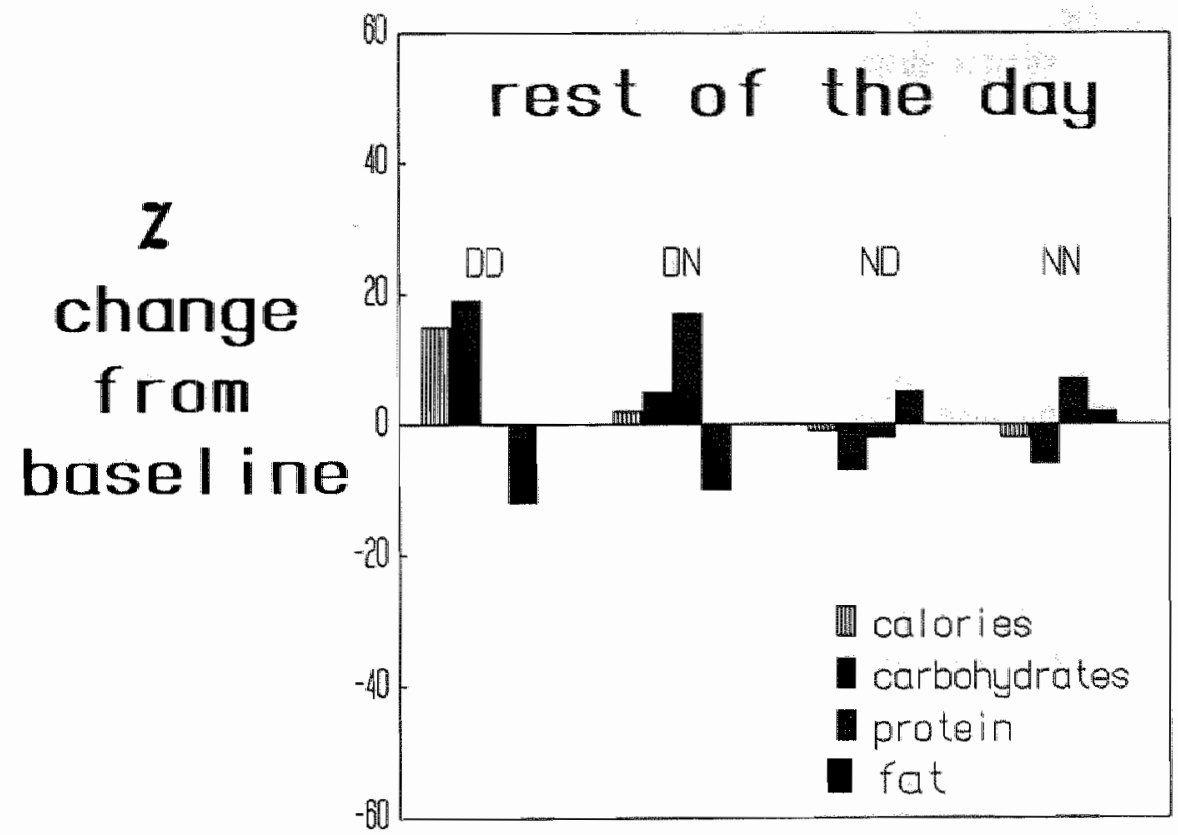

figure 2: dieters' and non-dieters' post-experimental food intake during the rest of the day, expressed in percentage change from their pre-experimental intake.

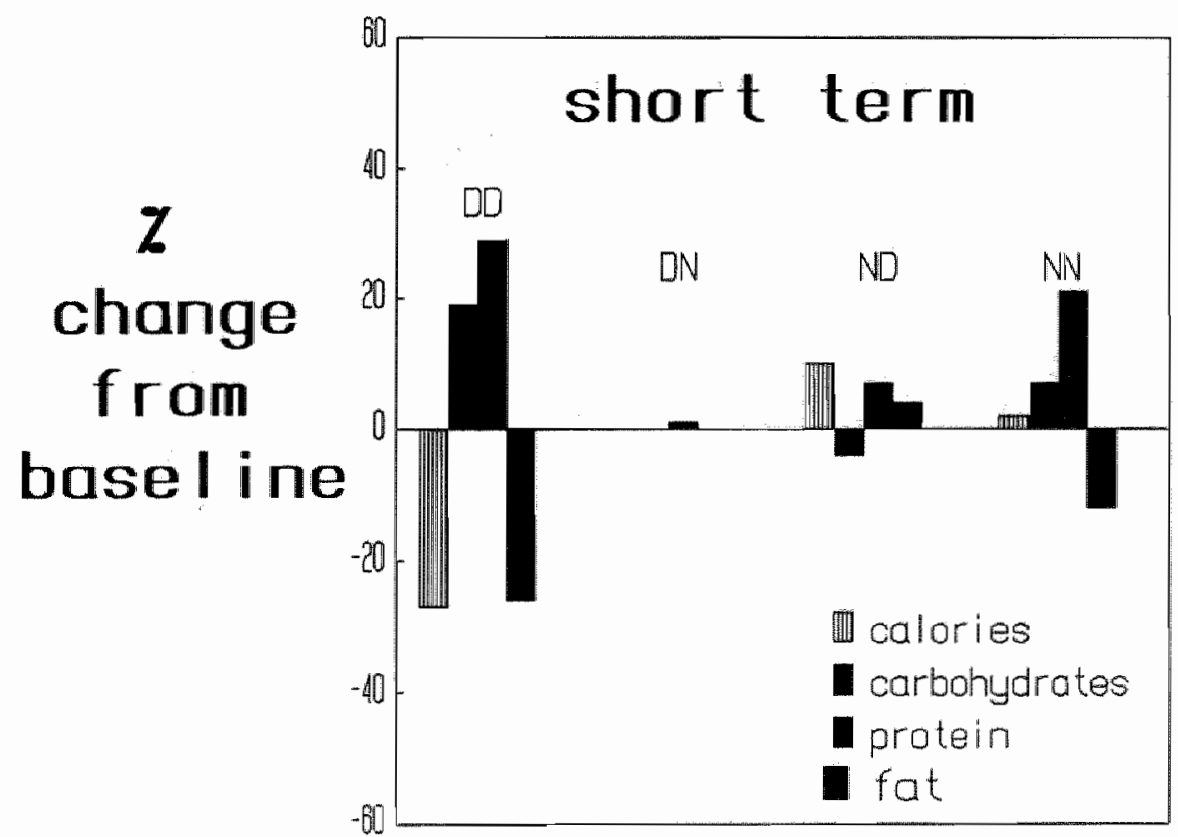

figure 3: dieters' and non-dieters" post-experimental food intake in the short term, expressed in percentage change from their pre-experimental intake. 


\section{discussion}

In the present study, dieters who overate in the laboratory did not counterregulate outside the laboratory. They did not do so in the short term, i.e. within 4 hours after participation in the experiment, during the rest of the day and not in the long term either, i.e. within 24 hours after the experiment. The data do not support the notion that dieters overeat during the rest of the day ance they consider their diet broken. 5-HT theory could not be confirmed either: no shift in macronutrient intake took place after the experiment.

Why do dieters not counterregulate outside the laboratory? It might be speculated that dieters stopped overeating after they left the laboratory because their hunger has been satisfied in the laboratory. If dieters" experimental overeating is considered as a consequence of a biologicall need (i.e. hunger), laboratory overeating should be sufficient to satisfy the biological need. But the idea of a biological need which has to be satisfied raises the question why non-disinhibited dieters do not overeat inside the laboratory. Non-disinhibited dieters were also confronted with food and were given the opportunity to eat but they could resist the alleged urge to eat.

Attention should be paid to the method of data gathering. Subjects were asked to recall their pre-experimental food intake, whereas they monitored their post-experimental intake. The post-experimental monitoring practices might have prevented dieters from overeating. The authors tried to restrict the monitoring-effect by assuring the subjects of optimal anonimity, but we cannot be sure that there was no intake reducing effect.

Neverthelless, the present study does not provide support for either the idea of (sustained) cognitive disinhibition or for the notion of a (transient) biological hunger which has to be checked. It might be hypothesized that dieters' overeating is stimulus specific. The presence of certain stimuli, such as a preload of ice cream or, as was the case in the present study, the intense smelling of food, might elicit craving in the dieter. As a result, the dieter will only overeat in the presence of certain stimuli, some of which were saliently present in the lab. After the dieter has left the lab, the stimulus is also left behind and craving will diminish. Because of this, overeating will also fail to occur. Testing this alternative and post-hoc explanation of stimulus-specific counterregulation might be fruitful.

acknowledgement

The help of Erik Schouten is gratefully acknowledged. 


\title{
RESTRAINED EATERS ARE RAPIDLY HABITUATING SENSATION SEEKERS
}

\author{
Antta Jansen*, Jacqueline Klaver, Harald Merckelibach and \\ MARCEL VAN DEN HOUT \\ Department of Mental Health Sciences, Limburg University, P.O. Hox 616 , \\ $6200 \mathrm{MD}$ Maastricht, The Netherlands
}

(Received 25 Jull: 1988)

\begin{abstract}
Summary--Several authors have pointed to similarities between enting disorders and addictive behavions. In earitier studies, addicts were found to score high on the Sensation Seeking Scale (\$SS) and to habituate rapidly to neutral stimuli, In this study, we found experimental support for an addiction modiel of eating disorders: restrained eaters also scored significantly higher on the Sensation Seeking Scale and also habituated significantly quicker to a teries of neural stimali than unrestrained eaters. No clewir evidence was Found for the hypothesis that restrained caters scofe lower on measurements of thxicty it is hypothesized that rapid habituation promotes sensation seeking, which ratay be manifested in excessive consumption of either drugs or food. Resirain may be at strategy to prevent negative consequenoss of sensation seeking and excessive consumption. The model is related to earkier experimental fondings.
\end{abstract}

\section{INTRODUCTION}

Several authors have pointed to similarities between eating disorders and addictive behaviors (Scott, 1983; Sinnet, Judd and Olsen, 1983; Dumont and Vamos, 1983; Brisman and Siegel, 1984; Lacey and Evans, 1986; Lacey and Moureli, 1986; Wardlle, 1987; Filstead, Parela and Ebbit, 1988). Both eating disorders and addictions are characterized by craving, preoccupation, and a loss of control over intake. Yet, so far the analogy between eating disorders and addictions is just a theoretical one, which has not been put to direct experimental tests.

Zuckerman (1979) found that individuals who are likely to develop habits of substance abuse are high sensation seekers, where sensation seeking is defined as "a need for varied, novel, and complex sensations and experiences, and the willingness to take physical and social risks for the sake of such experience" (Zuckerman, 1979, p.10). High sensation seekers seek stimulation and stimulation change (Gale and Edwards, 1986). Addicts were found to score higher on the Sensation Seeking Scale (SSS; Zuckerman, 1979) and they also habituated more rapidly to neutral stimuli than normal controls (Zuckerman, 1979). Considering the analogy between addictions and restrained eating (Wardle, 1987) it may be hypothesized that restrained eaters (1) score higher on the SSS, and (2) habituate faster to neutral stimuli than unrestrained eaters.

Indirect support for this hypothesis comes from a study of Calloway, Fonagy and Wakeling (1983). These authors found faster habituation rates of skin conductance responses (SCRs) in bullimic $S_{\mathrm{s}}$ than in normal controls and restricting anorexia nervosa (AN) patients. However, the results of this study should be interpreted cautiously; faster habituation rates in patients with bulimia may be induced by a disturbed skin conductance, as a consequence of the electrolyte imbalance resulting from purging activities. Calloway et ai. (1983) also found less spontaneous fluctuations in skin conductance of bulimics compared to AN-restricters and normal controls. Their finding of less spontaneous fluctuations and faster habituation rates in bullimics, and the fact that anxiety states are often associated with more spontaneous fluctuations (Orr and Pittman, 1987) and slower habituation rates (Lader, 1980; Lelliott, Noshirvani, Markis, Monteiro, Basoglu and Cohen, 1987) provided a third hypothesis: (3) restrained eaters score lower on anxiety measures than unrestrained eaters.

To sum up, the primary aim of this study was to investigate the tenability of the addiction model to restrained eating: do restrained eaters score higher on the sensation seeking scale and do they

\footnotetext{
"To whom all correspondence should be addiressed.
} 
habituate guicker to neutral stimuli than unrestrained eaters? Furthernore, we wanted to elaborate the Callowaly study by finding out if their data can be reproduced in a sub-clinical sample, and if indeed restrained eating is inversely related to measures of anxiety.

\section{METHOD}

\section{Subjects}

296 Female students of the Limburg University were invited to complete the Restraint Scale (Herman. Polivy, Pliner and Threlkeld, 1978). From the 73 students who completed the questionmaire, If high restrained and $1 /$ low restrained scorers were asked to participate in the experiment. 5 characteristics are shown in Table 1.

\section{Materials, assessment and measurement}

The psychological measurements consisted of Dutch translations of:

(1) the Restraint Scale (RS) (Herman et al., 1978), consisting of 10 items measuring attitudes toward eating, frequency of dieting, and weight fluctuations;

(2) the short Sensation-Seeking Scale (SSS) (Madsen, Das, Bogen and Grosman, 1987). This scale consists of 10 items and has proven to be a reliable and valid measure of sensation seeking. Scores on the short SSS correlate strongly $(r=0.78)$ with those on the total SSS;

(3) the Fear Questionnaire (FQ) (Marks and Mathews, 1979); a 15-item self-rating scale which has proven to give reliable and valid indications of avoidance of certain situations;

(4) the Spielberger State-Trait Anxiety Inventory (Van der Ploeg, Defares and Spielberger, 1980), a 40-item inventory measuring self-reported state anxiety and trait anxiety. State anxiety measures. momentary anxiety: a transitory emotional condition which varies in intensity and fluctuates in time as a reaction on a certain situation. Trait anxiety refers to a stable and enduring individual difference in anxiety proneness.

The physiological measurement consisted of skin conductance responses (SCRs) to a series of auditory stimuli. Skin conductance level (SCL) and SCRs were picked up from Beckman $\mathrm{Ag}-\mathrm{AgCl}$ electrodes (diameter $8 \mathrm{~mm}$ ), attached to the medial phalanges of the second and third finger of $S \mathrm{~s}^{\text {" }}$ right hand. Electrodes were connected to a Beckman Skin Conductance Coupler (Type 9844), using the method of constant voltage $(0.5 \mathrm{~V})$. Respiration rate was recorded with a Bieckman Respiration Belt, connected to a Beckman Pressure/Pulse/Voltage Coupler (Type 9884), SCR and respiration were monitored on a Beckman R711 polygraph.

The auditory stimuli were $14 \times 1000 \mathrm{~Hz}_{3} 85 \mathrm{~dB}$ tones binaurally presented through Beyer dynamic earphones (type DT 109) connected to a Sony cassette recorder (TCK 88). Signals were held on the exact dB level by a Dual Signal Gate (Symetrics, type SG 200). The tones were presented at random intervals. Intertrial intervals varied between 15 and $30 \mathrm{~s}$, with an average of $20 \mathrm{~s}$. Duration of the tone was $6 \mathrm{~s}$. A prefabricated tape was ased to generate the tones.

\section{Response definition and analysis}

SCLs were measured during the pre-experimental baseline period. SCRs were defined as the maximal deflections occurring between 1 and $5 \mathrm{~s}$ after stimulus onset. SCLs and SCRs were measured in micrombo and square-root transformed.

Two indices of habituation of the SCRs were used. Response decline over trials were analyzed by subjecting the SCRs magnitudes for each trial to a 2 (Group: Restrained vs Unrestrained) $\times 14$

Tuble 1. S characteristicis

\begin{tabular}{|c|c|c|c|c|}
\hline & $\begin{array}{c}\text { Restrained } 5 s \\
M(S D)\end{array}$ & $\begin{array}{c}\text { Unrestrained } S \text { s } \\
M(S D)\end{array}$ & 1 & $F^{*}$ \\
\hline $\begin{array}{l}\text { Age } \\
\text { BM! } \\
\text { RSS }\end{array}$ & $\begin{array}{l}22.4(3.4) \\
23.2(2.3) \\
14.5(3.5)\end{array}$ & $\begin{array}{r}20.5(2.6) \\
20.4(1.7) \\
4.5(1.4)\end{array}$ & $\begin{array}{l}1.48 \\
3.29 \\
8.83\end{array}$ & $\begin{array}{l}\text { MS } \\
0.002 \\
0.001\end{array}$ \\
\hline
\end{tabular}


(Trials) Anallysis of Variance (ANOVA), with the last factor being a repeated measure. Furthermore, a trials-to-criterion measure of habituation was used: habituation was said to have occurred when $S$ s falled to respond (SCRs smaller than 0.05 micromho) on two sucossive trials. Group differences in mean-irials-toncriterion were evaluated with a futest.

Additionally, spontaneous fuctuations (SFs) were counted. SFs were defined as SCRs which exceeded 0.05 micromho, occurring before stimulus onset or th least $5 \mathrm{~s}$ after stimulus offset:

Respiration was used as a control variable: trials with respiratory irregularities were excluded from the data analysis. SCR values for these trials were estimated on the basis of the mean SCRs on adjacent trials.

\section{Procedure}

After entering the laboratory the $S$ was asked to complete the short SSS and FQ. The $S$ sat in a comfortable chair which was placed in a dimly lit, sound-attenuated chamber. The tape recorder and recording apparatus were in an adjacent room. After cleaning $S^{*}$ s fingers with distilled water, electrodes were attached. Before baseline measurement started, the $S$ was told that during the experiment she would hear something through the earphones. Baseline measurement started and $\mathrm{SCL}$ was registrated. After a 4 min period of baseline measurement the series of tones was presented. Next, the $S$ completed the State-Trait Anxiety lnventory. Then her weight and height were measured, and finally, she was debriefed and paid for participation.

\section{RESULTS}

The results are shown in Table 2.

Tiable 2. Test scores and skin conductance mensures for 11 restrained and 11 waresirained eaters

\begin{tabular}{|c|c|c|c|c|c|c|}
\hline & \multicolumn{2}{|c|}{ Retrained $s$} & \multicolumn{2}{|c|}{ Untestrained 5 s } & 1 & $P *$ \\
\hline Sensattory Seking & 7.09 & $(1,45)$ & 5.55 & $(1.9$ & 2.45 & 0.01 \\
\hline Fear Quesilionnutive & 250 & $(6.39)$ & 31.6 & $(11,9)$ & 1.63 & 0.06 \\
\hline State Arusiety & 33.18 & $(9.2)$ & 34.55 & $(877)$ & 0.30 & NS \\
\hline Trait Aruxiety & 41.27 & $(13, n)$ & 37.82 & $(6.9)$ & 0.77 & NS \\
\hline Mern Ttials io Criterion: & 91.09 & $0.95)$ & $\$ 1.55$ & $(2.98)$ & 1.94 & 0.03 \\
\hline Spontaneous Fluctuations & 7.9 & $(6.5)$ & 10.6 & $(6,98)$ & 0.95 & $\mathrm{NS}$ \\
\hline
\end{tabular}

- Dre-tailed.

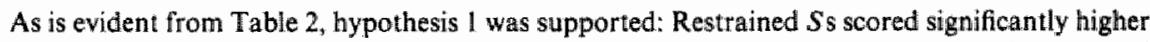
on the short SSS than Unrestrained $S$ s. The picture was less clear as the hypothesils of Restrained $S$ s being unanxious was concerned: Restrained and Unrestrained $S s$ did not differ in State and Trait Anxiety. On the Fear Questionnaire Restrained $S$ s tended to score lower; this difference was marginally significant. Closer inspectation of the data revealed no differences between Restrained and Unrestrained $S$ s on the three subscales (agoraphobia, social anxiety, and blood-injury) of the FQ.

Restrained and unrestrained $S$ s did not differ in mean $S C L$ at the start of the experiment, the means (micromho) being $7.4(\mathrm{SD}=3.4)$ and $7.0(\mathrm{SD}=2.9)$ respectively $[t(20)=0.23, \mathrm{NS}]$. Also, there was no difference in Orientation Response, defined as the $\$$ CR to the first stimulus, between Restrained and Unrestrained $S \mathrm{~s}$ : means were $2.2(\mathrm{SD}=1.2)$ and $1.8(\mathrm{SD}=1.7)$ respectively $[t(20)=0.63, \mathrm{NS}]$.

In line with the hypothesis, Restrained $S$ s habituated significantly faster to the series of tones than unrestrained $S$ s. The group differences in habituation were evident in both indices of habituation rate, (a) restrained $S \mathrm{~s}$ reached the criterion of non-responding much earlier than unrestrained $S \$$ (see Table 2), and (b) SCRs of restrained $S s$ declined more rapidly over trials than did SCRs of unrestrained $S$ s [Group $\times$ Trial interaction: $F(1,20)=2.1, P=0.01]$. To contral for BMI differences, the ANOVA was repeated with BMI as covariate. The ANCOVA showed significant main effects for Trials. $[F(1,20)=28.56, P=0.00]$ and for Groups $[F(1,20)=5.38$, $P=0.032]$, and again a significant Group $\times$ Trials interaction $[F(1,20)=2.1, P=0.01]$ emerged.

However, contrary to what was predicted, we observed no between group differences in the number of Spontaneous Fluctuations (see Table 2). 


\section{DISCUSSION}

The first and second hypothesis, stating that restrained eaters score higher on the short SSS and habituate quicker to a series of neutral stimuli than unrestrained eaters, were confirmed. The third hypothesis, of restrained eaters scoring low on measurements of anxiety, was partly supported: restrained eaters tended to score lower on the $\mathbb{F Q}$ than unrestrained eaters, but no difference emerged between both groups in State and Trait Anxiety. Also, the number of Spontaneous Fluctuations, the frequency of which was found to be higher in anxiety states (Lader, 1980; Orr and Pitman, 1987), did not differ between restrained and unrestrained eaters.

The finding of our study fit with the addiction model of restrained eating. Zuckerman (1979) showed that addicts are rapidly habituating sensation seekers, and in line with this we showed that restrained eaters are rapidly thabituating sensation seekers. Since especially high scorers on the "disinhibition". subscale of the total SSS showed fast habituation of the SCR (see Gale and Edwards, 1986) while this "disinhibition" subscale measures the hedonistic pursuit of pleasure through extrawerted activities such as social drinking, sex and parties-it may be of interest to test whether restrained eaters are particularly high "disinhibition" scorers.

The fact that we could reproduce Calloway"s findings in a subclinical sample of restrained eaters strongly supports that Callowayss findings did not result from purging activities of their bulimics, but that they are associated with addiction-like behavior. Calloway"s observation of fewer SFs in bulmics is in sharp contrast with our findings: we found only marginal differences in anxiety measurements between groups. Calloway et al. (1983) relate bulimia to psychopathy because of their faster habituation rates and fewer SFis in Skin Conductance. However, it should be noted that the psychophysiology of psychopathy is different. Psychopaths are characterized by faster habituation rates, but also by tonic lower levels of SC and smaller ORs (Zahn, 1986). In our study and in the study of Calloway et at. (1983) no differences in OR and SC levels were found between restrained eaters and bulimics respectively, and normal controls. A resemblance of the electrodermal activity of bulimics and psychopaths may thus be restricted to rapid habituation it does not include ORs and SCLs.

Research on overeating after a preload may help elucidate the present findings. Analogous to a binge of bulimics, which may be triggered by eating a small amount of food, restrained eaters in the laboratory were found to lose control over their food intake after a small preload (Herman and Mack, 1975; Hibscher and Herman, 1977; Jansen, Merckelbach, Oosterlaan, Tuiten and van den Hout, 1988a; Jansen, Oosterlaan, Merckelbach and van den Hout, 1988b). This uncontrollability of food intake after a preload is usually thought to be a consequence of the preload breaking the restraint. The common line of reasoning runs as follows. Binges of bulimics, and subiclinical over-eating in laboratory situations, are typically preceded by periods of dieting (Wardle, 1980; Polivy and Herman, 1985; Ruderman, 1985, 1986). The explanation given for owereating is that dieting suppresses the body weight below a biological set-point for body weight. Breaking the psychological restraint, e.g. by eating a preload, triggers a biological urge to eat (Hernian and Mack, 1975). However, the concept of set-point is rather untestable, and analogous to the overeating/bingeing response in $S$ s preoccupied with eating, is the drinking response of restrained alcoholists after a preload of alcohol. After drinking a small amount of alcohol the alcoholist engages in a "drinking binge" (Scott, 1983). And it is questionable whether this has anything to do with an inborn, maturally predetermined, set-point.

Considering that (1) rapid habituation to a series of neutral stimuli is characteristic of addicts as well as restrained eaters, (2) addicts and restrained eaters are high sensation seekers, and (3) overconsumption after breaking their restraint is characteristic of both addicts and restrained eaters, the following speculation is made. People who are rapidly habituating to stimuli need a lot of stimulation to reach an optimal level of stimulation: they are high sensation seekers. When high sensation seekers give in to their need of much stimulation, they run the risk of being excessive consumers. This excessive consumption may have negative consequences, e.g. being fat or having a hangover. In order to prevent these negative consequences, the rapidly habituating sensation seekers need to restrain themselves. In this view, restraint is considered to be a consequence of the rapid habituation: rapidly habituating individuals seek stimulation and thus are prone to excessive intake. Then restraint is a preventive means for not suffering from aversive results following 
excessive consumption. Breaking the restraint leads to owerconsuntion, and has thus much more to do with the rapid habituation rates and treed for stimulation than with a biologically predetermined set-point for body weight. Schematically:

rapid habituation $\stackrel{+}{\longrightarrow}$ sensation seeking $\stackrel{+}{\rightarrow}$ excessiveness $\stackrel{+}{\rightarrow}$ negative consequences

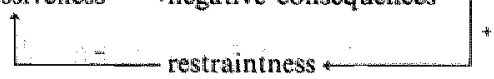

There are various lines of evidence to support this wiew.

First, there is the often reported cross-over and co-existence in addlictive behavior. Eatingdisordered patients often report excessive alcohol drinking or drug abuse in the past or present (Brisman and Siegel, 1984; Jonas and Gold, 1988; Beary, Lacey and Merry. 1986; Lacey and Moureli, 1986), and several studies indicate that certain groups of drug abusers may have (had) elevated rates of eating disorders. (Jonas and Gold, 1988). Clearly may often simply be replaced by/or be accompanied with excessiweness in another modality in order to be stimulated one way or the other. It would be of interest to test whether the sub-clinically restrained eaters also show restraint in other behaviors, like drinking or drug abuse.

Second, from this theory it can be predicted that slowing down the habituation rate may reduce the need for external stimulation and thus excessive consumption. If someone is exposed to high levels of environmental stimulation, habituation rate will be reduced (Zahn, 1986). Thus, it may be hypothesized that restrained eaters (1) will habituate normally when they are exposed to high levels of environmental stimulation, and (2) will regulate normally for a preload when they are optimally stimulated. Indirect support for this hypothesis is given by a recent study of Herman, Polivy, Lank and Heatherton (1987). As mentioned before, laboratory studies on food intake stress the importance of dieting status and degree of repletion, i.e. being preloaded or not, as main determinants for food intake: restrained eaters do not regulate their food intake after a preload, while unrestrained eaters do (Herman and Mack, 1975; Hibscher and Herman, 1977; Herman and Polivy, 1980; Ruderman and Christensen, 1983; Jansen et al. 1988a, b). Herman et al. (1987) stressed the importance of a third factor: level of anxiety. In particular, the interaction between dieting status, degree of hunger/repletion and level of anxiety is supposed to determine food intake. In a recent study, Herman and co-workers (1987) found that only preloaded dieters in a low anxiety condition counter-regulated. Dieters in a high anxiety condition regulated: they ate less after a preload than without one.

Highly intriguing in the study of Herman et al. (1987) is that highly anxious restrained eaters regulated their food intake after a preload, just like lowly anxious unrestrained eaters do. Post hoc analysis of our own data on food intake of restrained and unrestrained eaters after a preload or no-preload (Jansen et al., 1988a) revealed the same pattern of regulation in highly anxious dieters after a preload. To explain the disappearance of counterregulation in anxious dieters, Herman et al. (1987) suggest that only a first disinhibitor (anxiety or a preload) induces overeating in restrained subjects. After a first disinhibitor the diet is mo more intact and, as a consequence, a second disinhibitor will hate no more effect, "Anxiety cannot disinhibit a dieter who is already disinhibited" (p. 266). Thus, when restrained eaters are either preloaded or anxious, they will counterregulate, but when they are prelloaded and anxious, only the first disinhibitor will be an effective disinhibitor. However, if that is true, one should not expect highly anxious restrained eaters to regulate their food intake after a preload. This explanation does not cover the available data. It should be noted that either the preload or the anxiety should have disinhibited the restrained eater and should thus have resulted in excessive food intake. This was not the case. With the explanation given by Herman et al. (1987) the crucial issue remains unsettled: what causes lowly anxious restrained eaters not to regulate their food intake after a preload, while highly anxious restrained eaters do regulate for a preload just like normally unrestrained eaters? From the present model it appears that the introduction of anxiety slowed down the habituation rates of restrained eaters. The slower habituation rate as a consequence of increased anxiety diminishes the need for external stimulation and thus excessive consumption, leading to normal regulatory behavior. This post-hoc explanation of the Herman el al. data has to be subject to experimental tests: do restrained eaters (a) habituate normally when they are exposed to high levels of environmental stimulation, and (b) will they regulate normally for a preload when they are optimally stimulated? 
The model given earlier in this discussion was suggested by the present data and it covers some existing findings quite well. Meanwhile, a model is as good as the predictions that flow from it. Some of the most straightorward implications are given below. As mentioned, restrained eaters (1) should especially be high "disinhibition" scorers, (2) should also show restraint in other behawiors, like drinking or drug use, (3) should habituate normally when they are exposed to high levels of enwironmental stimulation, and (4) should regulate normally for a preload when they are optimally stimulated. Furthemore, (5) it is postulated that the sensation seeking, excessiveness, and restraint result from rapid habituation. The model predicis that rapidly habituating people (a) score thighter on sensation seeking scales; (b) score higher on restraint scales, and (c) show more excessive behaviors than slowly habituating people. Finally, (6) it is theorized that sensation seeking leads to excessive consumption and ends up in restraint: are high sensation seekers more often either excessive consumers or restramed $S$ s than low sensation seekers? Clarification of these issues may help understand the intriguing relationship between eating disorders and substance abuse; it may prove a rewarding enterprise. 


\title{
5.8 on being led into temptation: 'counterregulation' of dieters after smelling a 'preload'
}

\author{
Anita Jansen ${ }^{1} \&$ Marcel van den Hout ${ }^{1}$
}

Addictive Behaviors, in press

\section{abstract}

In the present study, it was found that dieters lost control over their food intake and 'counterregulated' after merely smelling a 'preload', while dieters without a 'preload" were able to maintain control over their food intake. Non-dieters, however, even ate marginally less after smelling a 'preload' than they did in a "no-preload' condition. Apparently, actually breaking one's diet and such subsequent thoughts as "I've blown my diet, I might as well continue to eat"' is not necessary for counterregulation to occur. The observation that merely smelling a 'preload' is sufficient to produce 'counterregulation' in dieters but not in non-dieters challenges the explanatory power of the widely held cognitive explanation of experimental counterregullation in preloaded dieters. With reference to earlier findings on counterregulation and to findings in the field of addictive behaviors, the authors suggest that overeating may result from a preparatory hyperinsulinemia/hypoglycemia response which can be elicited by several disinhibitors.

\section{introduction}

A well-documented finding in laboratory research on food intake is that dieters eat more after forced consumption of a preload than when they are not given a preload. This phenomenon is called counterregulation and is usually explained in cognitive terms. The general idea is that it is the awareness of a broken diet that disinhibits the dieter. Dieters tend to respond to a violation of their diet with thoughts such as "ve blown my diet, I may as well continue to eat", and, thus, are led to temporarily abandon their restraint (Polivy, 1976; Ruderman and Wilson, 1979; Polivy

1 Dept. of Mental Heatth Sciences / Experimental Psychopathology, Limburg University, P.O. Box 616,6200 MD Maastricht, the Netherlands. 
and Herman, 1985; Ruderman, Belzer and Halperin, 1985; Ruderman, 1985,1986 ). However, there is reason to doubt about the explanatory power of the assumed disinhibitive thoughts. Until now, no unequivocal support for the "cognitive explanation" of counterregulation has been documented. And what's more, an experimental study of dieters' self-talk during overeating provided no confirmation of the very widely accepted view that dieters are disinhibited by thoughts; non-regulating dieters were not characterized by a different set of cognitions or self-talk during food intake than regulating non-dieters (Jansen et al., 1988).

It should be noted that the measurement of cognitions poses serious methodological problems, and it is questionable whether it is ever possible to precisely analyze the stream of consciousness that accompanies certain behaviors of people. It may be more fruitful to deduce testable hypotheses from the cognitive perspective on counterregulation. A direct implication of the idea that dieters in the usual preloadparadigm only are disinhibited by the very awareness of a broken diet is that not breaking the diet will logically not result in a counterregulatory response. In the present study, the diet was not broken; subjects merely concentrated intensely on the smell of a 'preload'. Despite the fact that no real preload was given and thus no real counterregulation could take place, the authors have chosen to use these terms to stress the similarity of design of the present study with the usual preloadparadigm. Because no evidence of disinhibitive elements in the stream of consciousness of nonregulating dieters could be found in the Jansen et al. (1988) study, it was reasoned that not only may disinhibitive thinking be unnecessary for counterregulation but actually preloading dieters may not be a sine qua non for counterregulation. It was, therefore, hypothesized that dieters would lose control over their food intake and 'counterregulate' after merely smelling the 'preload', while dieters who do not smell the 'preload' would not lose control over food intake and, thus, be able to keep to their diet. It was further hypothesized that non-dieters in both conditions would maintain control over their food intake and eat similar amounts whether or not they had smelled the "preload' intensively.

\section{method}

subjects

Fifty-one female students and employees of the University of Limburg volunteered to complete a questionnaire on food preferences. The hypotheses under review concern differences between restrained and unrestrained subjects. To increase chances of finding the hypothesized effect, it was decided beforehand to compare relatively extreme groups. Given the fact that the median split score of our subject sample on the RS in an earlier study was 12 (Jansen et al.,1988), it was decided to classify subjects scoring a quarter higher $(\geq 15)$ as high restrained eaters, i.e. 
dieters, and subjects scoring a quarter lower $(\leq 9)$ as low restrained eaters, i.e. non-dieters. Sixteen subjects scored between 9 and 15 on the RS and they were not included in the analysis of the data. We thus ended up with 36 subjects. Subject characteristics are shown in Table 1.

table 1: subject characteristics

\begin{tabular}{lllr}
\hline $\begin{array}{l}\text { dieflers } \\
(\mathrm{n}=19)\end{array}$ & $\begin{array}{l}\text { non-dieters } \\
(\mathrm{n}=17)\end{array}$ & $t$ \\
\hline age & $24.4(6.7)$ & $20.9(2.0)$ & $2.0^{*}$ \\
BMI $^{\#}$ & $25.2(3.5)$ & $19.9(1.3)$ & $5.8^{* *}$ \\
RS $^{\# \#}$ & $19.6(3.3)$ & $6.9(2.1)$ & $13.6^{* *}$ \\
\hline
\end{tabular}

* $\mathrm{p}=0.05 ;$ *" $\mathrm{p}=0.000 ;$ " BMI = Body Mass Index (weight/height ${ }^{2}$ ); ${ }^{\# \#}$ RS = Restraint Score

assessment

The following instruments were used:

The Restraint Scale (RS) (Polivy et al., 1978), measuring attitudes toward eating, frequency of dieting, and weight fluctuations.

The Perceived Control List (PCL). A list of six statements concerning perceived control over food intake was composed by the authors (see Table 2). Each statement was scored on a $100 \mathrm{~mm}$ visual analogue scale (VAS), with scores ranging from 0 ("not at all") to 100 ("extremely").

The dependent variable was the total caloric intake.

table 2: the Perceived Control List (PCL)

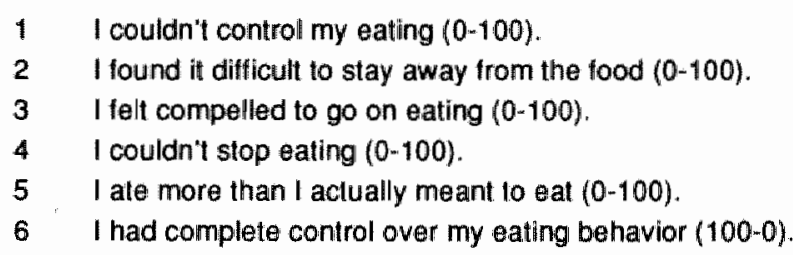

\section{procedure}

Ss were asked to have breakfast, lunch, or dinner 1-3 hours before participating in the study. Food intake thus served as a caloric overload and could not be influenced by deprivation. Ss were randomly assigned to the 'preload' or "no-preload' condition. All Ss were run individually between $9.00 \mathrm{a} . \mathrm{m}$. and 5.00 p.m. Care was taken to balance the number of Ss run in each condition at various times of the day. After entering the 
laboratory, Ss in the 'no-preload" condition spent 12 minutes completing a questionnaire on sensation seeking which, for this study, was irrelevant. They did this in a neutral place. Subjects in the "preload" condition were directly presented with 750 grams of Dutch liquorice, 900 grams of English licorice, 500 grams of cake, 500 grams of smarties, 400 grams of nuts, 400 grams of spiced biscuits, 350 grams of shortbreads and 400 grams of soft sweets. The food was presented in large amounts and, when necessary, broken into small pieces so that later in the experiment subjects could inconspiciously eat a lot. Subjects in the 'preload' condition were stimulated by the experimenter, who was in the same room as the subject, to hold the dishes with the food directly under her nose and to concentrate on the smell of the food. Subjects completed a questionnaire on the smell of the different food items. After 12 minutes of exposure, subjects were given a questionnaire on preferences concerning the food items they had been presented with. Subjects in the 'no-preload' condition entered the room with food items after their 12 minutes in the no-exposure, neutral place. They were also given the food preference questionnaire. Subjects in both conditions were instructed to fill in the questionnaire and they were invited to eat as much as they wanted to, but they were not obliged to do so. The food preference questionnaire was constructed in such a way that tasting the food was not necessary in order to answer the questions; this way the subject had the option of eating nothing at all. Each subject was left alone for 15 minutes to complete the food preference questionnaire (in a pilot study it was found that subjects needed 7 to 8 minutes to complete the questionnaire). After their 15 minutes alone in the room with the food items, the experimenter returned and the subject was asked to answer the questions of the $\mathrm{PCL}$ with regard to their behaviour in the previous task, i.e. when completing the food preference questionnaire. The subject was then taken to a second experimenter in another room where she filled in the RS. Her weight and height were determined and, after debriefing, she was paid for her participation. The food that remained was then reweighed by the first experimenter and, after conversion into calories, the subjects' total caloric intake was determined.

\section{results}

\section{analysis}

Because dieters and non-dieters differed significantly in BMI and age (see Table 2), analyses of covariance (ANCOVA) were carried out on the data. The main factors were Group (dieters vs non-dieters) and Condition ('preload' vs "no-preload'), with BMI and age as covariates. If hypotheses 1-3 were true, the Group $\times$ Condition ANCOVA would show specific interaction effects, namely, 'counterregulation' and a perceived loss of control after a 'preload' in the case of dieters, and no effect of the 'preload' 

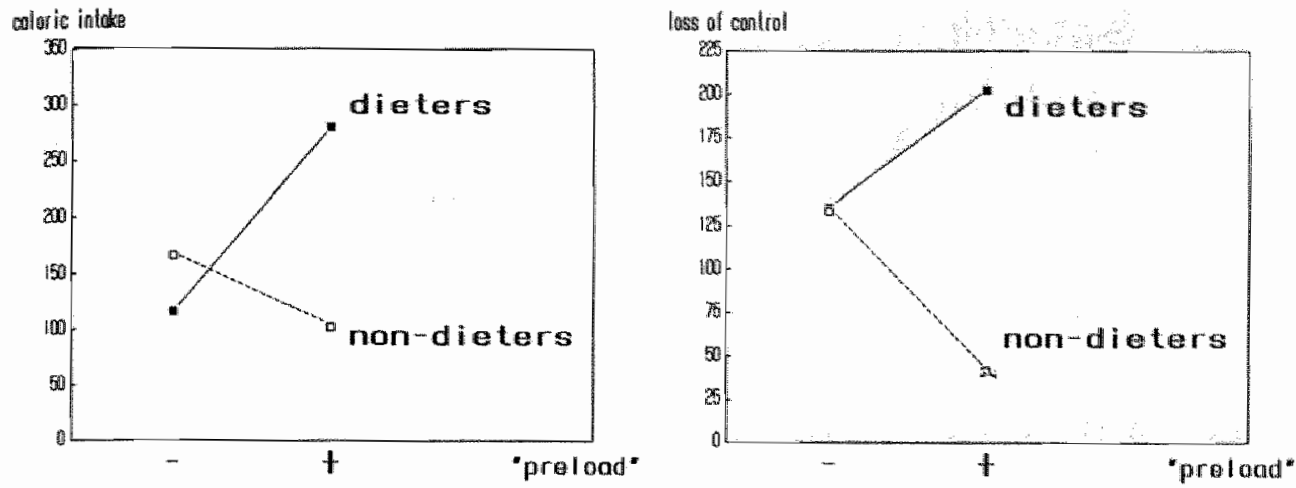

figure 1: caloric intake and loss of control of dieters and non-dieters after "preload" and without a 'preload'.

in the case of non-dieters. The interactions were tested by means of pre-planned contrasts, and the specific within-group effects were tested by means of t-Tests. The results are shown in Fig.1.

\section{caloric intake}

The ANCOVA showed a significant main effect for Group (pre-planned contrasts: $t(1,35)=2.0, p=0.03$, one-tailed), meaning that dieters' caloric intake was higher than non-dieters' caloric intake. As hypothesized, the Group $\times$ Condition interaction was significant $(t(1,35)=1.85, p=0.04$, on $\theta$ tailed); thus, the 'preload' was related to a higher caloric intake in dieters, whereas it was related to marginally less intake in non-dieters. Closer inspection of the data by t-Tests showed that dieters ate significantly more after smelling the 'preload' intensively than they did when not smelling a 'preload' ( $t(17)=1.95, p=0.03$, one-tailed), and although non-dieters ate less after smelling the 'preload' than when not smelling one, the difference in food intake was not significant $(t(15)=1.13, N S)$.

\section{perceived control}

Ss retrospectively rated their perceived control over food intake on the 6-item PCL. For each subject, the scores on the six PCL items were added up, with a higher total score meaning a heightened perceived loss of control. The ANCOVA showed a significant main effect for Group $(t(1,35)=1.93, p=0.03$, one-tailed), meaning that dieters retrospectively perceived more loss of control than non-dieters. Also, as hypothesized, the interaction Group $x$ Condition was found to be significant $(t(1,35)=1.9$, $\mathrm{p}=0.03$, one-tailed). As is clear from Figure 1 , no differences in perceived control emerged between dieters and non-dieters in the 'no-preload' condition. However, in the 'preload' condition, i.e. after smelling the food intensively, dieters lost control while non-dieters even managed to increase control. 


\section{discussion}

In the present study, the typical pattern of 'counterregulation' was replicated. In accordance with the retrospectively reported loss of control over food intake, dieters in the 'preload' condition 'counterregulated' after merely smelling the 'preload'. In contrast, dieters in the "no-preload' condition did not report a loss of control over food intake; they were, indeed, able to keep to their diets. Surprisingly, but in line with their subjectively experienced heightened control, non-dieters even ate less atter the exposure ritual.

It should be noted that the present data were derived from subject samples selected on the basis of extreme scores on the RS. When data post-hoc were re-analyzed using a median split categorization, the observed interaction dropped to a non-significant level. In most of the relevant studies on counterregulation after eating a preload, dieters and non-dieters are selected by a median split procedure. Possibly, a strong manipulation (eating a preload) requires less stringent selection criteria (median split), whereas a weaker manipulation (smelling a preload) requires stringent selected subject samples (extreme scorers) to find the effect, i.e. counterregulation.

The fairly exact replication of 'counterregulation' in dieters who were merely exposed to, and intensively smelled, the "preload' but whose diets were not actually broken, raises a problem for the cognitive explanation that dieters counterregulate after eating a preload because their diet has already been broken. The present study shows that, in the preloadparadigm, breaking a diet is not necessary for counterregulation to occur; merely smelling a 'preload' is enough to make high restrained subjects lose control and overeat. Of course, the present findings do not exclude the disinhibitive power of certain cognitive manipulations. A most intriguing finding is that manipulation of the dieters' beliefs concerning the caloric content of the preload influences subsequent consumption (Polivy, 1976; Spencer and Fremouw, 1979). In a very elaborate study, Spencer and Fremouw (1979) found that dieters who were just told that they had consumed a preload rich in calories counterregulated, while dieters who believed their preload was low in calories did not overeat.

How should we account for these apparently conflicting findings? Counterregulation of dieters has been found to occur on several occasions. Generally speaking, dieters have been found to lose control over food intake after forced consumption of a preload (Herman \& Mack, 1975; Hibscher \& Herman, 1977; Jansen et al., 1988), when they are in a strong emotional state, as when depressed or anxious (Baucom \& Aiken, 1981; Frost, Goolkasian, Ely \& Blanchard, 1982), after manipulation of cognitive beliefs (Polivy, 1976; Spencer \& Fremouw, 1979) and, as the present study shows, after intensive smelling of food. Despite the fact that various disinhibitors lead to the identical phenomenon of overeating, different processes are proposed to explain how a particular disinhibitor leads the 
dieter to overeat. For example, the perception of having overeaten is supposed to be the reason why a preload disinhibits the dieter, while a loss of motivation to diet is thought to be the disinhibitive factor in depressed dieters. Yet, one should not rule out the possibility that one and the same mechanism underlies all of the aforementioned counterregulatory challenges. For reasons of parsimony, a unifying theory seems preferable.

The analogy between addictive behaviors and overeating may be of relevance here. In the past decade several authors have pointed to similarities between substance abuse disorders and overeating (Bemis, 1985; Wardlle, 1987; Jansen et al.,1989). Both addicts and individuals who overeat are characterized by a preoccupation with a particular substance, a craving for the substance, and a loss of control over intake (Bemis, 1985; Ruderman et al., 1985; Wardle, 1987; Jansen et al., 1988). The results of recent animal studies provide empirical support for a classical conditioning model of craving and drug tollerance. After repeated association of cues specifically related to the substance taken, these cues (conditioned stimuli; CS) come to elicit a response (conditioned compensatory response; $C C R$ ) which is opposite in direction to the unconditioned response of the substance (Siegel, 1983). Over the course of repeated substance administration in the presence of perceivable cues, the CCR moderates the unconditioned substance response and tolerance is acquired. The CCR, which is triggered by contextual cues (CS), may be considered a "preparatory" response, that is, the CF anticipates and compensates for the effects of the substance in order to maintain a homeostatic balance. It is this CCR that may cognitively be labeled as "craving" (for reviews, see Siegel, 1983 and Macrae et al., 1987). Conceptualizing dieters' overeating response as addictive behavior, the cues normally associated with excessive food intake would be considered CS. Interestingly, exteroceptive as well as interoceptive stimuli may act as CS's (Ludwig and Wikler, 1974). Exteroceptive stimuli comprise a variety of environmental stimuli associated with prior food-taking behavior, such as the smell of food, seeing other people eating, or being in an environment where overeating often takes place. Interoceptive stimuli refer to the internal physiological effects of a preload as well as to emotional dysphoria and cognitive processes (Ludwig and Wikler, 1974).

With respect to the CCR, insulin release and blood sugar level may play a role. Normally, eating elevates the blood sugar level, and insulin is then released in order to bring the blood sugar level back down again. Several authors have pointed to environmental and cognitive influences on insulin secretion (see Rodin, 1985). Tasting, smelling, or even merely seeing or thinking of food is found to trigger an insulin response (Rodin, 1985). The hyperinsulinemia response has been associated with increased hunger, heightened perceived pleasantness of sweet taste, and increased food intake (Rodin, 1985). This anticipatory hyperinsulinemia response may be considered a "preparatory" response: with heightened insulin secre- 
tion blood sugar level declines, thereby anticipating and compensating for the effects of subsequent food intake. It is the increase in insulin and subsequent decline in blood sugar levell (CCR) that may subjectively be experienced as "craving".

Indirect support for the idea of learned responses being responsible for binge eating/counterregulation comes from salivation studies. Dieters on a highly invariable diet repeatedly were found to salivate significantly less to food cues than dieters on a highly variable diet (Legoff, Leichner and Spigelman; 1988; Klajner et al., 1981; Herman et al., 1981; Wooley \& Wooley, 1981). If certain cues (olfactory, taste, visual, cognitive etc.) are sometimes followed by particularly strong UCSs (high calorie intake) it can be expected that "unsuccessful' dieters (i.e. high scorers on the Restraint Scale, see Jansen et al., 1988) show strong CRs to any cues that typically predict food intake. It follows that counterregulation of dieters should occur not only if actual diet breaking is expected, as cognitive theory would predict. The clinicall implication that follows from the assumption that binges follow exaggerated CRs that are due to the probabilistic CS (cue) UCS (extreme food intake) contingencies. Then it follows that breaking the bond between CS and UCS is broken, the exaggerated CRs will extinguish (see also Jansen et al., 1989).

The conditioning model specifies a way in which the overeating response of dieters after a variety of disinhibitors may take place. Although the model post hoc covers the range of existing findings from overeating to insulin levels quite well, the predictive validity of the compensatory response model with respect to the overeating response of dieters still has to be proven. Future research should focus on the predictions that follow directly from the model. They are (1) that classical conditioning of food intake (UCS) to exteroceptive and interoceptive stimuli (CS) will, after repeated association, result in an anticipatory hyperinsulinemia and a compensatory hypoglycemia response (CCR); (2) that after a variety of disinhibitors (cognitive manipulation, eating a preload, smelling a preload, and emotional agitation) individuals who overeat will show the anticipatory hyperinsulinemia response and the compensatory decline in blood sugar level; (3) that this hyperinsulinemia/hypoglycemia response will be subjectively experienced as craving; and (4) that inducing a hyperinsulinemia/hypoglycemia response in non-dieters will trigger craving and an overeating response.

\section{acknowledgements}

The authors are very grateful for the assistence of Arnoud Arntz, Henriëtte Swijgman, Harald Merckelbach, Peter de Jong and Ronald Jansen. 


\title{
A CASE OF BULIMIA SUCCESSFULLY TREATED BY CUE EXPOSURE
}

\author{
A. JANSEN*, M. A. VAN DEN HOUT*, C. DE LOOFt, \\ J. ZANDBERGENT and E, GRIEZ† \\ Limburg University, Masstricht, The Netherlands
}

\begin{abstract}
Summary - In the present case-study, a 22-year-otd lemale patient with a 7 year history al bulinia nerwosa was unated by cue-exposure. During cue-exposure sessions the relationship between $C S$ (stimnll associated with binge-eating behwiour) and UCS (the sensations rendated to the intake of binge lood) was broken. As predicted, the patients" crawing for food declined within as well as between cue exposure sessions and radical decrease in the frequency of binge-ating persisted for at least nine months. Although during the therapy no cxplicit attention was paid to the patiens"s low mood and irrational self-talk, mood was improved and beliefs were fess irrational after cue-exposure and at the follow ups. The data suggest that cue exposure may be an effective part of the reatment of bulimia nervosa
\end{abstract}

Bulimia nervosa is characterized by recurrent episodes of uncontrollable binge-eating, in which large amounts of food are consumed rapidly (APA, 1987). Recently, several authors have pointed to the similarities between bulimia and addictive behaviors (Scott, 1983; Dumont \& Vamos, 1983; Brisman \& Siegel, 1984; Jonas \& Gold, 1988; Wardle, 1987; Filstead et al., 1988; Jansen et al., 1988, 1989). Both bulimia and addictions are characterized by craving, preoccupation with and loss of control of intake and by relapse. Also, experimental data supports the addictive interpretation of bulimia: restrained eaters were found to be rapidly habituating sensation seekers, just as addicts are (Jansen et al., 1989). The analogy between addictions and bulimia may have therapeutic implications.

\section{Consideraitons Regarding Treatment of Addictive Behaviors Relevant To The Management of Bulimia}

Recent developments with respect to "cue exposure" may be of relevance here. Based on an impressive data base primarily from animal work, Siegel and co-workers stressed the importance of contextual cues and preparatory responses in the persistence of addictive behaviors (Siegel, 1983; Macrae et al., 1987; Niaura et al., 1988). In short, after repeated drug administration, the set of stimuli (CS) specifically associated with the drug taking behavior (UCS) will ellicit physiological responses that are the biological basis of craving. The CS (cues) will elicil craving as long as the CS remains a specific predictor of the UCS (drug). Therefore, according to this paradigm. effective treatment of substance abuse should be directed at decreasing cue reactivity. Extinction of the craving may be achieved by prolonged exposure to the CS (cues) without UCS (drug) reinforcement. This so-called "cue exposure" appears to hold promise for the behavioural treatment of drug addicts (Siegel. 1983) and alcoholics (Rankin er al., 1983).

If bulimics' bingeing is conceptualised as behavior similar to that of addicts, cue exposure may also be effective in the treatment of bulimia. The intake of binge food may be

Requests for reprints should be addressed to A. Jansen. "Dept. of Mental Heath Sciences/Experimental Psychopathollogy, Limburg Uniwersity, P.O. Box 616.6200 MD Maastrich, the Netherlands.

Diept. of Climical PsychiatrylExperimental Psychopathology. Limburg University. the Netherlands. 
considered as the UCS, while the CS consists of the stimuli specifically associated with the binge-eating behavior. In the present case study, a bulimic patient was treated with cue exposure. The aim of the study was to test whether breaking the probabilistic relationship between CS and UCS by cue exposure is effective in diminishing the bulimic's craving for food and the frequency of binge-eating. Attention was also directed at changes in mood and specific thinking patterns.

\section{Method}

\section{Subject}

The subject was a 22 -year-old single female. who met the DSM-III-R criteria for bulimia nervosa (APA, 1987). She had suffered from uncontrollable binge eating episodes for 7 years. Although she was of normal weight, her weight thuctwated extremely, e.g. about $10 \mathrm{~kg}$ in four weeks. After bingeing, the patient vomited. Her eating pattern was chatic; binge eating episodes alternated with strict dieting episodes in which she merely ate "healthy" food, e.g. no sweets and much fruit. A strong preoccupation with weight and appearance was evident, as well as dichotomous all-or-nothing reasoning and depressed mood. The patient agreed to being subjected to an experimental new treatment.

\section{Assessment}

Several self-report instruments were employed before and after treatment and at the 2month and 9 -month follow-ups. They included (a) an enting diary from which the frequency of self-reported binge-earing was calculated, (b) the Beck Depression Inventory, range 0-63. and (c) a Self-Talk List, composed by the first author for the present study, and containing 10 statements concerning all-or-nothing reasoning and irrational thoughts about weight, appear. ance, and eating behaviour. Some statements were derived from clinical interviews wh the patient. Each statement was rated by the patient on a ("I don"t agree at all") to $100 \mathrm{~mm}$ ("I fully agree") Visual Analogue Scale (see later).

During cue-exposure sessions the patient rated her craving every 5 minutes on a 0-100 mm VAS ("How strong is your urge to eat?" from "none at all" to "extreme").

\section{Measurement Periods}

The first goal of the treatment was to reduce the frequency of binge-eating episodes and, the second was to enable the patient to keep food without eating it all. To this end, a list of food items was made. The patient was instructed to buy all these food items, and, when runnirg out of the relevant food, to restock the supply directly. In the continuous presence of this food, she monitored her eating behavior for exactly 21 days, which forms the pre-treatment measurement (PRE). The patient also com pleted the Self-Talk List and the Beck Depression Inventory at the start of this pre-treatment measurement.

The patient continued registering her food intake during and between cue exposure sessions. Promptly after the last cue exposure session, the patient completed the inventories again and registered her food intake for 25 days (POST).

Two and nine months after treatment she monitored her food intake for another 32 days, these being first and second follow-ups (FU1 and FU2). During both the POST and the FU registration periods. the patient kept the same food items as during the pre-treatment registration period. On the last day of the FU1 and FU2 the patient completed both inventories again.

\section{Identifying The CS}

During pre-treatment monitoring. 4 sessions of behavior analysis took place. The therapist (the first author) and the patient exactly 
identified the contextual cues (CS) in which the patient's binges occurred. Contact with the patient focussed on future in wivo exposure treatment, and aspects of such exposure were discussed. Care was taken not to engage in cognitive restructuring. The patient nearly always binged on specific food items (Malaga ice cream, chocolate, cookies. shortbread. liquorice all-sorts, Dutch liquorice, bananas. currant buns, milk, 7-up light, and tea). The binge was really a ritual event; first, the patient put on comfortable clothes (jogging trousers). Then, she arranged all the binge food on a tray, after which she would sit down on her couch, pick up a particular magazine and start to "read". While "reading", she stuffed herself with all the food in about a quarter of an hour. The magazine was considered a specific binge cue. The patient reported that she had forbidden herself to read this kind of magazine except during binges. Buying the magazine heralded a binge-eating episode. The bingeeating ritual depended on the contextual binge cues which constituted its CS. The UCS was defined as the consumption of binge food - food sweet and rich in calories which the patient lnad forbidden herself to eat. (The UCS is actually a sequence of events confronting the food, eating it, and the consequent pleasurable sensations.)

\section{Treamen Procedure}

After the monitoring period of 21 days, in vivo cue exposure was started, and continued for 16 successive days. Breaking the CS-UCS probability relationship was aimed at in two ways. First, the patient was exposed to the contextual cues predicting a binge (CS), while she was prevented from eating (UCS). During the cue exposure sessions, the patient was asked to touch the food, to raise it to her mouth and nose, to smell it and to act as if she was going to eat it. Exposure sessions lasted at least $1 \mathrm{hr}$ each day and the patient rated her craving every 5 min. Second, before each exposure session, the patient was forced to eat. together with the therapist, a preload of binge food (UCS) in a different place not predicting a binge, e.g., to eat an ice cresm in an icecream parlor. After having eaten binge food in a non-binge environment, the patient went home and confronted herself with the binge food and contextual binge cues without eating anything. In continuation of these strategies for breaking the CS-UCS probability relationship, she confronted binge food all day. She took along large amounts of binge food every day and ate small bites of one of the binge food items, without eating all of it, two or three times a day. Except for the first session, the patient did the exposure sessions on her own.

Results

\section{Craving}

Figure 1 shows that the first five cue exposure sessions were very effective as to the extinction of the urge to eat within sessions. Also, the starting level of the patient's craving decreased considerably between the sessions. After the fifth exposure session she reported that she no longer experienced any craving. The therapist and the patient then agreed to make the exposure more difficult by introducing more food items. This is clearly reflected in a raised starting level of craving at the sixth session. However, habituation again took place within and between the sessions.

\section{Frequency of Binge Easing}

As can be seen from Figure 2, the frequency of binge-eating decreased substantially after treatment. The patient monitored 16 binges during the pretreatment registration period (averaging over 21 days, 0.76 binges a day) .0 binges during cue-exposure. 1 binge during the post treatment registration period (averaging over 25 days, 0.04 a day), 4 binges during the 2 month follow-up (averaging over 32 days, 0.13 a day) and 0 binges during the 9-month followup. 


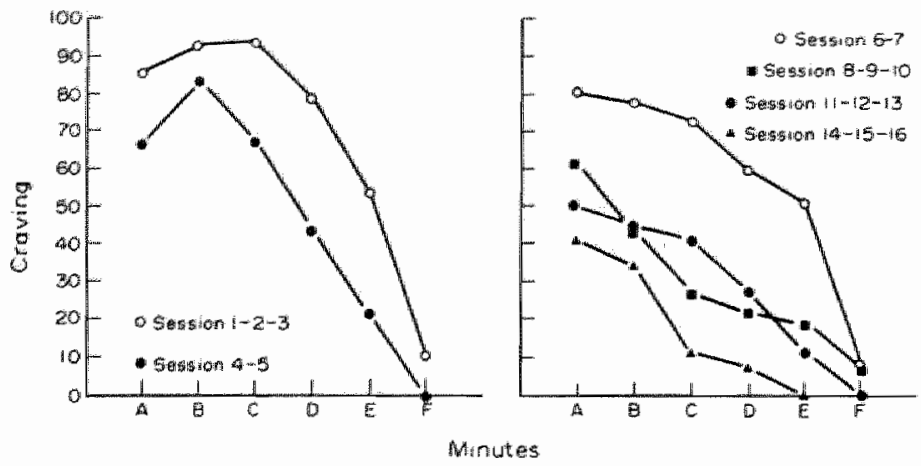

Figure 1. Habilution of craving whin and between exposute sessions. The dots in Fig. 2 indicate the aberage of three ratings of cruving in exch session. In this way, the dot over A represents the average of the ratings after 5.10 , and 15 minutes, the dot over $B$ after 20,25 . and 30 mins. $C: 35,40.45$ mins., D: 50.55 , 60 mins., E: 65. 70.75 mins. and $\mathrm{F}$. 80, 85 . and 90 mins. The lines conneting the dots indicate the average of the ratings of craving over wo or three sessions.

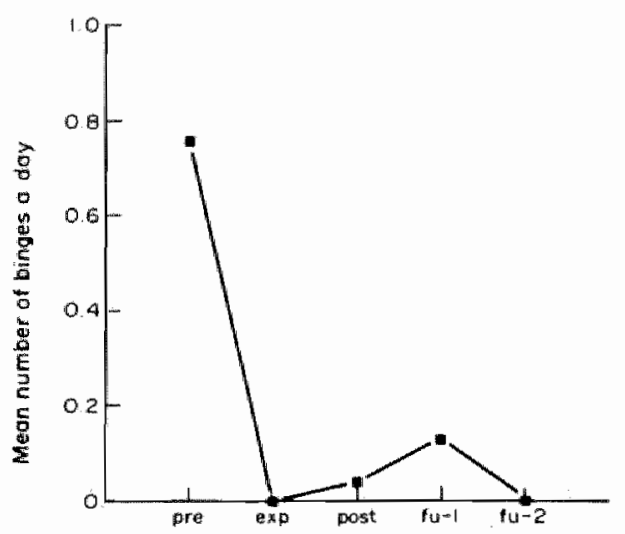

Fugure 2. Fropuency of binge-ating belore, during. andist alter cue-exposure, and at 1 WO and mine-month follon-ups.

\section{Depression and Self-ralk}

Before treatment, the patient's mood was low $(\mathrm{BDI}=22)$. Promptly after treatment, the patients' mood had improved (BDI $=6$ ). At the first follow-up. mood was lowered again $(F U 1 ; B D I=15)$, but at the second follow-up mood had again improved (FU2; $\mathrm{BDI}=9$ ).

Surprisingly, the patient thought in a less dichotomous manner and less irrationally after cue exposure without specific cognitive inter- ventions. To a lesser degree, this improvement continued during the post and follow-up measurements (see Figure 3 ).

\section{Discussion}

This case-study shows that cue exposure may be an effective form of treatment for bulimia nervosa. As predicted, craving declined both within and between cue exposure sessions, and a radical decrease in the frequency of bingeeating persisted for at least nine months. The changes in mood and self-talk after cue expo. sure therapy are interesting. Although before and during the therapy, no explicit attention was paid to the patient's low mood and dichotomous/irrational self-talk, her mood had perceptibly improved after cue exposure. Also. without any specific cognitive intervention, the patient thought in a less dichotomous manner and less irrationally, as measured by the Self. Talk List. At the follow-up her self-talk seemed to have worsened a bit. Despite the fact that some improvement on the cognitive items was noticeable after cue-exposure, dysfunctional thinking patterns were still present after cue-exposure, and cognitive therapy might have been indicated. 

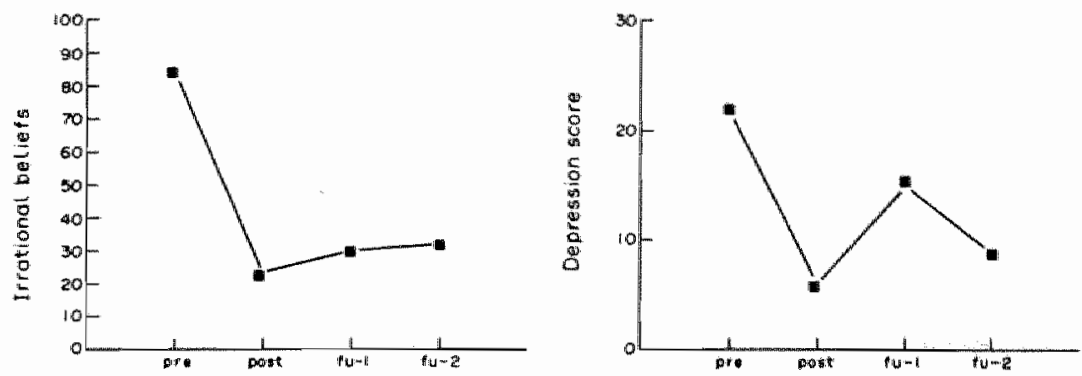

Figure 3. Scores on the Beck Depression Inwentory and the Self talk List before, during, and after entexposure and at the 2 - and 9 -month follow-ups. The irrational belie score represents the mean scores on 10 irrational belief statements ("What others think of me is most importan:" "I am not pleased with ray looks" "Sweet things are the beginning of ald misery". "I must not eat sweet things". "If I do not have complete control of myself, everything will go wrong", "I am worthless if I am fat", "It is all or nothing", "If I eat over 1000 cal, a day, everything is lost", "If I weigh less, everything will be better" and "The way 1 look determines my sell confidence"). The patient rated agreement with uhe statements on a. ("I don't agree at all") to $100 \mathrm{~mm}$ ("I fully agree") VAS.

The notion that exposure may be helpful in the treatment of bulimia is not new. By analogy with the rituals of obsessive. compulsive disorders, Wilson and co-workers (1986) argue that the vomiting in bulimia reduces anxiety and underline the importance of exposure and response prevention of vomiting in the treatment of bulimia. However, Schmidt and Marks (1988) noted that that is very aversive and that the control of binges rather than of vomiting may be more acceptable. Therefore, Schmidt and Marks (1988) treated four bulimics with prolonged cueexposure. Their results were "moderately encouraging" (p. 671); two subjects showed considerable improvement of frequency of bingeing and vomiting, while one dropped out of treatment, and one improved mainly after, but not during, the treatment. However, the most crucial aspect of the cue-exposure rationale is breaking the CS-UCS bond. Therefore, among other things, cue-exposure should take place in the usual binge-environment. Schmidt and Marks (1988) exposed their patients to binge food in the laboratory/clinic and not in the binge-environment (UCS). This may be the difference that explains the more positive results in our case than in the four cases of Schmidt and Marks.

All in all, the data suggest that cue exposure is an effective treatment of bulimia. However, the limitations of data from a single case are well known.

There should be replication in controlled outcome studies. Currently, stimulus-control techniques often form part of the treatment of bulimia. However, their effects are opposite to those of the CS-UCS model. To learn stimulus-control techniques is, in fact, to learn avoidance; i.e. to avoid the stimuli associated with binge-eating. In contrast "exposure to the $\mathrm{CS}$ extinguishes the craving. Since food can harclly be avoided entirely, much more relapse is likely after interventions based on avoidance, than after those based on exposure.

If cue-exposure is indeed effective in bulimia nervosa, we need to know how many exposure sessions are needed for the craving to extinguish, how the sessions should be spaced. whether it is necessary for the patient to abstain completely between cue exposure sessions, and how broad the range of cues should be for maximizing the effects. 



\section{1 general discussion}

The starting point of the present dissertation was the observation that certain 'disinhibitors' produce counterregulation in dieters as weil as binge eating in bulimics. The question was: "why?".

Some answers were given and dismissed. They appeared to be untenable on theoretical and/or empirical grounds. Set point theory is repeatedly put forward by researchers of counterregulation. But the introduction of a 'set point' is merely an easy way out when one is completely at a loss. The theory is inapplicable to the lab data on counterregulation. Set point theory requires rather successful dieting for someone's body weight to drop below its alleged 'set point'. Dieters counterregulating in the lab are especially unsuccessful dieters: it is unlikely and, what is more important, still untestable that unsuccessful dieters' weight is below set point. Apart from that, it is useless to take the 'set point' for granted as so many researchers of counterregulation do. With the use of 'set point' as a self-evident explanation, the discussion about the etiology of counterregulation is closed too easily. Such premature, unjustified consensus is counter-productive when it comes to the development of new theories (e.g. that the maintenance of overeating has nothing to do with food restriction and hunger, but everything with impulsive, addictionlike behavior).

Besides the set-point theory, the 5-HT hypothesis was also put forward. Originally, the 5-HT theory focussed on the clinical binge. Bingeing was thought to serve a self-medicational purpose: by eating relatively large amounts of carbohydrates bingers were thought to restore their otherwise low 5-HT levels. To make 5-HT theory convincing, it is a prerequisite that binges are relatively rich in carbohydrates, but research has proved that they are not (cf.5.3).

Moreover, both the set point theory and the 5-HT theory do not explain satisfactorily why "disinhibited' dieters counterregulate whereas "non-disinhibited' dieters do not. 'Disinhibited' as well as 'non-disinhibited' dieters should, according to both theories, be characterized by a biological deficit. For explaining the counterintuitive behavior of dieters in the lab, auxiliary hypotheses about the intermediate mechanism which has been put into operation in 'disinhibited' dieters but not in 'non-disinhibited' subjects, will always be needed.

Cognitive theory can explain the mechanism. It makes it clear why 'disinhibited' dieters overeat whereas 'non-disinhibited' dieters do not. The 
underlying idea is that the different disinhibitors lead to overeating via certain "disinhibitive" cognitions which are only present in 'disinhibited" dieters. After dieters perceive their diet as broken, they think thoughts such as "I"ve blown my diet, I might as well continue to eat" and they sult the action to the word. This explanation may sound plausible. However, there is not one single controlled indication that disinhibitors will lead to 'disinhibitive' thoughts (ct. 5.5). Moreover, the theory fails when it comes to explaining why dieters overeat after non-food related disinhibitors, such as mood induction.

In sum, somehow or other existing theories fail when it comes to explaining why dieters counterregulate after various challenges. The main contribution of the present dissertation is the presentation of an alternative explanation which covers the range of challenges quite well. In the course of the present research, similarities between addicts and bullimics caught the attention. The loss of control that is repeatedly reported by dieters (cf. $5.1 \& 5.5$ ) and the rapid habituation rates (cf.5.8) support the alleged addiction analogy. With the use of experimental data on classically conditioned compensatory responses in addictive behaviors, an analogous model for counterregulation/binge eating can be construed. The idea is that binge eating and counterregulation are cue-dependent. They are supposed to result from learned compensatory responses (hypoglycemia) which prepare the organism for the intake of food. The compensatory response model, which is outlined in section 3.5 , seems to be promising. The model specifies the way in which dieters" counterregulation or binge eating after a variety of disinhibitors may take place. An important difference between the currently especially popular cognitive explanation of counterregulation and the present model lies in the exchange of stimulus and process (see below). The cognitive model states that a "disinhibitor' (stimulus) leads to counterregulation (response) via disinhibitive cognitions (process in the organism). The compensatory model states that a "cue' (stimulus) leads to counterregulation (response) via physiological compensatory responses (process in the organism):

\section{Cognitive modell}

\begin{tabular}{|c|c|c|c|c|}
\hline $\begin{array}{l}\text { I } \\
\text { disinhibitor }\end{array}$ & $\Rightarrow$ & $\begin{array}{l}\text { II } \\
\text { disinhibitive } \\
\text { cognitions }\end{array}$ & $\Rightarrow$ & $\begin{array}{l}\text { III } \\
\text { overeating }\end{array}$ \\
\hline
\end{tabular}

\section{Conditioning model}

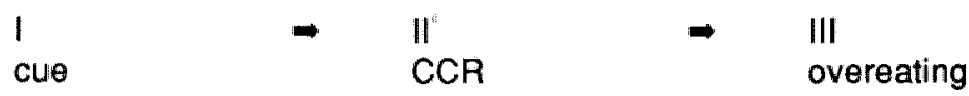


According to the cognitive model, the process that accounts for counterregulation is formed by cognitions. It should be noted that, according to the compensatory model, cognitions may act as cues (stimuli), but are not included in the process according to which counterregulation takes place. The cognitive 'disinhibitor' is, in fact, a cue, whereas the real 'disinhibitor' is a classically conditioned compensatory response (CCR).

Post hoc, the model covers earlier findings quite well, and some predictions following from it could also be corroborated (cf. 5.8 \& 5.9). It was, for example, predicted that if certain CSs are sometimes followed by strong UCSs, unsuccessful dieters will also counterregulate after any of these cues that typically predict food intake. Dieters did counterregulate after they had merely smelled a 'preload'. This is in flat contradiction with cognitive theory, which states that dieters overeat because they perceive their diet as broken, whereas, in this case, it was not.

Future research should further concentrate on this model; mine certainly will. First, attention should be paid to fundamental predictions. Later on, research on clinical issues will possibly also be warranted.

\section{2 fundamental research}

According to the model, dieters counterregulate because of a classically conditioned anticipative compensatory response. It was argued that in response to a cue, an insulin-induced hypoglycemia has to be undone by eating, that is, the hypoglycemia has to be compensated for by large food intake to restore blood sugar level.

The following hypotheses can be formulated:

1 after repeated association of a specific set of cues (CS) with large food intake (UCS), presentation of merely the CS will elicit a compensatory hypoglycemic response (CCR). See figure.
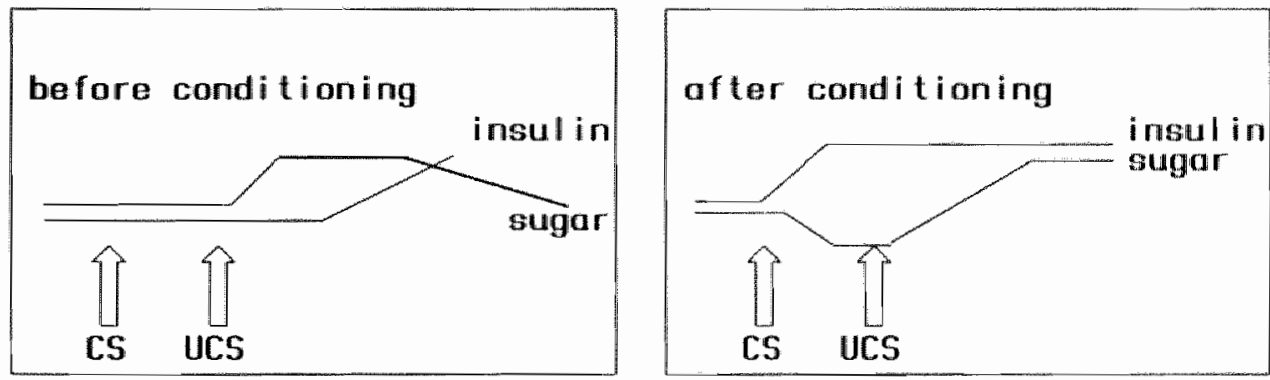
2 the decline in blood sugar level (CCR) is mediated by an anticipatory insulin response (CPR).

3 the hyperinsulinemia/hypoglycemia is subjectively experienced as craving.

4 the classically conditioned compensatory response, i.e. the hypoglycemia, will be positively correlated to the amount of ad lib food intake.

5 counterregulation of dieters in the lab will be accompanied by an anticipative hyperinsulinemia and a compensatory hypoglycemia response.

6 insulin-induced hypoglycemia will trigger craving and an overeating response in unrestrained subjects after a preload.

\section{3 clinical issues}

Insofar as counterregulation/bingeing actually follows from classical conditioned cue responses, there is a straightforward clinical implication (see also section 3.5). The model states that cue responding is maintained because certain CSs are often reinforced by large intake. Cues elicit CCRs because they are predictors of UCSs (large food intake). Pavlovian learning theory predicts that if the CS-UCS relationship is broken, CCRS will be extinguished and counterregulation/bingeing should be extinguished as well.

Interestingly, the type of therapy that follows from this will be highly similar to the behavioral techniques that rank among the most effective therapies for curing compulsive disorders and phobias: in vivo exposure (Emmelkamp, 1982). Compulsive behavior, phobic anxiety and avoidance are typically cue controlled. In vivo exposure boils down to confronting the patient with the stimulus for prolonged periods, without avoidance behavior (response prevention). Success percentages are approximately $70 \%$ for severe clinical phobias and compulsions, while results in longterm follow-up are very good (Emmelkamp, 1982). The CCR theory likewise states: exposure \& response prevention. More specifically: long exposure to cues (smell, sight, touch etc.) and response prevention (i.e. not eating). In this way extinction is expected. The very fact that dozens of clinical trials established in vivo exposure as highly effective in the area of anxiety disorders promises well for the management of eating disorders.

In 5.9 a case history was described of a woman who was successfully treated with cue-exposure. The present author is fully aware of the limitations of this case history (ct. 3.5). However, a case study is useful in generating hypotheses. Of course, controlled trials are necessary for determining whether cue-exposure is really as effective as it is supposed to be.

Though CCR theory implies that certain factors are important in maintenance and therapy, we do not have any insight into parameter values. 
Such insights may be required before clinical trials will be conducted. More specifically, explicit attention should be paid to the following questions:

1 how many exposure sessions are needed for craving to be extinguished completely?

2 how should sessions be spaced?

3 is it necessary for the subject to abstain completely from binge eating between the cue exposure sessions?

4 how broad should the range of cues be?

Finally, it should be noted that the exposure strategy is radically different from the current treatments of eating disorders by self-control and stimulus-control techniques. These techniques, in fact, mean learning avoidance strategies; the patient learns to avoid stimuli associated with overeating (see e.g. Mizes \& Lohr, 1983; Hsu \& Holder, 1986; Laessle et al., 1987). In this way craving will never be extinguished. The model that has been presented states that it is only exposure to the cues associated with binge eating and response prevention (no binges) that will lead to the extinction of craving. The empirical implication is that, in the long term, much more relapse is expected after learning self-control techniques than after exposure. Research will tell. 



\section{summary}

Excessive eating and self-induced vomiting are timeless phenomenona. Whereas the old Roman's stuffing and vomiting is considered to be an aristocratical custom, in the 17th, 18 th, and 19th century the stuffingvomit habit was registered as a typical medical disease. In chapter 1 it is reported that nowadays there are also individuals who periodically experience recurrent episodes of uncontrolled and excessive eating. When this is attended by persistent overconcern with body shape and weight, the Diagnostic and Statistical manual of Mental Disorders speaks of bulimia nervosa. The episodes of excessive eating are followed either by self-induced vomiting, or use of laxatives, or strict dieting or fasting, or vigorous exercise in order to prevent weight gain.

In chapter 2 a laboratory model of bulimia nervosa is discussed. Subjects selected on the criterium of the intention to restrict food intake (i.e. dieters) are considered to be a subclinical variant of bulimia nervosa. Dieters respond in a different way to various experimental manipulations than non-dieters do. Non-dieters regulate their food intake: they eat little after a food preload and they eat a large amount without a preload. Non-dieters are less conventional. They eat little without a preload and a large amount after a preload: they counterregulate. A preload is not the only stimulus which induces excessive eating in dieters. Emotions such as depressed mood or anxiety, the anticipation of a high-calorie meal, and the idea that one ate a high-calorie preload are also stimuli which lead dieters to overeat. Why do dieters not regulate their food intake?

Various explanations are offered. Two biological theories (set point theory and the serotonin hypothesis) and a psychological explanation (dysfunctional thoughts) are critically discussed in chapter 3 . The three theories cannot satisfactorly explain the typical behaviour of dieters. Auxiliary hypotheses are needed. If the set point theory, the serotonin hypothesis, and the cognitive theory cannot offer a satisfying expanation on theoretical and empirical grounds, how then can it be explained that dieters and bulimic patients experience recurrent episodes of uncontrolled and excessive eating?

Based on the experimental findings reported in the present dissertation and shortly summarized below, a new model was developed to explain counterregulation of dieters. This model is described in section 3.5.

In chapter 5 , empirical studies by the present author are presented. An overview of the studies is given in chapter 4. 
In summary, the main findings are:

1 Clinical binges (of bulimic subjects) differ in severity from non-clinical binges (of non-bulimic subjects). The DSM-III-R criteria discriminate clinical binges quite well from normal eating episodes. Hunger is of no importance in the development of binges (ct. 5.1), which is not easily compatible with the set point explanation of $\mathrm{BN}$.

2 Non-regulation of food intake is characteristic for people preoccupied with caloric intake, but independent from being characterized as a successful or an unsuccessful dieter (cf. 5.2). This finding of successful and unsuccessful dieters non-regulating their food intake casts doubt on the validity of the set point explanation.

3 Bullimic's binges were not characterized by a higher carbohydrate/protein ratio than their normal eating episodes and eating episodes of a normal control group (cf. 5.3). This is contrary to the 5-HT hypothesis.

4 Dieters' counterregulation is mood-dependent: happy dieters regulated their food intake whereas depressed dieters did not. The unusual behaviour of non-dieters (they did not regulate their food intake, neither when happy, nor when depressed) warrants caution in generalizing the findings (cf. 5.4).

5 Dieters who did not regulate their food intake did not show more disinhibitive thoughts than other dieters and non-dieters. Also, dieters did not think in a more irrational way than non-dieters (cf. 5.5). This is contrary to the cognitive hypthesis.

6 The overeating response of the dieters took place in the lab. After participation in a laboratory experiment disinhibited dieters did not overeat outside the laboratory. Also, pre-experimental macronutrient intake did not differ from post-experimental macronutrient intake (cf. 5.6). This finding suggests that overeating is cue-dependent.

7 The galvanic skin response of dieters habituated significantly more rapidly than the galvanic skin response of non-dieters to a series of neutral auditive stimuli. Also, dieters scored significantly higher on the Sensation Seeking Scale (cf. 5.7). Addicts also habituate more rapidly and score higher on the Sensation Seeking Scale than normal subjects. The data support the addiction model of Bulimia Nervosa.

8 Dieters 'counterregulated' after intensive smelling of a 'preload' whereas non-dieters did not. Dieters also reported a subjective loss of control over eating after smelling the "preload' whereas non-dieters actually reported more control (ct. 5.8). The experiment was designed to allow for a crucial test of two theories. The data falsify the cognitive hypothesis. It corroborates the notion that overeating in dieters can be provoked by exposure to cues that bear a probabilistic relation to actual food intake.

9 In a $n=1$ study breaking the probabilistic relation between CS and UCS ('cue-exposure') seemed to be effective in the treatment of bulimia nervosa. 
The model as presented in section 3.5 is related to modern Paviovian explanations of addictive behaviour. It is postulated that binges are cue-dependent. Certain stimuli, which have become reliable predictors of excessive food intake, are supposed to elicit an anticipative compensatory response. One could speculate about an anticipative decline in blood sugar. The model explains post facto why disinhibitors elicit counterregulation in dieters and do not in non-dieters. The various stimuli are all potential conditioned responses. Of more importance is the model's prediction that olfactory stimulation is enough to elicit counterregulation in dieters. This was indeed the case (see above). In chapter 6, a series of clinical and experimental implications are formulated. 



\section{samenvatting}

Onmatig eetgedrag en zelfopgewekt braken komt al sinds jaar en dag voor: het is een tijdloos fenomeen. Pleegde men het bunkeren en braken van de oude Romeinen als een aristocratische gewoonte te karakteriseren, in de $17^{\mathrm{e}}, 18^{\mathrm{e}}$ en $19^{\mathrm{e}}$ eeuw stond het e.e.a. te boek als een typisch medische kwaal. In hoofdstuk 1 wordt gerapporteerd dat ook tegenwoordig individuen zich bij tijd en wijle te buiten gaan aan ongekontroleerde eetbuien. Indien dat gepaard gaat met een overmatige bezorgdheid over uiterlijk en gewicht, dan spreekt men, overeenkomstig het Diagnostic and Statistical manual of Mental Disorders, van Bulimia Nervosa. Het overmatig eten wordt dan gekompenseerd door bijvoorbeeld te braken, te lijnen en/of excessief te sporten.

Psychopathologische fenomenen kunnen in het laboratorium bestudeerd worden. Dat heeft het voordeel dat kondities optimaal gekontroleerd kunnen worden. In hoofdstuk 2 wordt melding gemaakt van een analogon van Bulimia Nervosa zoals dat al vanaf de zeventiger jaren in het gedragslaboratorium wordt onderzacht. Gevonden werd dat lijners anders reageren op verschillende experimentele manipulaties dan niet-lijners. Niet-lijners reguleren steeds hun voedselinname: zij eten weinig nadat $z i j$ vooraf iets gegeten hebben (= preload) en veel zonder preload. Lijners daarentegen gedragen zich minder konventioneel. Zij eten weinig zonder preload en veel na een preload: lijners counterreguleren. Een preload is niet de enige stimulus die overmatig eten in lijners ontlokt. Andere stimuli waarvan regelmatig werd gedokumenteerd dat zij lijners tot overmatig eten aanzetten zijn emoties als somberheid en angst, anticipatie op het eten van een hoogkalorische maaltijd, en de idee een hoogkalorische preload te hebben gegeten. Hamvraag is: hoe komt het dat lijners hun eetgedrag niet normaal reguleren?

Verschillende verklaringen zijn geopperd. Twee biologische verklaringen (de set-point theorie en de serotonine hypothese) en een psycholagische verklaring (dysfunktionele gedachten) worden in hoofdstuk 3 kritisch besproken. De drie theorieën kunnen het typische gedrag van lijners niet op bevredigende wijze verklaren. Steeds zijn hulphypothesen nodig. Als de set-point theorie, de serotonine hypothese en de kognitieve theorie op grond van theoretische en empirische overwegingen geen bevredigende verklaring bieden, hoe kunnen de periodiek optredende eetbuien van 'lijners' en BN patiënten dan verklaard worden?

N.a.v. de experimentele bevindingen die in dit proefschrift worden gerapporteerd en die hieronder uiterst summier zijn samengevat, werd een 
nieuw model ontwikkeld dat de counterregulatie van lijners verklaart. Dit model vindt de lezer beschreven in paragraat 3.5.

In hoofdstuk 5 worden eigen empirische- en experimentele studies gepresenteerd. Voor een overzicht van de studies raadplege men hoofdstuk 4.

De belangrijkste bevindingen zijn kort samengevat de volgende:

1 Klinische eetbuien verschilden in ernst van niet-klinische eetbuien. De DSM III kriteria diskrimineerden klinische eetbuien goed van normale eetepisodes. Honger speelde geen rol van betekenis in het ontstaan van eetbuien (cf. 5.1), hetgeen in strijd is met de set-point hypothese.

2 Het niet reguleren van de voedselinname bleek kenmerkend voor mensen die gepreokkupeerd zijn met kalorische inname, doch onafhankelijk van karakterisering als suksesvol of onsuksesvol lijner (ct. 5.2). De bevinding, dat zowel suksesvolle als niet suksesvolle injers hun voedselinname niet reguleren plaatst vraagtekens bij de set-point theorie.

3 Eetbuien van BN-patiënten werden niet gekenmerkt door een hogere koolhydraat/proteïne ratio dan gewone eetepisodes van BN-patiënten en eetepisodes van een normale kontrolegroep (cf. 5.3). Dit is in strijd met wat de $5-\mathrm{HT}$ hypothese doet vermoeden.

4 Counterregulatie van lijners bleek afhankelijk van stemming: vrolijke lijners reguleerden hun voedselinname in tegenstelling tot sombere lijners: I.v.m. het ongebruikelijke gedrag van niet-lijners (niet-lijners reguleerden hun voedselinname niet, onafhankelijk van stemming) is voorzichtigheid geboden bij het generaliseren van de bevindingen (cf. 5.4).

5 Lijners die hun voedselinname niet reguleerden werden niet gekenmerkt door meer disinhibitieve gedachten dan andere proefpersonen. Ook dachten lijners niet irrationeler dan niet-lijners (cf. 5.5). Dit is in strijd met de kognitieve hypothese.

6 Het overeten van lijners bleek enkel binnen het laboratorium op te treden: na deelname aan een experiment in het laboratorium overaten experimenteel 'gedisinhibeerde" lijners zich niet nog eens buiten het laboratorium. Ook de inname van macronutriënten verschilde pre- en post-experimenteel niet (cf. 5.6). Het suggereert dat overeten stimulusspecifiek is.

7 De huidgeleidingsreaktie van lijners habitueerde signifikant sneller aan een serie neutrale auditieve stimuli dan die van niet-lijners. Ook skoorden lijners signifikant hoger op de 'Sensation Seeking Scale" dan niet-lijners (cf. 5.7). Daarin stemmen zij overeen met verslaafden. De bevindingen verlenen enige steun aan het verslavingsmodel van $B N$. 
8 Lijners 'counterreguleerden' nadat zij intensief aan een "preload' geroken hadden. Voor niet-lijners geldt dit niet. Ook rapporteerden lijners na het ruiken een subjektieve beleving van kontroleverlies over eetgedrag terwijl niet-lijners juist een verhoogd gevoel van kontrole rapporteerden (cf. 5.8). Dit falsifieert de kognitieve hypothese en ondersteunt de theorie dat counterregulatie athankelijk is van een stimulus (cue).

9 Doorbreking van de probabilistische relatie tussen CS en UCS ('cueexposure') lijkt effektief in de behandeling van BN.

Het model zoals weergegeven in paragraaf 3.5 is verwant aan moderne pavloviaanse verklaringen van verslavingsgedrag. Gepostuleerd wordt dat eetbuien stimulus specifiek zijn. De idee is dat bepaalde stimuli, zodra zij betrouwbare voorspellers worden van overmatige voedselinname, op den duur een voorbereidende kompensatoire respons in het organisme zullen ontlokken. Gedacht wordt aan een anticipatieve bloedsuikerdaling. Het model verklaart post facto waarom de in de literatuur gerapporteerde stimuli ("disinhibitors') bij lijners wel en bij anderen niet leiden tot counterregulatie. De verschillende stimuli zijn allen potentieel gekonditioneerde stimuli. Belangrijker wellicht is dat het model leidt tot de (juist gebleken) voorspelling dat olfactoire stimulatie een voldoende voorwaarde is voor het provoceren van counterregulatie in lijners. In hoofdstuk 6 werd een serie klinische en experimentele implikaties geformuleerd. 



\section{literature}

Abell, C., Farguhar, D., Galloway, S., Steven, F., Phillp, A., \& Munro, J. (1986). Placebo controlled double-blind trial of Fluvoxamine maleate in the obese. Journal of Psychosomatic Research, 30, 143-146.

Abramson, L.Y., \& Seligman, M.E.P. (1977). Modeling psychopathology in the laboratory: History and rationale. In: J.D. Maser, \& M.E.P. Seligman (Eds), Psychopathology: Experimental Models. San Francisco: Freeman \& $\mathrm{Co}$.

Abramson, E.E., \& Wunderlich, R.A. (1972). Anxiety, fear and eating A test of the psychosomatic concept of Obesity. Journal of Abnormal Psychology, 79, 317-321.

Abraham, S., \& Beumont, P. (1982). How patients describe Bulimia or binge eating. Psychological Medicine, 12, 625-635.

Aghajanian, G.K. (1972). Influence of drugs on the firing of serolonincomtaining neurons in the brain. Federation Proc., 31, 91-196.

Agras, W. Dorian, B., Kirkley, B., Arnow, B., \& Bachman, J. (1987). Imipramine in the treatment of Bulimia: A double-blind controlled study. International Journal of Eating Disorders, 6, 29-38.

Altshuler, K.Z., \& Weiner, M.F. (1985). Anorexia Nervosa and Depression: A dissenling view. American Joumal of Psychiatry, 142, 328-332.

American Psychiatric Association (1980). Diagnostic and statistical manual of mental disorders (3rd edi.). Washington, DC: Aulhor.

American Psychiatric Association (1987). Diagnostic and statistical manual of mental disorders (3rd ed. rev.). Washington, DC: Author.

Baucom, D.H., \& Aiken, P.A. (1981). Effect of depressed mood on eating among obese and nonobese dieting and nondieting persons. Journal of Personality and Social Psychology, 41, 577-585.

Beary, M.D., Lacey, J.H., \& Merry, J. (1986). Alcoholism and eating disorders in women of fertile age. British Journal of Addictions, 81, 685-689.

Bemis, K.M. (1985). 'Abstinence' and 'Nonabstinence' models for the treatment of Bulimia. International Journal of Eating Disorders, 4, 407-437.

Bennett, W., \& Gurin, J. (1982). The dieters dilemma: Eating less and weighing more. New Yark: Basic Books Inc.

Berken, G., Weinstein, D. \& Stern, W. (1984). Weight gain: A side effect of tricyclic antidepressants. Journal of Affective Disorders, 7, 133-138.

Berthoud, H.R., Bereiter, D.A. Trimble, E.R., Siegel, E.G. \& Jeanrenaud, B. (1981). Cephalic phase, reflex insulin secretion. Neuroanatomical and physiological characterization. Diabelologica, 20, 393-401.

Beumont, P.J.V., Chambers, T.L., Rouse, L., \& Abraham, S.F. (1981). The diet composition and nutritional knowledge of patients with Anorexia Nervosa. Journal of Human Nuirition, 35, 265-273.

Blanchard, A.J., \& Frost, R.O. (1983). Two tactors of restraint: Concern for dieting and weight fluctuation. Behaviour Research and Therapy, 21, 259-267.

Booth, D.A. (1981). The physiology of appetite. British Medical Bulletin, 37, 135-140.

Boskind-Ladahl, M. (1976). Cinderella's stephsisters: A feminist perspective on Anorexia Nervosa and Bulimia. Signs: Journal of Women in Culture and Society, 2 , 342-356.

Brewerton, T.D., Brandt, H.A., Lesem, M.D., Hegg, A.P. Murphy, D.L., \& Jimerson, D.C. (1988). Serotonin dysregulation in Bulimia Nervosa. Paper presented all the Second International Conference on Eating Disorders "New York. 
Brisman, J. \& Siegel, M. (1984). Bulimia and alcoholism: Two sides of the same coin? Journal of Substance Abuse Treatmen, 1, 113-118.

Bruch, $H_{.}$(1973). Eating disorders: Obesity, Anorexia Nervosa and the person within. Now York: Basic Books.

Brummer, A., \& Pudel, V.E. (1981). An attempt to demonstrate reliable salivary increases in the hungry state. Appetite: Journal for Intake Research, 2, 376-379.

Cabanac, M. (1971). Physiological role of pleasure. Science, 173, 1103-1107.

Cabanac, M., Duclaux, A. (1970). Obesity: Absence of satiety aversion to sucrose. Science, $168,496-497$.

Cabanac, M., \& Fanting, M. (1977). Origin of offacto-gustatory alliesthesia: Intestinal sensitivity to carbohydrate concentration? Psychology \& Behavior, 18, 1039-1045

Cabanac, M., Duclaux, R., \& Spector, N. (1971). Sensory feedback in regulation of body weight: is there a ponderostat? Nature, 229, 125-127.

Calloway, $P$. Fonagy, P., \& Wakeling, A. (1983). Autonomic arousal in eating disorders: Further evidence for the clinical subdivision of Anorexia Nervosa. British Journal of Psychiatry, 142, 38-42.

Cannon, W.B. (1920). Bodily changes in pain, hunger, fear and rage. New York: Appleton and Company.

Casper, R.L. (1983), On the emergence of Bulimia Nervosa as a syndrome. A historical view. International Journal of Eating Disorders, 2, 3-15.

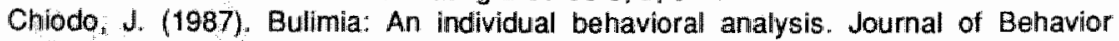
Therapy and Experimental Psychiatry, 18, 41-49.

Christensen, C.M., \& Navazesh, M. (1984). Anticipatory salivary flow to the sight of different foods. Appetite, 5, 307-315.

Clark, D.M. (1988). Personal communication.

Cooney, N.L., Baker, L.H., Pomerleau, O.F., \& Josephy, B. (1984). Salivation to drinking cues in alcoholic abusers: Toward the validation of a physiological measure of craving. Addictive Behaviors, 9, 91-94.

Cooper, P.J., \& Bowskill, R. (1986). Dysphoric mood and overeating. British Journal of Clinical Psychology, 25, 155-156.

Cooper, P.J., \& Fairburn, C.G. (1983). Binge-eating and self-induced vomiting in the community, a preliminary study. British Journal of Psychiatry, 142, 139-144.

Cooper, P.J., \& Fairburn, C. (1986). The depressive symptoms of Bulimia Nervosa. British Journal of Psychiatry, 148, 268-274.

Cooper, P.J., Charnock, D.J., \& Taylor, M.J. (1987). The prevalence of Bulimia Nervosa, a replication study. British Journal of Psychiatry, 151, 68.4-686.

Deutsch, $R_{x}$ (1974). Conditioned hypoglycemia: A mechanism for saccharin-induced sensitivity to insulin in the rat. Journal of Comparative and Physiologicall Psychology, 86, 350-358.

Dumont, F, Vamos, P. (1983). Addicts and anorexics: The basement and the attic; problems in the rehabilitation of addicts. International Journal of Therapeutic Communities, $4,212-219$.

Durrant, M., Royston, P. (1979). Short-term effects of energy density on salivation, hunger and appetite in obese subjects. International Journal of Obesity, 3, 335-347.

Ekelboom, R... \& Stewart, J. (1982). Conditioning of drug-induced physiological responses. Psychological Review, 89, 507-528.

Emmelkamp, P.M.G (1982). Phobic and obsessive compulsive disorders: Theory, research and practice. New York: Plenum.

Esses, V.M., Herman, P. (1984). Palatability of sucrose betore and after glucose ingestion in dieters and nondieters. Physiology and Behavior, 32, 711-715.

Fairburn, C.G. (1984). Bulimia: Its epidemiology and management. In: A.J. Stunkard, \& E. Stellar (Eds), Eating and its disorders (pp. 235-257). New York: Raven Press.

Fainburn, C.G., \& Cooper, P.J. (1982). Selt-induced vomiting and Bulimia Nervosa: An undetected problem. British Medical Journall, 284, 1153-1155. 
Fairtourn, C.G., \& Cooper, P.J. (1983). The epidemiology of Bulimia Nervosa, wo community studies. International Journal of Eating Disorders, 4,61-69.

Fairburn, C.G. \& Cooper, P.J. (1984). Binge-eating, sell-induced vomiting and laxative abuse: A community study. Psychological Medicine, 14, $401-410$.

Fairburn, C.G., \& Garner, D.M. (1986). The diagnosis of Bulimia Nervosa. International Journal of Eating Disorders, $5,403-419$.

Fainturn, C.G. Cooper, $Z$, \& Cooper, P.J. (1986). The clinical features and maintenance of Bulimia Nervosa. In: K.D. Brownell, \& J.P. Foreyt (Eds), Handbook of eating disorders: Physiology, psychology, and treatment of Obesity, Anorexila, and Bulimia (pp. 389-404). New York: Basic Books, Inc.

Fernstrom, J.s \& Wurtman, R. (1972). Brain serolonin content: Physiological regulation by plasma neutral amino acids. Science, $178,414 * 416$.

Fernstrom, J., Wurtman, R., Hammarstrom-Wiklund, B., Rand, W., Munro, H., \& David. son, C. (1979). Diurnal variations in plasma concentrations of tryptophan "tyrosine, and other neutral amino acids: Effect of dietary protein intake. American Journal of Clinical Nutrition, 32, 1912-1922.

Fernstrom, J.D. (1985). Dietary effects on brain serotonin synthesis: Relationship to appetite regulations. American Journal of Clinical Nutrition, 42, 1072-1082.

Filstead, W.J., Parrela, D.P., \& Ebbit, J. (1988). Highurisk situations for engaging in substance abuse and binge-eating behaviors. Journal of Studies on Alcohol, 49 " 136-141.

Franchina, J.J., \& Slank, K. (1988). Effects of deprivation on salivary flow in the apparent absence of food stimuli. Appetite, 10, 143-147.

Frost, R.O., Goolkasian, G.A., Ely, R.J., \& Blanchard, F.A. (1982). Depression, restraint and ealing behavior. Behaviour Research and Therapy, 20, 113-121.

Gale, A., \& Edwards, J.A. (1986). In: M.G.H. Coles "E. Donchin, \& S.W. Porges (Eds.), Psychophysiology, systems, processes, and applications (pp. 431-508). New York: Guilford Press.

Ganley, R.M. (1988). Emotional eating and how it relates, to dietary restraint, disinhibition, and perceived hunger. International Journal of Eating Disorders, 7, 635-647.

Garfinkel, P.E., \& Garner, D.M. (1982). The multidimensional nature of Anorexia Nervosa. In: P.E. Garfinkel, \& D.M. Garner, Anorexia Nervosa: A multidimensional perspective (pp. 188-213). New York: Brunner/Mazel.

Garner, D.M. (1986). Cognitive therapy for Anorexia Nervosa. In: K.D. Brownell, \& J.P. Foreyt (Eds). Handbook of eating disorders: Physiology, psychology, and treatment of Obesity, Anorexia, and Bulimia (pp. 301-327). New York: Basic Books, Inc.

Garner, D.M. \& Bemis, K.M. (1982). A cognitive-behavioral approach to Anorexia Nervosa. Cognitive Therapy and Research ${ }^{\prime}, 123-150$.

Garner, D.M., Fockent, W., Olmsted, M.P., Johnson, C., \& Coscina, D.V. (1985). Psychoeducational principles in the trealment of Bulimia and Anorexia Nervosa. In: D.M. Garner, \& P.E. Gartinkel (Eds.). Handbook of psychotherapy for Anorexia Nervosa and Bulimia (pp. 513-572). New York: Guiltord Press.

Geiselman, P.J., \& Novin, D. (1982). The role of carbohydrates in appetite, hunger and Obesity. Appetite: Journal for Intake Research, 3, 203-223.

Goldbloom, D.S. (1987). Serotonin in eating disorders: Theory and therapy, In: P.E. Gartinkel, \& D.M. Garner (Eds.). The role of drug treatments for eating disorders (pp. 124-149). New York: Brunner/Mazel.

Goldbloom, D.S., Hicks, L.K., \& Gartinkel, P.E. (1988). Platelet serotonin uptake in Bulimia Nervosa. Paper presented at the Second International Conference on Ealing Disorders, New York.

Goldfine, I.D.. Abraira, C., Gruenewald, D. \& Goldstein, M.S. (1970). Plasma insulin levels during imaginary food ingestion under hypnosis. Proceedings of the Society for Experimental Biology and Medicine ${ }_{n}$ 133, 274-276. 
Green, A.R. (1978). The cerebral regulation of 5-hydroxytryptamine synthesis and metabolism in rellation to functional physiological effects. In: D.J. Bouillon (Ed.), Serotonin in mental abnormalities. New York.

Greenberg, B.A. (1986). Predictors of binge eating in bulimic and nonbulimic women. International Journal of Eating Disorders, $5,269-284$.

Growdon, $4 . H$. (1979). Neurotransmitter precursors in the diet: Their use in the treattment of brain diseases. In R.J. Wurtman, \& J.J. Wurtman (Eds.), Nutrition and the brain, vol. 3. New York: Paven Press.

Guiora, A.Z. (1967). Dysorexia: A psychopathological study of Anorexia Nervosa and Bulimia American Journal of Psychiatry, 124, 391-393.

Gull, W.W. (1873), Anorexia Nervosa (Apepsia Hysterica, Anorexia Hysterica). Trans. Clin. Soc. London, 7.22.

Gull, W.W. (1888). Anorexila Nervosa. Lancet, 1, 516.

Guy-Grand, $B, \&$ Goga, $H$. (1981). Conditioned salivation in obese subjects with different weight kinetics. Appetite: Joumal for Intake Research, 2, 351-355.

Guy-Grand, B., \& Sitt; Y. (1975). Gustative alliesthesia: Evidence supporting the ponderostatic hypothesis for Obesity. In: A. Howard (Ed), Recent advances in Obesity research: I. London: Newman Publishing Ltd.

Halmi, K. A, (1985). Rellationship of the eating disorders to depression: Biological similarities and differences. International Journal of Eating Disorders, 4, 667-680.

Halmi, K.A. Falk, J.R., \& Schwartz; E. (1981). Binge-eating and vomiting: A survey of a college population. Psychological Medicine, 11, 697-706.

Halml, K., Eckert, E. Ladu, T., \& Cohen, J. (1986). Anorexia Nervosa: Treatment efficacy of cyproheptadine and amitryptiline. Archives of General Psychiatry, 43, 177-181.

Hansen, D.H., Bales, C.W., \& Hawkins, R. (1988). The effect of tryptophan supplementation on bingeing behaviour and mood state of bulimic subjects. Paper presented at the Second international Conference on Eating Disorders, New Yark.

Hawkins, F.C., \& Clement, P.F. (1980). Development and construct validation of a self-report measure of binge-eating tendencies. Addictive Behaviors ${ }_{\|} 5,219-226$.

Healey, K., Conroy, R., \& Walsh, N. (1985). The prevalence of binge-eating and Bulimia in 1063 college students. Journal of Psychiatric Research, 19, 161-166.

Heatherton, T.F., Pollivy, J., \& Herman, P. (1989). Restraint and internal responsiveness: Effects of placebo manipulations of hunger state on eating. Journal of Abnormal Psychology, 98, 89-92.

Heatherton, T.F., Herman, C.P, Polivy, J., King, G.A., \& McGree, S.T. (1988). The (mis)measurement of restraint: An analysis of conceptuall and psychometric issues. Joumal of Abnormal Psychology, 97, 19-28.

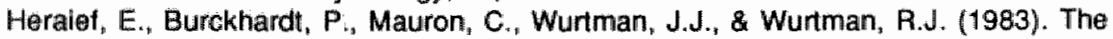
treatment of Obesity by carbohydrate deprivation supresses plasma tryptophan and its ratio to other large neutral amino acids. Journal of Neural Transmission, 57 , 187-195.

Heralet „E. Burckhardt, P., Wurtman, J., \& Wurtman, R. (1985). Tryptophan administration may enhance weight loss by some moderately obese patients on a protein-sparing modified fast (PSMF) diet. International Journal of Eating Disorders, 4, 281-292.

Herbert, F. (1987) . 5-HT, a neurotransmitter for all seasons? Biological Psychialry, 22, $1-3$.

Herman, C.P. \& Mack, D. (1975). Restrained and unrestrained eating. Journal of Personality, 43, 647-660.

Herman, C.P., \& Polivy, J. (1975). Anxiety, restraint, and eating behaviour. Journal of Abnormal Psychology, 84, 666-672.

Herman, C.P., \& Polivy, J. (1980). Restrained eating. In: A.J. Stunkard (Ed.), Obesily (pp. 208-225). Philadelphia: Saunders.

Herman, C.P., \& Polivy, J. (1984). A boundary model for the regulation of ealling. In: A.J. Stunkard, \& E. Steller (Eds.), Eating and its disorders. New York: Raven Press. 
Herman, C.P., Polivy, J., Pliner, P., Threlkeld, J., \& Munic, D. (1978). Distractability in dieters and nondieters: An allernative view of "extemality". Journal of Personally and Social Psychology, 36, 536-548.

Herman, C.P.,Polivy, J., \& Silver, R. (1979). Elfects of an observer on eating behaviour: The introduction of 'sensible' eating. Journal of Personality, $47,85-99$.

Herman, C.P., Polivy, J., Klajner, F., \& Esses, V.M. (1981). Sallivation in dieters and nondieters. Appetite, $2,356-361$.

Herman, C.P., Polivy, J., Lank, C.N. \& Heatherton, T.F. (1987). Anxiety, hunger and eating behavior. Journal of Abnormal Psychology, 96, 264-269.

Hibscher, J.A. \& Herman, C.P. (1977). Obesity, dieting, and the expression of "obese" characteristics. Journal of Comparative Physiology and Psychology, $91,374-380$.

Hinz, L.D., \& Williamson, D.A. (1987). Bulimia and Depression: A review of the effective variant hypothesis. Psychological Bulletin $102,150-158$.

Hodgson, R.J., \& Greene, J.B. (1980). The saliva priming effect, eating speed and the measurement of hunger. Behawloural Research and Therapy, 18, 234-247,

Hoes, M.J. Kreutzer, R.K.J., \& Sijben, N. (1981). Xanthurenic acid excretion in urine after oral intake of 5 grams L-tryptophan by health volunteers: Standardisation of the reference values. Journal of Clin. Chem. Clin. Biochem., 19, 259-264.

Hohlstein, L.A., Gwirtsman, H.E., Whalen, F., \& Enns, M.P. (1986). Oral glucose tolerance in Bulimia. International Journal of Eating Disorders, 5, 157-160.

Hudson, J., Laffer, P.S., \& Pope, H.G. (1982). Bulimia related to affective disorders by family history and response to dexamethasone suppression test. American Journal of Psychiatry, $139,685-687$.

Hughes, P.L., Wells, L.A., Cunningham, C.J., \& Ilstrup, D.M. (1986). Treating Bulimia with desipramine. Archives of General Psychiatry, 43, 182-186.

Huon, G.F., \& Wootton, M. (1987). Towards the prevention of eating disorders: Some preliminary findings from an empirical investigation. Psychotherapy \& Psychosomatics, $48,181-188$.

Hsu, L.K.G., \& Holder, D. (1986). Bulimia Nervosa: Treatment and short-term outcome Psychological Medicine, 16, 65-70.

Johnson, C., \& Pure, D.L. (1986). Assessment of Bulimia: A multidimensional model. In: K.D. Brownell, \& J.P. Foreyt (Eds.), Handbook of eating disorders. New York: Basic Books.

Johnson, C.L., Stuckey, M.K., Lewis, L.D., \& Schwartz, D.M. (1982). Bulimia: A descriptive survey of 316 cases. International Journal of Eating Disorders, 1, 3-16.

Johnson, W.G. \& Wildman, H.E. (1983). Influence of external and covert food stimuli on insulin secretion in obese and normal persons. Behavioral Neuroscience, 97, 10251028.

Johnson, W.G., Lake, L., \& Mahan, M. (1983). Restrained ealing: Measuring an elusive construct. Addictive Behaviours, 8, 413-418.

Jonas, J.M. \& Gold, M.S. (1988). Naltrexone treatment of Bulimia Clinical and theoretical findings linking eating disorders and substance abuse. Pharmacological issues in Alcohol and Substance Abuse, $29-37$.

Jones, R. (1968). A factored measure of Ellis" irralional beliefs system with personality adjustment correlates. Unpublished dissertation, Technical College, Texas.

Kaplan, A.S., Gartinkel, P.E., Darby, P.L., \& Gamer, D.M. (1983). Carbamazepine in the treatment of Bulimia. American Journal of Psychiatry, 140, 1225-1226.

Katz, J.L. \& Waish, B.J. (1978). Depression in Anorexia Nervosa. American Joumal of Psychiatry, 135, 507.

Kaye, W.H. Ebert, M.H. Gwirtsman, H.E., \& Weiss, S.R. (198.4). Differences in brain serotonergic metabolism between nonbulimic and bulimic patients with Anorexia Nervosa. American Journal of Psychiatry, 141, 1598-1601. 
Kaye, W.H. \& Gwirtsman, H.E. (1985). Mood changes and patterns ofl food consumption during bingeing and purging: Are there underlying neurofysiologic relationships? in: W.H. Kaye, \& H.E. Gwirtsman (Eds.), The treatment of normal weight Bulimia (pp. 20-36). Washington, D.C.: American Psychiatric Press, Inc.

Keesey, R.E. (1980), A set-point analysis of the regulation of body weight. In: A.J. Stunkard (Ed), Obesily. Philadelphia: Saunders.

Keesey, R.E. (1986). A sett-point theory of Obesity. In: K.D. Brownell, \& J.P. Foreyt (Eds), Handbook of eating disorders: Physiology, psychology, and treatment of Obesity, Anorexia, and Bulimia (pp. 63-87). New York: Basic Books, Inc.

Keesey, R.E., \& Corbett, S.E. (1984). Metabolic defense of the body weight set-point. In: A.ل. Sturikard, \& E Stellar (Eds.), Eating and its disorders (pp. 87-96). New York: Riaven Press.

Kendler, K.S. (1978). Amitriptyline-induced Obesity in Anorexia Nervosa: A case report. American Journal of Psychiatry, 135, 1107-1108.

Keys, A., Brozek, J., Henschel, A., Mickeisen, O., \& Taylor, H.L. (1950). The biology of human starvation. Minneapolis: The university of Minnesota press.

Kirschenbaum, D.S. \& Tomarken, A.J. (1982). Some antecedents of regulatory eating by restrained and unrestrained eaters. Journal of Abnormal Psychology, 91, 326-336.

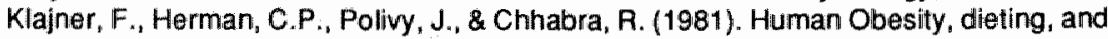
anticipatory salivation to food. Physiology and Behavior, 27, 195-198.

Krahn, D., \& Mitchell, J. (1985). Use of L-Tryptophan in treating Bulimia. American Joumal of Psychiatry, 142, 1130.

Lacey, J.H., \& Evans, C.D.H. (1986). The impulsivist: A multi-impulsive personality disorder. British Journal of Addiction $81,641-649$.

Lacey, J.H., Moureli, E. (1986). Bulimic alcoholics: Some features of a clinical sub-group. British Journal of Addiction, 81, 389-393

Lader, M. (1980). Psychophysiological studies in anxiely. In: Burrows \& Davies (Eds.) Handbook of studies in anxiety. Amsterdam: Elsevier North Holland Biomedical Press.

Laessle, R.G., Waadt, S., \& Pirke, K.M. ("1987), A structured behaviorally oriented group treatment for Bulimia INervosa. Psychotherapy \& Psychosomatics, 48, 141-145.

Laessle "R.G., Kittl, S, Fichter, M.M., \& Pirke, K.M. (1988). Cognitive correlates of depression in patients with eating disorders. International Journall of Ealing Disorders, $7,681-686$.

Laessle, R.G., Tuschl, R.J., Kotthaus, B.C. \& Pirke, K.M. (1989). Behavioral and biological correlates of dietary restraint in normal life. Appetite, 12, 83-94.

Lasegue, E.C. (1873), On Hysterical Anorexia. Trans. Clin. Soc. London, 7:25.

Leckie, E.V., \& Withers, R.F.J. (1967). Obesity and Depression. Journal of Psychosomatic Research, 11, 107-115.

Lee, N.F., Rush, A.J. \& Mitchell, J.E. (1985). Bulimia and Depression. Journal of Affective Disorders, 9, 231-238.

Legof, D.B. \& Spigelman, M.N. (1987). Salivary response to offactory lood stimuli as a function of dietary restraint and body weight. Appetite, 8, 29-35.

Legolf, D.B., Leichner, P., \& Spigelman, M.N. (1988). Salivary response to olfactory stimuli in anorexics and bulimics. Appetite, 11, 15-25.

Leibowitz, S.F. (1983). Hypothalamic catecholamine systems controlling eating behavior: A potential model for Anorexia Nervosa. In: A.R. Liss (Ed.), Anorexia Nervosa: Fecent developments in research (pp. 221-229). New York.

Leibowitz, S.F. (1984). Noradrenergic function in the medial hypothalamus: Potential relation to Anorexia Nervosa and Bulimia. In: K.M. Pirke \& D. Ploog (Eds.), The psychobiology of Anorexia Nervosa (pp. 35-45). Berlin: Springer Verlag.

Leibowitz, S.F. Weiss, G.F., Yee, G., \& Tretter, J.B. (1985a). Noradrenergic ininervation of the paraventricular nucleus: Specific role in control of carbohydrate ingestion. Brain Research Bulletin, 14, 561-537. 
Leibowitz, S.F. Brown, O., Tretter, J.R., \& Kirschgessner, A. (1985b). Norepinephrine, clonidine, and tricyclic antidepressants selectively stimulate carbohydrate ingestion through noradrenergic system of the paraventricular nucleus. Pharmacology Biochemistry \& Behavior, 23, 541-550.

Leibowitz S.F., Shor-Posner, G. (1986a). Brain serotonin and eating behavior. Appetite, supplement $1-14$

Leibowitz, S.F., \& Shor-Posner, G. (1986b). Hypothalamic monoamine systems for control of food intake: Analysis of meal patterns and macronutrient selection. In: M.O. Carnuba \& J.E. Blundell (Eds), Pharmacology of eating disorders: Theoreticall and clinical developmenls (pp. 29-43). New York: Raven Press.

Lieberman, H.R., Caballero, B., \& Finer, N. (1986). The composition of lunch determines afternoon plasma tryptophan ration in humans. Journal of Neural Transinission, 65 , $211-217$.

Lelliot, P.T. Noshirvani, H.F. Marks, I.M., Montero, W.O., Basoglu, M., \& Cohen, S.D. (1987). Relationship of skin conductance activity to clinical features in obsessive compulsive ritualizers. Psychological Medicine, 17, 905-914.

Levy, A.B., Dixon, K.N., \& Stern, S.L. (1989). How are Depression and Bulimia related? American Journal of Psychiatry, 146, 162-169.

Lowenkopf, E.L. (1982). Anorexia Nervosa: Some nosological considerations. Comprehensive Psychiatry, 23, 233-240.

Ludwig, A.M., \& Wikler, A. (1974). The first drink: Psychobiological aspects of craving. Archives of General Psychiatry, 30, 539-547.

Macrae, J., Scoles, M.T., \& Siegel, S. (1987). The contribution of Pawlovian conditioning to drug tolerance and dependence. British Journal of Addiction, 82, 371-380.

Madsen. D.B. Das, A.K., Bogen, I., \& Grosman, E.E. (1987). A short Sensation Seeking Scale. Psychological Reports, 60, $1179-1184$.

Marks, I.M. (1987). Fears, phoibias and rituals: Panic, anxiety and their disorders. Oxiord: University Press.

Marks I., \& Mathews, A.M. (1979). Briel standard self rating for phobic patients. Behavioural Research and Therapy, 17, 263-267.

McCown, W. (1988). Multi-impulse personality disorder and multiple substance abuse: Evidence from members of self-help groups. British Journal of Addiction, $83_{n} 431-432$.

McKenna, R.J. (1972). Some effects of anxiety level and food cues on the ealing behavior of obese and normal subjects: A comparison of the Schachterian and psychosomatic conceptions. Journal of Personality and Social Psychology, 22, 311. 319.

Mitchell, J.E., \& Groat, R. (1984), A placebo-controlled, double-blind trial of amitriptyline in Bulimia. Journal of Clinical Psychopharmacology. 4, 186-193.

Mitchell, J.E. Pyle, R.L. \& Ecken, E.D. (1981). Frequency and duration of binge-eating episodes in patients with Bulimia. American Journal of Psychiatry, 138, 835-836.

Mitchell, J.E., Pyle, R. Hatsukami "D. \& Eckert, E. (1988). Chewing and spitting out food as a clinical feature of Bullimia. Psychosomatics, 29, 81-84.

Mizes, S. (1985). Bulimia: A review of its symptomatology and treatment. Advances in Behaviour Research and Therapy, 7, 91-142.

Mizes, J.S., \& Lohr, J.M. (1983). The treatment of Bulimia (Binge eating and self-induced vomiting): A quasi-experimental investigation of the effects of stimulus narrowing, self-reinforcement and self-control relaxation. International Journal of Eating Disorders, 2, 59-65.

Moller, S.E. (1985). Effect of various oral protein doses on plasma neutral amino acid levels. Journal of Neural Transmission, 61, 183-191.

Moore, D.C. (1977). Amitriptyline in Anorexia Nervosa. American Journal of Psychiatry, $134,1303-1304$.

Mrosovsky, N. (1983). Animal anorexias, starvation "and Anorexia Nervosa: Are animal models of Anorexia Nervosa possible? Anorexia Nervosa: Recent Developments in Research, pp. 199-205. 
Mrosovsky, $N_{x,}$ Powley, T.L. (1977). Set points for body weight and tat. Behavioral Biology, 20, 205-223.

Nakra, $\mathbb{E}$, Plutland, P., Verma, S. \&aind, R. (1977). Amitriptyline and weight gain: A biochemicall and endocrinological siudy. Curr. Med. Res. Opin., 4, 602-606.

Nakra, B., \& Grossberg, G. (1986). Carbohydrate craving and weight gain with maprotiline. Psychosomatics, $5,376-381$.

Nassr, D.G. (1986). Succestul treatment of Bulimia with nomifensine. American Journal of Psychiatry, $143,373-374$.

Needleman, H.L. \& Wabeir, D. (1977). The use of amitriptyline in Anorexia Nervosa. In. R.A. Vigersky (Ed.); Anorexia Nervosa. New York: Raven Press.

Niaura, R.S., Rohsenow, D.J., Binkoft, J.A., Monti, P.M., Pedraza, M., \& Abrams, D.B. (1988). Relevance of cue reactivity to understanding alcohol and smoking relapse. Journal of Abnormal Psychology , 97, 133-152.

Nirenberg, T.D., \& Miller, P.M. (1982). Salivation: An assessment of food craving. Behavioral Research and Therapy, 20, 405-407.

Nisbett, R.E. (1968a). Taste, deprivation and weight determinants of eating behaviour. Journal of Personality and Social Psychology $10,107-116$.

Nisbett, R.E. (1968b): Determinants of food intake in Obesity. Science, 159, 1254-1255.

Nisbet, R.E. (1972). Hunger, Obesity, and the Ventromedial Hypothalamus. Psychological Review, 79, 433-453.

Nisbett, R.E. (1974). Starvation and the behavior of the obese. In: G.A. Bray, \& J.E. Bethune (Eds), Treatment and management of Obesity (pp. 45-57). Maryland: Harper \& Row:

Nisbett; A.E. \& Wilson, T.D. (1977). Telling more than we can know: verbal reports on imental processes. Psychological Review, 87, 231-259.

Norre, J., \& Vandereycken, W. (1986a). Beschrijving en behandeling van Bulimia Nervosa: Een literatuuroverzicht. Directieve Therapie en Hypnose, 6, 309-349.

Orbach, S. (1978). Fat is a feminist issue, the anti-diet guide to permanent weight loss. New York: Paddington Press Ltd.

Orbach, S. (1986). Hunger strike: The anorectic struggle as a metaphor for our age. New York: Avon Books.

Orr, S.P., \& Pitman, R.K. (1987). Electrodermal psychophysiology of anxiety disorders: Orienting response and spontaneous fluctuations. Biologicall Psychiatry, 22, 263-656.

Palmer, R.L. (1979). The dietary chaos syndrome: A useful new term? British Journal of Medical Psychology, 52, 187-190.

Pangborn, R.M., Whiterly, S.A., \& Jones, F. (1979). Parotid and whole-mouth secretion in response to viewing, handling and sniffing focd. Perception, $8,339-346$.

Paykel E.S., Mueller, P.S., De La Vergne, P.M. (1973). Amitriptyline, weight gain and carbohydrate craving: A side effect. British Journal of Psychiatry, 123, 501-507.

Ploeg, H.M. van der, Defares, P.B., \& Spielberger, C.D. (1980). Handleiding bij de Zelf-Beoordelings Vragenlijst: Een Nederlandse bewerking van de Spielberger StateTrait Anxiety Inventory. Lisse: Zwets and Zeitlinger B.V..

Polivy. J. (1976). Perception of calories and regulation of intake in restrained and unrestrained subjects. Addictive Behaviors, 1, 237-243.

Polivy, J., \& Herman, C.P. (1976a). Effects of alcohol on eating behavior: Influence of mood and percelved intoxication. Journal of Abnormal Psychology, 85, 601-606.

Polivy, J., \& Herman, C.P. (1976b). The effects of alcohol on eating behavior: Disinhibition or sedation? Addictive Behaviors, 1, 121-125.

Polivy, J., \& Herman, C.P. (1976C). Clinical depression and weight change: A complex relation. Journal of Abnormal Psychology, 85, 338-340.

Polivy, J., \& Herman, C.P. (1985). Dieting and bingeing: A causal analysis. American Psychologist, 40, 193-201.

Pollivy, J., Herman, C.P., \& Warsh, S. (1978). Internal and external components of emotionality in restrained and unrestrained eaters. Journal of Abnormal Psychology, 87, 197-204. 
Polivy, J., Herman, C.P., Younger, J.C, \& Erskine, B. (1979). Effects of a model on eating behaviour: The induction of a restrained eating style. Journal of Personality, 47 , $100-114$.

Polivy, J., Herman, C.P. Hackett, R., \& Kuleshnyk, I. (1986). The effects of sefl-altention and public attention on eating in restrained and unrestrained subjects. Journal of Personality and Social Psychology, 50, 1253-1260.

Pope, H.G., \& Hudson, J.1. (1982). Treatment of Bulimia with antidepressants. Psychopharmacology, 78, 176-179.

Pope, H.G., \& Hudson, J.I. (1984). New hope for binge eaters. New York: Harper \& Row.

Pope, H.G., Hudson, J.1. \& Jonas, J.M. (1983). Antidepressant treatment of Bufimia: Preliminary experience and practical recommendations. Journal of Clinical Psychopharmacology, 3, 274-281.

Pope, H.G., Hudson, J.I. \& Mialet, J.P. (1985). Bulimia in the late nineteenth century: The observations of Pierre Janet. Psychological Medicine, $15,739-743$.

Pope, H.G., Herridge, P.L. Hudson, J.I., Fontaine, R., \& Yurgelum-Todd, D. (1986). Treatment of Bulimia with Nomifensine. American dournal of Psychiatry, 143, 371 372.

Powley, T. (1977). The ventromedial hypothalamic syndrome, satiety and a cephalic phase hypothesis. Psychological Review, 84, 89-126.

Powley, T.L., \& Berthoud, H.R. (1985). Diet and cephalic phase insullin responses. The American Journal of Clinical Nutrition, 42, 991-1002.

Praag, H.M. van, \& Lemus, C. (1986). Monoamine precursors in the treatment of psychiatric disorders. In: R.J. Wurtman, \& J.J. Wurtman (Eds.), Nutrition and the brain, vol. 7: Food constituents affecting normal and abnormal behaviors (pp. 89-139). New York: Raven Press.

Praag, H.M. van, Lemus, C. \& Kahn, R. (1987a). Hormonal probes of central seroloner"gic activity: Do they really exist? Biological Psychiatry, 22, 86-98.

Praag, H.M. van, Kahn, R., Asnis, G.M. Lemus, C.Z., \& Brown, S.J. (1987b). Therapeu tic indications for serotonin-potentiating compounds: A hypothesis. Biological Psychiatry, 22, p. 205-212.

Price, J.M., Sheposh, J.P., \& Tiano, F.E. (1975). A direct test of Schachter's internal-external theory of Obesity in a naturalistic setting. In: A. Howard (Ed.), Recent advances in Obesity research: I (pp. 204-217). London: Newman Publishing Ltd.

Pudiel, V. (1975). Psychological observations on experimental feeding in the obese. In: A. Howard (Ed.), Recent advances in Obesity research: " (pp. 217-221). London: Newman Publishing Ltd.

Pyle, R., Mitchell, J., \& Eckert, E. (1981). Bulimia: A report of 34 cases. Journal of Clinical Psychiatry, 42,60-64.

Pyle, R.L., Mitchell, J.E., Eckert, E.D., Halvorson, P.A., Neumann, P.A., \& Goff, G.M. (1983). The incidence of Bulimia in treshmen college students. International Journal of Eating Disorders, 2, 75-85.

Fand, C.S.W. \& Kuldau, J.M. (1986). Eating patterns in normal weight individuals: Bulimia, restrained eating, and the night eating syndirome. International Joumal of Eating Disorders, 1, 75-84.

Rankin, H., Hodgson, R., \& Stockwell, T. (1983). Cue exposure and response prewention with alcoholics: A controlled trial. Behaviour Research and Therapy, 21, 435-446.

Rau, J.H. \& Green, R. (1975). Compulsive eating: A neuropsychologic approach to certain eating disorders. Comprehensive Psychiatry, 16, 223-231.

Robinson, P., Checkley, S., \& Russell, G. (1985). Suppression of eating by fenfluramine in patients with Bulimia Nervosa. British Journal of Psychiatry, 146, 169-176.

Rock, C.L., \& Yager, J. (1987). Nutrition and eating disorders: A primer for clinicians. International Journal of Eating Disorders, 2, 267-280.

Rodin, J. (1980). The externality theory today. In: A.J. Stunkard (Ed.), Obesity. Philadelphia: Saunders. 
Rodin, J. (1981). Current status of the internal-extemal hypothesis for Obesity. American Psychologist, $36,361-372$.

Fodin, J. (1985). Insulin levels, hunger, and food intake: An example of feedback loops in body weight regulation. Health Psychology, 4, 1-24.

Rosenthal, N.E, Heffernan, M.M. (1986). Bulimia, carbohydrate craving, and Depression: A central connection? In: F.J. Wurtman, \& J.J. Wurtman (Eds.), Nutrition and the brain, vol. 7 : Food constituents affecting normal and abnormal behaviors ( $\mathrm{pp}$. 139166). New York: Raven Press.

Rosenzweig $M$, \& spruil, J. (1987). Twenly years after Twiggy: A retrospective investigation of Bulimic-like behaviors. International Joumal of Eating Disorders, 6 , 59.65.

Rossilter, E.M. Wilson, G.T. (1985). Cognitive restructuring and response prevention in the treaiment of Bulimia Nervosa. Be havioural Research and Therapy ${ }_{1} 23$,349.359.

Fiossiter, E.M., Wilson, G.T., \& Goldstein, L. (1989). Bulimia Nervosa and dietary restraint. Behavioural Fesearch and Therapy, 27, 465-468.

Fuderman, A.J. (1983). The restraint scale: A psychometric investigation. Behaviour Research and Therapy, 21, 253-258.

Ruderman, A.J. (1985a). Dysphoric mood and overeating: A test of restraint theory's disinthibition hypothesis. Journal of Abnormal Psychology, 94, 78-85.

Ruderman A. (1985b). Restraint, Obesity and Bulimia. Behaviour Research and Therapy, $23,151-156$.

Ruderman, A.J. (1985c). Restraint and irrational cognitions. Behaviour Research and Therapy, 23, 557-561.

Puderman, A.J. (1986a). Bulimia and irrational beliefs. Behavioural Research and Therapy, 2, 193-197.

Ruderman, A. J. (1986b). Dietary restraint: A theoretical and empirical view. Psychological Bulletin, 99, 247-262.

Ruclerman, A.J., \& Wilson, G.T. (1979). Weight, restraint, cognitions and counterregulation. Behavlour Research and Therapy, 17, 581-590.

Ruderman, A.J., \& Christensen, H. (1983). Restraint theory and its applicability to overweight individuals. Journal of Abnormal Psychalogy, 92, 210-215.

Ruderman, A.J.; Belzer, L.J., \&alperin, A. (1985). Restraint, anticipated consumption, and overeating. Journal of Abnormal Psychology, 94, 547-555

Russell, G. (1979). Bulimia Nervosa - an ominous variant of Anorexia Nervosa. Psychological Medicine, 9, 429-448.

Russell, G.F.M. (1985). Bulimia revisited. International Journal of Eating Disorders, 4, $681-692$.

Sabine, E.J., Yonace, A., Farrinston, A.J., Barrat, K.H., \& Wakeling, A. (1983). Bulimia Nervosa: A placebo controlled double-blind therapeutic trial of mainserin. British Journal of Clinical Pharmacology, 15, 195S-202S.

Sahakian, B.J. (1981). Salivation and appetite: Commentary on the forum. Appetite: Journal for Intake Research, 2, 386-389.

Sahakian, B.J., Lean, M.E.J., Riabbins, T.W., \& James, W.P.T. (1981). Sallivation and insuline secretion in response to food in non-obese men and women. Appetite: Journal for Intake Research, 2, 209-216.

Sanderman ${ }_{4}$ R., Mersch, P.P., Sleen, J. van der, Emmelkamp, P.M.G., \& Ormel, J. (1987). The Rational Behavior Imventory (RB1): A psychometric evaluation. Personality and Individual Difference, $8,561-569$.

Sanders-Bush, E. (1982). Regulation of serotonin storage and release. In: B.T. Ho et.al., Serotonin in Blological Psychilatry (pp. 17-34). New York: Raven Press.

Schachter, S. (1968). Obesity and eating. Science, 161, 751-756.

Schachter, S. (1971). Some extraordinary facts about obese humans and rats. American Psychologist, 26, 129-144.

Schachter, S., Goldman, R., \& Gordon , A. (1968). Effects of fear, food deprivation, and Obesity on eating. Journal of Personality and Social Psychology, 10, 91-97. 
Scheurink, A J W. (1989). Central nervous control of metabolism: A study in exercising rats. Doctoral dissertation, Rijksuniversiteit Groningen.

Schlesier-Carter, B., Hamilton, S.A, O'Neil, P.M., Lydiard, R.B., \& Malcolm, A. (1989). Depression and Bulimia: The link between Depression and bulimic cognitions. Joumal of Abnormal Psychology, 98, 322-325.

Schmidt, U., \& Marks, 1. (1988). Cue exposure to food plus response prevention of binges for Bulimia: A pilot study. International Journal of Ealing Disorders, 7, 663-67?.

Schweiger, U., Warnhoff, M. Pahl, d., \& Pirke, K.M. (1986a). Effects of carbohydrate and protein meals on plasma large neutral amino acids, glucose, and insulin plasma tevels of Anorexia patients. Metabolism, 35, 938-943.

Schweiger, U., Laessle, R., Kitti, S., Dickhaut, B., Schweiger, M., \& Pirke, K.M. (1986b). Macronutrient intake, plasma large neutral amino acids and mood during weight-reducing diets. Journal of Neutral Transmission, 67, 77-86.

Schweiger, U., Poellinger, J., Laessle, R., Wolfram, G. Fichter, MM \& Pirke, KM. (1987). Altered insulin response to a balanced test meal in bulimic patients. International Journal of Eating Disorders, 6, 551-556.

Sclafani, A. (1980). Dietary Obesity. in: A.J. Stunkard (Ed.), Obesity (pp. 166-181). Philadelphia: Saunders.

Scott, D.W. (1983). Alcohol and food abuse: Some comparisons. British Journal of Addiction, 78, 339-349.

Scriver, C.R. \& Whetan, D.T. (1969). Glutamic Acid Decarboxylase (GAD) in mam. malian tissue outside the central nervous system. Annals of the New York Academy of Sciences, 166, 83-96.

Shorkey, C.T. \& Whiteman, V.L. (1977). Development of the Rational Bethaviour Inventory: Initial validity and reliability. Educational and Psychological Measurement, $37,527-534$.

Siegel, S. (1972). Conditioning of insulin-induced glycemia. Journal of Comparative and Physilological Psychology, 78, 233-241.

Siegel, S. (1983). Classical conditioning, drug tolerance, and drug dependence. In: R. Smart, F. Glaser, Y. Israel, H. Kalant, R. Popham, \& W. Schmidt (Eds.), Research advances in alcohol and drug problems, vol. 7. (pp. 207-246). New York: Plenum Press.

Siegel, S. (1984). Pavlovian conditioning and heroin overdose: Reports by overdose victims. Bulletin of the Psychonomic Society, 22, 428-430.

Siegel, S., Hinson, R.E., \& Krank, M.D. (1981). Morphine induced alternation of morphine tolerance. Science, 212, 1533-1537.

Siegel, S. Hinson, R.E., Krank, M.D., \& MCCully, J. (1982). Heroin "overdose" death: The contribution of drug associated environmental cues. Science, $216,436-437$.

Silverman, J.A. (1987). Robert Whytt, 1714-1766, Eighteenth century limner of Anorexia Nervosa and Bulimia, an essay. International Journal of Eating Disorders, 6, 143-146.

Simon, C., Schlienger, J.L." Sapin, R. \& Imler, M. (1986). Cephalic phase insulin secretion in relation to food presentation in normal and overweight subjects. Physlology \& Behavior, 36, 465-469.

Sims, E.A.H. (1974). Studies in human hyperphagia. In: G.A. Bray, \& J.E. Bethune (Eds). Treatment and management of Obesity (pp. 28-43). Maryland: Harper \& How. Sinne, E.R., Judd, B., \& Olson, M.A. (1983). Food, drugs and alcohol- A common temporal pattern of use. Perceptuial and Motor Skills, 57, 375-379.

Spencer, J.A $A_{n}$ \& Fremouw, W.J. (1979). Binge eating as a function of restraint and weight classification. Journal of Abnormal Psychology, 88, 262-267.

Spitzer, L., \& Rodin, J. (1987). Effects of fructose and glucose preloads on subsequent tood intake. Appetite, $8,135-145$

Spring, B., Chiodo, J., \& Bowen, D.J. (1987). Carbahydrates, tryptophan, and behavior: A methodological review. Psychological Bulletin, 102, 234-256.

Stein D.M., \& Laakso, W. (1988). Bulimia: A historical perspective. International Journal of Eating Disorders, $7,201-210$. 
Strauss, J. Ryan; R.M. (1988). Cognitive dysfunction in eating disorders. International Journal of Eating Disorders, 7, 19-27.

Striegel-Moore, F.H., Silberstein, L.R., \& Rodin, J. (1986). Toward an understanding of risk factors for Bulimia. American Psychologist, 41, 246-263.

Strien, T. van, (1986). Eating behawiour, personality traits and body mass. Lisse: Swets 8. Zeilinger.

Strien, T. van, Frijters, J.E.R., Bergers, G.P.A., \& Detares; P.B. (1986a). The Dutch Eating Behaviour Questionnaire (DEBO) for assessment of restrained, emotional "and external eating behavior. International Journal of Eating Disorders, 2, 295-315.

Strien, T. van Frifters, J.E.R., Staveren, W.A. wan, Detares, P.B., \& Deurenberg, P. (1986b). The predictive validity of the Dutch Restrained Eating Scale. International Journal of Eating Discorders. 5, 747-755.

Stunkard, A J., Messick, S. (1985). The three-1actor eating questionnaire to measure dietary restraint, disinhibition and hunger. Joumal of Psychosomatic Research, 29, 71-83.

Swift, W.J., Andrews, D., \& Barklage, N.E. (1985). The relationship between affective disorders and eating disorders: A review of the literature. American Journal of Psychiatry, $143,290-299$.

Thelen, M.H., McLaughlin Mann, L., Pruitt, J., Smith, M. (1987). Bulimia: Prevallence and component factors in college women. Journal of Psychosomatic Research, $3 \sharp$, 73-78.

Thompson, J.P., Palmer, R.L., \& Petersen, S.A. (1988). Is there a metabolic component to counterregulation? Internationall Journal of Eating Disorders, 7, 307-319.

Tomarken, A.J., \& Kirschenbaum, D.S. (1984). Effects of plans for further meals on couterregulatory eating by restrained and unrestrained eaters. Journal of Abnormal Psychology, 93, 458-472.

Tordoff, M.G., \& Friedman, M.I. (1989). Drinking saccharin increases food intake and preference-IV. Cephalic phase and metabolic factors. Appetite, 12, 37-56.

Trulson, M.E. (1985). Dietary tryptophan does not alter the lunction of brain serotonin neurons. Life Sciences, 37, 1067-1072.

Van Itallie, T.B. (1984). The enduring storage capacity for fat: Implications for treatment of Obesity. In: A.J. Stunkard, \& E. Stellar (Eds). Eating and its disorders (pp.109-119). New York: Raven Press.

Vigersky, R.A., \& Loriaux, D.L. (1977). The effect of cyproheptadine in Anorexia Nervosa: A double-blind trial. In: R.A. Vigersky (ed.), Anorexia Nervosa. New York: Raven Press.

Walsh, B.l. Stewart, J.W., Roose, S.P., Giadis, M., \& Glassman, A.H. (1985). A double-blind trial of phenelzine in Bullimia. Journal of Psychiatric Research, 19, 485-489.

Wardle, J. (1980). Dietary restraint and binge eating. Behaviour Analysis and Modification, 4, 201-209.

Wardle, J. (1986). The assessment of restrained eating. Belhaviour Research and Therapy, 24, 213-215.

Wardle, J. (1987a). Eating style: A validation study of the Dutch Eating Behaviour Questionnaire in normal subjects and women with eating disorders. Journal of Psychosomatic Research, 31, 161-169.

Wardle, J. (1987b). Hunger and satiety: A multidimensional assessment of responses to caloric loads. Physiology and Behavior, 40, 577-582.

Wardle, J. (1987c). Compulsive eating and dietary restraint. British Journal al Clinical Psychology, 26, 47-55.

Wardie, J., \& Beales, S. (1987). Restraint and lood intake: An experimentall study of eating patterns in the laboratory and in nomal life. Behaviour Research and Therapy, $25,179-185$.

Wardle, J., \& Beales, S. (1988). Control and loss of control over eating: An experimental investigation. Journal of Abnormal Psychology, 97, 35-40. 
Wardle, J., \& Beinart, H. (1981). Binge eating: A theoretical review. British Journal of Clinicall Psychology, 20, 97-109.

Weber, J.M. Klesges, R.C., Klesges, L.M. (1988). Dietary restraint and Obesity: Their effects on dietary intake. Journal of Behavioral Medicine, $2,185-199$.

Weingarten, H.P., Hendler, R. \& Rodin, J. (1988). Metabolism and endocrine secretion in response to a test meal in normal-weight bulimic women. Psychosomatic Medicine. $50,273-285$.

Wermuth, B.M., Davis, K.L., Hollister, L.E., \& Stunkard, A.J. (1977). Phenytoin treatment of the binge-eating syndrome. American Journal of Psychiatry, 134, 1249-1253.

Wilson, G.T. (1986). Cognitive behavioral and pharmacological theirapies for Bullimia. In: K.D. Brownell, \& J.P. Foreyt (Eds), Handbook of eating disorders: Pliyslology, psychology, and treatment of Obesity, Anorexia, and Bulimia (pp. 450-475). New York: Basic Books, Inc.

Wilson, G.T. (1987). Assessing treatment outcome in Bulimia Nervosa: A methodological note. International Journal of Eating Disorders, 3, 339-348.

Wilson, G.T., Rossiter, E, Kleifield, E.I. \& Lindholm, L. (1986). Cognitive behavioral treatment of Bulimia Nervosa: A controlled evaluation. Behaviour Research and Therapy, 24, 277-288.

Windholz, G. (1989). The discovery of the principles of reinforcement, extinction, gener" alization, and differentation of conditional reflexes in Pavlov's labatories. Pav. J. Biol. Sci., april-june, 35-42.

Woody, E.Z., Costanzo, P.R., Liefer, H., \& Conger, J. (1981). The effects of taste and caloric perceptions on the eating behaviour of restrained and unrestrained subjects. Cognitive Therapy and Research ${ }_{1}, 381-390$.

Wooley, S.C., \& Wooley, O.W. (1973). Salivation to sight and thought of food: A new measure of appetite. Psychosomatic Medicine, 35, 136-142.

Wooley, O.W., \& Wooley, S.C. (1975). The experimental psychology of Obesity. In: T. Silverstone (Ed.), Obesity: Its pathologenesis and management (pp. 93-121). Acton, MA: Publishing Science Group.

Wooley, O.W. \& Wooley, S.C. (1981). Relationship of salivation in humans to deprivation, inhibition and the encephalization of hunger. Appetite: Journal for Intake Research, 2, 331-350.

Wooley, S.C., \& Wooley, O.W. (1985). Intensive outpatient and residential treatment for Bulimia. In: D.M. Garner \& P.E. Garfinkel (Eds.), Handbook of psychotherapy for Anorexia Nervosa and Bulimia (pp. 391-401). New York: Guilford Press.

Wooley, O.W., Wooley, S.C., \& Dunham, R.B. (1972a). Can calories be perceived and do they affect hunger in obese and non-obese humans. Journal of Comparative and Physiological Psychology, 80, 250-258.

Wooley, O.W., \& Wooley, S.C., \& Dunham, A.B. (1972b). Calories and sweet taste: Effects on sucrose preference in the obese and nonobese. Physiology and Behavior, 9, 765-768.

Wooley, O.W., \& Wooley, S.C., \& Williams, B.S. (1976). Salivation as a measure of appetite: Studies of the anorectic effects of calories and amphetamine. In: Novin, $D$., Wyrwicka, W., \& Bray, G. (Eds.), Hunger: Basic mechanisms and clinicall implications (pp. 421-429). New York: Raven Press.

Wooley, O.W. Wooley, S.C., \& Williams, B.S. (1978a). Appetite measure made more sensitive. Abstract proc. 2nd int. congr. Obesity (p.495). Washington D.C.

Wooley, O.W., Wooley, S.C., \& Williams, B.S. (1978b). Restraint of appetite and sensitivity to calories. Abstract proc 2nd int. congr. Obesity (p.496), Washington D.C.

Wooley, O.W., Wooley, S.C., \& Woods, W.A. (1975). Elfects of callories on appetite for palatable food in obese and nonobese humans. Joumal of Comparative and Physiologicall Psychalogy, 89, 619-625. 
Wurtman, P.J., \& Wutman, J.J. (1981). Suppression of carbohydrate consumption as: snacks and at mealtime by dll-fenfluramine or tryptophan. In: S. Garattini (Ed.). Anorectic agents: Mechanisms of action and of tolerance (pp. 169-182). New York: Raven Press.

Wurtmam, J.J., Wurtman, R.J., Growidon, J.H., Lipscomb, A., \& Zeisel, S. (1981). Carbohydrate craving in obese people. Suppression by treatments affecting serotoninergic transmission. International Journal of Eating Disorders, 1, 2-11.

Wurtman, F, $y_{\text {, Heft, }} F_{\text {, }}$ \& Melamed, E. (1981). Precursor control of neurotransmitter synthesis Pharmacological Reviews, 32, 315-335.

Wurtman, R.J. (1982). Nutrients that modify brain function. Scientific American, 246 , 42-51.

Wurtman, R., \&urtman, J, (1984a). Nutritional control of central neurotransmitters. In: K. Pirke, \& D. Ploog (Eds.) "The psychobiology of Anorexia Nervosa. Berlin/Heidelberg: Springer-Verlag.

Wurlman, A, \& Wurtman, J. (1984b). Impaired control of appetite for carbohydrates in some patients with eating disorders: Treatment with pharmacological agents. In: $\mathrm{K}$. Pirke, D. Ploog (Eds.). The psychobiology of Anorexia Nervosa. Berlin/Heidelberg: Springer-Verlag.

Wurtman, J.J., Wurtman, R.J., Mark, S., Tsay, R., Gilbert, W., \& Growdon, J. (1985). D-Fenfluramine selectively suppresses carbohydrate snacking by obese subjects. International Journal of Eating Disorders, 4, 89-99.

Wurtman, A.J. \& Wurtman, J.J. (1986). Carbohydrate craving, Obesily and brain seroIonin. Appetite, 7, p. 99-103.

Zahn, T.P. (1986). Psychophysiological approaches to psychopathology. In: M.G.H. Cole, E. Donchin \& S.W. Porges (Eds.), Psychophysiology, systems, processes and applications (pp. 508-611). New York: Guilford Press.

Zuckerman, M. (1979). Sensation seeking: Beyond the optimal level of arousal. Hillsdiale, N.J.: Lawrence Erlbaum Associates. 


\section{dankwoord}

Dames en heren, beste lezer. $U$ allen dank ik voor het ter hand nemen van dit boek. En voor enkelen uwer reikt mijn dank nog veell verder.

Hooggeleerde Heer van den Hout, meester Marcel. Veel, héél erg veell dank ben ik aan jou verschuldigd. Er is vrijwel niets belangrijker voor een beginnend onderzoeker dan een snuggere promotor met een niet aflatend enthousiasme voor alles wat met empirie te maken heeft. Je intellektuele hartstocht is zéér besmettelijk: ik heb verdomd veel van je geleerd en hoop op nog veel meer.

Als bezielend leider van de onderzoeksgroep Experimentele Psychopathologie (EPP) bood je me alle vrijheid, ruimte en middelen om onderzoek te doen naar wat mij interessant voorkwam. Ook al had dat niets met angst of pijn te maken. Voor die gastvrijheid ben ik jou, en ook alle andere onderzoekers van EPP, zeer erkentelijk.

Maatje Marcel, ook buiten het wetenschapsbedrijf konden we het altijd goed met elkaar vinden. Dan heb ik het niet alleen over bergen plezier en vermaak. Het verlies van mijn ouders had me de afgelopen jaren goed te pakken. Zonder jouw steun zou het zwart gitzwart zijn geweest. Dat was een indringende ervaring. Woorden schieten te kort als blijk van mijn innige dank.

Weledelzeergeleerde Harald, waarde kollega en goede vriend. Van je eruditie mocht ik buitengewoon veel opsteken. Mijn oprechte dank daarvoor. Maar die lucide sleutelwoorden 'black (w)holes' en 'schizolimia' vergeef ik je natuurlijk nooit.

Angela, duizendpoot, duizendkunstenaar, sekretaresse uit duizenden. Niet alleen een perfekte organisatie kenmerkt jouw domein. Het was ook altijd een goed onderkomen voor lanterfanters zoals ik. Fijn dat ik je zo vaak van je werk mocht houden.

Bovenstebeste Erik Schouten. Rekenkoning van het Zuiden. Dank voor je snelle, deskundige en bovenal gezellige hulp bij het oplossen van allerhande ingewikkelde vraagstukken.

Dan dat kluppie 'geakademiseerde klinici' van de RIAGG. Steph, Susan, Arnoud, Ken, Rense en Hanny. Ik zal geen gelegenheid meer voorbij laten gaan om jullie te bedanken voor het skoren van die lastige lijsten met gedachten. Nogmaals dank, dus.

Ook aan alle (oud-)medewerkers van het Akademisch Angst Centrum (Vijverdal) ben ik het e.e.a. verschuldigd. Dokter Jan, jij kunt prikken op de meest rare plaatsen. Dat werkt akuut, vooral op de lachspieren. Julien, Louis, François, Catrien, Abett, Armida, Ruud en Ron. Zonder dat jullie precies wisten wat ik allemaal uitspookte werd mij alle vrijheid op de 
afdeling geboden. Dank voor het onvoorwaardelijk vertrouwen dat jullie in mij stelden. En bovenal Eric Griez. Aan jou ben ik de meeste dank verschuldigd. Voor je steeds weer heldere kommentaar op mijn werk en je meer dan kollegiale steun.

Nog tientallen anderen waren onmisbaar. Bij Alex en Jannet vond ik altijd weer een bed. Dorien, Anny, Pamela, Marijke en Ineke hielpen heel consciëntieus met de data- en tekstverwerking. Juf Margo en oudgediende Reinier speelden een sleutelrol nog voordat de hier verzamelde eetstudies startten. En zonder studenten, stagaires, proefpersonen en patiẻnten was dit werk nooit begonnen, laat staan volbracht. Een ieder hartelijk bedankt!

Tot slot nog het volgende.

Mijn plezier in de wetenschap werd de afgelopen jaren overschaduwd door verdriet om het plotselinge verlies van mijn beide ouders. Een laatste dankbetuiging, aan mijn ouders, is op zijn plaats. 


\section{publications}

Hout, M.A. van den, Molen, G.M. van der, Griez, E., Lousberg, H. \& Jansen, A. (1987). Reduction of $\mathrm{CO}_{2}$-induced Anxiety in Patients with Panic Attacks After Repeated $\mathrm{CO}_{2}$ Exposure. American Journal of Psychiatry $144,788-791$.

Hout, M.A. van den, Boek, C.. Molen, G.M. van der, Jansen, A. \& Griez, E. (1988). Rebreathing to cope with hyperventilation. Experimental tests of the paper bag method. Journal of Behavioral Medicine, 11, 3, 303-310.

Jansen, A., Molen, G.M. van der \& Hout, M.A. van der (1987). Over-ademen; hyperventilatie en klassieke konditionering. De Psycholoog, 5, 221-226.

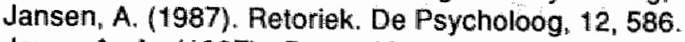

Jansen*, A. (1987). Bespreking van "Psychofysiologie van de ademhaling en het hyperventilatiesyndroom" (Garssen, B., Ed.). De Psycholoog, 6, 318.

Jansen*, A. (1987). Bespreking van "lk word ineens zo raar", (Roborgh, M., Ed.). De Psycholoog. 7/8, 364-365.

Jansen, A. \& Merckelbach, H. (1988). De wens is de vader van de gedachle. De Psycholoog, 2, 41-44.

Jansen, A., Merckelbach, H., Hout, M.A. van den \& Griez, E. (1988). Over-eten, koolhydraten en serotonine. Nederlands Tijdschrift voor de Psychologie, 43, 159-167.

Jansen, A., Merckelbach, H., Oosterlaan, J., Tuiten, A. \& Hout, M.A. van den (1988). Cognitions and Self-talk During Food Intake of Restrained and Unrestrained Eaters. Behaviour Research and Therapy, 26, 5, 393-398.

Jansen, A., Oosterlaan, J., Merckelbach, H. \& Hout, M. A. van den (1988). Non-regulation of Food Intake in Restrained, Emotionall, and External Eaters. Joumal of Psychopathology and Behavioral Assessment, 10, 4, 345-354.

Jansen, A. (1988). Over-eten, lijnen en gedachten: een experimentele studie. Gedragstherapie $4,339-352$.

Jansen", A. (1988). Bespreking van "Anorexia Nervosa Bij Jongeren" (W.L. WeedaMannak, Ed.). De Psycholoog, 10, 636-637.

Jansen", A. (1988), Fatale afloop. Bespreling van "Catherine, zij stierf aan Anorexia Nervosa" (Dunbar, M., Ed.). De Psycholoog, 11, 671-672.

Jansen, A., Klaver, J., Merckelbach, H. \& Hout, M.A. van den (1989). Riestrained eaters are rapidly habituating sensation seekers. Behaviour Research and Therapy, 27, 3, 247-252.

Jansen, A. (1989). Over-eten, koolhydraten en serolonine. Discussie/antwoord. Nederlands Tijdschrift voor de Psychologie, 44, 39-41.

Jansen, A. (1989). Weerwoond. De Psycholoog, 24, 6, 320-321.

Jansen, A., Hout, M.A. van den \& Griez, E. (1989). Does bingeing restore bulimics alleged 5-HT deficiency? Behaviour Research and Therapy, 5, 555-560.

Jansen, A., Hout, M.A. van den, Loof, C. van, Zandbergen, J. \& Griez, E. (1989). A Case of Bulimia succesfully treated with cue exposure. Behavior Therapy and Experimental Psychiatry, 20, 4. 327-332

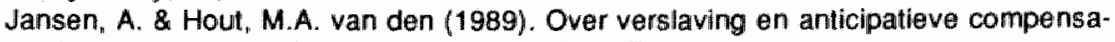
toire responsen. De Psycholoog, 24, 9, 432-437.

Jansen*, A. (1989). Slank-zijn. Bespreking van "Als slank-zijn een obsessie wordt" (Vandereycken, W., W.L. Weeda-Mannak \& C.C. Wittstock, Eds.), De Psycholoog. 1, 28-30.

Jansen*, A. \& Merckelbach, H. (1989). Geluk. Bespreking van "De vererkracht van het geluk" ((Kohnstamm, R., Ed.). De Psycholoog, 24, 5, 250-251. 